\title{
CRITICAL DISCOURSE FOR CRITICAL POLICY: EXAMINING THE DISCURSIVE CONSTRUCTION OF THE CHILDCARE POLICY “PROBLEM” IN CANADIAN NEWSPAPERS BETWEEN 2008 AND 2015
}

\section{By}

Brooke Richardson, B.A. (Hons) (2009) Ryerson University, M.A. (2011) Ryerson University

\author{
A dissertation presented to \\ Ryerson University \\ in partial fulfillment of the requirements of a \\ Doctor of Philosophy in \\ Policy Studies
}

Toronto, Ontario Canada

(C) Brooke Richardson 2017 


\section{Author's Declaration}

I hereby declare that I am the sole author of this dissertation. This is a true copy of the dissertation, including any required final revisions, as accepted by my examiners. I authorize Ryerson University to lend this dissertation to other institutions or individuals for the purpose of scholarly research. I further authorize Ryerson University to reproduce this dissertation by photocopying or by other means, in total or in part, at the request of other institutions or

individuals for the purpose of scholarly research. I understand that my dissertation may be made electronically available to the public. 
Critical discourse for critical policy: Examining the discursive construction of the childcare policy "problem" in Canadian newspapers between 2008 and 2015.

Brooke Richardson

Doctor of Philosophy (Ph.D.), Policy Studies, Ryerson University, 2017

\begin{abstract}
This study provides insight into the wide and chronic gaps between childcare research and policy in Canada. More specifically, connections are made between how childcare policy was discussed in newspapers between 2008 and 2015, power relationships in society and policy outcomes. The theoretical ideas and methodological tools of political scientist Carol Bacchi and Norman Fairclough inform a what-is-the-problem-represented-to-be (WPR) and critical discourse analysis (CDA) respectively. The data was broken up into two periods: Period A (Jan 2008-Oct 2014) when childcare policy was peripheral on the federal policy agenda and Period B (Oct 2014-Nov 2015) when childcare policy re-emerged on the agenda. Data from both periods was analysed using WPR while only Period B data were analyzed using CDA.

The findings reveal low levels of coverage of childcare policy during Period A, though coverage that did exist included a variety of problematizations. In Period B, when the volume of coverage of childcare coverage notably increased, the diversity of problematizations was much more limited and polarized. Childcare was most frequently represented as a private/family problem, a free market problem and/or a public problem - though the CDA revealed that the latter problematization was often superficially treated. The CDA revealed ideological tensions through a tendency of authors to dichotomize parental and non-parental care of children (care as
\end{abstract}


a barrier/support to parenting). Gendered differences to reporting on childcare policy were also observed whereby male reporters asserted stronger modal claims than female authors, although female authors appear to have made a more concerted effort to contextualize their muted claims.

Overall it is concluded that representation of childcare policy problems was limited to ideological ideals that perpetuate gendered, hegemonic power relations in society. It is suggested that this has contributed to a continuation of the status quo - with no significant shift in childcare policy at the federal level. A closer analysis of selected texts published in the year leading up to the 2015 election revealed that several text and discourse proces ses allowed dominant discourses not in the interests of those most affected by childcare (i.e., women, children and families) to remain largely unchallenged. 


\section{Acknowledgement and dedication}

I would first like to acknowledge and thank my incredibly supportive, patient, responsive and kind supervisor Rachel Langford. Without your gentle encouragement and stubborn confidence in my ability to successfully complete this program from day one I simply would not have begun - let alone finished - this journey. I would also like to thank the other members of my committee: Duncan MacLellan, Patrizia Albanese, Wendy Cukier and my external examiner Linda White. I feel privileged to have had the opportunity to work with such an accomplished group of academics. Your input along the way and in the final stages of the process have been invaluable.

I would like to thank the people who witnessed this process day in and day out: my parents, Steve, Holly, Ava, Kai, "Nana" and Megan. You have been my constant cheerleaders, supporting me with everything from a hand to hold, shoulder to cry on or a "funny show" to cheer me up.

But I wish to dedicate this dissertation to my Grandma - or “Gigi” to my children. While I won't be able to hand you the final product as I had hoped, you will be always be with me and I know how proud you are. Yes Grandma I'm still "doing too much" and "running around all over the place", but I can only do this because you have always provided me a space and place to come home to. You were, and will continue to be, my rock, my inspiration and my biggest fan. As I embark on a career with social justice at its heart, I hope I can be half the woman you were/are. 
Contents

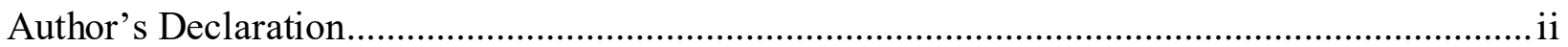

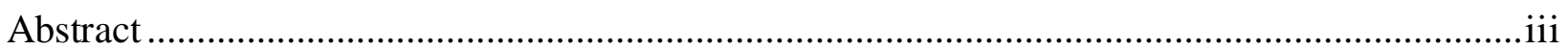

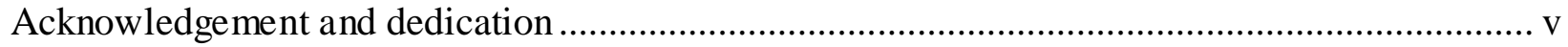

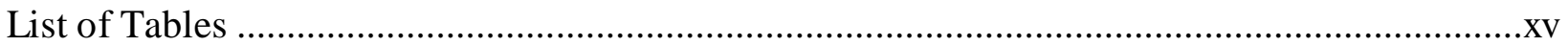

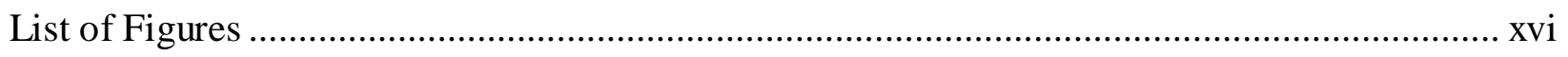

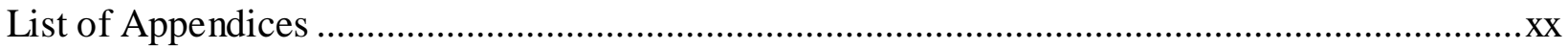

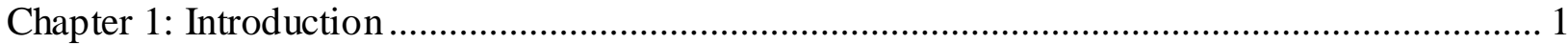

Historical overview of childcare policy in Canada ............................................................. 8

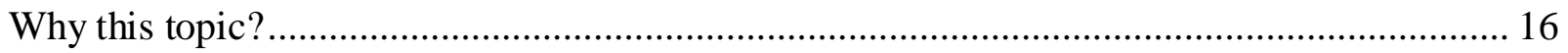

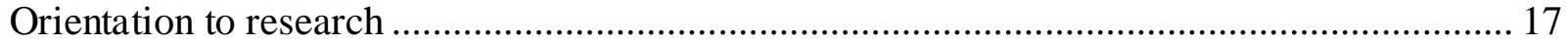

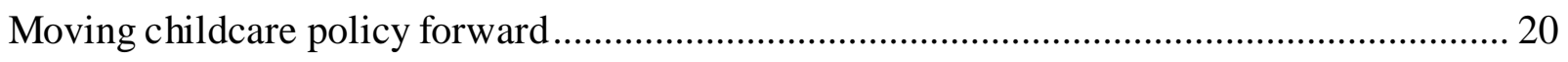

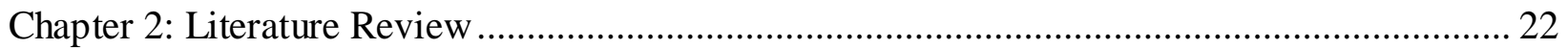

Rationales supporting comprehensive, publicly funded childcare policy ............................ 22 


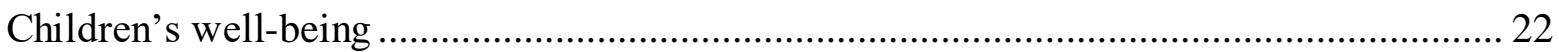

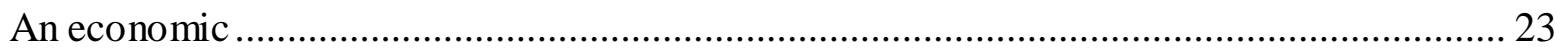

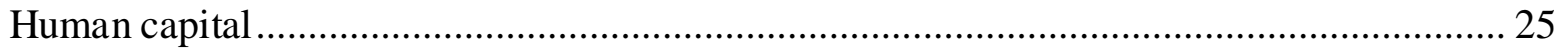

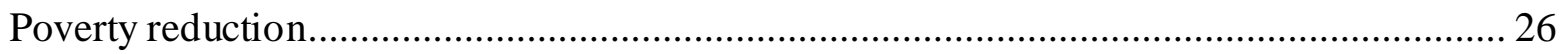

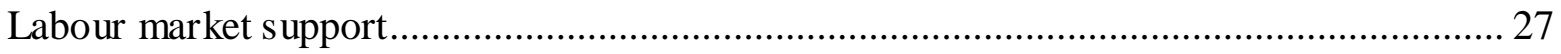

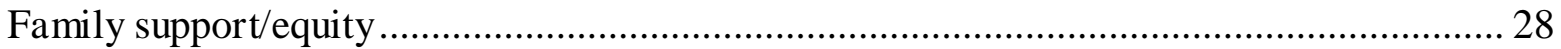

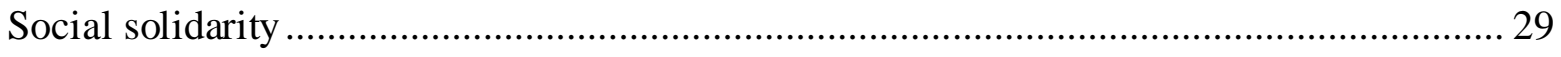

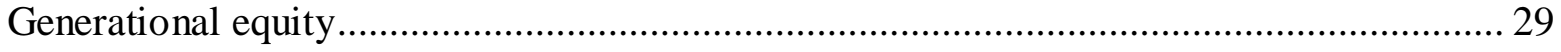

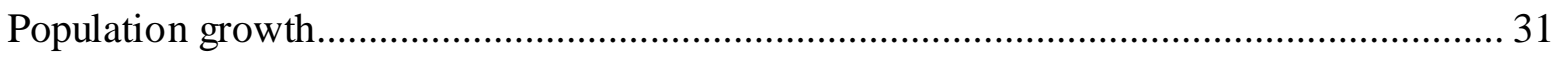

Literature Review: Childcare policy representation in the Canadian press ............................ 33

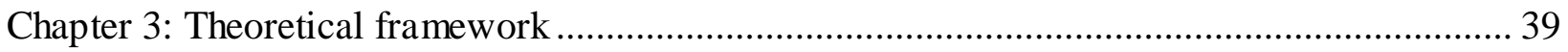

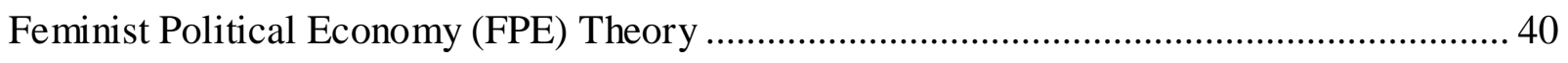

Social reproduction and the women's equity rationale .......................................... 41

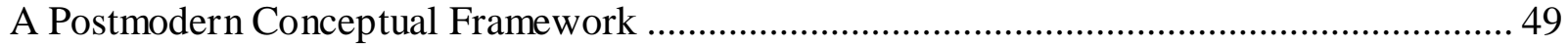

Foucault on power/knowledge and discourse ....................................................... 50

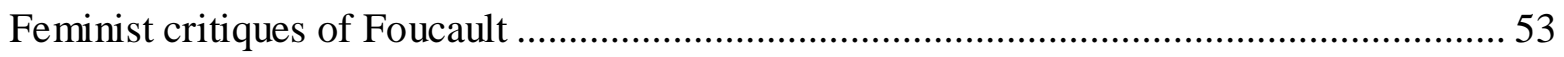

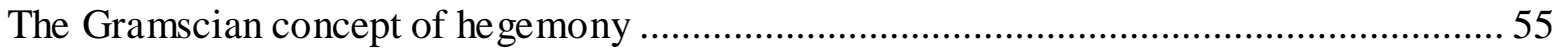

A framework for conceptualizing ideology ............................................................ 56 
Habermas' theory of communicative action in the public sphere ................................... 62

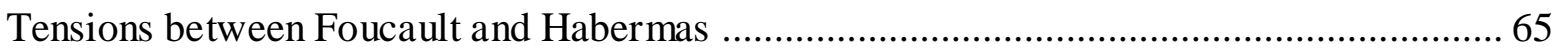

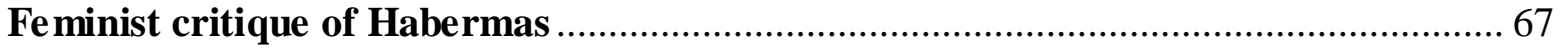

Theoretical foundations of Critical Discourse Analysis (CDA) ......................................... 69

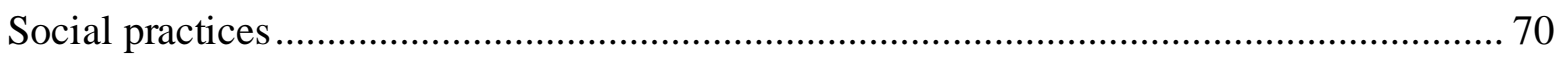

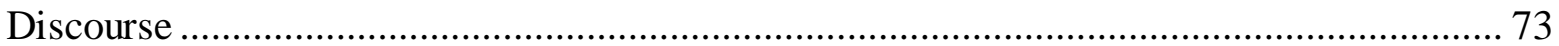

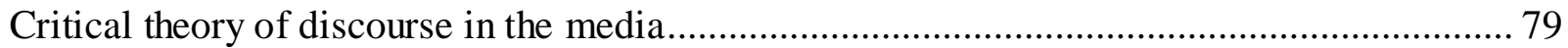

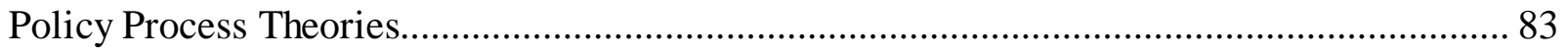

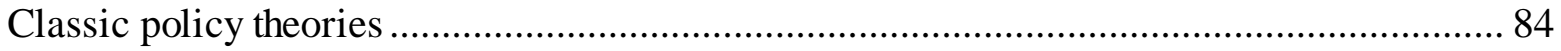

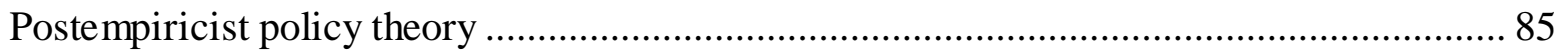

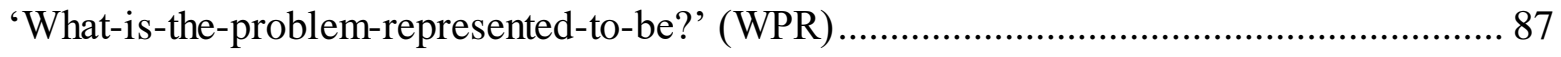

CDA as a tool to build on WPR from a theoretical perspective .......................................... 93

Chapter 4: Methods Part I .............................................................................................. 101

CDA as a tool to build on WPR from a methodological perspective................................ 101

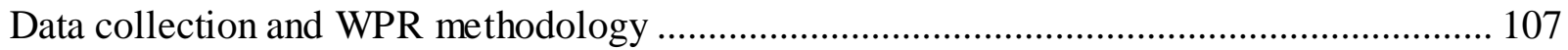


Research questions

Part I: Identifying the policy representations.

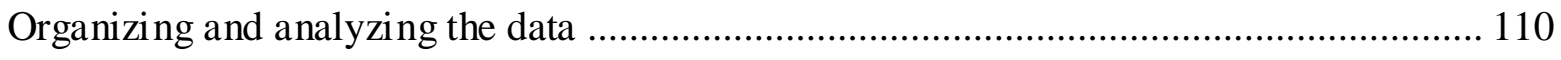

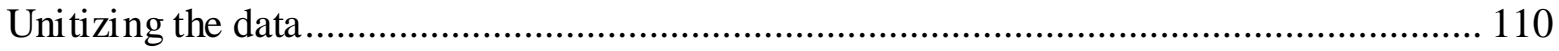

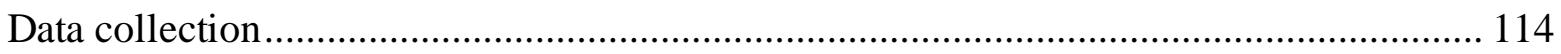

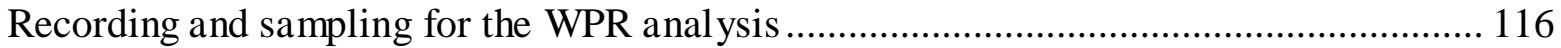

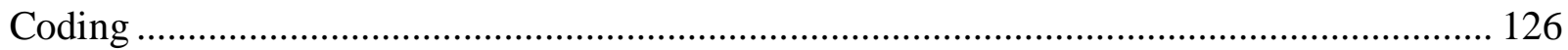

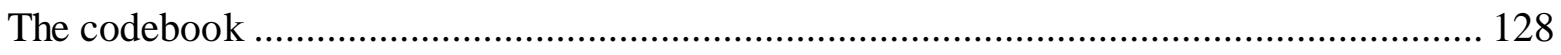

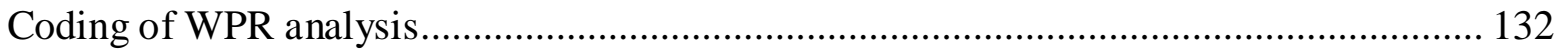

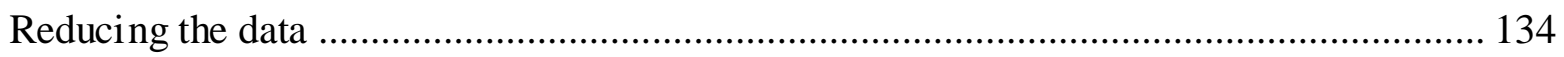

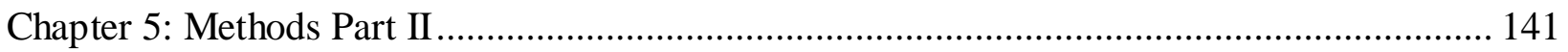

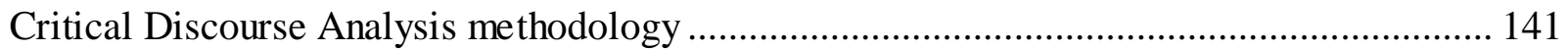

Sampling of newspaper articles for Critical Discourse Analysis ........................................... 142

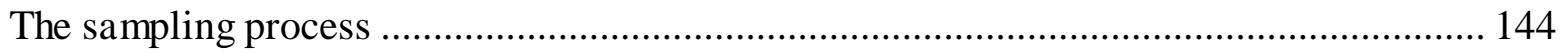

Critical Discourse Analysis applied to the articles and platforms ......................................... 145 
CDA at the level of text analysis.

Discourse analysis

The order of discourse - Interdiscursivity and Intertextuality 152

Modality

Legitimation. 158

Existential and propositional assumptions 159

Chapter 6 162

Part 1: Overview of data and WPR findings 162

Number of articles that met search criteria by paper, period and year 162 A closer look at Period A 166

A closer look at Period B 170

Word counts: Depth of coverage 174

What is the problem represented to be? 176

Observations of problematization in Period A 178 Observations of problematizations in Period B 184

Chapter 7 
Part 2: Descriptions and examples of problematizations in both time periods

Free market problematization ............................................................................ 192

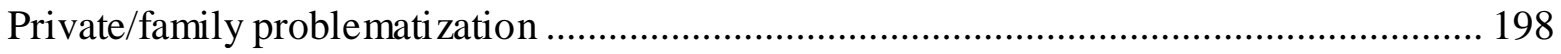

Labour market support problematization ................................................................. 203

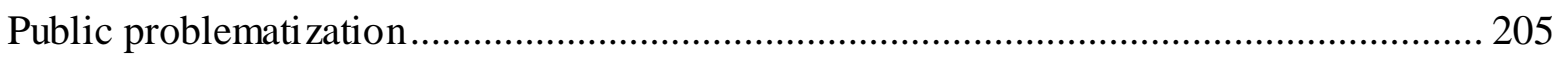

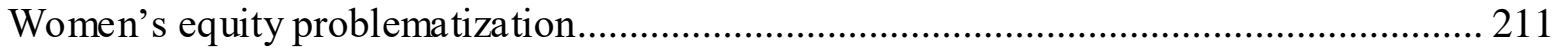

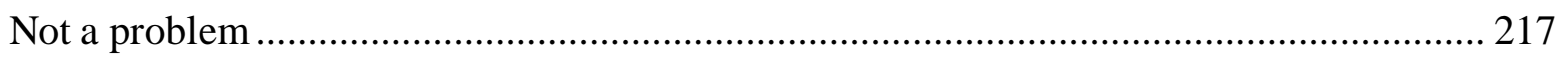

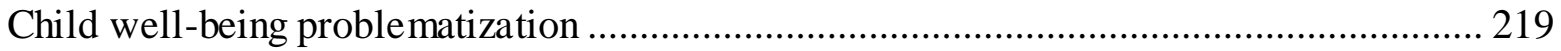

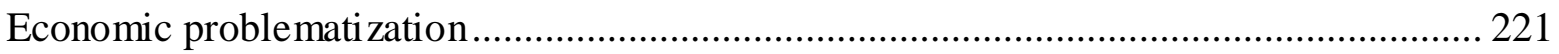

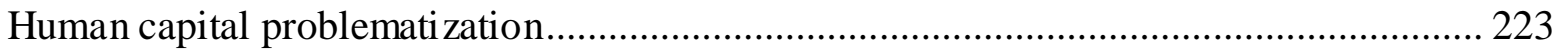

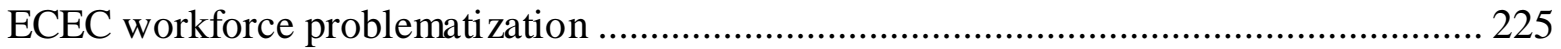

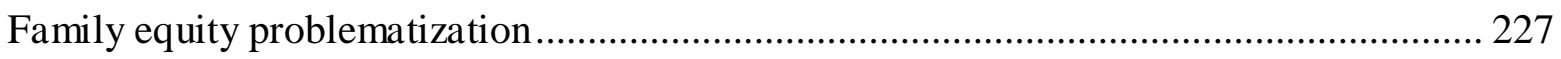

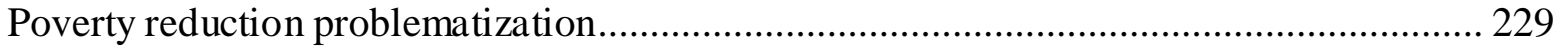

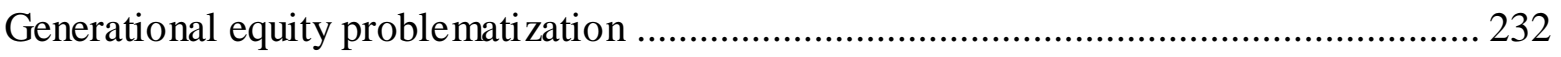

Population growth problematization ................................................................ 233

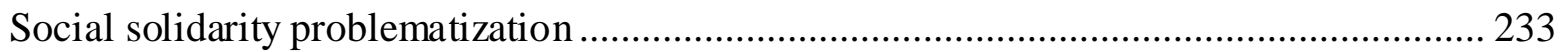

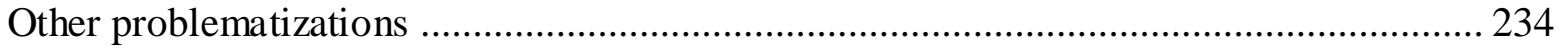

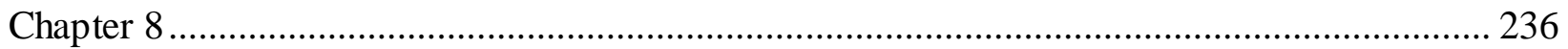

Critical Discourse Analysis of Period B Data ................................................................ 236 
CDA at the Level of Text Analysis

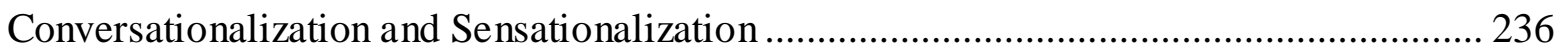

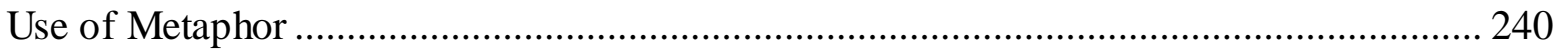

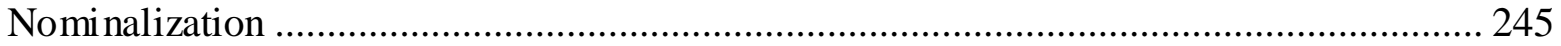

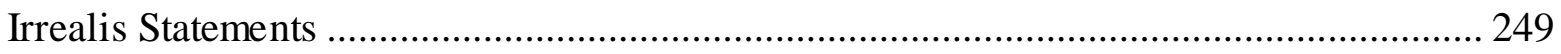

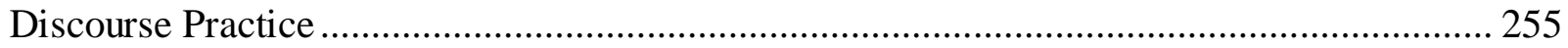

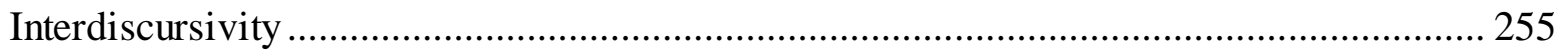

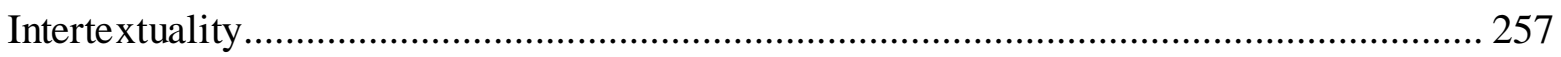

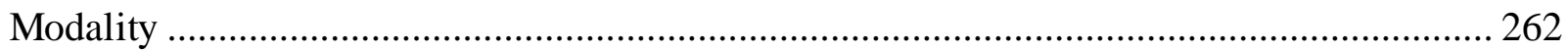

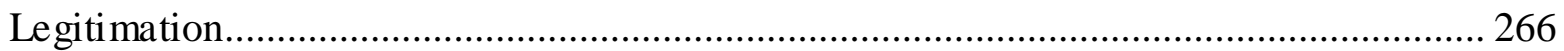

Existential and Propositional Assumptions .......................................................... 282

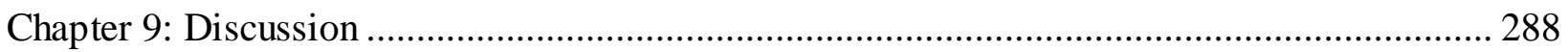

Colonization of the lifeworld by systems - volume of coverage ................................... 290

Peaks in media coverage of childcare policy within this colonial process.......................... 292

Colonization through superficial depth of coverage ..................................................... 294 
Implication of colonization: Occlusion of other ways of being

A narrow and increasingly polarized conceptualization of the childcare policy "problem" ... 299

The limitations of the discursively constructed public problematization

Discursive articulation of childcare as a private problem reinforced a hegemonic and gendered sociopolitical order.

Discursive reinforcement of the private/family problematization 306

The role of individual authors in the reporting process - examining the position and gender of authors in relation to the discursive construction of the issue 310

Gendered differences in reporting 313

Chapter 9: Conclusion. 318

Implications 318

Recommendations

A renewed focus on political messaging by advocates, politicians and journalists alike.... 322 Increased advocacy and knowledge mobilization efforts, and structural support for these efforts, from academics and researchers 325 
Research probing the existing understanding of childcare services and policy by

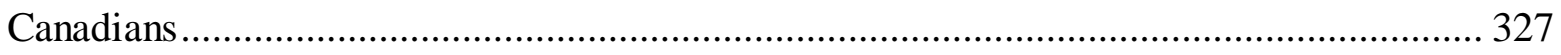

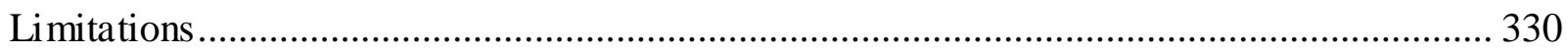

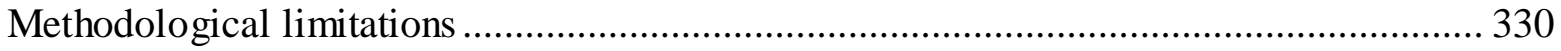

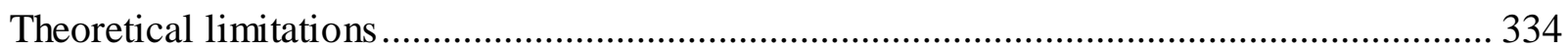

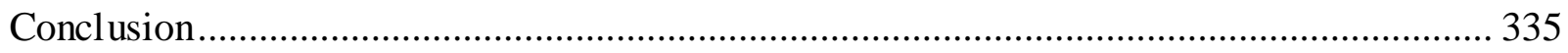

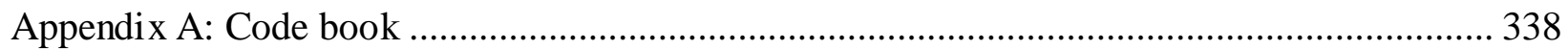

Appendix B: Summary of childcare platforms in the 2015 federal election ........................... 339

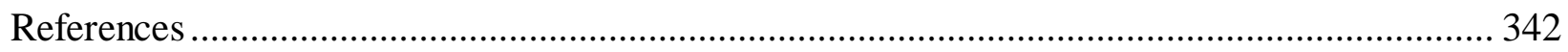




\section{List of Tables}

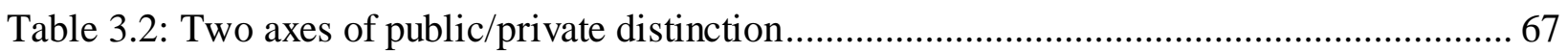

Table 4.1: Number of articles meeting the search criteria in each time period ........................ 118

Table 4.2 Categories for the length of articles .............................................................. 122

Table 5.1: Concepts, definitions and questions applied to the text on the level of text analysis 149

Table 5.2: Defining and applying the order of discourse to the text................................... 154

Table 6.1: Number of articles meeting the search criteria in all three papers by year .............. 164

Table 6.2: Overview of dominant problematizations by paper and time period....................... 177

Table 6.3: Frequency categories for problematizations .................................................. 179 


\section{List of Figures}

Figure 2.1: Neural pathways under construction. Reprinted from Early Years Study 3 by M.

McCain, F. Mustard and K. McCuaig (2003). Retrieved from

http://ecereport.ca/media/uploads/pdfs/early-years-study3-2011.pdf, pg.32 ........................... 26

Figure 3.1: “A framework for identifying ideological orientations to social policy in modern welfare states" from Dean, H. (2012). Short Introductions: Social policy. Cambridge, United

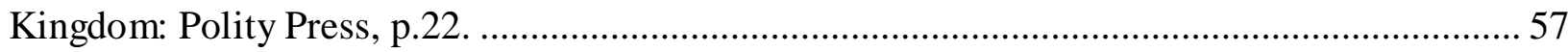

Figure 3.2: Fairclough's 3-dimensional conceptualization of discourse. Fairclough, N. (1992).

Discourse and Social Change. Cambridge, UK: Polity Press, 73 ......................................... 77

Figure 4.1: Screenshot of data collected from The National Post in 2011 ............................. 123

Figure 4.2: Sampling approach for Period A data ......................................................... 125

Figure 4.3: Sampling approach for Period B data ............................................................ 126

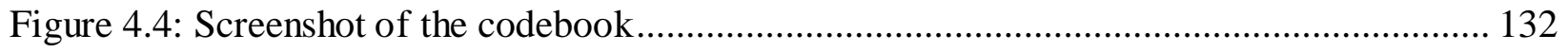

Figure 4.5: Screenshot of master spreadsheet of period A data ......................................... 136

Figure 4.6: Data re-arranged in a separate spreadsheet ................................................... 138 
Figure 4.7: Screenshot of master spreadsheet of period B data 140

Figure 5.1: Screenshot of sampled articles for the CDA 145

Figure 5.2: Blank Charts used in coding data 147

Figure 5.3: Screen shot of intertextuality 156

Figure 6.1: Number of articles (all papers) with coverage of childcare policy from 2008-2015 163

Figure 6.2: Number of articles addressing childcare policy by paper in Period A and Period B 165

Figure 6.3: Number of articles published in each paper in Period A 166

Figure 6.4: Number of articles discussing childcare policy in all papers in Period B 170

Figure 6.5: Number of articles discussing childcare policy in Period B by month and paper .... 171

Figure 6.6: Average word counts across papers by year. 176

Figure 6.7: Frequency of problematizations in all newspapers in Period A 179

Figure 6.8: Frequency of problematizations in the Toronto Star in Period A . 181

Figure 6.9: Frequency of problematizations in The Post in Period A. 182 
Figure 6.10: Frequency of problematizations in The Globe and Mail in Period A 183

Figure 6.11: Frequency of problematizations by new spaper in Period A 184

Figure 6.12: Frequency of problematizations by newspaper in period B 185

Figure 6.13: Frequency of problematizations by newspaper in Period B 186

Figure 6.14: Frequency of problematizations in The Star in Period B compared to period A ... 188

Figure 6.15: Frequency of problematizations in The Post in Period A and Period B 189

Figure 6.16: Frequency of problematization in The Globe period A and Period B..... 190

Figure 7.1: Frequency of market problematization across newspapers and time periods 197

Figure 7.2: Frequency of the private/family problematization across newspapers and time periods. 202

Figure 7.3: Frequency if the labour market supply problematization by newspaper in both periods 205

Figure 7.4: Frequency of the public problematization by newspaper and time period. 211 
Figure 7.5: Frequency of the women's equity problematization by newspaper and time period

Figure 7.6: Frequency of the "not a problem" problematization by newspaper and time period 219

Figure 7.7: Frequency of the children's well-being problematization by newspaper and time period 221

Figure 7.8: Frequency of the economic problematization by newspaper and time period 223

Figure 7.9: Frequency of the human capital problematization by newspaper and time period .. 225

Figure 7.10: Frequency of the childcare workforce problematization by newspaper and time

period

Figure 7.11: Frequency of the family equity problematization by newspaper and time period . 229

Figure 7.12: Frequency of the poverty problematization by newspaper and time period 232 


\section{List of Appendices}

Appendix B: Summary of childcare platforms in the 2015 federal election 


\section{Chapter 1: Introduction}

Despite being one of the wealthiest countries in the world, Canada's ranking on early childhood education and care (ECEC) is among the lowest in advanced industrialized countries. UNICEF (2008) noted that Canada met only one of ten benchmarks of quality ECEC services, ranking last out of 25 developed nations - behind the United States and Mexico in terms of the accessibility and affordability of childcare services as well as the education levels of the workforce. Similarly, the Organization for Economic Co-operation and Development (OECD) (2006) described Canada's childcare as "patchwork" and "fragmented" (p.6) observing in 2005 that a proposed national childcare system was in its "initial stages" ${ }^{1}$. In the decade since, there has been remarkably little ECEC policy change on the national level ${ }^{2}$. In stark contrast to Canadian parents of school-age children who have come to expect a universally accessible, high quality education system, Canadian parents of infants, toddlers and preschoolers consider themselves "lucky" if they can find and afford childcare at all (Albanese \& Farr, 2012).

\footnotetext{
${ }^{1}$ At the time of this OECD report, Canada was in the process of implementing the Early Learning and Childcare Foundations program - this program was cancelled prior to release of the OECD report.

${ }^{2}$ In the absence of federal policy leadership and funding, responsibility for ECEC fell entirely to provinces during this period, each with differing levels of commitment to ECEC. Each province and territory has its own unique approach to funding, regulating and delivering ECEC services to families (see Friendly Grady, Forer \& Macdonald, (2015) for a detailed description of provincial/territorial approaches to childcare and ECEC policy).
} 
Canadian mothers continue to cope with the ongoing "stress" and "frustration" of having little support to engage in both paid work and unpaid social reproductive work (Albanese \& Rauhala, 2015). During the era of Harper's Conservative government, pan-Canadian "childcare"3 policy was limited to the Universal Child Care Benefit (UCCB) - a taxable \$100 (later \$160) per month payable directly to parents for each child under the age of 6 . Childcare advocates argued that this market-based intervention sidestepped efforts to meaningfully address affordability and access to quality childcare in Canada. Canada remains in the same "laggard" (Mahon, 2009, p.27) childcare position today as it did a decade ago, though Justin Trudeau's current Liberal majority government has promised to "begin work on a new National Early Learning and Child Care Framework, to deliver affordable, high-quality, flexible, and fully inclusive child care for Canadian families" (Liberal Party of Canada, 2015, p. 20). One of the first policy actions of Trudeau's government was to cancel the UCCB and roll the monies into the Liberal's Child Tax Benefit - a benefit to families based on income and number of children, aimed at offsetting the high cost of raising children. It is important to note however that the CTB is not and does not claim to be childcare policy.

Most perplexing about the stagnant state of childcare in Canada is the concurrent and growing body of robust empirical evidence highlighting the centrality of accessible, high quality childcare from an economic (Cleveland \& Krashinsky, 1998; Fairholm, 2010), child

\footnotetext{
3 "Childcare" is placed in quotation marks to emphasize the idea that the UCCB was not directly tied to childcare services in any meaningful way.
} 
development (McCain, Mustard, \& McCuaig, 2011; National Research Council and Institute of Medicine, 2000), generation squeeze (Kershaw, 2015), children's rights (Friendly, 2006), poverty reduction (Campaign2000 \& Family Service Toronto, 2015) and women's rights (Dobrowolsky \& Jenson, 2004; Dobrowolsky, 2009; Prentice, 2009b) perspectives. A plethora of empirical evidence illustrates the importance of safe, nurturing and stimulating environments in the early years for optimal brain development (McCain \& Mustard, 1999; National Research Council and Institute of Medicine, 2000). Economists repeatedly estimate economically efficient cost/benefit analyses in which the lowest return on every dollar has been projected at $\$ 2$ (Cleveland \& Krashinsky, 1998; Fairholm, 2010). Social scientists and policy analysts clearly articulate the social and demographic reality that parents work and working parents need safe and affordable childcare for their own and their children's well-being (Albanese \& Farr, 2012; Cleveland, Krashinsky, Colley, \& Avery-Nunez, 2016; Friendly, Grady, Macdonald, \& Forer, 2015). For some time now, research indicates that four out of five Canadian mothers with preschool-aged children are in the paid labour force - yet availability of regulated childcare spaces has hovered around 20\% for several years (Friendly et al., 2015).

Before proceeding, it is important to explicitly bring to attention how "childcare" is defined in this dissertation. "Early childhood education and care" (ECEC) is the formal term typically used in an international policy context to refer to all policies and services that affect the care and education of young children. However, in this study, the term "childcare" is preferred for the following reasons. First, ECEC includes a broad range of policies and services, including kindergarten, parent-support programs, part-day nursery schools, facilitated play groups and a 
host of other programs. The specific focus of this dissertation is childcare, or services that provide care/education for children for the duration of a full-day from birth until school-entry. "Childcare" is not distinguished from early learning or education as these are seen as interdependent and inseparable processes in the experiences of young children.

From January 2007 until October 13, 2014 (the day the federal New Democratic Party proposed their $\$ 15 /$ day childcare system in anticipation of the 2015 federal election), the vast body of empirical and demographic evidence supporting public leadership and investment in high quality affordable childcare was dismissed by then Prime Minister Harper and his federal Conservative government. Instead, this government followed through on its 2006 election promise to implement the UCCB - a taxable $\$ 100$ paid directly to the lower income spouse (typically the mother) for each child under age 6. This policy was widely criticized as reflecting childcare in name only because $\$ 100 /$ month paid to parents did very little to reduce the steep cost of childcare, completely overlooked the severe shortage of regulated childcare spaces, and glossed over the OECD's observation that existing spaces were "mediocre" in quality (Organization for Economic and Community Development, 2004, p. 80). Furthermore, the UCCB was expensive. Friendly (2014) notes that in 2013 alone, almost \$7 billion was spent on the Universal Child Care Benefit and the Child Care Expense Deduction (CCED) (an income tax measure established in 1971 that allows the lower earning spouse to claim portions of child care costs as a deduction from taxable income). Reflecting the socially conservative orientation of Harper's Conservatives, the UCCB and CCED reinforced (and continue to reinforce in the case of the CCED) the traditional nuclear family model by providing more generous benefits to 
families with a stay-at-home/lower-earning parent and offering tax breaks to those families that can afford the up-front cost of childcare services.

The national childcare policy conversation shifted on October 13, 2014, when New Democratic Party (NDP) leader Thomas Mulcair announced his plan to work with the provinces to provide one million childcare spaces at a cost to parents of no more than $\$ 15 /$ day (New Democratic Party of Canada, 2015). Three weeks later, on October 30, 2014, Harper’s Conservatives responded with an increase in the UCCB to a maximum of $\$ 160 /$ month for each child under 6 plus an additional \$60/month for children between the ages of 6-18 (Conservative Party of Canada, 2015). The increase to the UCCB was coupled with a proposed plan to implement "family taxation", typically referred to as income-splitting. This proposed policy would allow parents with children under 18 to transfer up to $\$ 50000$ of their income to the lower earning spouse in an effort to pay taxes in a lower tax bracket (Macdonald, 2014). Shortly after this announcement (though planned long in advance of any of these official announcements) the 4th national childcare conference brought together childcare advocates, policy-makers, researchers, early childhood educators and other stakeholders from across the country. Liberal Party leader Justin Trudeau, not making any formal childcare promises at this time, sent a video message to the conference confirming the Liberal's dedication to affordable, accessible, high quality childcare.

In the span of a few short weeks at the end of 2014, childcare policy re-emerged on the national policy agenda for the first time in almost a decade. Trudeau's Liberal government swept 
the 2015 federal election, winning a majority government for the first time in 20 years. Unfortunately, childcare policy has not been a focus of Justin Trudeau's Federal government. The current Minister of Families, Childcare and Social Development, Jean Yves-Duclos, met with childcare researchers and advocates throughout 2016 though no formal funding or government announcements pertaining to the program have yet been made. In 2016, $\$ 500$ million of the $\$ 22$ billion social infrastructure fund was earmarked for a national childcare policy framew ork with $\$ 100$ million specifically targeted to Indigenous children and families .

In the recent 2017 federal budget, the Liberals earmarked $\$ 7$ billion towards "to support and create more high quality, affordable child care spaces across the country" (Ministry of Finance, 2017, p. 131). While this sounds like an impressive investment, the Child Care Advocacy Association of Canada (CCAAC) points out that: "funding increases by only $\$ 5$ million between 2018-2019 and 2020-2021...there is no increase in 2021-2022. Then, funding jumps to $\$ 725$ million in 2022-2023 and slowly rises each year until the allocation reaches $\$ 870$ million in 2026-2027”' (Child Care Advocacy Association of Canada, 2017, p. 1). So while a $\$ 7$ billion commitment appears progressive, the details reveal that these monies would not begin to flow to provinces until well after another federal election.

On the broadest level, the primary objective of this study is to make connections between how childcare policy was discussed in newspapers between 2008 and 2015, in order to identify power relationships in society and policy outcomes. Discourse (defined on page 73) is the object of study as it is conceptualized as a key mechanism through which power relationships are 
negotiated and the parameters of social policy action defined. Newspaper articles from Canada's three most broadly circulated newspapers - The National Post, The Globe and Mail and The Toronto Star - are the key source of discourse, given their ease of availability and accessibility to the general public. A primary objective of this project is to document coverage of childcare policy in newspapers during a time when it was peripheral (January 2008 to October 13, 2014 referred to as "Period A") and central to the Federal policy agenda (October 14, 2014 to Election Day 2015 referred to as "Period B"). A second objective of this study is to critically analyze sampled newspaper articles in an effort to provide insight into how childcare policy's discursive representation contributes to the positioning of childcare policy in the contemporary sociopolitical Canadian context.

The analysis of articles is achieved through two theoretical and methodological approaches: a what-is-the-problem-represented-to-be (WPR) analysis and critical discourse analysis (CDA). The WPR analysis, guided by theory and methods of Carol Bacchi (1999, 2009), identifies the presence and frequency of various childcare policy problematizations in sampled articles through both time periods. The second part of the project applies critical discourse analysis (CDA), as conceptualized and operationalized by Fairclough (1995, 2003), to a sample of newspaper articles published in Period B. Whereas the WPR identifies how a lack of childcare policy was represented to be a "problem" (or not), the CDA provides insights into how discursive approaches were used to secure dominant problematizations (and ignore others). The unique approach of building on WPR with CDA is a third objective of this study. This is 
discussed in the conceptual framework chapter (Chapter 3) and operationalized in Chapters 4 and 5.

Like the methods chapters, the findings chapters are also broken down into two parts with Chapter 6 focusing on the volume of coverage and frequency of problem representations and Chapter 7 focusing on reporting the findings from the CDA in Period B. Chapter 8 discusses the findings in light of the conceptual tools and literature discussed in Chapters 2 and 3. Finally, Chapter 9 will outline some of the key limitations of the study as well as suggest the implications of the research and possible recommendations for childcare policy stakeholders moving forward. The remainder of this chapter will focus on reviewing both the historical and contemporary Canadian childcare policy context, rationalize the importance of research that places an emphasis on childcare policy representation in the media, and briefly review my overall orientation to research.

\section{Historical overview of childcare policy in Canada}

Childcare first arose as a national policy issue in 1942 when men went off to war and women were employed in essential wartime industries. With the influx of women into the paid labour market, the Canadian government implemented the Dominion Provincial Wartime Day Nurseries Act (Friendly \& Prentice, 2009). This Act provided federal funds to childcare centres caring for children whose mothers were employed outside the home. Despite the fact that women's labour force participation rates never receded to their pre-war levels, the program was 
cancelled in 1945 immediately after the war. To this day, the Wartime Day Nurseries Act remains the only national childcare legislation that the government of Canada has enacted.

Childcare did not resurface at the federal policy level until the late 1960s when childcare policy was stumbled upon "almost accidentally" (Friendly \& Prentice, 2009, p.74) through the Canadian Assistance Plan (CAP). This federal-provincial cost-sharing mechanism facilitated federal support directly to childcare centres delivering through its mandate to reduce unemployment and reliance on social assistance (Kelly-Scherer, 2001). While it may not have been an intentional childcare policy decision, CAP's welfare approach to funding facilitated the growth of the childcare sector - particularly the not-for-profit sector - across the country. In 1971 the Child Care Expense Deduction (the first of many demand-side ${ }^{4}$ funding strategies) was also enacted, allowing parents to deduct a portion of childcare expenses from their annual income tax (Friendly \& Prentice, 2009).

Throughout the late 1960s and 1970s, childcare was embraced as a central component of the women's movement and a community of childcare advocates was formed (Campbell, 2001). The idea that women had a "right" to high quality, accessible and affordable childcare arose in the public childcare policy conversation. This idea motivated the first of four national childcare conferences $(1971,1984,2004,2014)$ calling for a national childcare system. In 1982, the Child

\footnotetext{
${ }^{4}$ Demand-side funding refers to funds that go to those demanding care - in the case of childcare services, parents. Demand side funding strategies may include vouchers, tax breaks or cash benefits.
} 
Care Advocacy Association of Canada (CCAAC) was established and received federal funding to support its advocacy efforts. Two years later, Pierre Trudeau's Liberal government appointed the Katie Cook Task Force to examine the childcare issue (Kelly-Scherer, 2001). Before this task force had reported its findings, Trudeau's government fell. Brian Mulroney's Conservative government was voted into power and established all-Party Special Parliamentary Committee on Child Care. Though the Katie Cook Task Force continued its work, its recommendation for a "universal, high quality, publically funded, not-for profit childcare system" (Friendly \& Prentice, 2009, p.78) was disregarded in favour of the Parliamentary Committee's recommendation - "tax breaks for parents, grants to for-profit centres and business incentives to create workplace child care" (Childcare Resource and Research Unit, 2012).

Bill C-144, the proposed Canada Child Care Act, came out of these latter recommendations and was the first national childcare policy tabled since the Dominion Wartime Agreements. The Child Care Act proposed $\$ 3$ billion over 7 years to develop childcare spaces in both not-for-profit and for-profit centres. Bill C-144 boldly proposed the elimination of childcare funding from CAP, offered tax deductions for childcare expenses and tax credits for parents who stayed home with their children (White, 2001). Facing fierce opposition from childcare advocacy 
groups, this Act was revised and tabled, but when parliament dissolved in 1988 the Canada Child Care Act died 5 .

From this point until 2003, national childcare policy received limited attention. Jean Chretien's Liberal Red Book policy platform in 1993 promised expansion of childcare through federal funding and significant decreases in parent fees, but these promises remained little more than political rhetoric when the threat of Quebec separation trumped the national agenda in 1995 (Friendly \& Prentice, 2009). This threat also led to significant changes in the social infrastructure of Canada. CAP was replaced with the Canadian Health and Social Transfer (CHST), a lump sum of federal funds transferred to provinces and territories to spend on social programs at their discretion. This alternative funding model effectively meant that childcare was in competition with other social programs (including healthcare) for limited funds. Ironically, the elimination of childcare from the CAP had been the central reason childcare advocates rejected Bill C-144. Only 10 years later, CAP was dismantled anyway ${ }^{6}$.

While childcare centres and advocacy groups continued to lobby for resources from a reduced funding pool, it was not until 2003 that Jane Stewart, the federal Human Resources

\footnotetext{
${ }^{5}$ White (2001) questions the strategic choice of childcare advocates to oppose Bill C-144 given it at least provided the opportunity to enshrine childcare in legislation - even if the parameters were not ideal.

'The question today remains whether advocates should have embraced a "half-loaf" (White, 2001) approach which would compromise some key elements of progressive policy but would at least promote the existence of a national childcare policy.
} 
Minister, "took the first step towards a national childcare program" (Friendly \& Prentice, 2009, p.83). The Multilateral Framework Agreement on Early Learning and Child Care (MFA) promised $\$ 1$ billion in federal transfers to provinces to be spent on childcare. All provinces except Quebec signed on, with Quebec providing support-in-principle for the initiative. A year later, Paul Martin's Liberal government introduced the Early Learning and Child Care (ELCC) Framework agreements, promising $\$ 5$ billion over 5 years to the establishment of a national childcare system. When Martin's minority government fell in late 2005, childcare became a key component of the Liberal platform for the 2006 Federal election. An additional $\$ 6$ billion was promised for childcare centres that met the QUAD principles (quality, universality, affordability, developmentally appropriate practice). Heading into the 2006 election, all provinces had developed bilateral agreements-in-principle (not legislation ${ }^{7}$ ) stating how the funds would be allocated.

During this federal election campaign, the Conservative Party introduced the Universal Child Care Benefit (UCCB). This policy offered a taxable $\$ 100$ a month payment to parents for every child under 6 to spend on childcare of their "choice". On January 23, 2006, the federal Conservative Party, led by Stephen Harper was elected to govern Canada and the first policy announcement was the cancellation of the ELCC Framework agreements and the implementation of the UCCB. Between 2006 and 2014, more than $\$ 7$ billion has been spent on the UCCB though

\footnotetext{
${ }^{7}$ This has been referred to as a "handshake" deal given there was nothing legally binding about the bi-lateral agreements.
} 
Canada's childcare sector has little to show for it (Friendly, 2014). The rate of childcare expansion has actually decreased since 2006 and parent fees now exceed the cost of university tuition in most provinces (Macdonald, 2015). Today, four out of five mothers work in the paid labour market yet there are only enough regulated childcare spaces available for less one in five children (Friendly et al., 2015). Even if/when parents are able to secure a childcare space, high parent fees create an often insurmountable barrier to accessing these few spaces. According to a recent report from the Canadian Centre for Policy Alternatives, a family with two young children in regulated care would typically spend $48 \%$ of the median family after-tax income on childcare fees (Macdonald, 2015). Finally the OECD's observation that childcare services are only "mediocre" in quality is another major concern for all stakeholders (Organization for Economic and Community Development, 2004).

These policy choices translate into difficult decisions and situations for women, children and families in their daily lives. Well-intentioned parents often do not have any option but the unregulated childcare sector. An inevitable and unfortunate result of childcare policy neglect is that children are being cared for in unregulated environments, where there is no way to go about gathering critical information about the health, safety or well-being of the children and/or caregivers (Marin, 2014). Government officials have no way of systematically identifying the number of unregulated childcare homes and illegal childcare centres, as no central registry exists. Enforcement around the number of children being cared for in unregulated childcare settings is left largely to the public, through a complaint-based system (Marin, 2014). A 2013 Marketplace documentary produced by the Canadian Broadcasting Corporation (CBC) illustrated the dangers 
inherent in informal, unregulated childcare. While this is an extreme case, findings showed that children were found sleeping in a furnace room, were being transported without car seats and that ten children were being cared for by one untrained adult (Foxcroft, 2013). Even more tragic is the fact that there have been multiple child deaths in unlicensed childcare homes across Canada every year, with four infant deaths occurring in a seven month period between 2013 and 2014 (Marin, 2014).

This is not to say the majority of unregulated childcare is reflective of these conditions, but it does attest to the fact it is relatively easy for such inadequate care arrangements to exist. When the majority of working parents depend on unknown, unregulated childcare arrangements where the well-being (and mere survival) of young children can be at risk, it should be a clear red flag for policy-makers, politicians and citizens that public policy is in need of reform. While several provinces have taken initiatives in this social policy area, most notably Prince Edward Island in $2010^{8}$ and Ontario in $2016^{9}$, the role of the federal government in childcare policy remains unclear throughout the country. The current federal government is engaging with the childcare community, but no meaningful childcare policy actions have yet been taken.

\footnotetext{
${ }^{8}$ In 2010 Prince Edward Island rolled out its Preschool Excellence Initiative which provided significant funding to childcare centres opting to become a government-funded Early Years Centre (EYC). EYCs provide a wage-grid for the ECEC workforce, funding to upgrade workforce qualifications and cap parent fees.

${ }^{9}$ In September 2016, Premier Kathleen Wynne's government announcement the creation of 100000 new childcare spaces in the province doubling the province's licenced childcare capacity. The government is currently in the process of engaging with the childcare community to plan the implementation of these spaces.
} 
It is worth acknowledging that the federal government bears no constitutional responsibility for childcare services across the country. Similar to other areas of social policy (i.e., education, child protection), childcare officially falls under provincial jurisdiction. As has been demonstrated above however, past federal Canadian governments and federal Liberal and NDP parties have pursued childcare policy at the federal level in various capacities. This paper takes as a fundamental assumption that federal funding and leadership is necessary (not sufficient) to achieve consistent, stable, affordable, accessible, high quality childcare programs and services across the country. Like Canada's national healthcare system, an area of social policy that also constitutionally extends beyond the scope of the federal government, progressively challenging Canada's privatized approach to childcare services cannot be done solely at the provincial level. For example, while Quebec has taken strides towards a provincial system, the province remains plagued by many of the same challenges that children, parents and childcare providers experiences across the country. Most notability, the quality of childcare services remains undermined by a market model as the childcare workforce remains significantly undervalued with overall low levels of education. Since 2004, Quebec's publicly funded system has moved further towards private provision and tax breaks rather than publicly-funded services. While provinces will remain the primary drivers and decision-makers regarding how childcare services are delivered (or not), the parameters of action for provincial governments will remain extremely limited without a significant federal role in providing a vision and funding for childcare services across the country. 


\section{Why this topic?}

The dissertation takes as a general assumption that the public/voters typically are not and cannot be intimately familiar with every policy issue under discussion. Instead, they are limited to an understanding of the issues through readily available means- often newspaper articles in print or digital form (Fairclough, 1995). Also, it is important to know the nature and extent of content related to childcare in newspapers by journalists, experts, stakeholders and by political parties to appreciate if and how the issue was presented to citizens. To do this, one must explore what social problems/solutions childcare policy is/has been associated with and observe how/if this has changed over time (Bacchi, 2009, 2012). Furthermore, it is essential to critically question how the issue's presentation (observable through discourse) came to be and to probe the implications of existing childcare policy discourses.

This study attempts to provide insights into how the representation and discussion of childcare policy in newspapers, particularly during the 2015 federal election campaign, may have interacted with public understanding of the issue. In a policy context where empirical, rational and economic evidence repeatedly points to the importance of significant public investment in a national, high quality childcare system, examining representations of the issue through the analysis of discourse becomes the intuitive route to understanding how and why comprehensive childcare policy remains elusive in Canada. Put more simply, if concrete evidence is overwhelmingly in favour of comprehensive childcare policy, an examination of popular representations of the issue should provide a possible path to understanding the stubborn lack of 
childcare policy initiative at the federal level. These insights may then be used to explore discursive approaches to influencing progressive childcare policy developments.

\section{Orientation to research}

As stated above, the central concern of this research is the identification and critical examination of different childcare policy "truth(s)", represented through discourse, and its/their relationship to policy outcomes. This research is rooted in the assumption that widely available discourses (often at the expense of other discourses) are both a product of truth as well as a key mechanism of its construction. Consistent with this assumption, is the conceptualization of truth as multiple, shifting, bi-directional and evolving. I situate myself directly within this research - I am not the neutral, third party observer that a positivist research model demands. I have my own subjective reasons for studying childcare as well as my own lens through which I am analyzing the truth of others, as constructed through discourse. I come to the study of childcare policy in Canada as a mother, a woman, an early childhood educator and an advocate. Though methodologically robust and systematic, the insights offered ultimately reflect my subjective orientation to the issue. They do not and cannot sit outside of me as they are very much a part of my own interpretation and understanding of the data.

This research is best characterized as postmodern (Guba \& Lincoln, 2003) with elements of both the constructivist and critical paradigms to knowledge generation and "truth" 10 claims

\footnotetext{
${ }^{10}$ "Truth" is placed in quotation marks to highlight its permeable and ever-changing nature.
} 
(described in Chapter 3). Truth is conceptualized as co-constructed, a product of conflict and consensus, fluid and multiple. As a female, white, partnered, upper-middle class mother of three children, my truth is mediated by my perception and experiences of the world. I come to the phenomenon I study from a sociopolitical position in a given historical time period. My understanding is based on what I have witnessed and what I continue to experience in my everyday life. I conceptualize myself as a constructor of knowledge in the research process, a feminist, and an advocate for the sociopolitical causes to which I am dedicated. This project could also be described as "advocacy-participatory" (Creswell, 2014) in that I, the researcher, identify as a childcare advocate. My research is a mechanism of gaining greater insight into the discursive representation of childcare policy in the hopes that more accurate/effective childcare policy discourse may begin to affect progressive policy change.

The focus of my research in the discipline of Policy Studies is analyzing how policy issues are linguistically represented through discourse. I am interested in how a sociopolitical order $^{11}$ is established and challenged through the generation of knowledge and truth constructed through the communicative process. My approach to creating, modifying and challenging knowledge/truth is inspired by critical discourse analysis (CDA) scholars, most notably the theoretical work of Chouliaraki and Fairclough (1999) who bring "critical social science and

\footnotetext{
${ }^{11}$ In this study, the term "sociopolitical order" is used to refer to the combination of social and political factors and forces that come to constitute normative ways of being. As the next chapter will illustrate, this can be best described as neoliberal given the unyielding focus on unattached individuals within private, increasingly marketized systems.
} 
linguistics together within a single theoretical and analytical framework" (p.6). These authors put forth a theory of discourse as "structuralist constructivism" whereby "seeing and researching social life is both constrained by social structure and an active process of production which transforms social structures" (Chouliaraki \& Fairclough, 1999, p.1).

The work of political scientist Bacchi $(1999,2009)$ also heavily informs my work. Bacchi focuses on the socially constructed and constitutive role of discourse specifically in the representation of policy problems - though she does not use "structuralist constructivism" to describe her research. Bacchi $(1999,2009)$ is concerned with policy analysis rather than the analysis of "discourse". Her "what-is-the-problem-represented-to-be?" (WPR) approach to policy analysis has been instrumental in the development and evolution of this project. As is discussed in detail in Chapter 3, Bacchi illustrates the connection between the conceptualization of policy problems and the parameters of possibilities for policy solutions. She highlights the importance of critically deconstructed commonly held ideas about how social issues become or don't become policy "problems". Though the focus for Bacchi is not linguistic per say, it is recognized that language is an essential component of constructing, communicating and deconstructing problematizations. Therefore, though they operate in separate academic disciplines, the approach of CDA and WPR to policy analysis actually complement each other well in a project where deconstructing and critically challenging the ideas underlying current or potential public policy is the goal. 
Having said this, these two theoretical approaches to research, and the methodological tools they instantiate, are not typically discussed or used together. ${ }^{12}$ Therefore, in addition to documenting and analyzing the discursive representation of the childcare policy "problem" in mainstream newspapers between 2008 and 2015, a second key objective of this project, is to methodologically synthesize these complimentary theoretical and methodological approaches to analyzing policy "problems" through deconstructing discourse. ${ }^{13}$

\section{Moving childcare policy forward}

The final objective of this dissertation is to mobilize knowledge gained through making informed recommendations to childcare policy advocates, politicians, reporters and other childcare policy stakeholders. While the discussion chapter will focus on understanding the findings from various theoretical perspectives (including a discussion of how childcare policy representations interact with hegemonic power relations and policy outcomes), the conclusion recommends possible ways to construct policy representations that will challenge dominant norms. An advocacyparticipatory research agenda necessitates that insights be translated into social action in some way (Creswell, 2014). Because the current federal government is open to working with childcare stakeholders in the pursuit of a national childcare policy framework, advocates, newspaper

\footnotetext{
12 Fairclough \& Bacchi have recently engaged with and critiqued each other's work (Fairclough, 2013; Bacchi, 2015). These critiques are elaborated on in Chapter 3 . There have also been a handful of scholars who have bridged WPR and CDA in empirical studies (also discussed in Chapter 3). Nevertheless, this project engages with these two theories and methodological approaches in a way that has not been attempted elsewhere.

13 The epistemological and ontological congruencies and tensions between CDA and WPR are explored in Chapter 3. Briefly, both theories emphasis a critical constructivist paradigm whereby the discursive representation of social issues/practices is central to uncovering and understanding power relationships in society.
} 
reporters and other childcare policy stakeholders must be ready to act in an informed, consistent and united way when opportunities arise. Translating the academic insights this dissertation provides into tangible, discursive possibilities for the future is explored in the final chapter. 


\section{Chapter 2: Literature Review}

Before undertaking a comprehensive theoretical discussion of how research and knowledge are conceptualized in this project, first it is important to succinctly describe why childcare policy matters. There is little value in critically deconstructing conceptualizations of an issue if the phenomena itself is not deemed essential to affecting positive change in the experiences and lives of people. This chapter will review the wide body of empirical literature rationalizing public investment and federal leadership in high quality childcare from a children's well-being, economic, human capital, poverty-reduction, labour market support, social solidarity, generational equity, family equity, and population growth perspective (the next chapter will explore the women's equity rationale at length as this is a key component of the theoretical orientation to this project). The final portion of the chapter will review literature that has specifically examined the representation of Canadian childcare policy in the media. While this is a relatively small body of literature, there does appear to be a growing interest in the role of the media in influencing public understanding of the issue and policy outcomes (Albanese \& Rauhala, 2015; Albanese et al., 2010; Rauhala et al., 2012; Richardson, Langford, Friendly, \& Rauhala, 2013).

\section{Rationales supporting comprehensive, publicly funded childcare policy} Children's well-being

A children's well-being rationale justifies public spending on comprehensive childcare policy and services from a human rights perspective. In theory, Canada promised to provide the 
basic childcare services needed for children to be well in Article 18 of the United Nations Convention on the Rights of the Child (UNCRC) (1989): "state parties...shall ensure the development of institutions, facilities and services for the care of children". Over a decade ago, Friendly (2006) wrote a compelling piece illustrating several Articles of the UNCRC that Canada's lagging childcare policies have failed to address (Article 3, 4, 18 and 23). Regardless of the fact that international consensus recognizes the necessity of safe, accessible and publicly supported childcare services as a component of children's basic rights and that Canada promised to fulfill this, Canadian governments have yet to act on this (White, 2014). Outside of regular reports that must be submitted to the Committee on the Rights of the Child located in Geneva to monitor the country's progress towards the UNCRC's goals (on which the committee provides comments and suggestions), the $\mathrm{UN}$ has few enforcement mechanisms to ensure ratifying countries are making progress towards the UNCRC's goals. Ultimately, the care and well-being of children, let alone their opportunities for civic engagement, remains at the margins of contemporary Canadian society. As it stands now, the well-being of children remains largely tied to the socioeconomic status of their parents who face significant barriers in providing and/or accessing high quality childcare services.

\section{An economic}

A body of literature supports state involvement in childcare policy funding and development from an economic perspective. Taking into consideration the increased labour force participation rates of mothers, the positive developmental impacts on children and the growth of the childcare sector, Canadian economists Cleveland and Krashinksy (1998) concluded that the 
cost/benefit ratio would at minimum provide a $\$ 2$ return for every $\$ 1$ of public funds invested in high quality childcare services. Drawing on data from 2008, Fortin (2011) noted that Quebec's low-cost childcare system significantly increased the labour force participation of women $(+3.8 \%)$, increased provincial GDP by $\$ 5.2$ billion $(+1.7 \%)$ and "was entirely self-financing within the provincial budget" (Fortin, 2011, p.15). Similarly, Canadian statistics compiled by the CCHRSC (2009a) noted that ECEC is an effective employment ${ }^{14}$ and GDP multiplier ${ }^{15}$ creating $^{2}$ 40 jobs for every $\$ 1$ million invested in the sector (40\% higher than the next highe st industry). Childcare GDP multiplier estimates suggest that every dollar invested in childcare increases the economy’s output (GDP) by \$2.30 (Child Care Human Resources Sector Council, 2009a). The CCHRSC (2009a) concludes that:

Not only is the GDP multiplier for the ECEC sector one of the highest of all industries, but a comparison of the employment multipliers to similar employment multipliers for major industries illustrates that per dollar of increased output, the ECEC sector has by far and away the highest employment multiplier of all these industries (p.29).

\footnotetext{
${ }^{14}$ An employment multiplier refers to the number of jobs created per million dollars spent in an industry (CCHRS, 2009).

15 The GDP multiplier reflects the increase in overall output in Canada from a change in output by a particular industry" (CCHRC, 2009, p.29).
} 
Finally, Canadian economist Fairholm (2010) also draws on the concepts of GDP and economic multipliers to reveal that public spending on ECEC services are recouped through higher government revenues at a rate of more than $\$ 2$ for every $\$ 1$ invested.

\section{Human capital}

The human capital rationale supporting public investment in childcare policy and service is closely related to the economic rationale and indeed is often used to project long-term economic calculations. The human capital rationale rests on the assumption that human potential can be maximized through the stimulation of developmental opportunities in the early years. This rationale fits with a neoliberal sociopolitical order in that it conceptualizes children as a vehicle of capital investment (Prentice, 2009a). Language referring to "critical periods" and/or "neural plasticity" emphasize early childhood as foundational to future physical, emotional, linguistic, academic and social achievement. This rationale is heavily associated with a psychosocial and biological perspective such as that illustrated below by McCain, Mustard and McCuaig (2011). The figure below, borrowed from the Early Years Study 3, captures the idea that high quality ECEC environments are essential for optimal brain functioning in the future. Colloquially speaking, this rationale reflects the idea that governments can contribute to "building a better baby". 


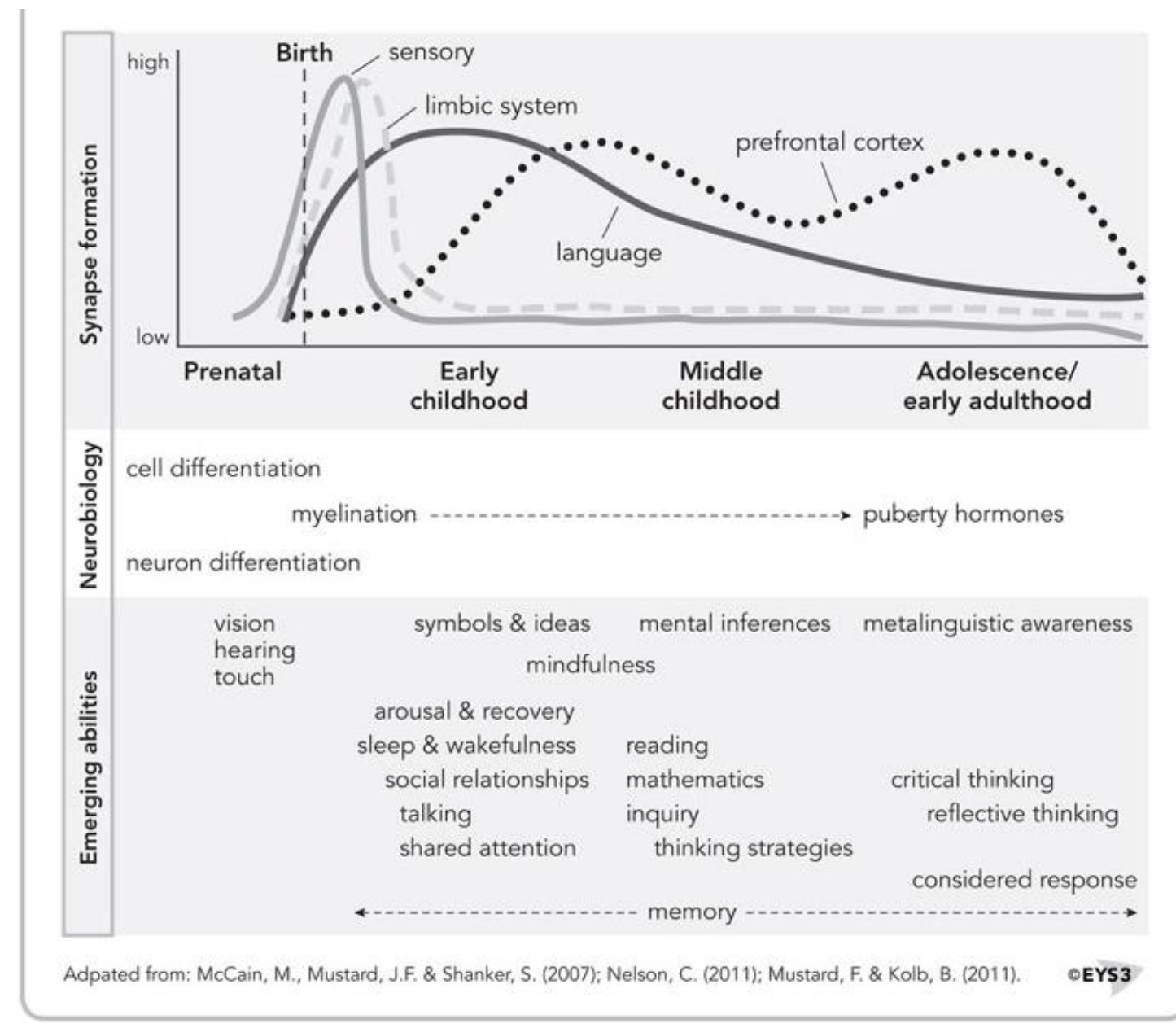

Figure 2.1: Neural pathways under construction. Reprinted from Early Years Study 3 by M. McCain, F. Mustard and K. McCuaig (2003). Retrieved from http://ecereport.ca/media/uploads/pdfs/early-years-study3-2011.pdf, pg.32.

\section{Poverty reduction}

Affordable, high quality childcare services have long been identified as a central pillar of the anti-poverty movement in Canada. One of the key organizations spearheading this movement, Campaign 2000 (founded in 1991 with the goal of eliminating child poverty by the 
year 2000), has always identified childcare as a necessary resource to lift families with young children out of poverty. In the 2015 National Report Card, Campaign2000 (2015) notes that "low-income families are especially poorly served both by prohibitive fees and lack of access to regulated childcare" (p.10). Such a lack of services perpetuates the cycle of poverty whereby parents are either unable to participate in the labour market or children are placed in precarious, unregulated (often unknown and unsafe) childcare.

\section{Labour market support}

Closely related to the poverty reduction and economic rationales is the labour market support rationale. This rationale justifies public spending on childcare from the perspective that childcare is necessary for all parents to be able to join and remain in the labour force. This rationale is not specific to families living in poverty, single parents, or women per se, but more broadly emphasizes childcare as a resource for labour market participation of citizens as well as optimal functioning of the labour market itself. This rationale may draw on the idea that employers benefit from childcare programs that limit the absenteeism of employees (County of Wellington Childcare Services, 2012) and/or that parents who are able to access childcare have higher labour force attachment rates than those who cannot access these services. The optimal functioning of the labour market, rather than the well-being of parents, mothers or families, remains the focus with this rationale. 


\section{Family support/equity}

A family support/equity rationale favouring comprehensive childcare policy is rooted in the idea that high quality childcare is an essential family support for families with young children. This rationale emphasises the need for childcare that meets the complex needs of families so that families with young children have equitable opportunities as families without young children. The Canadian Association of Family Resource Programs (FRP Canada) takes the position that "all-day early learning and care programs are intended to alleviate the stress of finding child care for part of the day" (Canadian Association of Family Resource Programs, 2011) recommending an "an integrated [family support] system through partnerships between schools, childcare centres, prenatal programs and other community-based organisations" (p.7). The family support/equity rationale tends to downplay childcare as a women's issue preferring the gender neutral term "families". For example, in the Family Resource Canada journal, Schatz and Mann (2006) state:

A women-centered framework for child care makes mothers the primary consumers of non-parental child care and isolates them from the context of their whole family. It tends to perpetuate gender inequity by placing ownership of the issue and all responsibility for it on the shoulders of women (p.20).

It is important to note that this rationale as conceptualized here reconciles the important and necessary role of the family and childcare rather than that prioritizing family care over childcare, but does so from a gender neutral lens. 


\section{Social solidarity}

Childcare is often discussed as a key mechanism for achieving social cohesion/solidarity. In fact, the Childcare Resource and Research Unit (CRRU) (2013) highlights social solidarity as one of the four pillars underscoring comprehensive childcare services in Canada (along with parental employment, equity and lifelong learning) noting that ECEC services have the potential to be a "central point for enhancing the visibility of children and families in civil society and helping build social cohesion at the community level" (para.3). Canada is a country that prides itself on diversity and inclusion of all people. Multiculturalism is referred to as a "fundamental characteristic of the Canadian heritage and identity"(Government of Canada, 1985, p. 3) in legislation enacted more than 30 years ago. High quality childcare environments are also essential to including children and families of all developmental abilities (Bancroft \& Underwood, 2015). Finally, in a sociopolitical and economic context where there is increasing class division and a general erosion of the middle class, affordable, accessible childcare services offer a route to both closing the divide (i.e., allowing more parents to join the middle class through increased and sustained employment) and bridging the divide with a concrete point of contact between classes in that working parents of all classes require high quality childcare services.

\section{Generational equity}

Recently a generational equity perspective has come to be associated with the childcare advocacy movement in Canada. This rationale, closely related to the social solidarity rationale, 
highlights the growing inequity between generations - mainly baby boomers and "boomlets" (the children of boomers). Kershaw (2015) notes that the combined average spending of different levels of government for Canadians over 65 is at least 3 times higher than for Canadians below age 45. While differences in spending appear logical in that aging retired persons likely require more support from the government, it is pointed out that Canadian families with young children are facing significantly more barriers today to achieving equal participation in society than they were thirty years ago. For example, Kerhsaw (2015) notes that young people today have to save up to three times longer to put down a $20 \%$ down payment on a house than they did 40 years ago, despite the fact that most families now have two incomes and work significantly more hours.

Despite being more educated, Canadians under age 45 are having increasing difficulty securing full-time, stable jobs with benefits, while the cost of living (adjusted for inflation) has significantly increased. Furthermore, changing demographics of the family (i.e., two parents working, an increase in single-parent families) necessitate high cost services such as childcare. For many young families, it becomes impossible to achieve a stable economic position that includes the option to save and invest money as opposed to just paying off substantial debts . Furthermore, many of the boomers currently retiring have benefited from full-time, stable work and property ownership throughout their lifetimes leaving them in a position where government support may not be as necessary as it was in past generations. Investing in high quality childcare services across the country is one way to positively impact the generational policy and funding divide. This rationale provokes a critical examination of contemporary Canadian redistributive 
social policies, established in a historical, very different sociopolitical context, that heavily support one generation at the potential expense of another.

\section{Population growth}

Finally, it must be acknowledged that comprehensive childcare policy is important for the regeneration of society. It is easy to forget that choosing whether or not to have children is still a relatively new option for women and families. Governments can no longer assume that the population will sustain/grow itself with no policy intervention. The high cost of living (including the often prohibitive cost of childcare) and necessity of paid labour-force participation of women act as a deterrent for families considering whether or not to have children, and if so, how many (Kershaw, 2015). Furthermore, the window of opportunity for childbearing is very much biologically determined. Women are delaying child-rearing later than at any other point in history - a socially celebrated phenomena but troublesome at a biological level. Very few women are economically and emotionally ready (in relationships or not) to become mothers in their prime childbearing years (early 20s). According to Statistics Canada (2013) "women in their thirties now experience higher fertility rates than women in their twenties" (para.3). It is fair to say that if women had access to high quality, affordable care options while pursing studies or their careers, they may be more inclined to have children earlier and possibly have more children. Indeed, accessible child care has been correlated with higher birth rates in many countries (Daly, 2007). 
Immigration has become a key alternative mechanism for increasing the Canadian population. However, Canadian immigration policies have made it increasingly difficult for all classes of immigrants to be admitted to Canada and then to "integrate" into Canadian society. Over the past decade neoliberal immigration policies that compromise the security of people in favour of immediate economic productivity have created greater barriers to family reunification (Bragg \& Wong, 2016), systematically deskilled workers (Tungohan, 2013) and failed to recognize international education and credentials - particularly for non-European, visible minority populations (Banerjee, 2009).

With people living longer than at any other point in history, a younger generation of workers/taxpayers is necessary to sustain the economy and existing social infrastructure. Governments can no longer work under the assumption that the Canadian population will replenish itself. In the decade between 1996 and 2006 (the most recent data available), the percentage of Canadians $0-14$ years of age dropped from $20.5 \%$ to $17.7 \%$. As of July 1, 2015, Statistics Canada (2015) estimates that this number has dropped to about $16 \%$. Despite the declining number of young Canadians to replenish the population, the Canadian government has made it increasingly difficult for immigrants to enter and integrate into Canadian life. Whether it be providing systemic supports to increase the birth rate of Canadians (i.e., childcare), or facilitating inclusive immigration strategies, Canadians have a vested interested in the regeneration of the population. Recognizing the decreasing population in the $0-18$ years demographic, Hertzman (2004) suggests Canadian governments continue to fund this demographic at a constant rate despite of the decreasing population. He argues that the surplus 
saved from funding fewer children/youth be reinvested into the $0-5$ age bracket lending itself to more high quality services for young children. He refers to this approach as a "demographic harvest" (p.3) whereby citizens on a population level are better situated to become productive members of society. At the same time, with more comprehensive services available for young children and families, it is foreseeable that families will have the supports they need to have (more) children.

\section{Literature Review: Childcare policy representation in the Canadian press}

In light of a strong body of evidence supporting comprehensive childcare policy and funding, of which a significant portion is consistent with prevailing neoliberal values, it is puzzling to understand how or why Canadian national childcare policy remains in its laggard position (Mahon, 2011). How childcare policy is discussed and understood in widely accessible policy forums becomes a key piece for understanding the extreme disconnect between sound policy research and the lack of policy action on childcare. Several studies related to various topics have empirically supported the relationship between public opinion and consumption of mediated texts (Fladmoe, 2011; Flaxman, Goel, \& Rao, 2016; Zhao, 2016) while others have linked mediated communications to public policy and agenda setting (Tan \& Weaver, 2010; Zeitel-Bank, 2017)

This is not the first study to critically question the representation of childcare in the media - though its focus on childcare policy is unique. One of the first studies to empirically examine the representation of childcare in the mass media was carried out in the United States 
between 1994 and 1998. Dorfman \& Woodruf (1999) examined 18 major U.S. newspaper articles and stories that devoted substantial content (1/3 of article) to the discussion of childcare. These authors were interested in the quantity of coverage, use of sources, and childcare frames throughout the articles. Their findings illustrate that discussions of childcare were most frequently related to policy initiatives, childcare health and safety regulations, advice for parents, and crime and tragedy in childcare centres. The authors go on to reveal that childcare advocates, parents and childcare providers were the most frequently quoted sources in the articles, while dominant pro-childcare frames encouraged the government to become involved in the provision of affordable and high quality childcare services for children and families. These authors also note anti-childcare sentiments, consistent with a "parents (mothers)-should-be-at-home-withtheir (her)-kids" and "if-you-can't-take-care-of-your-kids-don't-have-them" frame. Overall Dorfman \& Woodruf (1999) observe that "the needs of parents, rather than children, are the focus of the news coverage" (p.12). It worth noting that this study reveals a secondary focus on the childcare workforce, including advocating for better training and wages for early childhood professionals.

A small but growing body of literature has examined childcare's representation in the Canadian media in the past decade. Each of these studies highlights the period between late 2005 and early 2006 when childcare was featured as a key campaign issue heading into the January 2006 federal election. Thériault (2006) provided an analysis of The Nanny State series that was featured in The National Post in late 2005. This series deconstructed the right-winged framing of the childcare issue (a national childcare system as a "massive top-down government run 
program”) from a rational, empirical perspective. Thériault effectively exposed a concerning gap between ideological representations of the issue in the media and empirical evidence, noting that ideology can often trump practicality when it comes to the public's understanding and appreciation of important policy issues.

Rinehart (2008) provides a broader analysis of over 80 newspaper articles from Canada's two national dailies (The Globe and Mail and The National Post) published in 2005/06. Also included in this study are interviews with childcare policy experts, parents, advocates and journalists (both within and beyond the papers analyzed). She argues that childcare got an "easy ride" in the media during this election because of a male editorial bias that "failed to recognize the importance of these 'soft' news issues to readers and federal policy-making"' (Rinehart, 2008, p.24).

Two years later, Albanese, Rauhala, Ferns, Johnstone, Lam and Atack (2010) published an inaugural piece which documented the quantity and placement of childcare coverage in four Canadian daily newspapers (The Toronto Star, The National Post, The Globe and Mail, The Ottawa Citizen) from 2000 to 2007. Albanese et al. (2010) reveal that coverage was highest in election years (i.e., October 2000, May 2004) and actually doubled during the 2005-2006 election campaign. They also note high levels of coverage around childcare policy developments - specifically the Federal/Provincial/Territorial Service Ministers meeting in February 2005 and April 2007 when the Conservatives implemented the UCCB. The Toronto Star, identified as the most "liberal" of the papers, had the highest number of articles and highest average word count 
while The National Post had the lowest number articles and lowest word count. It was relatively rare across all papers for childcare to be featured on a front page or section front, leading Albanese et al to conclude that "newspaper editors deemed childcare of little relevance to readers" (p.831). It is interesting to note that during times of increased coverage (i.e., more articles that discussed childcare) there was not an increase in the word count in these articles. The authors suggest that this indicates that childcare remained "superficially treated" (p.830).

Rauhala, Albanese, Ferns, Law, Haniff \& Macdonald (2012) build on Albanese et al (2010) to examine newspaper articles to determine who was quoted and when. Rauhala et al (2012) limited the analysis to the 55 days before, 55 days during and 55 days after the 2006 federal election (a longer than usual campaign given it took place over the winter holidays). Their research reveals that the voices of politicians, specifically Liberal leader Paul Martin and Conservative leader Stephen Harper, were "overwhelmingly the most quoted sources" (p.102) in comparison to activists, parents and child care providers. Parents were quoted less than $10 \%$ of the time in all papers while pro-childcare advocates, who are recognized for their "decades-long expertise in policy development" (Rauhala et al, 2012, p.104), were quoted the least. Interestingly, parents were quoted significantly more often in the more "conservative" National Post, in comparison to the more "liberal" Toronto Star. Advocate voices were largely ignored across the board. While quoting parents may be seen as a progressive, bottom-up approach to policy input, it could be argued that such an approach to reporting occludes the policy-level perspective in which childcare advocates and experts are intimately familiar. Most recently Albanese \& Rauhala (2015) merged findings from their ongoing study of newspapers between 
2000 and 2007 and qualitative interviews with mothers in rural Ontario and Quebec. The authors note an overall absence of mother's voices in newspaper articles (instead observing the gender neutral terms such as "parents" and/or "families") alongside observations from interviews that mothers experience significant, daily "stress and frustration" due to a lack of high quality, accessible childcare services (Albanese \& Rauhala, 2015).

Building on this work, Richardson (2011) provides a critical discourse analysis of policy platforms, political leaders' speeches and representation of the childcare issue in newspapers during the 2006 federal election campaign. This major research paper identified the "choice" discourse, rooted in a conservative ideology favouring the stay-at-home-mom family model, as the dominant representation of childcare. Richardson, Langford, Friendly \& Rauhala (2013) went on to problematize this narrow conceptualization and representation of childcare suggesting that emotionally laden ideologies overshadowed rational and critical policy debates in the media. Similar to Thériault's (2006) conclusion, the nostalgic notion that "mothers know best" appeared to trump logical policy arguments that clearly illustrate the prudent economic, social and moral arguments for comprehensive childcare policy in Canada (Richardson et al, 2013).

More Recently, Langford, Albanese, Prentice, Summers, Messina \& Richardson (2013) examined the discursive resources employed by childcare organizations in publicly available media releases and annual reports. This study was specifically concerned with analyzing discourse through the lens of professionalism. It compared documents produced by professionalized childcare organizations, working on behalf of the childcare workforce, and 
grassroots childcare organizations concerned with the broader childcare system issues. Findings reveal that these two types of childcare organizations generally present common concerns, play down the role of the market in childcare provision, and rely on the 'business case' frame in their documents. Particularly relevant to this study is the finding that the business case policy frame outnumbered other policy frames. At the same time the authors made the overall observation that there was an "underutilization of framing" (Langford et al, 2013). It will be interesting to note any connection between the policy frames used by childcare organizations and those used by the popular press. While media releases and annual reports are publicly available, their audience is limited in scope. The nature and number of frames that are constructed in the popular press may shed light on wider conceptualizations of the childcare issue.

Overall then, the discussion of childcare policy in the media and by advocacy organizations shifts depending on various social, political and economic factors. There appears to be an ongoing tension between broad ideas and values in which the care of children is embedded and the empirical evidence/research that one would think would/should seemingly direct politicians and policy-makers (i.e., economic arguments, changing demographics) to pursue progressive childcare policy. The "ideal" role of the family, state and market in caring for young children is deeply connected to ways of being in the world that are not easily communicated on a political level. The purpose of this project is to discover how these ongoing tensions have revealed themselves at a time when childcare policy was peripheral and central to the federal policy agenda. 


\section{Chapter 3: Theoretical framework}

The purpose of this chapter is to outline the orientation to research as well as explore the specific social theories central to the conceptualization and operationalization of this study. First a feminist political economy lens theoretically contextualizes this project, whereby the contemporary positioning of childcare in the family-state-market nexus is explored and critiqued from a gendered perspective. Grounded in this framework, key concepts from post-World War II social theorists that have been foundational to the contemporary theories embraced in this project - critical discourse analysis (CDA) (Chouliaraki \& Fairclough, 1999) and what-is-the-problemrepresented-to-be (WPR) - are then applied. Third, the theoretical foundations of CDA and WPR, (originating in the academic discipline of Linguistics and Political Science respectively) are first explored on their own and then in relation to each other as they are applied in this project. The overview of CDA as a theory focuses on the role of discourse in establishing/changing social practices while the overview of WPR highlights the role that discursive representation of policy "problems" play in establishing/changing normative ways of being (Bacchi, 1999). Finally, this chapter seeks to justify the use of CDA as a theoretical and methodological tool to build on WPR. Such an approach not only bridges academic disciplines, but provides a way of making important connections between discourse, public policy, normative ways of being/knowing and illuminating possibilities for other ways of being/knowing. 


\section{Feminist Political Economy (FPE) Theory}

From a social policy perspective, political economy theory brings to light what the role of the government is or should be in stabilizing/stimulating the free market economy and securing the well-being of and opportunities for its people (Dean, 2012). Consistent with a global shift, Canada has experienced a neoliberal entrenchment over the past several decades characterized by the preference for the reduced role of government and pervasiveness of free-market principles favouring the unattached, white male (Mahon, 2009). According to FPE theorists, this has resulted in the invisibility of gendered, paid and unpaid social reproductive work negatively impacting the well-being of women, mothers, the childcare workforce and children (Dobrowolsky, 2009). FPE explicitly challenges neoliberal political economic theory bringing attention to how the interplay of public (government) and private sectors (family and market) positions women in society (Bezanson, 2006; Bezanson \& Luxton, 2006; Braedley \& Luxton, 2010).

Bakker (2003) identifies three premises on which neoliberalism rests, all of which are problematized from a FPE perspective. These premises include: 1) the primacy of autonomous individuals; 2) the market as the most efficient mechanism to secure welfare; and 3) that all public goods should support the market. Embracing the unattached, heterosexual, white, employed male as the Homo Economicus (prototypical individual on which the market is theorized), neoliberalism is blind to the unique position and needs of individuals and groups that do not fit neatly into this category. Neoliberalism typically reduces public policy to economic cost/benefit analyses, replacing the pursuit of the well-being of individuals with the economic 
well-being of the nation. Measures of "successful" policy become defined by economic growth rather than measures such as gender equity, the reduction of child poverty, and/or the actualization of long-ago promised children's rights (i.e., such as those mentioned in the aforementioned UNCRC). Neoliberalism has meant that state priorities have shifted from the post-war Keynesian era of protecting the well-being and opportunity of citizens to protecting the well-being and opportunity of capital (Bakker \& Gill, 2003). In an increasingly neoliberal globalized world, the trend for public policies has been to reduce risk for the privileged, while compromising the security of the majority of the population (Bakker, 2003). It is increasingly common for wealthy, industrialized nations such as Canada to pursue policies allowing the rich to protect their wealth (i.e., corporate tax breaks and international tax havens), while the living conditions of the lower and middle class deteriorate (i.e., carry more debt, forego property ownership, delay childcare rearing). FPE critiques a neoliberal understanding of political, economic and social practices to illuminate the primacy of social reproductive work predominantly carried out by women.

\section{Social reproduction and the women's equity rationale}

Braedley \& Luxton (2010) suggest that what is unique about neoliberalism, compared to classic liberalism, is that it "has brought the logic of the market to bear on seemingly every facet of social life" (p.7). Most relevant to women, neoliberalism occludes the underpaid and unpaid social reproduction work overwhelmingly carried out by women. Bezanson and Luxon (2006) define social reproduction is defined as: 
...the processes involved in maintaining and reproducing people, specifically the labouring population and their labour power on a daily and generational basis. It involves the provision of food, clothing, shelter, basic safety and health care along with the development and transition of knowledge, social values and cultural practices and the construction of individual and collective identities (p.3).

According to FPE theorists, neoliberalism's embrace of the unattached, white, male, heterosexual, employed Homo Economicus routinely takes this work for granted rather than conceptualizing it as a valuable and necessary component of formal market production. Both Bezanson and Luxton (2006) and Braedley and Luxton (2010) argue neoliberalism's narrow conceptualization of "production" has led to the downloading of social reproduction to individual women, with the most vulnerable women usually bearing the largest load. While the federal Canadian state has never played a leadership role in the funding and delivery of childcare services in Canada (outside of the short-lived Dominion-Provincial Day Wartime Day Nurseries Act enacted during a global state of emergency), past policies such as the Canada Assistance Plan directed more money to regulated, not-for-profit childcare than is available today. For example, only Manitoba (MA) and Saskatchewan (SA) restrict funding to NFP operators on the provincial level, while other provinces are neutral (or defer responsibility to other levels of government) as to whether for-profit operators are eligible for government funds (Friendly et al., 2015). Not surprisingly, the bulk of new childcare spaces created in Canada (outside of MA and SA) have been in the for-profit sector over the past several decades (Friendly et al., 2015). Despite the fact that labour force participation of Canadian women continues to increase (Statistics Canada, 
2014), funding to childcare programs and services have remained woefully underfunded.

Women, often racialized, with lower socioeconomic status, and with precarious citizenship status, have filled the increasing void in care often at the cost of exploitation (Arat-Koç, 2006;

Brickner \& Straehle, 2010). Viewed through an FPE lens, affordable, accessible, high quality, publicly supported childcare services is a necessary component of all women's equal participation in society, but particularly racialized, classed and newcomer women (discussed more below).

\section{The limitations of neoliberalism in relation to gendered, social reproductive work}

FPE theory highlights four problems with neoliberalism's narrow understanding of production as limited to the economic sphere: 1) women are less visible in the formal market economy (particularly in high-level positions); 2) neoliberalism devalues social reproductive work carried out in the formal market economy (i.e., the childcare workforce); 3) it takes forgranted/occludes the value of social reproduction work outside the formal market economy (unpaid social reproductive labour); and 4) it nullifies the possibility of "nonmarketable" (i.e., public) social reproduction resources (whatever is produced through work must be marketable) (Bakker, 2003).

At first glance, the Canadian workforce appears to be almost equally made up of women and men $-47 \% / 53 \%$ respectively (Statistics Canada, 2014). However, it quickly becomes apparent that women are overrepresented in part-time, undervalued work in the healthcare and social service sectors. According to Statistics Canada (2011), 67\% of women are employed in 
teaching, nursing and service occupations compared to $31 \%$ of men. Furthermore, women are twice as likely to be employed part-time as men. Not surprisingly, The Conference Board of Canada (2011) reports that men are 2-3 times more likely to hold managerial positions than women. Clearly, while women may be entering the labour force in large numbers, they are overwhelmingly employed in part-time, service work and are much less likely to climb the corporate/professional ladder. Illustrating the link between these figures and childcare, a recent report commissioned by the Government of Ontario to examine the stubborn gender-wage gap in the province prioritized the implementation of an affordable, accessible quality childcare system as its number one recommendation to government (Austin, Davis, Heyninck, \& Singh, 2016). Consistent with this, FPE theory situates childcare services as an essential component of women's equal participation in the paid labour market and subsequent equity in society.

Second, the low wages and poor working conditions of most paid caregivers directly flows from the dominant neoliberal conceptualization of "work" in the formal economic sphere. In the Canadian childcare sector, the most recent data reveal that female full-year, full-time early childhood educators and early childhood education assistants earned \$20,155 compared to $\$ 41,401$ for women across other occupations (Child Care Human Resources Sector Council, 2009b, 2013). Instead of supporting and employing a well-educated and remunerated childcare workforce, Canada has largely come to rely on immigration policy as a mechanism for providing inexpensive social reproduction work. Of note, Canada's Live-In Caregiver (LIC) program grants citizenship to vulnerable women from less wealthy countries who work for Canadian families requiring care. Caregivers entering Canada through the LIC program may apply for 
citizenship status after two years of employment with a sponsoring family. ${ }^{16}$ Newcomer caregivers are dependent on the sponsorship of their employers leaving them with little recourse should their wages or living conditions be exploitative (Brickner \& Straehle, 2010). Furthermore, it is often the case that women entering Canada through the LIC program must leave their own dependents behind, rendering care work doubly invisible both Canadian and immigrant women must hide/offload their caregiving responsibilities in order to produce in the market economy (Arat-Koc, 2006). From an FPE perspective, the work of women carrying out social reproductive work - whether Canadian-born or newcomers - must also be highlighted and valued. This idea informs the childcare workforce problematization (identified in code book) in this project as it highlights how a lack of childcare policy (often in combination with other areas of policy - in this case immigration policy) in Canada marginalizes those carrying out care work. It is concerning that the regulated childcare workforce remains grossly underpaid to the point where immigration policies actively recruit vulnerable women to carry out the work in unregulated settings. However, neoliberal logic permits and even encourages these arrangements to continue.

Third, neoliberalism occludes the necessity and value of social reproductive work. FPE scholars highlight social reproduction as the backbone of market production (Braedley \& Luxton, 2010). One cannot go to work if not fed, clothed, skilled/educated, socialized and in

\footnotetext{
16 Under Prime Minister Harper's Conservative government the number of eligible applicants who may apply for citizenship was capped at 2750 considerably compromising the possibility that caregivers will access citizenship (Black, 2014)
} 
good health. On a more absolute level, without biological reproduction (i.e., the bearing and raising of children) there would be no workers or consumers. Society and the economy would cease to exist. Instead, neoliberalism recognizes people only as a result of formal market production, regardless of any social reproductive work. As pointed out by Mahon (2009), one of the main problems with this is that it treats women exactly like men (p.52). Women, including mothers to whom childcare responsibilities typically fall (Doucet, 2015; Kan, Sullivan, \& Gershuny, 2011), are expected to partake in the paid labour force on the same terms as men with fewer (or no) childcare responsibilities. That women work is not the problem, and in fact, in many ways is empowering for women who no longer must be dependent on a husband for their security. The problem arises when the social programs and services that are necessary for women to engage in formal economic production in addition to the social reproductive are absent. Individual Canadian mothers struggle to achieve an ultimately fictitious "balance" between paid and unpaid labour that neoliberal ideals demand (Principe, 2014; Sauve \& People Patterns Consulting, 2009).

Ironically, "intensive mothering" has concurrently emerged alongside neoliberalism's preferred occlusion of social reproductive tasks. Over the past several decades there has been increasing expectations on mothers (regardless of attachment to the paid labour force) to be more available, nurturing and stimulating than ever before (Johnston \& Swanson, 2006). Mothers are strongly encouraged to breastfeed (and breastfeed longer), to provide consistent guidance and emotional support and also constant stimulation and learning opportunities for their young children. So, at the same time that a mother's paid labour is ever more necessary to maintain a 
stable and decent standard of living, a mother's social reproductive tasks have also intensified. Canadian mothers continue to struggle to "do it all", seldom having the time or space to question the overarching systems and neoliberally entrenched policies and politics that have positioned them in society. The end result of this for many Canadian mothers, is individual/private feelings of guilt for not being a "good" mother, while they endlessly struggle to maintain their formally recognized/paid role that deems them a contributor to society (Principe, 2014).

Finally, neoliberalismallows little, if any, room for direct public provision of social resources (Bakker \& Gill, 2003). Neoliberal logic reduces that which is necessary for well-being to 'goods' and/or 'services' - both of which can be produced/sold in the formal market economy. That nonmarketable resources are necessary for the functioning of society (i.e., publicly delivered and financed childcare) is simply beyond the comprehension of a neoliberal framew ork. In Canada, universal healthcare was rolled out prior to neoliberal entrenchment and remains the site of much controversy and political tension as neoliberal governments have sought to privatize healthcare resources (a public good) into health services (a market commodity). Furthermore, government institutions whose primary purpose was the advancement of equity in society (i.e., the National Action Committee on the Status of Women) have been systematically dismantled. To cite a more recent example, Human Resource and Skills Development Canada replaced its core funding to various human resource sector councils (including childcare) with a grant-based system in 2013. This policy shift has effectively silenced the voices of women and women's organization who now must compete for reduced funds. 
To summarize, FPE theory challenges neoliberalism occlusion of paid and unpaid closed sector councils - including the Child Care Human Resources Sector Council (CCHRSC) - whose primary purpose was to document and demystify employment trends and analysis in various sectors across the country (CCHRSC, 2013). For the childcare workforce, this meant a widespread elimination of data needed to expose low wages, poor benefits and inadequate working conditions of the childcare workforce. Social reproductive work in which women are over-represented and narrow conceptualization of formal, paid production in which women are underrepresented. Instead, FPE scholars position social reproductive work -predominantly carried out by women - as central to the functioning of modern political economies. In doing so, FPE scholars permit an increased role of the state in mediating the state-market-family nexus through which well-being - particularly the well-being of women - is achieved. This theory provides the basis for a women's equity rationale supporting publicly funded affordable, accessible, high quality childcare services as it prioritizes the equitable opportunities of women from all classes and demographics.

In this project, FPE theory is a starting point which can be empirically validated through an exploration of discourse. To do this however, conceptual and methodological tools are needed. The next part of this chapter will explore how and why the critical analysis of discourse has been chosen as a path to both understand and challenge the existing neoliberal sociopolitical order. Beginning with a broad introduction to a postmodern theoretical orientation to research, the next section will review the pioneering work of post-World War II social theorists that laid 
the foundation for both CDA and WPR. Feminist critiques of these foundational social theorists are also offered in relation FPE theory described above.

\section{A Postmodern Conceptual Framework}

This project is rooted in a postmodern theoretical framework. Catlaw \& Stout (2011) describe postmodernism as embracing the following premises: 1) individuals are inextricably connected to power relations in society; 2) there is no underlying social, historical, linear pattern to society; and 3) language/words always mediate knowledge. Premises one and three are particularly relevant to how postmodernism manifests itself in the present study in that language and discourse become the key mechanism of both oppression and emancipation.

Within the postmodern framework, the critical and constructivist paradigms are foundational to this project. These paradigms share the premise that truth as dialogical - it is not only constructed by people but also constructs people (Catlaw \& Stout, 2011). One's identity, whether an individual, group or nation-state, is grounded in understandings of truths that are mediated and gain meaning through language. Unique to the critical paradigm is the idea that researchers come to their research with a particular sociopolitical commitment or stance on the issue being studied. As mentioned in the introduction, Creswell (2009) labels such research “advocacy-participatory" (p.9), highlighting the subjectivity of the research and his/her/their commitment to using research as a tool to affect the greater sociopolitical/economic order. This project embraces the idea that dominant constructions of the truth are always embedded within 
relations of power in society that are never static. Critical analysis becomes the first step to affecting progressive change in these power relationships.

Key concepts from Michel Foucault, Jürgen Habermas and Antonio Gramsci are foundational to the theoretical ideas and concepts of both CDA and WPR. It is important to point out that the complexities and nuances of the concepts borrowed from these iconic social theorists are not, and cannot, be adequately explained and honoured in the brief description provided below. What is important is that the ideas of Foucault, Habermas and Gramsci are acknowledged as foundational to the concepts drawn upon in the contemporary social theories used in this project.

\section{Foucault on power/knowledge and discourse}

Foucault's emphasis on the interdependent relationship between power and knowledge and the emancipatory potential of power/knowledge is central to this project. Foucault (1980) placed a "/" in-between these words instead of separating them, referring to it as power/knowledge. In Foucault's (1980) own words: “it is not possible for power to be exercised without knowledge and it is impossible for knowledge not to engender power" (p.52).That power (inseparable from knowledge) exists in relationships, is exercised rather than possessed, is productive as well as repressive and operates from the bottom up (Olssen, 2006), revolutionized my approach to knowing and being in society. An overarching theoretical question most relevant to this project and its specific research questions identified later is how? How does one "know" 
and how does that influence one's ability to exercise power in society? What unwritten or unspoken ways of "knowing" regulate one's thinking?

This is where Foucault's conceptualization of discourse becomes relevant. Quoting Foucault, Mills writes that "discourse transmits and produces power; it reinforces it, but also undermines it and exposes it, renders it fragile and makes it possible to thwart it" (Mills, 2003). It was Foucault's assertion that through observing and naming discursive notions of truth and knowledge they become challengeable thereby affecting the often invisible power structures that play a central role in constructing society. Critically analyzing the linguistic units constitutive of discourse thus offers the potential to better understand ("know") how and why society functions the way it does, as well as influence change.

Foucault also coined the term 'order of discourse', a concept which is methodologically operationalized in CDA. Foucault (1981) stated:

In every society the production of discourse is at once controlled, selected, organised and redistributed by a certain number of procedures whose role is to ward off its powers and dangers, to gain mastery over its chance events, to evade its ponderous, formidable materiality (p.52).

Foucault (1980) goes on to illustrate the idea that discourse is inextricably connected to what is or can be "known" with some discourses, or ways of knowing, privileged over others. Discourse may be specific to a given discipline (his example being psychiatry) and/or a genre of 
text, for example a personal diary or newspaper text. Some discourses in some genres carry more weight in terms of determining 'the way things are'. Those individuals and groups who are the architects of dominant discourses (a medical discourse is his example) actively constitute the social world to a greater degree than others. At risk of grossly oversimplifying, critiquing the order of discourse means questioning social norms about who may speak, about what, and in what manner.

Related to the order of discourse is Foucault's concept of governmentality. In his own words, Foucault (1978, p. 790) states:

'Government' does not refer only to political structures or to the management of states; rather, it designates the way in which the conduct of individuals or of groups might be directed... To govern, in this sense, is to control the possible field of action of others .

Through the concept of governmentality, Foucault shifted the emphasis of government from the body which carries out concrete, tangible and observable actions (in its most basic sense a noun), to the dynamic, changing and negotiable process of governing. Foucault broadly conceptualized governmentality as the regulation of behaviors - something that extends far beyond the constraints of formal government bodies. Discourse, and the order of discourse, are identified as key mechanisms of governmentality. A hierarchy of knowledges, some with widespread authority (again we can refer back to a medical discourse), actively influences and in many ways determines the behavior of a population. Normative ways of thinking underscore the parameters 
for acceptable social action. Again, discourse becomes a site of struggle not only for what $i s$ but what can be - what "rules" or ways of being and knowing are permissible and which are not.

\section{Feminist critiques of Foucault}

It is important to acknowledge that many feminist scholars have been highly critical of Foucault's work. While feminist theories themselves are diverse, they generally agree that social theory should challenge women's ongoing, systematic oppression and affect material/political changes that liberate women. McLaren (2002) notes that feminist critiques of Foucault tend to interpret his work as rendering people, including women, passive subjects vulnerable to the dominant discourses and practices in which they are embedded. Many feminists take issue with Foucault's conceptualization of power, arguing that its relational and productive aspects render women responsible for their oppression in society (Hartsock, 1990). Others suggest that his complete rejection of social norms makes establishing new social norms - those of equity and justice, for example - impossible (Fraser, 1985). Finally, it has been argued that Foucault's work does not press for political, material change and is rather an academic exercise in social theorizing (i.e. Harstock, 1990). McLaren (2002) addresses these (and many more) critiques of Foucault's work systematically.

In reference to the first point critique about power, McLaren (2002) argues that Foucault's conceptualization of power in fact allows the possibility of empowerment, though she concedes that much of his work is devoted to critiquing and becoming aware of how social forces contribute to relationships of domination. Within relationships of domination, McLaren 
(2002) argues that Foucault advocates active acts of resistance - most concretely through social/bodily practices (i.e., refusing sex). McLaren (2002) interprets Foucault's work as arguing that even within relations of domination, power is not possessed but exercised, rendering empowerment possible. Such an interpretation does not hold women responsible for their oppressed position, but allows the possibility (with knowledge) that active resistance is possible. McLaren (2002) suggests that not only is such resistance possible, but necessary to Foucault's conceptualization of power.

In regards to the common critique about Foucault's abandonment of social norms, a critique not only of Foucault but postmodernism more generally, McLaren (2002) argues that Foucault advocates emancipatory social and historically bound ways of being rather than universal truths. McLaren (2002) describes Foucault as a "skeptic" whose work was primarily concerned with questioning the "normalizing function of norms from within a situated social and historical context" (p.46). In this way, the contextualized experiences of people is to serve as a guide for what is desirable rather than ahistorical ideals.

Finally, the feminist critique that Foucault's work is apolitical and not rooted in material reality is perhaps the most concerning critique of his work - particularly in this project where informing progressive ways forward is a central goal of the project. As McLaren (2002) points out, Foucault himself was actively involved with social movements and political struggles which materially contradicts this criticism. While acknowledging that this element of his work remained undertheorized and discussed, McLaren (2002) convincingly argues that his strong 
resistance of universal norms and truths is inherently political. Though he did not discuss political strategy, he repeatedly emphasized the importance of questioning what $i$ and why. He cautioned against accepting what may appear to be progressive (i.e., shifting form execution to imprisonment) and actively resisted domination (McLaren, 2002). Foucault encouraged the embodied person to actively challenge and resist social norms in a given social, historical and cultural location.

\section{The Gramscian concept of hegemony}

Gramsci (1993) introduced the concept of hegemony, defined as a relationship "not of dominance by means of force, but of consent by means of political and ideological leaders" (Simon, 1982). Rather than being coerced by an individual, the state or any group, Grasmci noted the often consensual nature of domination. According to Gramsci, intellectual and moral leadership rooted in ideology establishes what is seen as common sense (Grasmci, 1993). When the ideas of leaders (or "ideologies") become taken-for-granted and go unchallenged, these ideas and principles become one's own and hegemony ensues. These ideas/ideologies come to underscore what is seen as "truth" and "knowledge", thereby regulating discourse. Whether they are "true" or "false" in any sort of objective light is essentially irrelevant according to Gramsci. Instead, that they are at all and that they are widely distributed and accepted throughout society renders them an integral part of the power/knowledge process. While Gramsci himself was dedicated to the liberation of subordinate actors based on class struggles, his concept of hegemony yields itself to feminists who have long struggled, and continue to struggle, for equal status, citizenship and voice as men. The not-uncommon rhetoric that women have achieved 
equality is but one sweeping example of hegemony in 2017. When it comes to discussion of childcare on a policy level, it is essential to remain cognizant of if and/or how hegemony perpetuates an exclusionary citizenship regime for women and children.

\section{A framework for conceptualizing ideology}

Since Gramsci’s inaugural work connecting ideology to politics and democracy, many scholars have attempted to label or categorize different ideological approaches to modern welfare states. Esping-Anderson's (1990) three typologies of capitalist welfare states (social democratic, conservative and liberal) are perhaps the most widely drawn upon and internationally recognized tool for identifying the ideological orientations of nation states. However, Esping-Anderson's (1990) work was primarily concerned with definitively categorizing existing capitalist states' approaches to social policy rather than critically exploring the underlying values and beliefs which motivate states to pursue policy in particular directions. Furthermore, Esping-Anderson (1990) does not distinguish between social liberalism and neoliberalism - an important distinction in the case of childcare policy. Dean (2012) builds on Esping-Anderson's (1990) ideas to refine a framework specifically for examining ideology in relation to social policy. Dean's (2012) framework (illustrated in Figure 3.1) presents ideology as a continuum on two axes: the horizontal axis represents the degree to which values are solidaristic (people share responsibility for each other's well-being) or individualistic (every individual is responsible for himself/herself) while the vertical axis represents the degree to which values are egalitarian (equity is pursued) or conservative (inequity is just and fair). The four ideological orientations to 
social policy identified by Dean (2012) fall into the four quadrants defined by these axes: social democratic (egalitarian and solidaristic), social liberal (egalitarian and individualistic), social conservative (solidaristic and conservative) and neoliberal (conservative and individualistic).

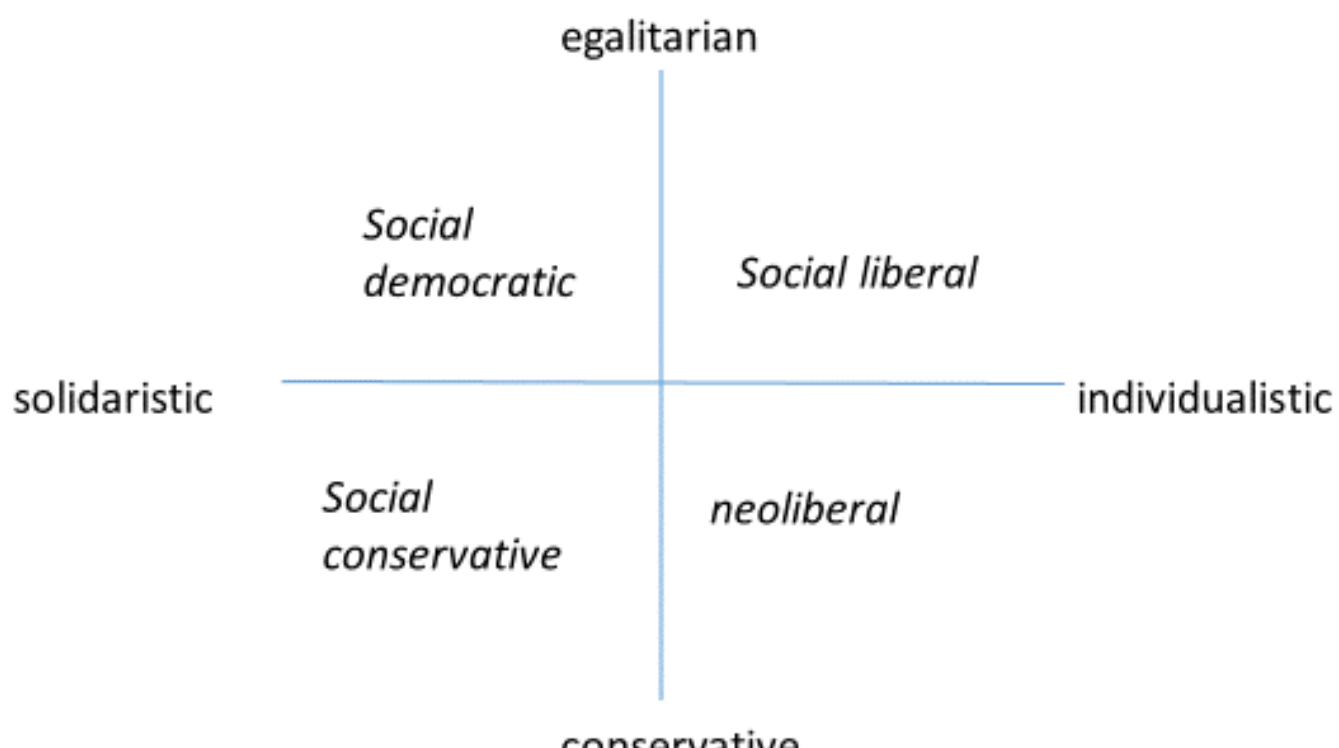

conservative

Figure 3.1: "A framework for identifying ideological orientations to social policy in modern welfare states" from Dean, H. (2012). Short Introductions: Social policy. Cambridge, United Kingdom: Polity Press, p.22.

\section{Social democratic}

Social democratic values embrace the idea that citizens should be equal and united in ensuring the well-being and opportunity of all people. Esping-Anderson (1990) describes a social democratic welfare regime as providing "a basic floor beneath which no one would be allowed to fall" (Esping-Anderson, 1990, p.46). Social democrats attempt to make visible and challenge the 
structural inequities which exist in modern capitalist societies, thereby bringing about social equity whereby the human rights and dignity of all people (including children) are respected. The most vulnerable in society, who may or may not be able to contribute to the formal market economy through traditional means, are still considered worthy of a basic level of well-being. Unlike socialism, social democratic values are congruent with capitalism "but seek to change it democratically from within" (Dean, 2012, p.23).

Relating this to childcare policy, a social democratic perspectives supports the idea that a public, high quality, universal, affordable and accessible childcare system should be made available to all families and children on the basis of human rights and equity. Gendered perspectives, which highlight the central role of childcare in ensuring women's full inclusion in society, are embraced. The idea that children are citizens, regardless of the fact they do not yet contribute to the formal market economy, renders them worthy of significant public investment in high quality services. Social democratic values do not reject the importance of the free market in motivating a prosperous economy, but conceptualize that which is necessary to engage in the market as public resources rather than private goods.

\section{Social liberal}

Dean (2012) suggests that social liberalism demarcates itself from neoliberalism in that there is a shift from rugged individualism to "reluctant collectivism" (p.23). While the underlying belief that each individual is responsible for themselves still prevails, the concurrent idea that citizens experience equality of opportunity is paramount. Social liberals are not out to 
ensure social equality but to ensure that "every individual would be free to build a life for himself or herself' (p.23).

When social liberal values are applied to childcare policy, the idea that childcare provides an essential opportunity for children to get a good start in life and/or that childcare provides parents the opportunity work in the paid labour market prevail. Both of these opportunities are considered necessary opportunities for citizens to build a "good life". Social liberal values may support a public system of, or at least public funding to, childcare services for those children and families who are disadvantaged in society. Rather than supporting universality, social liberals would be more likely to support targeted programs in an effort to even the playing field for groups who face significant barriers to earning a living in the market.

\section{Social conservatism}

Social conservativism embraces unity rather than individualism, while still maintaining a hierarchical society. Esping-Anderson's (1990) conceptualization of conservatism is most applicable to this ideological category. He states: "individuals are not meant to compete or struggle, but to subordinate self-interest to recognize authority prevailing institutions" (EspingAnderson, 1999, p.38). To put it most simply, social conservatives embrace tradition - mainly the tradition of the church and family. The idea that people have a responsibility for each other is embraced, but seen as something that should be handled privately, through charitable giving and/or the voluntary delivery of services, rather than state authorities. Social conservatives are generally resistant to social change, preferring what is familiar, known and therefore "safe". 
People or institutions with money and social influence are considered worthy of their position in society while those with few resources and influence are conceptualized sacrificing for the greater social good (Dean, 2012).

In relation to childcare policy, social conservative values reinforce the traditional heteronormative family model whereby mom stays home with the children and dad is the primary breadwinner. The state is seen as either having no role in the provision or funding of childcare or as having no role beyond that of a cash payment to parent to spend on the care of children in whatever way they feel is best.

\section{Neoliberalism (as an ideology)}

Within this study, neoliberalism as a set of practices informing policy has already been defined and critiqued from a gendered perspective above. Consistent with this, neoliberalism is discussed here as a set of values and beliefs. As an ideology, neoliberalism maintains that individuals are responsible for themselves and social stratification is just. As in EspingAnderson's (1990) classic conceptualization of liberal welfare states, the free market is considered to be the mechanism of emancipation for citizens whereby success in the market "mirrors effort, motivation, adeptness and self-reliance" (p.62). While neoliberalism is rooted in the same fundamental values as classic liberalism(work hard and prosper), it emerged after decades of welfare state growth (in Canada and in beyond) rationalized through Keynesian economic theory. The post-WWII idea that the state should play a key mediating role in the free market to ensure citizens had the opportunities needed to compete in the free market (social 
liberalism) gave way to unencumbered individual competition as the defining characteristic of human relations (Monbiot, 2016). Neoliberalism erodes citizenship in favour of consumerism, whereby democratic practice is reduced to one's ability to purchase/sell goods and services in the free market.

In the context of childcare, neoliberal values generally inform two approaches to childcare policy. First and most preferred by neoliberalism is that state money devoted to "childcare" be given through a demand-side funding structure - more specifically vouchers or cash payments to parents to help offset the high cost of childcare services. This approach to public funding reinforces market mechanisms whereby consumers (in this case parents, though children are the actual consumers) theoretically drive the supply, demand and cost of childcare services. In the second approach, neoliberal values may be reconciled with public funding directly into childcare services, though the key motivation for such investment is the immediate and long-term economic return on investment. Neoliberal values would further ensure that any supply-side funding be made available to all providers (including for-profit/corporate) rather than the not-for-profit providers/organizations whose services are typically higher quality and therefore more linked to the well-being of children and families.

It is important to point out that these ideological classifications are not definitive but meant as a "heuristic device" (Dean, 2012, p.23). Social policies are complex and may contain any number of elements or clauses that appeal to different ideological values. While no framework categorizing ideology can ever capture the nuances of particular countries, 
governments, political parties or policies, this framework best lends itself to the identification of ideological struggles of modern welfare states - particularly childcare policy in Canada.

\section{Habermas' theory of communicative action in the public sphere}

Like Foucault's conceptualization of power that recognizes the role of resistance, Habermas was also interested in "illuminating potentials for social change" (Finlayson, 2005), p.9). Habermas highlights consensus, through language, as the medium through which knowledge and democratic social order is achieved (Habermas, 1984). According to Habermas, knowledge is established through linguistically debating and arriving at a consensus regarding what is true, right and valid in the world. Habermas outlines 3 principles of validly (also referred to as validity claims): 1) what we say is true to us (truth);2) what we say is normatively "right" (rightness); and 3) we are honest and sincere in our communications (truthfulness) (Finlayson, 2005). Communication is rooted in the assumption that these validity claims are acknowledged and agreed upon. What is said must be true to the speaker, "right" in that it is generally agreed upon by others and be free from sarcasm or satire. ${ }^{17}$

Habermas introduces the concept of the "public sphere" as a place where people voluntarily come together, adhere to the principles of discourse and participate as equals in open public debates (Habermas, 1991). The defining characteristics of the "public sphere" as defined by Habermas (1991) are its rational and critical nature and its accessibility to all members of

\footnotetext{
${ }^{17}$ These validity claims map nicely onto CDA's operationalization of legitimization discussed in Chapter 5 .
} 
society. The public sphere offers an alternative to mediated images/texts where citizens can directly engage in dialogue regarding an issue deemed to be "public". The public sphere, as conceptualized by Habermas, is part of the "lifeworld" - an area of social life that is theoretically and categorically separate from the state and economic systems. An overarching tenant of Habermas' social theory is that there is a problematic "colonization of the lifeworld by systems." Table 3.1: Characteristics of the "lifeworld" and "systems" as described by Habermas

\begin{tabular}{|l|l|}
\hline Lifeworld & Systems \\
\hline $\begin{array}{l}\text { Domain of social life concerned with } \\
\text { symbolic and cultural reproduction } \\
\text { (socialization, culture) }\end{array}$ & $\begin{array}{l}\text { Domain of social life concerned with } \\
\text { material reproduction }\end{array}$ \\
$\begin{array}{l}\text { The public sphere - Unregulated } \\
\text { communication }\end{array}$ & - $\begin{array}{l}\text { Guided by money (capitalism) and } \\
\text { power (political) subsystems }\end{array}$ \\
$\begin{array}{l}\text { Unmarketized, informal (i.e., family, } \\
\text { culture, voluntary organizations) }\end{array}$ & $\begin{array}{l}\text { Not related to consensus or genuine } \\
\text { understanding }\end{array}$ \\
$\begin{array}{l}\text { Nourishes communicative action and } \\
\text { discourse - Primarily concerned with } \\
\text { furthering knowledge }\end{array}$ & $\begin{array}{l}\text { Reinforce patterns of action without } \\
\text { revealing why (why is rooted in } \\
\text { unchallenged, taken-for-granted } \\
\text { validity claims) }\end{array}$ \\
$\begin{array}{l}\text { Open to change, but change is gradual } \\
\text { - Social integration - coordinates } \\
\text { actions of others based on genuine } \\
\text { consensus }\end{array}$ & $\begin{array}{l}\text { System integration - coordinates } \\
\text { actions of others superficially }\end{array}$ \\
$\begin{array}{l}\text { Conducive to autonomy - encourages } \\
\text { one to arrive at self-chosen ends }\end{array}$ & $\begin{array}{l}\text { Departs from the principles of discourse } \\
- \text { strategic communication }\end{array}$ \\
\hline
\end{tabular}




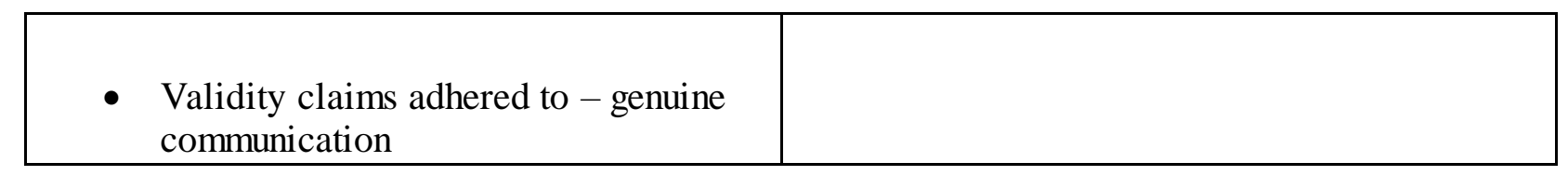

Habermas suggests that as society gets larger and increasingly complex, systems (mainly economic and state systems) take over the communicative task of coordinating social action. Today, the media is but one economic system that has come to play a central role in mediating knowledge. While these systems do provide short-cuts, Habermas suggests that once they are established they are largely immune to consensus. One of the only channels citizens have to directly influence the state is the occasional vote. In this way, it becomes very easy for the "truths" of systems (and the ideologies which these truths are based) to become accepted as the truth. As lay individuals, we are rarely in a position to question validity claims of an entire system. We simply do not have an effective venue to voice our concerns and have these concerns meaningfully addressed. Habermas' conceptualization of the colonization of the lifeworld by systems is fruitful in that it clearly illustrates the ways in which modern society undermines the processes of democratic deliberation.

Habermas purports that genuine communication in the public sphere offers emancipatory possibility. Habermas (1984) distinguishes between communicative action in the public sphere (part of the "lifeworld") and strategic action (linked to "systems"). According to Habermas (1984), communicative action has two characteristics: 1) it takes place in the aforementioned "public sphere" and 2) it is motivated by a genuine desire to reach understanding. In contrast, 
strategic action is characterized as a type of instrumental action where the goal is to get other people to do things as means to realizing one's own end. It is when action that purports to be communicative is more characteristic of strategic action that colonization occurs. In this case and his critics (including Foucault) argue that this is most often the case - knowledge and truth are pursued under false pretenses. Communications that have been made available through the mass media, as is the case with newspapers, is vulnerable to such colonization given the media is itself an economic system whereby "news" is the product. While Habermas problematizes this in great detail, his theory does not delve deeper into the complex process of how power relationships and knowledge construction break down. His theory simply notes that once discourse through communicative action is departed from, truth and knowledge claims are no longer genuine in that sociopolitical and economic systems significantly influence the process.

\section{Tensions between Foucault and Habermas}

In borrowing concepts from both Foucault and Habermas it is important to point out that these social theorists have been accused by some of 'mud-slinging' back and forth (Flyvberg, 1998, p. 224). Flyberg (1998) succinctly sums up their points of agreement and contention when he says:

Foucault and Habermas agree that rationalization and the misuse of power are among the most important problem of our time. They disagree as to how one can best understand and act in relation to these problems (p.227). 
While Habermas insists that democratic transformation of the public sphere is possible through communicative action that is rooted in the principles of discourse ethics, Foucault rejects this notion. For Foucault, the purpose of engaging with discourse is to become aware of and actively resist dominant social forces (dominant orders of discourse) rather than attempting to establish an order of discourse. Foucault cautions that any dominant social order is always embedded in power relations and that the constant revaluation, questioning and resistance to these forces is central to democracy. Habermas, on the other hand, seeks to minimize conflict through open and rational debate whereby the "better argument" serves as the basis for democracy (Flyvberg, 1998).

In this project, both theorists contribute ideas that are helpful. Creating policy is always about creating a social order or normative way of doing things. Policy is essentially a set of rules to which all citizens are bound. In this way, Habermas' appeal to democracy rooted in rational argumentation is valid - if a society is to have rules than these rules should be democratically agreed upon and enforced. However, it is also true that the complexities the social world makes it impossible to abide by the ethics of discourse in pursuit of a utopian public sphere. Foucault's notion of resistance through discourse is thus also equally valid. The key ideas from Habermas' theory that are drawn upon here are actually those that describe the departure from his utopian democratic public sphere. What Habermas refers to as the problematic 'colonization of the lifeworld by systems' is congruent with Foucault's notion that dominant discourses (today typically rooted in neoliberal systems) must be challenged. 


\section{Feminist critique of Habermas}

Fraser (1989) problematizes Habermas' binary conceptualization of "public" and "private". In essence, the public includes the aforementioned (and somewhat problematic) "public sphere" and the institutions of the state. Private is conceptualized as activity that takes place in the formal market economy and in the domestic sphere. According to Habermas (1991), social order breaks down when market systems infiltrate the domestic sphere and institutions of the state overshadow and/or replace democratic deliberation in the public sphere.

Table 3.2: Two axes of public/private distinction

\begin{tabular}{|l|l|l|}
\hline & Public & Private \\
\hline Systems & State & Market \\
\hline Lifeworld & Public sphere & Family \\
\hline
\end{tabular}

Fraser (1989) points out that such distinctions are problematic for women who are overrepresented in the private "lifeworld" and underrepresented in the state, public sphere and to some degree, the market. Certainly historically, but also contemporarily, the voices and experiences of women are subordinate to the louder voices of men. As Chapter 2 pointed out, men continue to occupy positions of power within the state (i.e., elected politicians, senior level policy-makers) and the market (i.e., CEOs, business leaders) disproportionately to women. 
Similarly, communication in the so-called "public sphere" - increasingly reduced to communication in the mass media - also appears to be dominated by male journalists and reporters (Rinehart, 2008). The domain of the woman continues to be limited to the domestic and even there, women's voices (as in the case of marital rape) are often occluded (Fraser, 1989).

This conceptualization of "public" and "private" is also problematic in that symbolic 18 and market reproduction are not and cannot be considered categorically separate production domains. As a FPE perspective outlines, each mode of production is entirely dependent on the other, though one is formally economically remunerated and the other is not. Paid work in the formal market economy is reliant on the unpaid work in the home, which is predominantly carried out by women. Furthermore, there is a significant informal under-paid market economy of care which occurs within private homes (including unregulated childcare and nannies). Though women today, particularly in Canada, participate in the paid labour market in large numbers, this has not diminished their share of unpaid "symbolic" reproduction. FPE theorists critique the neoliberal/neoconservative logic that situates the care of children on the backs of women (particularly marginalized and vulnerable women), without the structural support necessary to be a right-bearing citizen. So while Habermas' social theory is helpful and

\footnotetext{
${ }^{18}$ The very term "symbolic" reproduction, as used by Habermas, is troubling from a feminist perspective. Limiting material production to dollars is hegemonic in and of itself given it is by no means more concrete and/or valuable than the reproduction of children, cooked meals, and sustained culture. Indeed, material dollars are more of a symbol than what continues to be produced predominantly by women, unpaid, in the home.
} 
instrumental to understanding how market and state forces have infiltrated the public and private lifeworld, it is equally important to remain cognizant of how his distinctions of "public" and "private" situate women in a subordinate role to men.

\section{Theoretical foundations of Critical Discourse Analysis (CDA)}

In many ways, CDA picks up where Habermas left off, elaborating on and operationalizing the process through which language and discourse constructs and is constructed by social practices (particularly in the contemporary context of neoliberal economic, social and political systems). While CDA is commonly thought of as a methodology rather than social theory, it instantiates both.

This project embraces the ideas and concepts which Fairclough and his colleagues have drawn upon, theorized and developed over many years. Part of the chapter will explore Fairclough's pioneering work on discourse and social change (Fairclough, 1992), his work on mediatized discourse (Fairclough, 1995), and his and his colleagues further development of the theoretical underpinnings of CDA (Chouliaraki \& Fairclough, 1999). Chapter 6 zeroes in on the specific methodological tools needed to critically analyse discourse (Fairclough, 2003) as well as acknowledges his most recent work operationalizing CDA for political discourse ${ }^{19}$.

\footnotetext{
${ }^{19}$ Norman Fairclough has written several books and articles on Critical Discourse Analysis, though he often writes with others. "Fairclough's" theory and method of CDA is referred to throughout, though it is recognized that he often worked with others who are referenced by name in relation to specific publications.
} 
Following a rapid academic interest in the use of CDA as a methodology in the social sciences in the 1990s and concerned about the integrity of CDA as a social theory, Chouliaraki \& Fairclough (1999) published a book explicitly addressing CDA's theoretical underpinnings. These authors identify CDA as the coming together of critical social theory and linguistics with the goal of situating the study of language in the social process. Ontologically and epistemologically, they characterize CDA as 'structuralist constructivism', in an effort to highlight "social life as both constrained by social structures and an active process of production which transforms social structures" (Chouliaraki \& Fairclough, 1999, p.1). While "structuralism" and "constructivism" appear to be at odds with each other, with the former situating social subjects as 'effects' rather than agents in social life and the latter as the architects/builders of the social world, CDA argues that "what is" is a product of both. Put more simply, our world and experience of it is constructed both for us and by us through social, cultural and economic processes.

\section{Social practices}

At the heart of CDA is untangling the complex relationship between different spheres of social life and social activity through the study of language. Central to this is zeroing in on what can be observed in a specific time and place, labeled social "practices". While social practices most certainly include physical actions (i.e., going to work in the morning, taking children to school, preparing food, hugging a crying child) CDA is most interested in symbolic practices, mainly achieved through and by discourse. 
Before delving into the role of discourse, it's important to first define Chouliaraki \& Fairclough (1999) conceptualization of social practices. These authors describe the following defining features of social practices:

1. They are a form of production.

2. Every practice is embedded in relationships with other practices.

3. Practices have a reflexive dimension.

In labelling both physical and symbolic social practices as a form of production, the authors intend to challenge the dominant conceptualization of production limited to the economic sphere (Chouliaraki \& Fairclough, 1999). In this way, one is producing and being produced through writing a blog, reading the newspaper, caring for a child, meeting a friend for lunch, going to a party, and so on. One is producing social life in his/her/their casual conversations with neighbours, a night out with friends and interactions on social media, rather than simply his/her/their economic output in paid labour. While this may seem like common sense, neoliberalism continues to more narrowly define production in economic terms (see Chapter 2).

That every practice is embedded within a complex relationship with other practices makes the study of symbolic practices incredibly complex. No one action ever happens in isolation as different motivations (cultural, social, personal, economic, etc....) come into play. Chouliaraki \& Fairclough (1999) describe practices as "networks" in which each social practice becomes a "moment which transforms them" (p.21). Like neurons firing in the ever changing and complex neural network in our brain, social practices constantly spur new connections, 
strengthen existing connections and let others deteriorate. Our way of understanding and being in the world is never static, but is rather part of an ever-changing process that is constantly overlapping and interacting with other practices.

Having said this, an overarching structure of these networks does exist. There are boundaries, often discursively constructed, to what is knowable, thinkable and doable. The networks are rooted in habitualized ways of being/understanding that do not change easily or without effort. Chouliaraki \& Fairclough (1999) note that social practice networks are "held in place by social relations of power" (p.24). The authors draw on the Gramscian concept of hegemony, relations of domination through consensus rather than force, to explain the difficulty in recognizing alternative ways of knowing and being in the world. Because our social world is so deeply entrenched in a neoliberal logic, social subjects come to understand themselves and act in ways that are consistent with this logic whether or not it is actually in his/her/their interest. The single mother of infant twins rapidly accumulating debt due to high childcare fees comes to understand her struggles as a personal failure rather than an impossible situation. She consents to, believes in and furthers the oppressive neoliberal discourse. That she has a right to affordable, high quality childcare is beyond what is thinkable, never mind what is doable. Even if she had the insight to recognize the hegemonic and unjust nature of her situation, she is limited in what social action she can take as this insight does not extend far beyond her (invoking Foucault's concept of governmentality). There simply are not the social structures/resources in place physical or symbolic - for her to live her life in a different way. 
Finally, Chouliaraki \& Fairclough (1999) argue that practices are inherently reflexive in that people "constantly generate representations of what they do as part of what they do" (p.2526). In this way, an inherent part of social practices are the discursive theories/representations of these practices. While we may not actively and consciously think about it, we all have 'reasons why' we do or don't do what we do (or don't do). These theories have an inalienable discursive element in that they provide "constructions of practices from particular perspectives" (p.26). This reflexive element of practices opens up the possibility of critically reflecting on taken-forgranted assumptions or ways of being in the world. While it may not often be done, it is possible to challenge our theories of why we do what we do. This is the essence of what makes CDA critical. At its core, it is about rethinking how we know, what we know, and questioning some of the most basic premises on which the social world is based.

\section{Discourse}

Discourse is discussed in two different ways in Fairclough's work, though they are complimentary and inclusive of each other. In its most basic sense, Chouliaraki \& Fairclough (1999) refer to discourse as the "semiotic elements of social practices" (p.38). Here, discourse is conceptualized as symbolic/discursive resources that comes to be in a moment of articulation thereby providing an observable site of reflection and deconstruction. In this view, discourse is synonymous with text/language: "discourse is the language used in representing a given social practice from a particular point of view" (Fairclough, 1995), p.56). In using discourse in this way, Fairclough departs from more broad theorizations of discourse, particularly those of 
Foucault who was resistant to the idea that discourse could be identified/analyzed through text (Fairclough, 1992).

Fairclough $(1999 ; 2012 ; 1992,1995)$ does not limit discourse to a text/language level. He devotes much of his theorizing of discourse to the level of discourse practice, emphasizing what discourse does and how it comes to be rather (verb) rather than an entity (i.e. text) that can be examined (noun). Figure 3.2 illustrates how discourse as text/language in embedded within discourse practice, which is further embedded in the sociocultural/political context. The underlying characteristic of discourse practice is its dialectical nature - it both constitutes the social world (constructivist) and as well as being determined by the social world (structuralist).

This conceptualization of discourse is more consistent with a Foucauldian perspective. Fairclough (1992) emphasizes the importance of "avoiding the pitfalls" of overemphasizing its constructivist or structuralist nature (precisely what feminist critics of Foucault warn against), with the former reducing discourse to a mere "reflection" on the social world and the latter conceptualizing discourse as the "source" of the social (Fairclough, 1992, p.65). He goes on to distinguish three aspects of social life that discourse helps to construct: 1) social identities/social positions, 2) social relationships between people and 3) systems of knowledge. Again, while identities, relationships and ideas about how the world works are not entirely discursive (i.e., they exist in the lived experiences of human beings), there are discursive scripts or categories in which individuals come to identify themselves, their relationships with people and 
understandings of his/her/their role/position in social life. Each of these comes to be through and is created by discourse. Fairclough (1992) draws on the example of teachers and their pupils:

The identities of teacher and pupils and the relationship between them which are at the heart of a system of education depend upon a consistency and durability of patterns of speech within and around those relationships for their reproduction (Fairclough, 1992, p.65).

Such a dialectical-relational conceptualization of discourse opens up the possibility for discourse as a mechanism of social transformation. It stands to reason that if identities, relationships and systems of knowledge are reproduced, then they may also be changed or "reinvested" (Fairclough, 1992, p.67) with new or different discursive formations. It is here that appreciating Fairclough's (1995) discussion of the 'order of discourse' becomes useful. While this term/phrase originated in the work of Foucault (discussed above), Fairclough adapts this concept to refer to the "normal ways of using language" (Fairclough, 1995, p.55). In this way, discourse (as discourse practice) is used to mediate between text/language and sociocultural practice. Common discursive practices (determined through social order(s) of discourse) differ between societies as well as in institutions within society. Much of CDA empirically involves untangling normative ways of using language in a particular sociocultural location. In some cases, simply noting what the "normal" way of using language is, and the underlying ways of thinking it is rooted in, can provide valuable insight into power relationships in society. In the same way, recognizing how unitary or variable, stable or changeable the order of discourse can 
be a "barometer of cultural change" (Fairclough, 1995, p.60). In other words, if there is a great deal of variety in terms of how an issue is discursively constructed (what knowledges are recognized in society), it indicates active political and/or ideological struggle - usually the precursor to social change.

Finally, Fairclough consistently situates the study of discourse (more narrowly defined and observable through text) and discourse practice within the broader sociocultural/political practice. Discourse and discourse practice are always embedded within ways of knowing and being in the social, cultural and political world as well as constitutive of the social, cultural and political world. In this way, discourse (as language) and discourse practice are as much shaped by the sociopolitical world as they are play an active role in sustain/changing the sociopolitical world. In his own words:

Discourse as a political practice is not only a site of power struggle, but also a stake in power struggle: discourse practice draws upon conventions which naturalize particular power relations and ideologies, and these conventions themselves and the way in which they are articulated are a focus of struggle. (Fairclough, 1992, p.67)

This quote illustrates how the political world, and the discourses and experiences that constitute it, become a necessary component of CDA theory. What happens in politics, what decisions are made or not made, what receives attention or does not, what the ideas behind the way citizens "should" live their lives become central to understanding and progressively changing the social world. Indeed, Fairclough is explicit in stating that research rooted in CDA must be committed to 
emancipatory social change in some way (consistent with Creswell's advocacy-participatory worldview). Chouliaraki \& Fairclough (1999) problematize a political discourse which "distances itself from rational arguments" noting this is "worrying implications for democracy" (p.131).

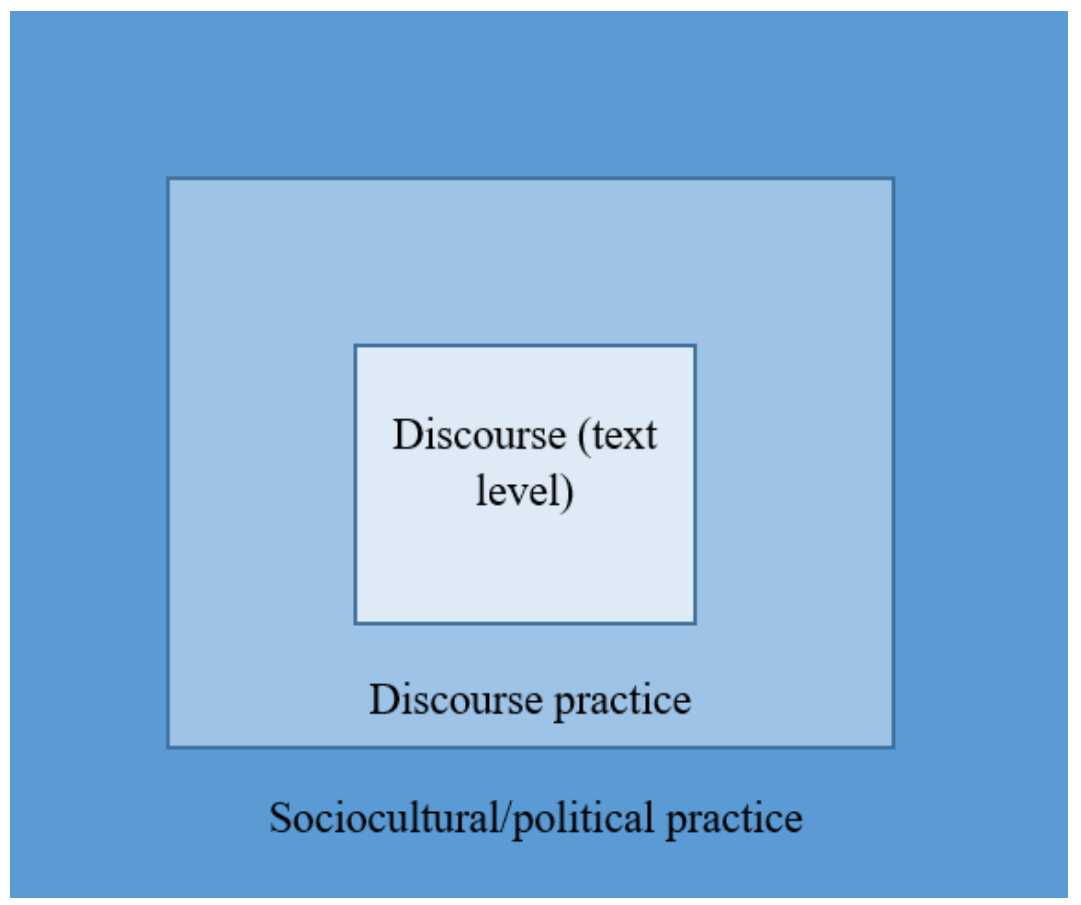

Figure 3.2: Fairclough's 3-dimensional conceptualization of discourse. Fairclough, N. (1992). Discourse and Social Change. Cambridge, UK: Polity Press, 73

More recently, recognizing the wide uptake of CDA in political science and policy studies, Fairclough \& Fairclough (2012) developed a framework for the critical analysis of political discourse - Political Discourse Analysis (PDA). PDA draws on the same theoretical foundation of CDA, though it specifically focuses on the constitutive and constructive role of political discourse in social practices. Consistent with CDA (and Habermas' notion of communicative 
action in the public sphere), PDA embraces deliberative democracy ${ }^{20}$ as a normative ideal in which "actual practice can be evaluated and a goal for those who seek to take policies in a more democratic direction" (p.34). PDA also begins from the premise that all political discourse is both practical and deliberative. Stated succinctly by Fairclough \& Fairclough (2012), "the purpose of political discourse is ultimately not to describe the world but to underpin decision and action" (p.13). In achieving this, PDA identifies five premises in need of critical analysis in deliberative/argumentative political communications: a value premise (what political actors concerned about or ought to be concerned about); a goal premise (a future state of affairs); a circumstantial premise (actors context of action); a means-goal premise (a practical line of action which connects values to goals); and a claim (what ought to be done). These premises are not meant to be discreet, but simply provide a framework for considering each premise both independently and in relation to each other. While PDA offers a very useful framework for the analysis of political discourse as a whole, this study focuses mainly on the circumstantial premise - or the critical analysis of what is seen/projected/accepted to be true or valid in the context of deliberation. CDA of the circumstantial premise (as identified in PDA) seeks to

\footnotetext{
${ }^{20}$ A deliberative democracy occurs when "citizens' preferences are not only expressed but also transformed through public reasoning in a context where everyone has the right to advance and response to reasons, propose issues and solutions for the agenda and justify or criticized proposals"(Fairclough \& Fairclough, 2012, p.30).
} 
untangle how existing power dynamics and relationships in society come to establish what $i s^{21}$ which, as is suggested below, forms the foundation of what can be.

This project is unique in that the texts undergoing analysis are not policy or political documents themselves, but rather widely distributed, newspaper texts, which purport to communicate relevant components of political documents to a broad audience. It is lay citizens who access their information primarily through widely available and accessible texts that will act on the outcome of their deliberations. In this way, the theoretical and methodological concepts and tools developed in Fairclough's earlier work, where he specifically theorizes about the role of mediatized discourse (i.e., 1995 and 2003) in social and political practices are concurrently, embraced in this project.

\section{Critical theory of discourse in the media}

Fairclough (1995), like Habermas before him, is particularly concerned about communication with a far reach (i.e., consumed by a large number of people), given his ontological commitment to emancipatory social change. In 2016 , it is the rare person who is not actively online or a moment away from being online (through a phone or computer) for most waking hours. Breaking news or key social/political developments are instantly made available through websites and then "shared" or "tweeted" across other online networks. Instead of waiting

21 The reason for the focus on the circumstantial premise is further explained in light of Bacchi's WPR method. 
for the evening news or reading a newspaper first thing in the morning, YouTube videos and newspaper articles pop up on cell phones and tablets almost instantaneously. Writing long before the information superhighway of the internet exacerbated the reach and immediacy of mediated communication, Fairclough (1995) notes key features of media communications that are as relevant (perhaps even more relevant) today:

1. Major temporal and spatial disjunctions - where the text is produced and consumed differ in space and time.

2. One-way, in that consumers cannot usually directly respond to producers (in this way the term 'communication' is a bit of a misnomer).

3. Represent material from the public domain (i.e. political events), while texts are consumed in the private, domestic sphere.

4. On the other side of this, events typically occurring in the private domain (i.e., people experiencing grief) is made available in the public domain.

5. Draw on a repertoire of technologies (voice recording, video, music, word processing) absent in non-mediated communications.

6. Permanently documented through these technologies.

7. Under professional/institutional control ${ }^{22}$

\footnotetext{
${ }^{22}$ It could be argued that communications are less and less under professional/institutional control with the rapid expansion of social media. At the same time, much of what is available through social media - published newspaper articles or clips of newscasts - has gone through the journalistic process.
} 
These features of mediated communications, most of which are rooted in what Habermas calls "systems", make their critical analysis all the more essential. That discourse practice, and the texts through which it acts, are inextricably linked to social/political/economic/cultural context and that this context is incongruent between production and consumption is problematic. Consumers cannot directly and consistently challenge the underlying assumptions, or knowledges, on which the text is based leaves little room for social/political struggle (indeed suggesting that 'communication' may not be the best term for it after all). In this way, mediated texts are the antithesis of a Habermasian 'public sphere' and therefore problematic for ‘deliberative democracy’ as defined by Fairclough \& Fairclough (2012). Mediated communications have tools available to them (i.e., word processing, exponential editing) that non-mediated communicative events do not, which fundamentally alters the nature of exchange. Finally, mediated communications' greatest contribution to society could be considered its ability to bridge the divide between the "public" and "private", making public concerns available to private citizens and vice versa. However when mediated texts come to act as a/the mechanism of social understanding and potential change there are inherent limitations. Stated succinctly by Habermas' (1962): “publicity came to serve manipulation of the public as much as legitimation before it" (p.178). When it comes to media texts, CDA's primary concern is identifying such manipulation $^{23}$ and opening up space for authentic communicative action. When such texts are

\footnotetext{
${ }^{23}$ It is important to acknowledge that such manipulation is not necessarily intentional or strategic on the part of authors, though it may be. Authors/producers of mediated texts are themselves embedded within complex networks of social and political practices that influence possible fields of action.
} 
political in nature, the necessity of their critical analysis as a prerequisite for a deliberative democracy is even more pressing.

Of particular concern to Fairclough (1995) are two tensions within contemporary media discourse that significantly play into this process: that between information and entertainment and the aforementioned tension between the public and private. Mediated communications to the masses is a multi-billion dollar industry - an economic system in and of itself. Far from the insular lifeworld Habermas described, communications in the mass media are best conceptualized as a commodity whereby "audiences become spectators rather than participants, and are addressed as consumer rather than citizens" (Fairclough, 1995, p.44). Communication itself has become its own formal market system. Stories are purchased, images/videos sold while editor's, producer's and publisher's very existence is dependent on the market's bottom line. While the state may play a role in the production and dissemination policies that govern the communications trade, and even more rarely may directly access publication mechanisms themselves (i.e., public broadcasting networks), the sales of mass communications (and advertising space) overwhelmingly determine its viability and/or existence.

The mass media's use of colloquial language characteristic of the private sphere offers both limitations and possibilities in that political concepts and ideas become accessible to "the people" with relative ease. At the same time, the complexities of these concepts/issues may be disregarded. This leaves discourse vulnerable to ideology - defined by Fairclough (1995) as "propositions that generally figure as implicit assumptions in texts, which contribute to 
producing or reproducing unequal relations of power" (p.14). Ideology is a key way to perpetuate relations of domination, given it inherently adopts one way of viewing the world as the way of viewing the world. The neoliberal ideology discussed and critiqued in Chapter 2 is also heavily critiqued and problematized by Chouliaraki \& Fairclough ${ }^{24}$ (1999). Fairclough (1995) cautions that ideology should not be seen as a "constant and predictable presence in all media discourse by definition" (p.47), but rather that it is necessary to identify and deconstruct ideologies where they do exist.

Because this is a dissertation in Policy Studies rather than Linguistics or Communication and Culture however, it is now necessary to situate CDA within foundational theories of the policy process, most of which have been developed by Political Scientists.

\section{Policy Process Theories}

Following a brief overview of what are largely regarded as normative (often positivist) policy process theories, Bacchi's $(1999,2009)$ postmodern policy process theory highlighting the role of problem representation will be discussed in relation to the methodological elements of CDA. Many of Bacchi's ideas and concepts are remarkably congruent with those of Fairclough's, although she is specifically interested in how representations of policy problems play into the making of public policy (the circumstantial premise), rather than how they

\footnotetext{
${ }^{24}$ Other ideologies are defined and described in the methodology section.
} 
influence and are influenced by social practices more broadly. Classic and post empiricist policy process theories will first be discussed to lay the groundwork for Bacchi's $(1999,2009)$ pioneering work.

\section{Classic policy theories}

Policy process theories, the bedrock of Policy Studies, attempt to explain policy stasis and policy change. These theories tend to sit within the well-established discipline of political science (i.e., most of the pioneering policy process theorists identify with political science), although "policy studies" is, by definition, "interdisciplinary" 25 (Smith \& Larimer, 2013). Given the perceived second tiered nature of "interdisciplinary" studies within the academic community, there have been attempts (mainly by those rooted in a political science background) to construct robust predictive models of the policy process. Sabatier (2006) claims that any model or theory of the policy process must be predictive, linear and hence follow "rules", in order to be considered "legitimate". Pioneering policy process models, many of which continue to hold considerable weight today, are rooted in a positivist ontological and epistemological worldview, embracing the pursuit of an objective truth "out there". In contrast to the broad conceptual framew ork described above, positivist policy process theories embrace technocratic knowledge, "facts" produced by "experts", whereby the ultimate goal is finding the "best" solution to an

\footnotetext{
${ }^{25}$ Interdisciplinary studies are widely regarded as secondary or less-than the well-established academic disciplines. Indeed the focus of the first plenary session at the International Public Policy Conference in Milan in 2015 (a conference with over 3000 delegates) was acknowledging, deconstructing and calling for a shift in that thinking.
} 
objective social problem (Ostrom, 2006). Though such rational approaches to the policy process are most widely accepted and respected by those coming from a political science background, these theories simply cannot explain childcare policy development (or lack thereof) in Canada. By all objective measures, public investment in high quality childcare $i s$ the rational policy choice. As explained in the literature review, robust empirical evidence from a child development, short and long term economic gain, poverty reduction, women's equity, population growth, and intergenerational equity perspectives have clearly and repeatedly illustrated the benefits outweigh the costs of affordable and accessible high quality childcare for Canadian families, women and children.

\section{Postempiricist policy theory}

Policy Studies scholars have softened to the idea that there is no "right", "best" or even "one" way of thinking about social problems and their policy solutions. In fact, as early as 1959, evidence of postempiricst thinking was emerging. For example, Lindblom $(2005)^{26}$ questions the idea that public policy offers a solution to public problems, instead arguing that public policy is instead about slowly "muddling through", and incrementally making changes based on policyanalyst's value laden evaluations of policy outcomes. Paving the way for critical Policy Studies scholars to come, scholars such as Jones \& Baumgartner (1993) bridge the positivist/postpositivist divide. Beginning from their empirically supported premise that the policy process is stable with the occasional burst or rapid change, Punctuated Equilibrium

${ }^{26}$ This publication included a reprint of Linblom's original work published in 1959. 
Theory (True et al, 2006) draws attention to the role of policy images in the policy process. Emphasizing that policy images are rooted in both fact and emotion, they identify these images as a key mechanism through which policy changes. Yet again, their theory does not sufficiently explore how or why policy images come to be or how they trigger (if they indeed do) policy changes.

Frank Fischer, a professor of Political Science at Rutgers University, was one of the first widely recognized scholars to significantly diverge from the positivist, rationalist policy process models in Policy Studies. Fischer (2003) zeroed in on the "nonrational" ${ }^{27}$ attempting to tease apart the complex relationship between power, ideas, language and discourse. It is important to note that Fischer (2003) does not reject empirical inquiry, but calls for the recognition and appreciation of subjectivity in research contributing to a more "textured and sophisticated understanding of social and political reality" (p.viii). Fischer (2003) heavily criticized the importance of technocratic/expert knowledge in the policy process insisting that the "effort to eliminate subjectivity is futile" (p.37). Labelling himself a "postempiricist", Fischer (2003) describes a discursive approach to understanding the policy process whereby political action is "shaped and controlled by the discourses that supply it with meaning" (p.23). Fischer (2003) embraces a Foucauldian conceptualization of discourse whereby it is socially constitutive rather

\footnotetext{
27 "Nonrational" does not equal "irrational" (Smith \& McBeth, 2009). Irrationality suggests a complete abandonment of logical reasoning while non-rationality highlights the role of logical reasoning rooted in ideology rather than rooted in rational interest/utility maximization.
} 
than merely descriptive. Furthermore, Fischer argues that political discourses are derived from "moral or ideological positions that establish competing views of the good society" (p.56). In other words, what is "true" or "real" is socially constructed and inextricably connected to moral values/ beliefs about what is "good" or "right". For example, the lack of high quality childcare for Canadians problem will only be considered a "real" political problem if bettering the wellbeing (again defined by value laden markers of what "well-being" means) of families and young children is a priority for the majority of Canadians. To this end, Fischer (2003) embraces Habermas" view of communicative action whereby what is "true" and/or "real" is what society agrees is "real". In this way, Fischer (2003) insists on some parameters around what is "real" though the means through which to determine this "reality" are discursive, and therefore ideologically constructed in the social world.

\section{'What-is-the-problem-represented-to-be?' (WPR)}

Like Fischer (2003), Bacchi (1999, 2009) situates the discursive representation of the policy problem at the heart of policy analysis by assuming that policy problems "achieve their reality in language” (Bacchi, 2009, p.37). Both Fischer and Bacchi speak about policy discourse as "frames" that define parameters around what a policy issue includes/excludes. Bacchi (1999) also agrees with Fischer (2003) that policy analysts/those studying the policy process cannot sit outside of their analyses in any sort of "objective" place. For both, it is subjective, human understanding that brings meaning to the construction of social issues mainly through discursive representations of these issues. Where Bacchi diverges from Fischer, as well as Fairclough to some degree (discussed further below), is on the Habermasian notion of communicative 
consensus. Bacchi (1999) insists that any "normative consensus in policy deliberation" (p.33) indicates traces of positivist thinking. For Bacchi (1999), boundaries around $a$ "truth" is always problematic and limiting to a full understanding/appreciation of the policy process. Fischer's (2003) insistence on the necessity of defining policy problems, be it through a postempiricist, discursively/ideological lens rather than the traditional technocratic empirical lens (referred to by Bacchi as "political rationalism"), lead Bacchi to reject Fischer's policy postempiricist approach to the policy process and develop her own WPR approach.

Bacchi (1999) argues that the purpose of policy analysis is "to create space to consider competing constructions of issues addressed in the policy process, and the ways in which these constructions leave other issues untouched" (p.4). In this way, Bacchi is more interested in "the dog that did not bark", or what problem representations are missing, than those that dominate popular political debate. Beginning from the premise that "we cannot talk about them [policy problems] outside of their representations" (p.9), it is the representations of policy problems, rather than the definitively defined "problems" themselves, that are central to the policy process and in need of analysis. In other words, we may or may not be exposed or become aware of a policy problem represented in a certain way. This does not assume overt manipulation of those framing the problem, but simply notes that in framing a problem one way, other ways of understanding the problem are inherently overlooked. Bacchi calls for an exploration of other ways of representing and therefore understanding policy problems. 
Bacchi is heavily influenced by Foucault's concept of governmentality and discourse. Governmentality, or as Bacchi (2009) highlights, 'govern-mentality'places emphasis on "different kinds of thinking associated with particular approaches to governing" (Bacchi, 2009, p.276). As described briefly above, governmentality goes beyond the direct actions of the state to include the normative and insidious ways of thinking that come to influence people's behavior and lived experiences in the world. Bacchi (2009) emphasizes the necessity of deconstructing normative ways of knowing through which governance takes place, including the influence of professionals and experts who work through these knowledges. In her approach to theorizing the policy process, the way to recognize different forms of rule is through identifying and analyzing discursively constructed problematizations (Bacchi, 2009, p.30). Neoliberalism for example, with its focus on individual responsibility for well-being and opportunity in a free market economy, is not (always) directly enforced by governments. Yet it is a way of thinking that downloads much of the responsibility for social reproduction onto women - particularly the most vulnerable women (see Chapter 2). Similarly, neoliberal thought has concrete effects on women's decisions whether or not to have children given the high individual cost (financial, health, personal) to bearing and raising children. While there are certainly no laws saying women can only have 1 or 2 children, neoliberal entrenchment in modern Canadian society makes it difficult for any family to imagine caring for and supporting more than 2 or 3 children in addition to other necessary responsibilities.

Recall Foucault's argument that discourse has the potential to be a vehicle to contest prevailing notions of "truth" and "knowledge" (the building blocks of governmentality), 
challenging existing power structures and actively play a part in constructing society (Foucault, 1978). This is a central premise of "discourse" as defined by Foucault and "discourse practices" as discussed in CDA (Chouliaraki \& Fairclough, 1999). Bacchi $(1999,2009)$ also draws on this concept in her discussion of "discursive formulations" (another term originally used by Foucault), or "knowledges", to highlight the contestable nature of discourse. Most professions and sciences embrace $a$ knowledge to the exclusion of other ways of knowing. The most obvious example would be Foucault's example of the medical field, where what is "real", "true" and "right" usually emerges through a narrowly defined empirical process and is represented through its own discursive formation. When this "knowledge" is construed as $a$ knowledge rather than the only knowledge, it becomes contestable. Other ways of knowing exist becomes a possibility. Like Chouliaraki \& Fairclough (1999) who conceptualize discourse as a mechanism of establishing what is normative, Bacchi (1999) claims that it is through calling something a 'discourse' that allows one to question the normative: 'the focus on discourse challenges notions of immutable knowledge or truth since what is discovered is contesting claims to truth in different discourses" (p.40). Bacchi's theory is dedicated to the idea that discourses developed by and/or entrenched in state problematizations and/or policies are but one way of knowing, perceiving and/or understanding the world. That these dominant ways of knowing come to act as boundaries for what is perceivable is considered problematic in the policy making process. Identifying existing ways of knowing is also the primary concern of Fairclough \& Fairclough's (2012) circumstantial premise. Without a critical analysis of what exists, it is impossible to project imaginaries for change. 
Important to note that Bacchi does not assume intentionality behind discursive problematizations. While some scholars appear to indicate overt manipulation of policy discourse, particularly those from a political rationalism perspective, Bacchi does not assume this to be the case. In her own words, "I am more concerned with unpacking the implications of representations of problems than with attempting to understand them as deliberate or less deliberate distortions of situations" (Bacchi, 1999, p.36). She simply argues that any problematizations, particularly those endorsed by the state or media and therefore widely accessible, are limited and in need of deconstruction.

A WPR approach to the policy process, with its focus on recognizing and broadening the possibility of issue representation, is ontologically committed to recognizing and bringing into the political arena the most marginalized groups and members of society. The control of discourse is broadened to illuminate the voices of those resisting dominant knowledges. In line with this, Bacchi claims that active political debate is not adequate as an indicator of a "healthy" democracy. Instead, she calls for an immediate need to actively deconstruct dominant problematizations of social issues and scrutinize the ways of knowing that become taken-forgranted assumptions about the way things are. It is only then when a rich and nuanced discussion of public issues can be acknowledged, challenged and worked through.

\section{From the discursive to the material world - an example}

Adding strength to Bacchi's theory and also consistent with CDA are the concrete links she draws between the discursive and non-discursive effects of political/policy discourse 
(material "social practices" in CDA). These links illustrate why studies like this one matter. Far from being a solely academic pursuit, studies that employ a WPR approach highlight the current and potential possibilities in people's everyday lives. A WPR approach highlights: 1) the ways in which subjects/citizens come to be (or not) through discourse; 2) the omitted possibilities in peoples' ways of thinking; and 3) the 'lived effects', or the effects on people's daily lives. Of course, these three effects overlap and interact with each other. Throughout our history (as chapter 1 explains), a key avenue to citizenship for women (and her children) was through dependence on an able-bodied, Canadian, employed male partner. Single mothers have thus become discursively constructed as a social "problem" as they don't fit this model, rather than scrutinizing the structuring of citizenship in the Canadian welfare state.$^{28}$ Furthermore, the sexism, discrimination (overt and covert) and abuse that often place single mothers in vulnerable positions is overlooked when they become perceived as the "problem". They become understood as needy, weak and morally flawed through a social policy discourse that holds them personally responsible for their vulnerable status. That she is also a survivor worthy of dignity and respect with a right to state assistance (rather than charity) is often occluded from the single mother "problem". In this way, she likely will come to understand herself as the "problem", as a different understanding of herself and her situation is unavailable. More likely than not, she acquiescently accepts her lot in life, unaware that self-advocacy may be a worthwhile option. On

\footnotetext{
${ }^{28}$ A similar example is the disability movement who position the "problem" being an inaccessible society rather than a flaw within an individual. In this way, it is society that disables them rather than a medical "deficiency".
} 
a practical level, daily survival requires her constant attention and effort. She cannot work without quality, affordable childcare, which is extremely difficult to find, even for the most privileged women in society. Her priority will not be taking to the streets to demand a different conceptualization of her problem, but rather making sure that she and her children are safe, fed, and cared for. It quickly becomes apparent that critically studying the representation of policy problems is much more than an exercise in academic rigour - it is urgently needed and necessary to address the continued marginalization women's problematizations of social issues on the policy agenda.

\section{CDA as a tool to build on WPR from a theoretical perspective}

WPR and CDA share many similarities. Both work with the idea that discursive practices have important implications for social life, including politics and policy. Both consider it necessary to identify and deconstruct the way social issues are represented through a focus on language. Both link insights to processes of governmentality and hegemonic power relations (indicating shared links back to Foucault and Gramsci). Both agree that the representations of policy problems play a key role in policy processes (Fairclough refers to the "circumstantial premise" while Bacchi refers to "problematizations"). Fairclough and Bacchi also both conceptualize discourse as having a reflexive dimension. Bacchi (2009) suggests that "calling something a 'discourse' means putting its truth status into question" (p.35) while CDA is rooted in the assumption that one always engages in practices from a particular perspective, while overlooking others and that critically questioning these practices is necessary for social change. Similarly, Bacchi and Fairclough encourage critical reflection on the discursively constructed 
parameters of what is knowable, thinkable and doable in the social world. For both, the plurality of political discourse acts as an indicator of democratic deliberation whereby what is not represented is as important to analyze as what is represented.

With all they have in common, there are also some key point of differentiation between the two theorists. One key difference is the end goal of analysis. For Bacchi, critically analyzing policy problematizations provides the opportunity to explore "unexamined ways of thinking" (Bacchi, 2015, p.7) not necessarily with the goal of reaching consensus of the "way things are" or the way things "should be", but simply to expand the process of democratic deliberation. While Fairclough concedes the necessity of this, his work is more connected to embracing this knowledge as central to informing progressive social change. In his own words, Fairclough (2003) emphasizes discourse as "projective, imaginaries....tied to projects to change the world in particular directions" (p. 124). In this way, the analysis of problematizations through a CDA lens not only opens up possibilities for new and different ways of thinking about social issues, but also embraces the necessity of linking different ways of knowing/being/thinking to progressive change. CDA is also methodologically more developed, providing the concrete tools necessary to explore how certain problematizations have become dominant in mediatized discussions of political/social issues.

Along similar lines, WPR and CDA differ in their assumptions about the intentionality behind discourse. CDA appears to assume a greater level of strategy and/or awareness by those constructing discourse - particularly those in the mass media and in politics. This is empirically 
difficult to gauge, of course, because one does not have access to the motivations of those producing texts. However, Fairclough (1995) does identify and elaborate upon the unique features of mass communications (discussed above), including its immunity from direct public input and entrenchment in economic and political systems. Citizens' genuine understanding of social issues, a necessity for a democratic social order, is seen to be interrupted by and through the mass media. Bacchi (1999) on the other hand is "less concerned with understanding representations as deliberate or less deliberate distortions of situations" and more concerned with "unpacking the implications of representations of problems" (p.36). In this way, Bacchi remains focused on connecting representations of policy problems (or lack of) to the lived observable social practices rather than projected imaginaries for change ${ }^{29}$. Along similar lines, Bacchi's work is focused primarily on the analysis of political documents themselves rather than mediatized documents with political content. Fairclough $(1995,2003,1999)$, on the other hand is much more interested in critically analyzing widely accessible texts that play a key role underscoring social practices.

Theoretically, CDA also takes a slightly different position from Bacchi in regards to the role of ideology in texts. Fairclough (1995) states:

\footnotetext{
${ }^{29}$ In this project, the identification of problematizations in Part I is very much the starting point, rather than end point, of analysis. She does not reject that problematizations can be identified - and by default that they can be counted-but assumes the value in identifying the problematizations is in its connection to discursive possibilities and subjective effects rather than raw "counts" alone.
} 
Ideology should not be seen as a constant and predictable presence in all media discourse by definition. Rather it should be a working principle that the question of what ideological work is being done is one of a number of questions which analyst should always ask (emphases added) (p.47)

In other words, texts (in this case mediated texts) are not inherently ideological though one must constantly be on the lookout for it. In a WPR model, is impossible for problematizations to be devoid of ideology. For Bacchi, any problematization establishes the parameters of solutions in a particular direction - a direction ultimately congruent or incongruent with a set of values and beliefs. This distinction is one that Bacchi (1999) claims distinguishes a WPR approach to policy analysis from political rationalists (those who acknowledge the important role of values in the policy process but still work towards working outside of them). In line with this, she argues that ontologically conceptualizing problematizations as value-laden (and therefore ideological) means the WPR analyst cannot be considered value "neutral". While Fairclough makes the above claim, CDA concurrently and explicitly remains socially and politically committed to emancipatory social change (Fairclough, 1992). It is thus difficult to imagine a case where CDA would not somehow bring to light hegemonic power relations, uncovering ideological assumptions in the process. Nonetheless, he does assert that this could be possible while a WPR model does not.

Only very recently (while this project was being developed), have the two theorists actually begun to cite each other's work, building bridges across the historically segregated academic disciplines of Linguistics (Fairclough) and Political Science (Bacchi) (i.e., Bacchi, 
2015 and Fairclough, 2013). Even still these references do not delve into the intricacies of either theory and mainly acknowledge the existence of similar ideas. Fairclough (2013) refers to Bacchi as an example of a theorist who may overemphasize the relationship between problems and their solutions in the circumstantial premise. He cautions scholars against reducing the analysis of political discourse to representations, as he suggests this downplays the role of values and goals in the policy process. Similarly, Fairclough \& Fairclough (2012) state: "politics seems to be about imposing representations and about how representations serve power, there is no indication about how this can occur" (p. 22). This is agreeably a limitation of Bacchi's model, though one that can be built upon through drawing on the tools of CDA - precisely what this project attempts to do.

Bacchi (2015) also briefly refers to Fairclough (2013), acknowledging that he "takes issue with the ways in which some post structural researchers create a link between problems and solutions" (p.8). At the same time, Bacchi does not appear to situate herself in this category of researchers, as she emphasizes her theory as one rooted in "Foucault-influenced poststructuralism" whereby the purpose is to engage in "continuous critique" (p.9) rather than infer specific solutions from problematizations. Again, Bacchi's concern is identifying and critiquing the parameters of possibility inherent in policy problematizations rather than embracing one problematization or solution over another. In contrast, CDA's commitment to emancipatory social change does instantiate preferential treatment of problematizations from a social justice perspective. In this way, CDA builds on WPR moving beyond problem identification to engaging in questions of how dominant problematizations emerged and what the impacts on 
social practices may be. In the same vein, insights from CDA would appear to have implications for social actors attempting to affect progressive social change while insights from WPR would be limited to expanding the parameters of deliberation alone.

Not discussed in their critiques of each other are other key difference between these two scholars, including their starting and ending point. Bacchi begins with problematizing policy representations (or lack of) of social problems -that which is "problematic" and in need of policy attention (or not). In contrast, Fairclough begins with what is normative in the social practices observed in everyday life. Fairclough (1995) is particularly concerned with discursive representations of social practices available in the mass media, with its large dissemination base/easy of accessibility. His goal is to problematize what is taken as a given and illustrate policy implications. In contrast, Bacchi takes the opposite approach: she begins with what have been conceptualized as policy problems and connects this to what is or could be normative (though she remains critical of any normative representation). She questions how policy problematizations are "produced, disseminated and defended" in an effort to theorize how it could be "questioned, disrupted, and replaced" (Bacchi, 2009, p.236). The "produced, disseminated and defined" refers to the policy level while the "questioned, disrupted and replaced" refers to problem representation in everyday life. In her own words, her goal is to "understand how policy decisions close off the space for normative debate" (Bacchi, 1999, p.20). CDA on the other hand begins by reflecting on and intervening in the (re)production of normative social practices (what is available to "question", "disrupt" and "replace") in order to challenge the broader sociopolitical order (what is "produced", "disseminated" and "defined" on 
a mass level). Put more simply, CDA questions the "normative debate" and examines the implications for the policy level. Of course, the academic disciplinary roots of CDA and WPR become evident in these different starting points and end goals: WPR begins with policy "problems" and works towards an analysis of what is normative whereas CDA begins with what is discursively normative later extrapolating insights to the sociopolitical level. This project tries to understand the process from both directions. There is an effort to appreciate how the normative influences what is problematized and how problematizations define parameters for what is normative. Having said this, the data collection methods include the search term "policy" suggesting policy problems/solutions have already been defined in the texts to some degree.

The other key difference between Fairclough and Bacchi is the gendered lens Bacchi (1999) weaves throughout her work. While Feminist CDA (FCDA), has emerged under the leadership of Michelle Lazar (i.e., Lazar, 2005), CDA was not theorized or methodologically developed with a specific focus on the gendered nature of social practices. In contrast, Bacchi's theory and methods specifically arose in response to a need to illustrate the unique positioning (or lack of positioning) of women in public policy. This underscores her motivation to consistently and continuously raise awareness about missing problematizations from a gendered perspective. While CDA certainly acknowledges the importance of analyzing what is not available in texts as much as what is, CDA does not take an explicitly gendered approach (though it arguably provides the tools to do so if this is the sociopolitical cause in which the analyst is committed).

While coming from different academic disciplines, WPR and CDA both emphasize the 
critical role that discourse plays in becoming aware of and challenging the prevailing sociopolitical order. While WPR originated in the field of political science and therefore was and is primarily oriented to the analysis of public policy through its discursive representation, CDA is as relevant to the analysis of political/policy discourse and illuminating possibilities for progressive policy change. In this project, CDA builds on a WPR analysis offering insights into how childcare policy problematizations have become normative ultimately extrapolating progressive ways forward. The first section of the Chapter 4 will outline how CDA has been used as a methodological tool to build on WPR. 


\section{Chapter 4: Methods Part I}

\section{CDA as a tool to build on WPR from a methodological perspective}

As was explored in Chapter 3, WPR and CDA overlap and interact in interesting ways. One of the key differences between WPR and CDA, on a methodological level, is the degree to which each has developed an approach to systematically studying problem representation. In the last decade, CDA has become an increasingly recognized, utilized and developed a qualitative methodological approach to inquiry that is used across many disciplines. In fact, an entire academic journal, Critical Discourse Studies, is devoted to the theoretical development and application of the method. In 2009, Bacchi followed up her theoretical book (Bacchi, 1999) with a methodologically oriented book where she outlined five guiding research questions and subquestions that must be applied to a policy text from a WPR perspective:

1. How is the problem represented? Or, what is/are the problematization(s)?

2. What underlying assumptions and/or presuppositions are evident in this problematization?

3. How did this problematization emerge?

a. What historical events impacted the emergence of this problematizations?

4. What has been left unproblematized in the identified problematization(s)?

5. What are the effects of the problematizations?

a. Discursive effects - impacts on the limits of thought 
b. Subjectification effects - impact on "who we are, how we feel about ourselves, who is attributed responsibility the problem" (Bacchi, 1999, p.33)

c. Lived - material impacts on everyday life

These questions build on each other, moving from problem identification to a critical examination of the values, emotions and beliefs that undermine individuals' and societies' existence and experiences in the world. These questions also explore how identified policy problematizations emerged, what problematizations are missing and the ideological roots of problematizations. She requires the analyst to make connection between existing/missing policy problematizations and the limits of what is thinkable, an individual's understanding of her identity and place in the world and concrete experiences in everyday life. While these questions are helpful and essential, they are also arguably vague. For example, in addressing question 2 and 3, concrete tools as to how a research can systematically identify assumptions and/or deconstruction the emergence of the problematization (beyond the sociohistorical context) are not offered. Specific tools to answer these questions in more depth are a strength of CDA.

Keeping in mind the 5 questions Bacchi (2009) laid out, Fairclough (2003) lays out the following questions pertaining to each level of analysis in CDA (refer back to Figure 3.2 in Chapter 3). Each level of analysis is embedded within the next, shifting from the level of text analysis to critical examination of discourse as a socially constructing and constitutive mechanism. In this way, the analysis shifts from an analysis of the semiotic aspects of language to an interpretive analysis identifying overarching power relationships in society. 
Text

1. How much text is there dedicated to an issue or idea?

2. What are the dominant ways of representing the issue? OR what are the dominant discourses?

a. What words or phrases appear frequently or seldom in relation to an issue?

b. What words or phrases are missing in relation to an issue?

3. What specific grammatical/text mechanism are at work that may influence meaning?

a. Metaphor? More specifically, nominalization?

b. Conversationalization/sensationalization?

Discourse practice

1. What assumptions (propositional and/or existential) are available/unavailable in the text?

a. What are the underlying values and beliefs underlie the logic drawn upon?

2. What is the order of discourse?

a. What degree of intertextuality is evident?

b. What degree of interdiscursivity exists?

3. What is the modality of the text?

4. How is the text legitimized? 

a. Authorization?
b. Rationalization?
c. Moral evaluation?
d. Mythopoesis?

Sociocultural practice

1. What are the broader social, economic, political and cultural practices in which the text and discourse practice are interpreted/become meaningful?

a. What political party was in power? Is it an election period?

b. What was the economic status of the individual, community or nation?

c. What important international events/pressures were occurring at the time?

WPR questions 1, 2 and 4 correspond to the questions asked on the level of text and discourse practice in CDA. Identifying which policy problematizations are evident corresponds to identifying existing (and non-existing) policy discourses. In this study, policy problematizations are operationalized and observed through their discursive element. Like Chouliaraki and Fairclough's (1999) conceptualization of discourse that emphasizes the symbolic aspect of social practices, the study of policy problematizations in this project is limited to the symbolic, observed through text/language. In Part I of this study, where broad childcare problematizations/discourses are being observed (i.e., an economic problematization), the distinction between policy "problematizations" and policy "discourse" becomes semantic 
rather than conceptual. Problematizations are also heavily tied to the rationales discussed in Chapter 2 in that the "reasons why" a policy should or should not be pursued is inherently linked to an understanding of a problem (i.e., the women's equity rationale begins from the premise that women do not experience equal opportunity and that this is a "problem"). In the critical discourse component of the study, the term "discourse" is preferred given discourse provides the building blocks for problematizations and the analysis is much more thorough in scope. This language also more accurately reflects Fairclough's $(1995,2003)$ methods that provide the concrete tools to carry out the CDA component of the project.

CDA and WPR are also both concerned with identifying the most frequent representations of the issue, or which discourse(s)/problematization(s) is/are dominant. The primary purpose of the Part I of the project is to identify and count the frequency of problematizations/discourses in newspaper articles. Bacchi's second question about assumptions and presuppositions in policy problematizations/discourses corresponds to Fairclough's inquiry (discourse practice, question 1 above) about the role of assumptions in text. Fairclough (1995) provides categories for different assumptions (described in more detail in the CDA methods section below), leading to greater reliability and validity when applying these concepts across a number of texts. Fairclough's questions pertaining to legitimation corresponds to Bacchi's last question probing the connection between discourse/problematizations with what is perceivable, knowable and necessary to understand one's being and experiences in the world. If ideas, constructed through discourse, are not seen as legitimate, then their constitutional value is 
compromised. WPR and CDA also both insist on situating any analysis within the broader sociocultural/political and economic structure of society.

Both CDA and WPR elaborate on the subjectification effects of discourse on the lived experiences in people's lives, or how discourse is constitutive and reflective of social practices. Chapter 8 will explore this, making concrete connections between the insights revealed and what these may mean for individual's experience in and of the world. This is essential to explore in light of the FPE literature and overarching motivation for this study, which conceptualizes childcare policy as a necessity for women's full participation in society.

CDA is most focused on the specific linguistic/grammatical mechanisms that are drawn upon to construct policy discourse (the tangible aspect of problematizations). Identifying concepts such as intertextuality, nominalization, irrealis statements (predictive statements that are presented as if objectively "true") and conversationalization (described in detail below) shed light into how some policy discourses become more prevalent while others remain marginal or excluded entirely - an aspect of analysis which WPR does not provide the methodological tools to probe. It can be particularly perplexing when certain policy discourses/problematizations fade into the background, or do not emerge when they appear to be central to understanding an issue. Through identifying and exploring the specific linguistic mechanisms described in CDA, it often becomes understandable (though not necessarily acceptable) why policy issues are discussed the way they are. 
The research questions below have been arrived at using CDA as a methodological tool to build on WPR. The research questions are answered in stages. Part I of the project focuses on identifying the frequency of different childcare policy problematizations, though it also notes general trends in the entire data set (i.e., number of newspaper articles addressing the issue, word counts), while Part II elaborates on the content of specific articles published, leading up to and during the 2015 federal election campaign. Sampling procedures were used to reduce the data set for Period A in Part I, while the entire data set was coded in Part I for Period B. Sampling was used to reduce data in Part II of the study to determine which articles would undergo CDA. Only sampled newspaper articles from Period B underwent CDA, providing insight into research questions four and five. Generally, the analysis moves from broad observations offered through the WPR analysis to a more focused CDA analysis, with the former used to guide data sampling for the latter (described in detail below). While numbers are used to represent findings, particularly in Part I of the analysis where policy problematization is the focus, the coding process is qualitative in nature - possible only through careful reading and human coding of data.

\section{Data collection and WPR methodology}

The methods of this project are divided into two parts. The rest of this chapter will discuss the data collection process as well as the operationalization of the WPR. Chapter 5 will focus exclusively on the application of CDA.

Data consists of newspaper articles discussing childcare policy in Canada's two national newspapers, The National Post and The Globe and Mail and the high circulation, Greater 
Toronto Areas based The Toronto Star, between 2008 and 2015. Data was inputted into excel spreadsheet "books" organized by year with 3 "sheets" for each newspaper. As was mentioned in earlier chapters, the data collection period was also broken down into two distinct periods:

Period A) January 1, 2008 to October 13 2014, and Period B) October 14, 2014 - November 19, 2015. The first time period begins in 2008 as this is where other Canadian researchers studying childcare policy in Canadian newspapers left off (Albanese et al., 2010; Rauhala et al., 2012). Period A was cut off at the point when childcare policy re-emerged on the federal policy agenda. The second time period reflects the lead up to occurrence, and one month after the 2015 federal

election campaign. A broad analysis of newspaper articles (sampled articles in Period A and the entire population in Period B) identified discursively constructed childcare policy problematizations. A sub-sample of articles from period B were then further analyzed using the methodological tools of CDA (Fairclough, 1995, 2003) to gain insight in to the specific text/discourse drawn upon.

\section{Research questions}

The research questions this project answers are:

1. How much coverage of childcare policy was there in three Canadian daily newspapers in Period A and Period B?

2. What discursively constructed childcare policy problematizations emerged/did not emerge in these newspapers in Period A and Period B? 
3. What discursive techniques and/or resources contributed to establishing and sustaining dominant policy problematizations in sampled newspaper articles in period B?

\section{Part I: Identifying the policy representations}

Questions 1 and 2 above encompass WPR's first question (i.e., what is the problem represented to be?) as well as address the first two questions on the level of text analysis as posed by CDA (how much text is devoted to the issue? and what are the dominant representations of the issue?). Given Bacchi does not elaborate beyond the suggested question to apply to data (other than to provide concrete examples), tools from content analysis were borrowed to help organize the data in Part I.

Content analysis is still often thought about as an objective, quantitative approach to inquiry - clearly an approach to analysis that does not flow logically from my conceptual framework or fit with my research agenda. More recently, Krippendorff (2013) argued that "all reading of text is qualitative, even when certain characteristics of a text are later converted into numbers" (p.22). This part of the project borrows from Krippendorff (2013) conceptualization of content analysis in which quantitative mechanisms (i.e., counting the number of articles published on the topic, frequency of childcare policy problematizations, observing word counts of articles) were used to represent qualitative concepts. For example, a nominal measurement system was used to indicate which problem representations were evident in each article (discussed below). With a sense of the broader patterns in the data, critical discourse analysis 
methods are able to answer the more detailed and nuanced questions pertaining to CDA questions four and five, or the level of discourse practice.

\section{Organizing and analyzing the data}

The key contribution from Krippendorff's (2013) discussion of content analysis is his systematic approach to organizing, managing and approaching large textual data sets. Krippendorff (2013) recommends six steps to approaching content analysis, which guided the organization and analysis of data in this project. These are:

1. Unitizing: Decide what the unit of analysis will be and how it will be collected/observed.

2. Sampling: Limit observations to a manageable subset of representative units (in this case the population itself must first be identified before sampling can occur)

3. Recording: Create an "analyzable record of otherwise transient phenomena" (p.85).

4. Coding: Formulate observer-independent rules through which to categorize recorded material

5. Reducing data: Creating efficient representations of the data. In the quantitative, content analysis portion of this study this will include numerically representing the frequency of each discourse that emerges during a given time period in each paper.

6. Inferring and narrating: Making connections and meaning between the data and the "real world"

\section{Unitizing the data}

The units of analysis in Part I of this study were newspaper articles published between 2008 and 2015 in The Globe and Mail, The National Post and The Toronto Star that specifically 
discussed childcare policy. Initially, the policy platforms of the four major political parties (The Liberal Party, The New Democratic Party, The Green Party, The Conservative Party) in the 2015 election were included in the analysis, however these were later left out for a few reasons. First, the amount of text devoted to childcare policy in the platforms was minimal, even in the NDP platform where childcare policy was a central plank of the party's campaign. Second, data collection and analysis of newspapers in the two different time periods with two different methodological approaches was already quite complex. It was decided that critically analyzing party platforms would be best conducted as a separate project where comparisons could be drawn between each of the four political party's' platforms in 2008, 2011 and 2015 as well as with the findings from this project. Third, in a project that is interested in public understand and the democratic deliberation about policy issues in a public sphere, it is most likely that citizens access their information through mediatized channels rather than the policy document themselves. In our time pressed and hurried society, citizens are more likely to view a newspaper article that pops up on a Facebook feed or quick google search rather than going to party platforms. In order to get a full picture of how political parties were framing the childcare problem, other documents - including political speeches and/or interviews with politicians would be needed. Given the complexity of the existing project and already large quantities of data, it was decided that such an analysis would be best left for another project. Finally, an analysis of each party's 2015 childcare policy platform has already been made available through the Child Care Advocacy Association of Canada and included in Appendix B for reference. 
Newspapers, rather than other policy documents or media outlets, were chosen as the primary unit of analysis for several reasons:

1. They are widely accessible to the public, either in print or online format

2. They are an established and reputable source of information that has gone through the journalism process (i.e., selection, inclusion, editing, and publishing). This is to be contrasted with social media texts available on Facebook or Twitter.

3. They typically dedicate more time/space to describing and breaking down issues than other popular forms of news journalism. For example, television broadcasts typically allocate less than one minute to any one news story ${ }^{30}$.

4. They reflect and tie in the current sociopolitical context on a daily basis.

5. They usually include a range of perspectives, including input from full-time editors, regular or occasional columnists, guest experts as well as space for citizens to respond and/or contribute (though letters to the editor)

Articles were all available and systematically searchable through the Ryerson library.

The Globe and The Post were obvious inclusions given they are Canada's only two national newspapers and this study is concerned with national childcare policy. Although The Toronto Star is regionally based, it is also the most widely circulated newspaper across Canada, suggesting that childcare policy's representation in this paper is affecting Canadians

\footnotetext{
${ }^{30}$ Data from a recent American study has noted that the average story length on local television news decreased substantially over time: "In a Pew Research Center analysis of local news content from 1998 to 2002 , some $31 \%$ of the stories were more than a minute long and $42 \%$ were under 30 seconds. In 2012, only $20 \%$ of the local tel evision stories exceeded a minute while 50\% lasted less than 30 seconds" (Pew Research Center, 2013).
} 
understanding of childcare policy across the country. These papers also embrace different political orientations - with The Post described as right-leaning, The Globe central in the political spectrum and The Star the most left-leaning (Rauhala et al., 2012). Given that policy problematizations are inextricably connected to ideology, the choice of these three papers was thought to include diverse perspectives on the issue.

The other important point to address is the changing format of newspapers. Newspapers typify "print" media, though they are increasingly being published and disseminated online. It could be argued that information available to citizens in print is no longer relevant to large-scale representation and understanding of policy issues, given most people do not read printed papers to get their news. What is available online is much more easily accessed both because it is free and available anywhere, at any time. Digital articles can also be updated at any time. However, the print and online versions of news stories are usually not identical. Attempting to condense information for an audience with growing time restraints and shrinking attention spans, it is not uncommon for online version of print newspapers to omit portions of the story. Interestingly, newspaper databases, like those available through the Ryerson library, do not differentiate between versions of the articles available online or in print (all digital versions would include the most recently updated articles). Since this differentiation cannot be made and initial Google searches revealed that past articles are frequently removed from newspapers' freely available online databases, the full print article was used for analysis. Given the full print article always contains the same or more coverage of the issue (as the online article is either the full article or a 
condensed version), it is safe to assume the problematizations identified through print articles can be considered an optimistic reflection ${ }^{31}$ of available childcare policy problematizations.

\section{Data collection}

To identify relevant articles, the terms "child care" OR "childcare" OR "daycare" OR “early learning” AND "policy" were searched in the ProQuest Newsstand New Platform database between 2008 and 2015 (each year searched separately). The reason this database was chosen was because it contained all three papers in their entirety, during both time periods. The first 3 search terms were those used by Albanese et al (2010) and include the most common terms to refer to care services for children from birth to school-age ${ }^{32}$."Early learning" was added, given the Canadian government's preference of this term (particularly the Liberal government) stemming from the 2004 Early Learning and Child Care Foundations program (Langford et al, 2013). “Policy” was included as a separate search term, given this study's specific interest in childcare on the public policy level.

Once these initial articles were identified, some were omitted, specifically, articles that did not pertain to the social policy level, for example an article that discussed one childcare

\footnotetext{
31 The underlying assumption here is that print texts (available through online databases) would provide the bestcase-scenario in terms of the breadth of childcare policy discussion. Any abbreviated articles made available free of charge to non-subscribers would contain only portion of the text. In this way, an analysis of full texts would provide the most comprehensive overview of what was or was not available to readers.

32 The term "day care" was omitted as it did not contribute to any more inclusions than the three preferred terms.
} 
centre's policy about staff covering up tattoos, articles that mentioned childcare in passing (i.e., a shooting near a local daycare, a story about a romantic relationship beginning between two parents at a daycare) and articles that discussed doggie "daycare" were omitted. Obituaries were omitted. Congruent with Dorfman \& Woodruff (1999) and in contrast with Albanese et al (2010), opinion pieces (including letters to the editor and comments) were explicitly included given they illustrate what representations of the issue were available to the public.

The step-by-step procedure for data collection was as follows:

1. From Ryerson Library home page, click on "journals"

2. Search for newspaper desired (i.e., Toronto Star, Globe and Mail, National Post)

3. Choose the ProQuest Newsstand New Platform

4. Click on "advanced search"

5. Leave in the publication id number in the first search field

6. Add in search terms: "childcare" OR "child care" OR "daycare" OR "early learning" AND "policy"

7. Beside "publication date", click on "publication date range". Input January 1 of that year to December 31 of that year

8. When results appear, make sure to sort by "publication date" on the right hand side of the screen

9. Include articles in the excel spreadsheet that: 
a. Include "child care", "daycare" or "childcare" or "early learning" occurs at least twice $^{33}$ throughout the full-text of the article AND

b. Includes "policy” at least once AND

c. When "policy" it is used, it pertains to the public policy level

10. Exclude articles in the excel spreadsheet that:

a. Are obituaries

b. Use search terms in a way that does not pertain to childcare policy (i.e., "doggie daycare")

\section{Recording and sampling for the WPR analysis}

The titles, dates, authors, word count, section, placement in the paper and URL for articles that met the search criteria were placed into excel workbooks. This procedure generated a total of 9 excel workbooks - one for each year, plus an additional workbook for data published between October 13, 2014 until December 31, 2014 (Period B data that was published in 2014). Each workbook contained 3 spreadsheets (one for each paper) indicating the "population" of the study. Therefore, 7 excel workbooks (one for each year, each with 3 sheets) representing data

\footnotetext{
${ }^{33}$ It was usually the case that when the search terms were included at least twice in text, the article did focus on childcare in a meaningful way.
} 
from the first time period (January 1, 2008 - October 13, 2014 ${ }^{34}$ ) and 2 excel workbooks representing data from the second time period (October 14, 2015-November 19, 2015) were created.

As Table 4.1 below illustrates, this search criteria identified 538 published articles between January 1, 2008 and November 19, 2015.

${ }^{34}$ October 13, 2014 was chosen as the cut-off date for Period Aas the NDP announced their childcare proposal the next day, October 14, 2014.

35 November 19, 2015 was chosen as the cut-off date for period B as it was exactly one month after the election and coverage significantly slowed. On a more practical level, it was necessary to complete the coding of data for the first part of the project. 
Table 4.1: Number of articles meeting the search criteria in each time period

$\begin{array}{lllll} & \text { Toronto Star } & \begin{array}{l}\text { Globe and } \\ \text { Mail }\end{array} & \begin{array}{l}\text { National } \\ \text { Post }\end{array} & \text { Total } \\ 2008 & 40 & 12 & 17 & \\ 2009 & 19 & 22 & 9 & \\ 2010 & 10 & 16 & 10 & \\ 2011 & 27 & 10 & 22 & \\ 2012 & 16 & 7 & 10 & \\ 2013 & 24 & 25 & 8 & \\ \text { Jan } 1 \text { - Oct 13, 2014 } & 30 & 8 & 13 & \mathbf{3 5 5} \\ \text { TOTAL PERIOD A } & \mathbf{1 6 6} & \mathbf{1 0 0} & \mathbf{8 9} & \\ \text { Oct 14-Dec 31, 2014 } & 30 & 10 & 11 & \\ \text { Jan 1 - Nov.19, 2015 } & 58 & 36 & 38 & \mathbf{1 8 3} \\ \text { TOTAL PERIOD B } & \mathbf{8 8} & \mathbf{4 6} & \mathbf{4 9} & \mathbf{5 3 8} \\ \text { GRAND TOTAL } & \mathbf{2 5 4} & \mathbf{1 4 6} & \mathbf{1 3 8} & \end{array}$

Some broad observations were made pertaining to the entire data set in period A. For example, comparisons in the number of articles published in each paper were noted as well as trends in the depth of coverage. Like Albanese et al (2010), word count was used as an indication of the depth of coverage of the issue. Finally, the general focus of the articles was noted when spikes in coverage emerged.

\section{Part 1: Sampling Period A data}

Identifying all the childcare problematizations in 355 articles in the first time period was unrealistic for practical reasons. Using qualitative coding software, such as NVivo, was considered but decided against due to the nature of the coding process. The methodological approach of this study requires a careful reading of each article that cannot easily be reduced to digitized markers (i.e., words or phrases). Similarly, the context of how words were used 
(including subtext and/or phenomena such as sarcasm) cannot be detected by computer software. Most importantly however, reading, highlighting and making notes on hardcopies throughout the coding process was preferred by the researcher. Therefore, a systematic sampling procedure, embedded within a stratified sampling approach, was applied to data in Period A.

Krippendorff (2013) defines a stratified sample as one that recognizes "distinct subpopulations within a population" (p.116). As described above, data in Period A was drawn from the 3 different new spapers across 7 consecutive years (2008 - 2014). Data from each newspaper in each year thus represented a "sub" population. Rather than applying a random procedure to pull $\mathrm{x}$ number of articles for closer analysis, a procedure which may over represent/underrepresent some papers in some years, a stratified sample allowed the researcher to ensure all 3 newspapers and all years were represented. The number of options for determining how many and which articles from each newspaper and in each year were included in the representative sample are indefinite. It was decided that an equal number of articles from each paper in each year was preferable to proportionate sampling, given the purpose of the study is to examine how childcare policy has been discussed over time from various perspectives. As discussed above, each paper has a different readership and ideological orientation. Ensuring that equal weight was given to each paper allowed the project to capture the diversity of voices rather than analyzing more articles in one paper (even if more articles were published in one paper).. Once this decision was made, it was mathematically determined that 5 articles in each year would provide a practical/manageable sample while including about $1 / 3$ of the total population. 
Table 4.1 provides the total number of articles collected in both periods and from these, five articles per year, per newspaper were selected (the selection process is described below).

Number of articles to be included:

5 articles $\mathrm{x} 3$ papers $=15$

15 articles per year $\times 7$ years $=105$

The next step was deciding which 5 articles would be included in the sample for Period A. In an effort to include diverse voices and different length of articles, it was decided that one or two articles from each of the categories, below, were to be included:

1. At least 2 opinion pieces ${ }^{36}$

a. Including at least one letter to the editor if available

2. One "short" article

3. One "medium" length article

4. One "long" article

The rationale behind including 2 opinion pieces, including at least one letter to the editor if available, was because these pieces tend to take a stronger stance on issues. Most opinion

\footnotetext{
${ }^{36}$ Each of the three papers refers to their "opinion" sections slightly differently. In The Globe, "editorials", "letters
} to the editor" and "columnist" all fall under the broader title of "Opinion". In The Post, "FP comment", "letters to 
pieces, including comments, columns and "ideas", provide a venue for those associated with the paper to voice their perspective. Letters-to-the-editor provide citizens a direct venue for providing (usually) alternative perspectives. While Albanese et al (2010) and Rauhala et al (2012) made the decision to omit letters to the editor, given their interest in connecting newspaper coverage to the paper's ideological stance however, this project seeks to identify the range of discourse available from all ideological perspectives. Again, the diversity of childcare policy discourse is a primary concern of this research.

The other categories outlined, characterized by "small", "medium" and "large" word counts, were included to ensure articles with various depths of coverage were included. Given the average word count across all papers in all years was $930^{37}$, it was decided that a "small" article would be less than 500 words, mid-range between 501-900 words and a "long" article could be considered more than 1000 plus words

the editor" and "live comment" all fall under the broader category of "Comment". In the past The National Post had an "Issues and Ideas" section which also was often used for guest columnists. This is also included in "Opinion" for the purposes of this project. In The Star, "editorials", "letters to the editor" and "comments" all fall under the "Opinion" section. Where possible a letter to the editor will be included. When these are not available, another type of opinion piece (either a comment or column) will be included.

37 The lowest average word count was found in the National Post in 2010 with 605 while the and the highest was in The Globe and Mail in 2013 with 1744 
Table 4.2 Categories for the length of articles

\section{Word count}

\section{Category}

$\begin{array}{ll}\text { Short } & <500 \text { words } \\ \text { Medium } & 501-999 \\ \text { long } & 1000+ \\ \end{array}$

While the "small", "medium" and "large" 38 article categories and the requirement of 2 opinion pieces helped to set parameters around articles to be sampled, more criteria were needed in cases where more than one article met these criteria. Remaining systematic, the below hierarchical criteria guided inclusion:

i. Frequency of search terms in the body of article (more frequent mention of search terms warrants inclusion of less frequent inclusion of search terms) (highlighted in GREEN)

ii. Section front (highlighted in ORANGE)

38 The word count column was highlighted in shades of blue to indicate which category the article into ("small" was light blue, "medium" was mid blue and "high" was bright blue) 
iii. Mention of search terms in the title of the article (highlighted in PINK)

iv. National context

v. Diversity of authors (cannot include two articles from the same author in one year)

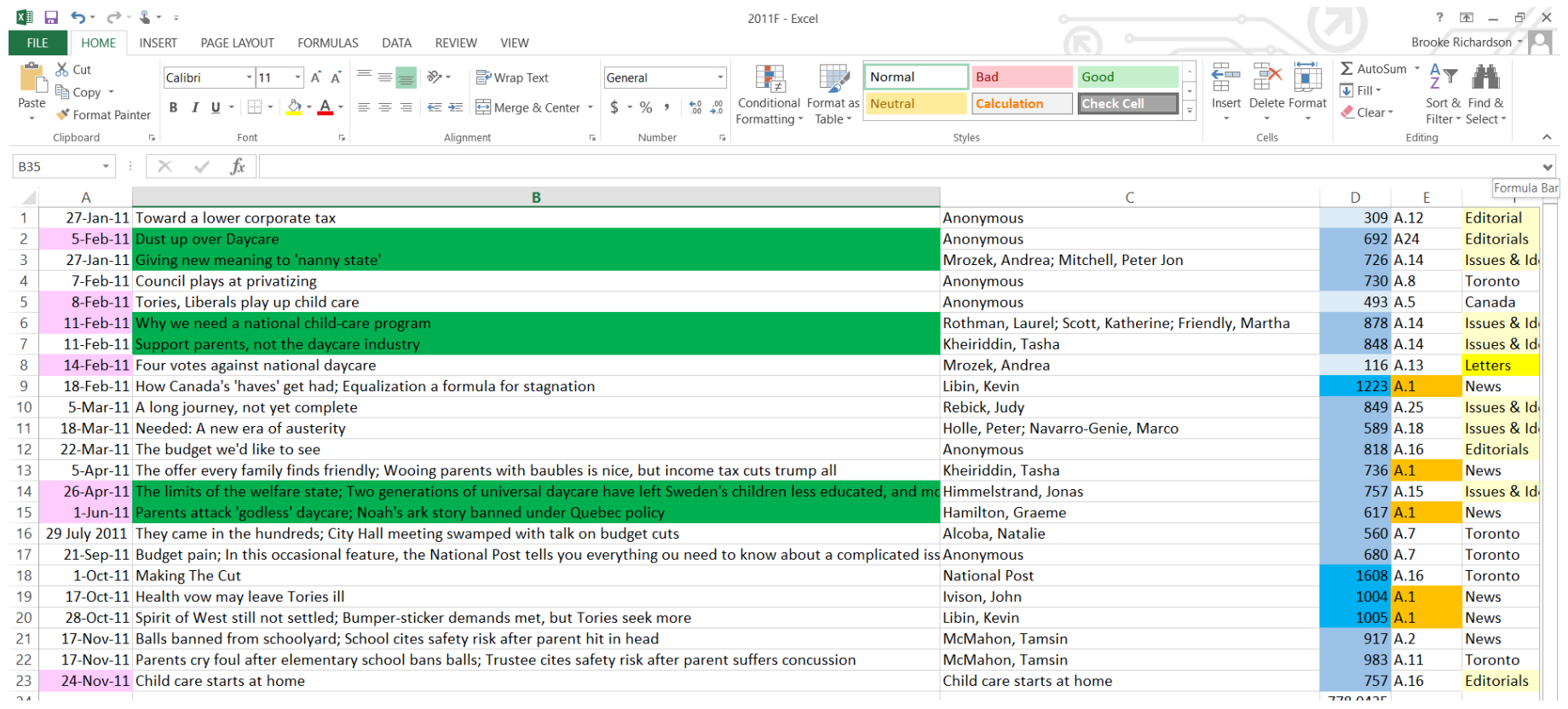

Figure 4.1: Screenshot of data collected from The National Post in 2011

While carrying out the initial data collection process, articles that contained "childcare" or "child care" or "daycare" or "early learning" at least five times and "policy" at least two times were highlighted in green. Articles that were included on a section front were highlighted in orange and articles that included the search terms in the title in pink (when articles met more than one of these criteria different columns were highlighted so all three colours were visible). 
When sampling, articles from highlighted columns were prioritized with articles with multiple colours taking precedence over one colour, and when one colour was present, green (frequency of search terms) took priority over orange (section front) and orange taking priority over pink (search term in the title). Furthermore, an effort was made to prioritize articles that pertained to the national level over those that pertained to the municipal or provincial level (when more than one article still qualified). Finally, diversity of authors was preferred. Where one reporter frequently reported on the issue, different voices were given priority ${ }^{39}$ (though again, this was not always possible in years with very little coverage).

While every effort was made to ensure the sampling procedure was as robust and comprehensive as possible, it was not without flaws. There were instances where more than one article was available in each category and was equally eligible for inclusion, based on the above criteria. In this case, an article was chosen at random. In the case where articles were not available in the five identified categories (i.e., no article less than 500 words, only one opinion piece that year), only four articles were collected for that paper in that year. In the end the sample for Period A was reduced to 97 articles, as articles were not available for the identified categories on 15 occasions (see Figure 4.2).

\footnotetext{
${ }^{39}$ At this point in the data collection process noting the gender of the author was not distinguished. Later in the analysis, differences in gender of the authors were noticed and probed.
} 


\title{
355 (all papers all years)
}

\author{
WPR Sample
}

\section{(105 reduced to 97$)$}

Figure 4.2: Sampling approach for Period A data

\section{Part I: Sampling Period B data for CDA}

The entire population, rather than a sample, was coded for Period B data (see Figure 4.3). After completing the coding of Period A data (described below), it was decided it was possible and preferable to identify the childcare policy problematization in all 183 articles in the population for Period B. The motivation for this decision was both practical and theoretical. First and foremost, the main focus of the project has always been the 2015 federal election campaign in which childcare re-emerged on the federal policy agenda. It was important to not exclude any data that would significantly affect the outcome of the findings during this period of childcare 
policy development in Canada. Second, after coding 97 articles in Period A and becoming more efficient and competent at the coding process, coding 183 felt manageable.

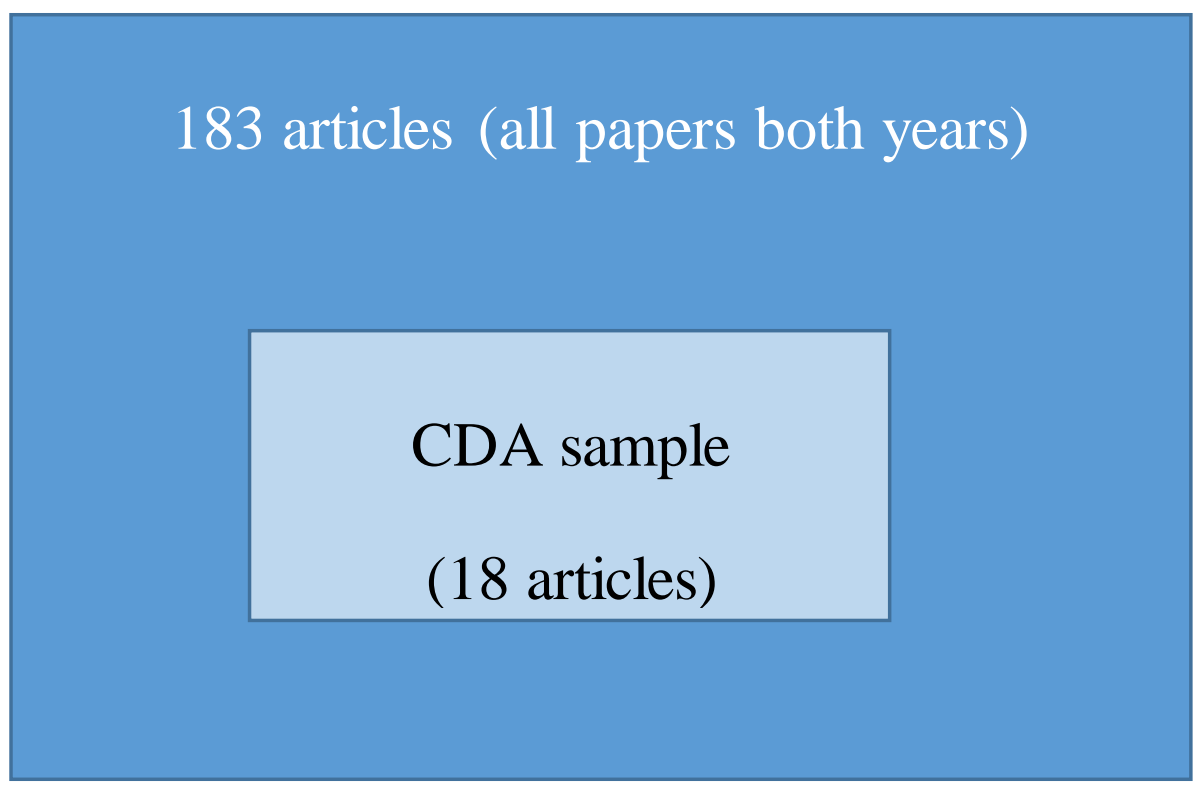

Figure 4.3: Sampling approach for Period B data

\section{Coding}

According to Krippendorff (2013), coding is the process of systematically organizing, categorizing and/or rating the data according to "observer-independent rules" (p.127). The researcher must construct detailed instructions that advise coders how and when to include/exclude data into predetermined categories of phenomena - broadly referred to as "interrater reliability". Equally important is intra-rater reliability-or that the coder(s) return the same results if data are coded at different times. In this way, the gold standard for content analysis allows little room for subjective interpretation. 
Having said this, there is always room for subjective interpretation in a project that attempts to identify projected social problems in discursively constructed policy solutions. The phenomena studied in this project were complex, requiring coders to be intimately familiar with the history, development and contemporary childcare events in Canada (Krippendorff, 2013). Coded categories were rarely designated by a single word, but rather had to be interpreted in the context of the broader text and sociopolitical context. Human interpretation, and the inherent inconsistence and flaws that go along with this, required the application of comprehensive definitions of concepts (developed through the codebook discussed below). Furthermore, it was as important to note what was absent as much as what was present.

At this stage in the project a mature, part-time $3^{\text {rd }}$ year Early Childhood Studies student employed as a childcare consultant for the City of Toronto assisted in the coding process. Krippendorff (2013) insists that coders share similar educational/professional backgrounds, are well versed on the phenomena being studied and are familiar with the theoretical orientations of the research. He also argues it is never ideal for the researcher to also be the coder given his or her inherent attachment to the research. Of course, rarely is a Ph.D. student in a position to not be the researcher and coder. The inclusion of another coder in this study enriched the validity and reliability of the results, given that any discrepancies in coding were immediately discussed and the coding process reworked to resolve points of disagreement. Through coding the first dozen articles together, the codebook was modified in a way that permitted as little divergence as possible in a project of this nature. More importantly however, any points of disagreement were consistently worked through and agreed on. For example, there was some confusion (described 
further below) differentiating between the economic and human capital problematizations given these two problematizations are closely related. The codebook was refined to indicate that the economic problematization was concerned with the immediate economic impacts while the human capital problematization was concerned about the long-term economic impacts of a welleducated population. This process was extremely valuable to not only clarifying but also clearly communicating conceptualizations of the childcare policy problematizations included in the codebook.

\section{The codebook}

According to Krippendorff (2013), a codebook is way of outlining the "syntax and semantics of the data language, preferable including the cognitive procedures that coders must apply in order to record texts efficiently and reliably"(p.128). Put more simply, the codebook specifically outlines words, phrases and ideas that provide coders with the necessary information to record whether or not data can be organized into a given node. While identifying words and phrases is relatively straightforward (and could probably be done by a computer), identifying "ideas" can be more complex. The primary concern of this project was how a lack of childcare in

Canada is discursively constructed as a policy problem - or not. The codebook (see Figure 4.4) predefined 16 potential childcare policy problematizations connected to the lack-of-childcare policy in Canada (i.e., the lack of affordable, accessible childcare in Canada is a problem in Canada because....). The problematizations were separated into distinct "nodes" each was colour-coded in the code book. As can be seen in Figure 4.5 (and Appendix A), the codebook 
included a written description of each problematization/node, noted connected policy solutions as well as identified some key words or phrases that may be associated with each.

For the most part, the nodes/problematization are rooted in the rationales discussed in Chapter 2, though other nodes/problematizations were added that differently situated the childcare "problem". One of the nodes included was the denial of the idea that Canada's lack of childcare is a problem. Two other added nodes, largely reflecting a social conservative and neoliberal ideological perspective, included the private/family problematizations and the free market problematizations. The private family node acknowledges that the lack of childcare policy in Canada is a problem, but situates private families as primarily responsible for providing this care. In the free market problematization - very much consistent with neoliberalism - the market is considered to be the ideal mechanism of addressing the lack of childcare policy in Canada. As the codebook reflects, this could include policy initiates that provides tax breaks to employers, cash to parents to purchase care in the market or any other market-oriented solutions. While these two nodes often (particularly in the context of the UCCB in Canada), they are conceptually distinct with one placing the onus on parents to directly care for their children and/or bear the majority of costs associated with purchasing care and the other focuses on spurring the market provision of childcare. A broad "public" problematization was also included to reflect the idea that the lack of childcare in Canada is a public problem. This problematization in many ways could be considered a parent node to all of the problematizations/nodes instituting a public solution. However, a brief overview of the data revealed that it was possible for a public problematizations to be put forward without mentioning or inferring any of the "reasons why" it 
should/could be considered this way. Finally, one category labelled "other", was included to categorize any unforeseen childcare policy problematizations. The inclusion of this category also served to make the coding categories exhaustive. 


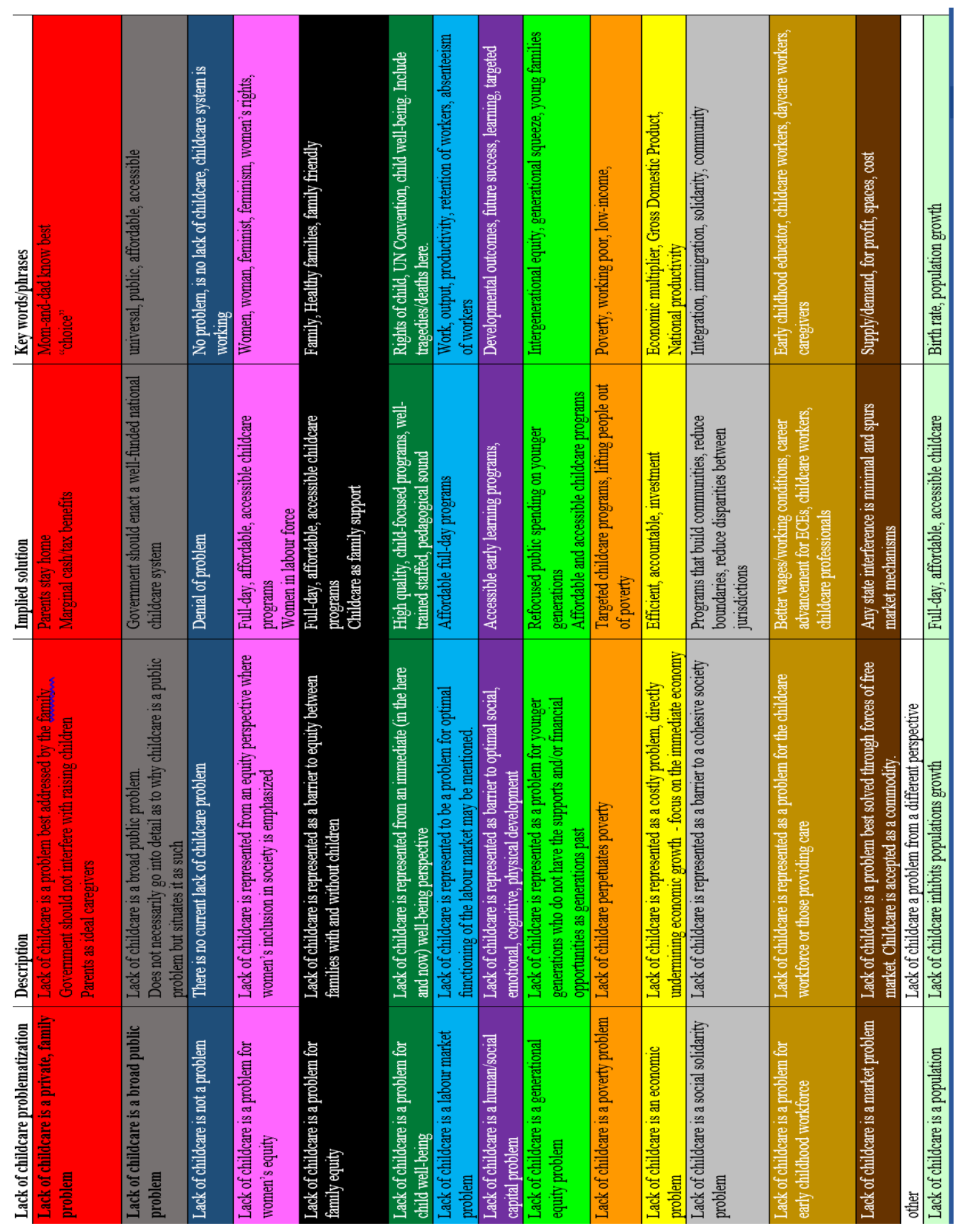


Figure 4.4: Screenshot of the codebook

The coding categories were mutually exclusive, meaning that data coded in one node could not be coded in another. Having said this, it was possible for several codes to be present in one article, or even one sentence. An author could make the argument that a lack of childcare denies many Canadians the opportunity gain the employment/skills/training necessary to earn above poverty-level wages, concurrently arguing that young families today are more vulnerable to poverty than they were a generation ago. In this case, both the "poverty" problematization and the "generational equity" problematization would have been coded. Recognizing some problematizations are more closely intertwined than others and all of the problematizations are related to each other in some capacity (they are all linked to childcare policy solutions), every effort was made to ensure that the most accurate problematizations were coded.

\section{Coding of WPR analysis}

Once a preliminary codebook was developed, coding began. All 97 articles were printed, photocopied and placed into binders, organized by paper and year. When content from the article reflected a problematization, it was underlined or highlighted with a coloured pen. Upon completion of reading the article, all colours that were used in that article were noted at the top of the page making it easy to see which articles contained which problematizations. To begin from a place of shared understanding, 12 articles were coded together by the lead researcher and research assistant. Text was analyzed line by line while clarifications in the code book were made to reflect resolutions to points of disagreement. 
This initial coding process was extremely valuable as researchers were able to clearly distinguish between nodes that often overlap, but are qualitatively different. For example, the idea that childcare as a private family problem (whereby children should be at home with their parents) and/or a private market problem (whereby a free market should determine access/affordability) often go hand-in-hand (i.e., they are your children so you pay for them if you can't care for them). Given the only national childcare policy in Canada during this time period was the UCCB, a policy which is linked to both problematizations, there was a concern that it would be difficult to distinguish, if both problematizations were always relevant. Since these problematizations have different solutions (one being that parents care provide full-time care for their children directly and the other that parents purchase this care through the market though the UCCB claims to tackle both), the nodes were kept separate. After coding several articles it became clear that it was possible for one, both or none of the aforementioned problematizations to emerge alongside mentioning the UCCB, thereby reinforcing the decision to keep them separate.

Another early difficulty was determining the difference between positions and problematizations. For example, one of the early articles challenged the market approach to childcare in Canada. The author was essentially making the argument that childcare could not be commodified via the free market, comparing the provision of childcare services to the provision of clock radios. In this case, the lack of childcare in Canada was problematized from a market perspective - though the position on the issue was to decommodify childcare. In other articles, the market problematization prevailed though the position was in favour of commodification of 
childcare, emphasizing that the market was the most effective route to achieving "choice" for parents and meeting the unique needs of consumers. In essence, it was necessary to distinguish whether the lack of childcare was problematized as a market problem (and therefore a market solution) or a problem with the market (i.e., a public solution). Initially the codebook did not distinguish between these two very different problematizations and implied solutions. This was quickly realized and altered so the codebook included a lack of childcare as a market problem (implying a hands-off approach of government) and lack of childcare as a problem with the market (necessitating public investment and/or governance).

After carrying out the initial coding together, data from time Period A was coded separately (though the researchers were in constant communication). Minor revision in the codebook were made and data was re-reviewed. All coded data was double-checked by the lead researcher.

Given the limited hours of the R.A., data for Period B were coded independently by the researcher. While there were more articles to code during this period, the process was more efficient at this point. To ensure intra-rater reliability, data was cross-checked and compared to coded data from Period A.

\section{Reducing the data}

Once all newspaper data had been coded, it was necessary to create efficient representations of the data. This meant numerically representing the frequency of each 
problematization in each newspaper in each year. Particularly skilled in Excel, the R.A. provided significant technical support and ideas regarding how to best use the software to get accurate and helpful illustrations of the data. Period A data were placed into a master spreadsheet where the titles of the sampled articles were listed along the $\mathrm{Y}$ axis and problematizations along the $\mathrm{X}$ axis. Given the binary nature of each problematization (present or absent), a nominal measure was used whereby a value of " 1 " indicated the presence of the problematization and a value of " 0 " indicated an absence of the problematization (see Figure 4.5 below). 


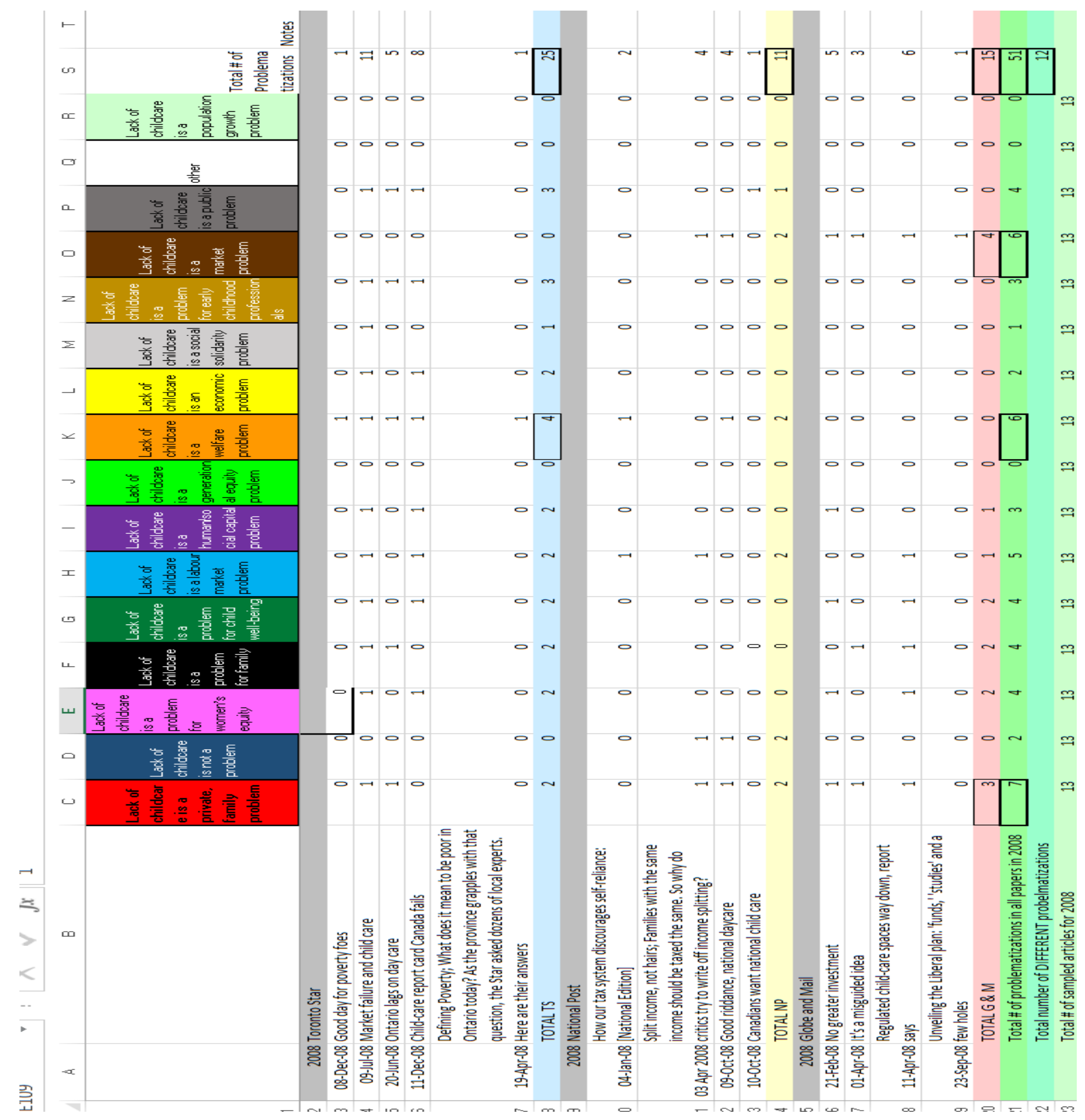

Figure 4.5: Screenshot of master spreadsheet of period A data 
As can be seen from Figure 4.5, this approach made it possible to easily see how many times each problematization occurred in each paper in each year as well observe the frequency of each problematization over time.. Cells from this master spread sheet were used to develop the charts and diagrams for the findings section. For example, the total numbers of each problematization was placed in a separate worksheet alongside the total number of articles sampled. The former divided by the latter gives a percentage of the frequency of each problematization. In all papers, the idea that childcare is a private/family responsibility arose in 40 articles. Out of the total 97 articles, this made it available in $44 \%$ of articles sampled in Period A. When data for each problematization was cut and pasted into a separate spreadsheet, these percentages could easily be translated into a bar graph format clearly illustrating and comparing the presence of different childcare problematizations. This is a matter of simply highlighting the desired data, clicking on "insert" in excel, viewing "recommended charts" and choosing the chart that best reflects the results being communicated (see Figure 4.6). 


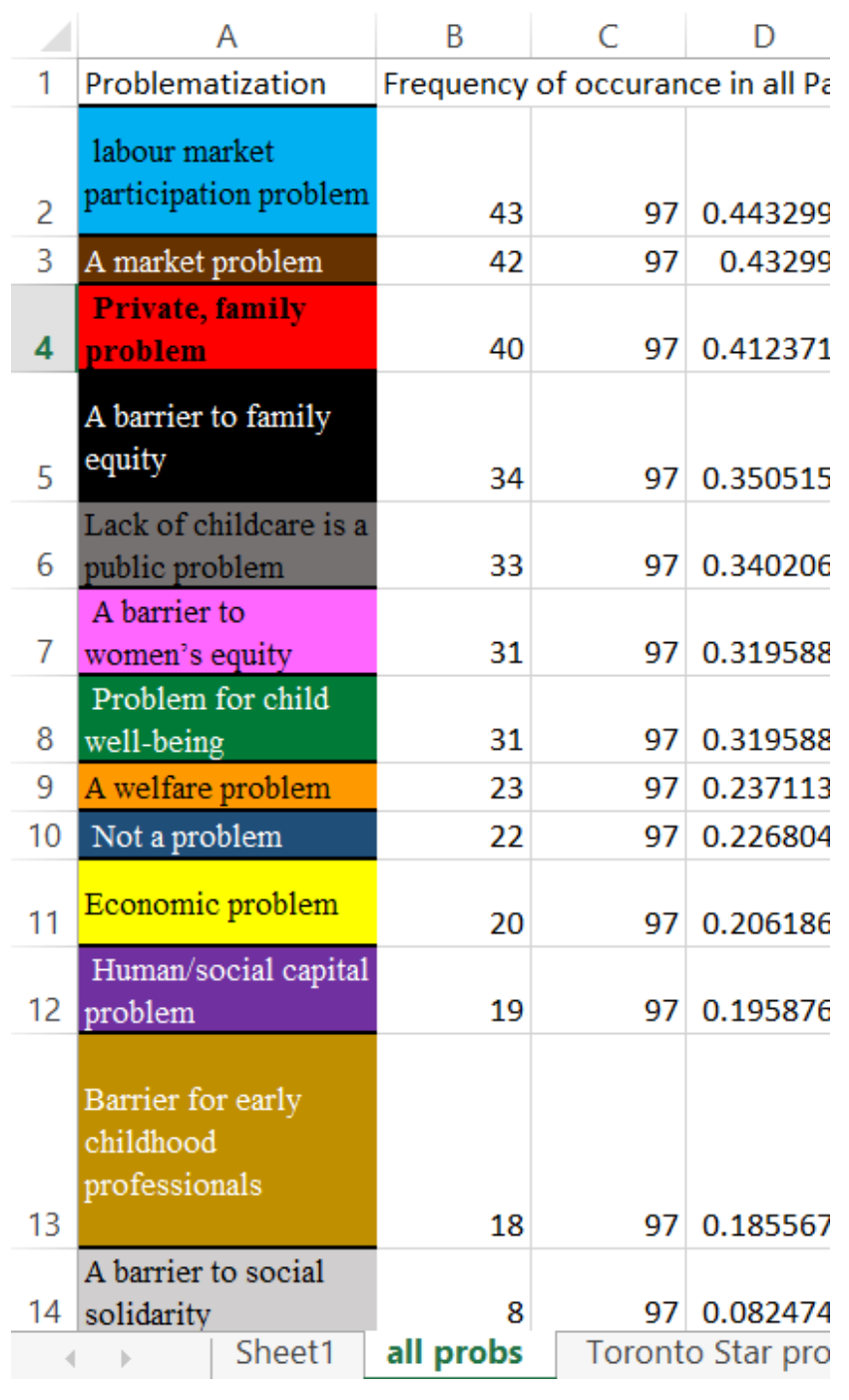

Figure 4.6: Data re-arranged in a separate spreadsheet

This same approach was then used to delineate the data by newspaper. The number of articles in which the problematization occurred in each paper (out of the total number or articles sampled in that paper) was placed into a separate spreadsheet. Charts were manually colour-coded in some cases to augment the representations of the data. 
The same approach to data analysis and representation was used for Period B data - a percentage of articles out of the total number of articles in which the problematization emerged was calculated and converted into bar graphs. Using a proportionate figure (i.e., percentages) allowed the researcher to compare the proportionate number of articles in each time period that included the problematizations. For example, it became clear that $85 \%$ of articles contained a public problematization of childcare in Period B, while only $40 \%$ of articles contained this problematization in Period A. While the raw number of articles examined differed, a sense of the relative frequency of each problematization could be achieved. Again to get a sense of the shift in problematizations over time, Period A data was included in Period B charts (in a lighter colour for easy comparison).

With some of the most frequent problematizations, charts were created that compared data across newspapers and time periods. Again, this was a matter of selecting appropriate cells from the master spreadsheets and accurately placing them in relation to each other and then selecting the chart that correctly illustrated the data.

The same data compilation method was used for Period B data - though this time there were several more articles over a reduced period of time. Figure 2 illustrates a portion of the Period B master spreadsheet listing articles published in the Toronto Star in September and October of 2015. 


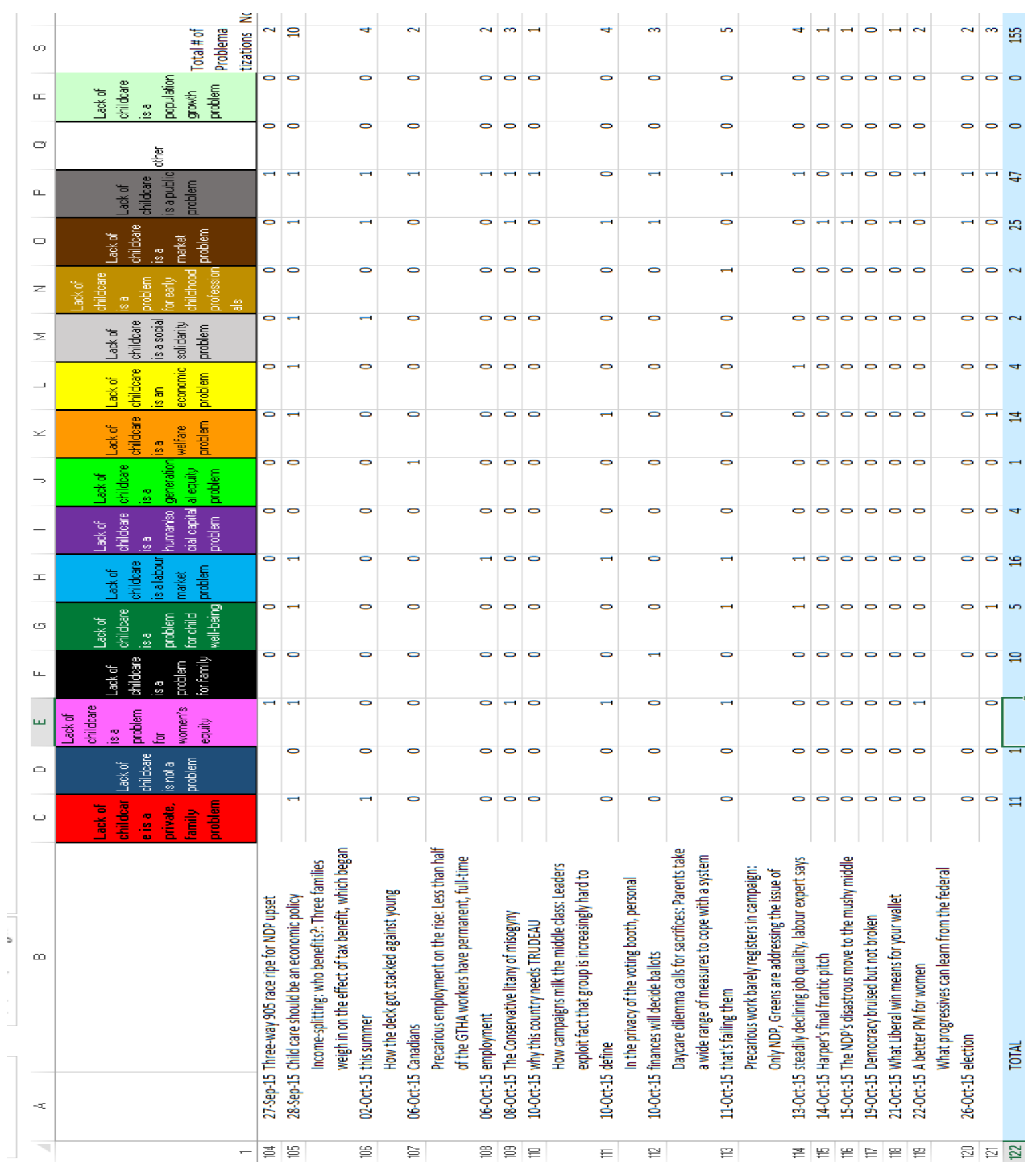

Figure 4.7: Screenshot of master spreadsheet of period B data 


\section{Chapter 5: Methods Part II \\ Critical Discourse Analysis methodology}

CDA is a time intensive detailed process of applying critical questions to a text and uncovering the subtle nuances that often operate below the level of conscious awareness. A typical reader is vulnerable to accepting underlying assumptions and values of a text when it is phrased in a way that resonates with them. CDA is about becoming aware of the critical connections between values, assumptions and language. Its purpose is to deconstruct these relationships, noting both the ideas and concepts available to readers and those that are not. CDA provides the concrete tools for a researcher to shift from being a consumer of text to an observer of text, though his/her own values and understandings can never be completely removed from the observation process. CDA is systematic whereby various concepts provide the overarching framework for detailed analysis. This component of the project is devoted to answering research questions 3 - What discursive techniques and/or resources contributed to establishing and sustaining dominant policy discourse(s) in sampled newspaper articles in Period B?

To adequately answer this question (and the many sub-questions they instantiate), the data set from Period B had to be reduced. Analyzing all newspaper articles and/or the policy platforms in their entirety was not realistic for practical reasons. Furthermore, the value of CDA lies in a thorough analysis of a smaller number of documents rather than observing general trends in a larger sample/population. The sampling procedures applied to the platforms and newspaper articles are described below. 
Sampling of newspaper articles for Critical Discourse Analysis

CDA is often used to analyze data on a case study basis and/or very small sample sizes (Richardson, 2007). Again, the purpose is not to determine the broad trends in discourse (this has been accomplished through the WPR content analysis), but rather to gain insight into specific approaches used in texts to construct these discourses. While still on the larger side, this project analyzed six articles from each newspaper published in period B. A total of 18 articles is ambitious but manageable. The following criteria were used to sample newspaper articles from the broader data set:

- 2 newspaper articles published between October 14, 2014 and December 31, 2014

- 4 newspaper articles published between January 1, 2015 - November 19, 2015

- Newspaper articles where the primary search term was evident at least 3 times were prioritized

- Relevant to childcare policy on the national level

- Relevant to 2015 campaign/election

- If not enough articles meet this criteria, an article from a section front was selected 
Initially, the population of each newspaper was reduced to only articles that mentioned the primary search term (i.e., "childcare"/child care") at least three times and "policy" at least once. These articles were previously highlighted in green as part of the data collection process for the WPR analysis and generally indicated childcare policy to be the main issue discussed in the article. From here, articles that did not pertain to childcare policy at the national level and/or in direct relation to the federal election campaign were eliminated. For example, a couple of Toronto Star articles in late 2014 reported on the Ontario Ombudsman's report revealing major health and safety concerns in Ontario's childcare system (Monserbraaten, 23 Oct, 2014). If more than two articles from the end of 2014 or more than four articles from 2015 remained articles were chosen randomly. ${ }^{40}$

It was decided that two articles published by the same author would be permitted if all other criteria were met. This is because some journalists specialize in certain policy areas and therefore publish frequently on the topic. In doing so, individual journalists come to play a role in how a paper discursively constructs the issue and problematizations through discourse. Given the purpose of CDA is to gain insight into the construction of dominant discourses in each paper (rather than analyzing the range of discourses/problematizations available), analyzing two

\footnotetext{
${ }^{40}$ Randomization was achieved by numbering the articles, placing the numbers in a hat, and picking numbers.
} 
articles by the same author actually provides more data in which to understand how dominant discourse were constructed by the authors/journalists and newspaper.

\section{The sampling process}

The National Post published two articles at the end of 2014 and six articles throughout 2015 that discussed national childcare policy in reference to the federal election, each with more than three mentions of the primary search (i.e., "child care"). The two articles from late 2014 were included, while only four of six could be included for 2015. Interestingly, three of six Post articles were published within a few days of each other. The random selection process ended up including two of these three articles as well as two other articles published earlier in the year.

In The Star in 2014, there were nine articles that met the criteria outlined above. Two of these articles were chosen at random. Only five articles published in The Star in 2015 mentioned the primary search terms three or more times and two of these were not relevant to childcare policy on the national level. The three articles that met the criteria were included while one additional article, a section front, was included. This process yielded articles that were spread out throughout 2015 .

Conveniently, only two articles published in The Globe in 2014 met the inclusion criteria immediately including them in the sample. In 2015, four out of the eight Globe articles were eligible articles were chosen at random. 


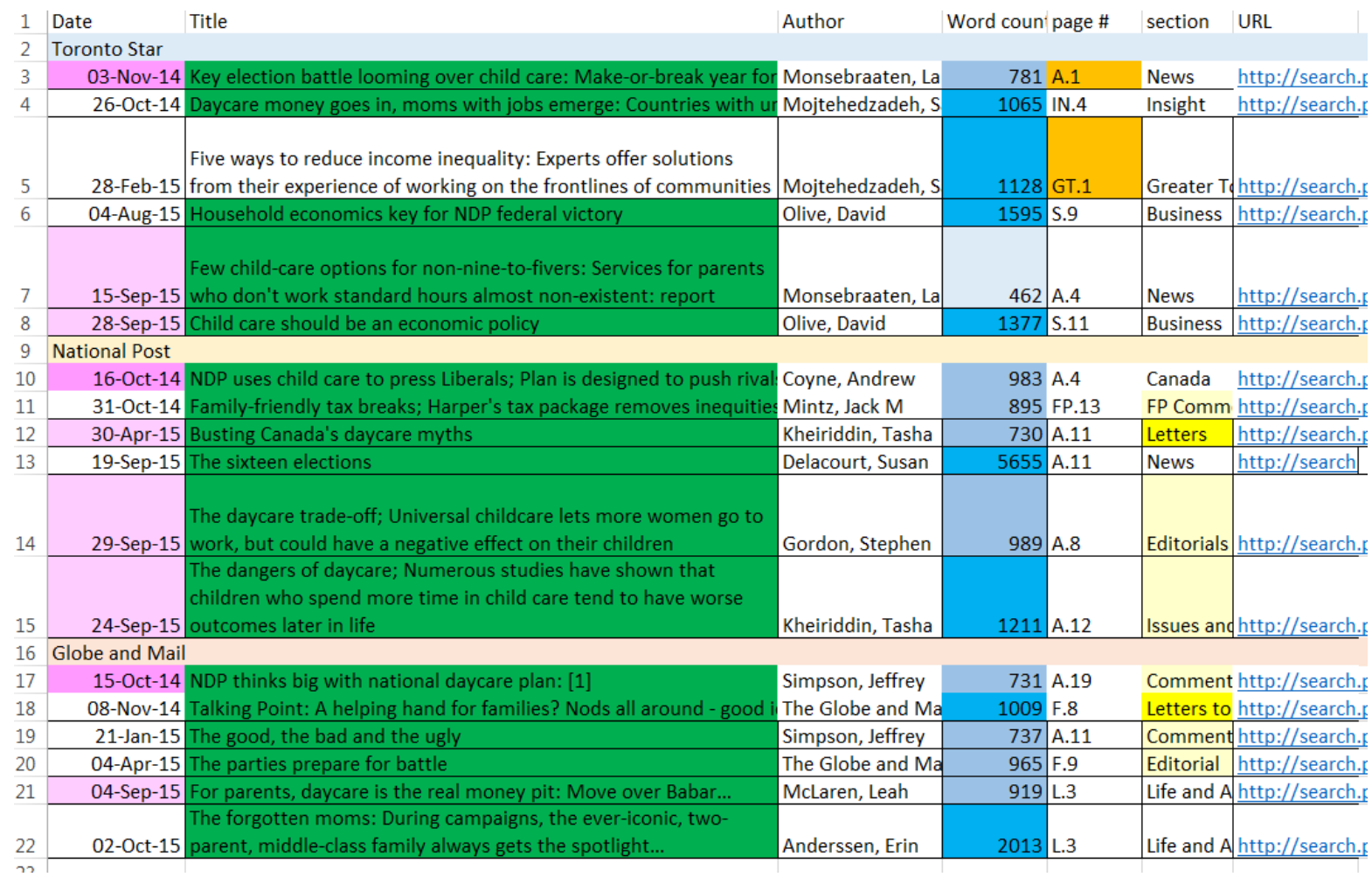

Figure 5.1: Screenshot of sampled articles for the CDA

Critical Discourse Analysis applied to the articles and platforms

Fairclough's $(1995,2003) 3$ three-tiered, systematic approach to CDA provided the overarching framework for the CDA. Unique to this approach of CDA is the idea that each level of analysis is embedded in the next so that analysis of "text" and "discourse" is not categorically separate from the other (see Figure 3.2). Concepts considered on the level of text analysis must be considered in the context of discourse practice and the broader sociopolitical context. This tiered approach to analysis is helpful to move from the level of words and sentences to the broader picture of meaning and potential action - particularly in the context of an election campaign. 
The overall approach to conducting the CDA was to examine each policy platform/article by concept. Each article in the sample was labelled by paper and numbered (i.e., Toronto Star Article 1, National Post Article 4). A blank chart which listed relevant concepts under the "text" and "discourse" level of analysis were constructed for article. This chart provided a tool whereby a systematic approach to analysis could be applied to all data consistently and recorded in the same way. Direct quotes were listed under the "example" column while the "notes" column provided the researcher a space to clearly articulate how or why the example was significant in the context of the broader study. Sometimes the "notes" column was used to contextualize the specific examples, while at other times background research outside of the text was necessary to validate or reject the claims made. 
Text analysis

\begin{tabular}{|l|l|l|}
\hline Concept & Example & Notes \\
\hline Metaphor & & \\
\hline Sensationalization/hyperbole & & \\
\hline conversationalization & & \\
\hline nominalization & & \\
\hline Irrealis statements & & \\
\hline
\end{tabular}

Discourse analysis

\begin{tabular}{|l|l|l|}
\hline Concept & Example & Notes \\
\hline Order of discourse & & \\
a. Intertextuality & & \\
b. Interdiscursivity & & \\
\hline Assumptions & & \\
a. Existential & & \\
b. Propositional \\
c. value & & \\
\hline $\begin{array}{l}\text { Legitimation } \\
\text { a. authorization } \\
\text { b. rationalization } \\
\text { c. moral evaluation } \\
\text { d. mythopoesis }\end{array}$ & & \\
\hline Modality & & \\
\hline
\end{tabular}

Figure 5.2: Blank Charts used in coding data

This approach to coding the data resulted in 18 charts (one for each article in the CDA sample), which varied in length from two to twenty pages of observations. Once completed, the charts were printed and placed in a binder and organized by newspaper and date. These charts provided the foundation for consolidating findings in the write-up process.

\section{CDA at the level of text analysis}

The innermost box in the Figure 3.2, the level of text analysis, is primarily concerned with word choice, the style of writing, the use of metaphor/imagery and the use of grammatical 
tools (i.e., nominalization) in relation to the social issue. If a word or phrase was used repeatedly or was in another way overtly emphasized this was noted.

Fairclough (2003) identifies several features of text that are particularly relevant to the critical analysis of newspapers, though these are expanded on by Richardson (2007). Informed by past research that applied CDA concepts to the study of childcare policy (Richardson, 2011; Richardson, Langford, Friendly, Rauhala, 2013). This project considers the following CDA concepts defined and discussed by Fairclough (2003) and Richardson (2007): sensationalization, conversationalization, metaphor, nominalization and irrealis statements. These concepts are defined in the chart below while the specific questions applied to the text relevant to each concept are listed. 
Table 5.1: Concepts, definitions and questions applied to the text on the level of text analysis

\section{Definition}

\section{Concept}

Sensationalization

Conversationalization

Metaphor

Nominalization

Irrealis statements information.
Excessive exaggeration made for rhetorical

effect (Richardson, 2007, p.65)

The use of language normative to a casual communicative environment into a formal communication event. It may include colloquial language, the use of phrases specific to a given culture, the oversimplification of scientific or

"Perceiving one thing in terms of another" (Richardson, 2007, p.67)

A specific type of grammatical metaphor which represents processes as entities by transforming clauses (including verbs) into a type of noun...often entails excluding social agents in the representation of events. (Fairclough, 2003, p.220).

Extrapolated or predictions/hypothetical statements that present as factual or objective in nature.

\section{Question applied to text}

Is there evidence of overly dramatic language used to heighten the emotional impact of the story? Are colloquialisms used?

Are culturally embedded "sayings" drawn upon?

Does the normative use of language in the text reflect the genre of the text?

Does one concept/phenomena/idea try to stand in place of another? Are processes reduced to products or one-dimensional outcomes? Are social actors evident in the description of events?

Are any statements presented as factual when they are more accurately described as predictive and/or an extrapolation? 
It quickly became apparent that there was a great deal of overlap between sensationalization and conversationalization. These concepts are particularly prominent in newspaper articles that are competing to attract and sell newspapers to a busy, distracted and time-pressed readership. Fairclough (1995) connects the use of conversationalization and sensationalization in the media to the increasing commodification of the media. Simply put, newspapers have a vested interest in making information relatable, accessible and urgently relevant to the lives of their readers in order to sell newspapers/advertising space. The financial viability of newspapers depends on readers concurrently acting as consumers, most frequently purchasing newspapers in some capacity - whether it be through online subscriptions, advertisements or paper deliveries. In the digital age, newspapers are competing for "likes" and "shares" where a larger audience bodes well for the sale of online advertisements accompanying the articles. While conversationalization and sensationalization may extend awareness of and interest in a particular issue, it may come at the cost of accurate information. Examples of when these textual processes undermined the integrity of the information presented was the primary concern of observing these phenomena. Due to significant overlap in data that was characteristic of both categories, these concepts are discussed together in the findings section.

Qualitatively different than conversationalization and sensationalization is the use of metaphor. Metaphor, in its broadest sense is a grammatical approach to making one idea or concept stand in place of another idea or concept (Richardson, 2007). In an election campaign, complex political and policy issues are often likened to experiences or phenomena to which the majority of people can relate. Like conversationalization and sensationalization, metaphors serve 
to make the issue accessible and heighten the urgency or scale of the policy issue being discussed. Again, however, while metaphors may act as an effective "hook", they often obscure or essentialize information or ideas in a way that is misleading to people who do not understand the nuances of the issue.

Discussed as a sub-component of metaphor is the more specific concept of nominalization. As Table 5.1 notes, nominalization is defined by Fairclough (2003) as: “A specific type of grammatical metaphor which represents processes as entities by transforming clauses (including verbs) into a type of noun and often entails excluding social agents in the representation of events" (p.220). Past research has noted the frequency with which the nominalization of the word "choice" has been used in relation to childcare policy in Canada (Richardson et al, 2013). Whether or not the nominalization of the word "choice" continued in the 2015 election campaign is examined, though the concept was not limited to an examination of "choice".

Finally, the use of irrealis statements - predictive or extrapolated statements that are presented as if objectively "true" - was examined. It is reasonable for the lay reader to assume information published newspapers has gone through a process of due diligence to ensure information is presented transparently and accurately. However, as has already been discussed, the underlying motivation in newspaper articles is to sell papers. These motivations leave individual journalists vulnerable to intentionally or unintentionally presenting what may be for 
what $i s$. During an election campaign, it is reasonable to assume that a heavy reliance on irrealis statements may skew understanding and opinion for readers.

\section{Discourse analysis}

Analysis becomes more nuanced and complex at the level of discourse analysis. It is here where four overarching elements of discourse were systematically deconstructed. These include: 1) the order of discourse (interdiscursivity and intertextuality); 2) legitimation (authority, rationality, mythopoesis, morality); 3) modality (including evaluation) and 4) assumptions (propositional, existential).

\section{The order of discourse - Interdiscursivity and Intertextuality}

Recall that, according to Fairclough $(1995,2003)$, the "order of discourse" broadly refers to the "normal" way of using language. How discourse is structured, including which discourse(s), and whose voices, is/are available to consumers of the text and plays a key role in mediating between language and sociocultural practice. The findings from the WPR analysis reveal which problematizations and underlying discourses were evident in each newspaper. The purpose of this portion of the CDA is to gain insight into how these problematizations were discursively constructed as well as how different problematizations and discourses interacted with each other.

Broadly, interdiscursivity refers to the mixing of discourses within a text (Fairclough, 2003). As became clear in Part 1, it was rare for any one text to exhibit only one 
problematization of childcare policy. Instead, different discourses were juxtaposed with each other sometimes legitimizing and sometimes refuting ideas about what childcare policy should or should not look like. Furthermore, it is important to point out that the presence of a discourse in the WPR analysis is in no way meant that the article supported this conceptualization of the issue - it simply meant that the problematization existed in the article. Examining the order of discourse involves going beyond which discourses were available and observing how the discourses were related to each other (or not), which discourses were reinforced and which (if any) were rejected.

Closely relating to interdiscursivity is intertextuality. Intertextuality is concerned with "the presence within a text of elements of other texts other than the author's own (Fariclough, 2003, p.218). Analyzing intertextuality includes noting what voices are available to readers. This includes identifying the author of articles as well as noting the presence of voices other than the authors. Intertextuality in and of itself is neither "good" or "bad", but can be achieved in a way that expands or limits the understanding of the reader. For example, an author may include a quotation from a reputable source or study that provides greater depth of understanding or perspective. At the same time, an author may opt to include a quotation that misrepresents the intentions behind the original communication (typically in the form of a decontextualized "sound bite"). Text that originated outside of the original source of text being analyzed may also be directly or indirectly reported. Direct reporting most often includes the use of quotation marks and the direct, word-for-word repetition of a previously spoken or written text. Indirect reporting 
occurs when text is interpreted somewhere along the line in a "he said/she said" manner. Table

5.2 below outlines how the order of discourse was defined in the context of this study.

Table 5.2: Defining and applying the order of discourse to the text

Definition Question applied to text

Concept

Order of discourse

The "normal" way of

using language.

Mediates between

language and

sociocultural practice.

The presence within a text of elements of other

a. Intertextuality texts (and therefore potentially other voices) other than the author's own. (Fariclough, 2003, p.218)
What other texts are evident in this text? What voices, other than the authors, are evident? Are these voices ordered or given different prominence?

Are different voices directly or indirectly reported?

Are voices decontextualized and/or recontextualized?

Is there evidence of several discourses within the text? If so, how are they juxtaposed with each

b. interdiscursivity The mixing of discourses (including problematizations) within a text. other? What, if any, discourse is favoured by the author? 


\section{Operationalizing Interdiscursivity}

Examining interdiscursivity links directly back to the findings of the WPR analysis. Each problematization identified in the content analysis is rooted in a discourse that embraces or rejects a given perspective on the childcare policy problem in Canada. When a text exhibits a high level of interdiscursivity, it suggests the policy issue had been considered from a number of different perspectives rather than committing to one seemingly objective way of understanding

the issue. As a result, one key component of examining interdiscursivity is noting the diversity of discourse within the articles examined which could be done by drawing on data from the WPR analysis (i.e., the number of discourses in each article). Though typically an analysis of interdiscursivity would include a detailed examination of each text and how the discourses were juxtaposed with each other, this was simply not possible with 18 articles. Instead, the degree of interdiscursivity across papers were noted and notew orthy examples highlighted.

\section{Operationalizing Intertextuality}

Operationalizing the concept of intertextuality, a qualitative concept, was also achieved in an atypical manner for CDA. Again with the large sample size of 18 articles, the first question to be answered was: how much of the text was original and how much of the text was from another source? To easily measure this, text in the newspaper articles that came from other texts was cut and pasted into a separate Word document. When all reported text was pasted into this separate document, the word count tool in Microsoft Word was used to calculate the total number of words of reported speech. This number was then divided by the total number of words in the article. This approach provided a numeric representation of intertextuality for each article 
that underwent CDA. For example in Mojtehedzadeh (2014, Oct 26), 278 words were reported speech out of a total of 1065 words meaning $26 \%$ of the text was from other texts. This approach wasn't perfect, as often it was difficult to determine the point at which reported text was distinguished from original text, but it generally reflected the degree to which texts drew on other texts. Any directly quoted content could easily be identified, while parts of sentences that included the words of others were coded conservatively. In an effort to gain insight into the diversity of voices included in the text, the number of different sources were counted and the sources were identified under the "notes" column in the coding chart.

In an effort to consolidate data, the researcher created excel spreadsheets to clearly record the degree of intertextuality in each newspaper article. Initially, three columns were listed, including the article number, number of sources, and the name of the sources. Halfway through completing this task, the researcher noticed a clear difference in the use of reported text among male and female authors. For this reason, the gender of the authors of each article was noted to make any gender differences in intertextuality explicit. Figure 5.3 is a partial screen shot of one of the excel spreadsheets where these observations were recorded.

\begin{tabular}{|r|r|l|l|l|}
\hline \multicolumn{2}{|l|}{ Star } & \multicolumn{2}{l|}{ Gender } & Notes \\
\hline Article \# & \% of text & \# of sources & source \\
\hline 1 & $38 \%$ & 5 & K & Ken Dryden, Martha Friendly, TD bank report, Stephen Harper, Mother \\
\hline 2 & $25 \%$ & 6 & CEO of YWCA, OECD, Jane Jenson, Fortin, Milligan, UNICEF \\
\hline 3 & $25 \%$ & 6 & F & United Way Directoro f research, rep for Access Alliance Health Service, rep f \\
\hline 4 & $25 \%$ & 4 & M & IMF, Mulcair, Wynne, Worker \\
\hline 5 & $50 \%$ & 3 & heavily quotes CUPW report, Friendly, McMaster study \\
\hline 6 & $13 \%$ & 3 & M & IMF, Conservative spokesperson, CCPA report \\
\hline
\end{tabular}

Figure 5.3: Screen shot of intertextuality 
This approach provided a clear picture of how much of each text originated in another text, the diversity of sources drawn upon, the gender of the journalist and a specific list of the people/organizations whose words were included. When the data had all been placed into the excel spreadsheet, it was colour coded to make it clearly visible which articles had low $(<20 \%$, blue), medium (20\%-30\%, orange), high (31\%-40\% green) or very high ( $41 \%+)$ levels of intertextuality.

\section{Modality}

Examining modality is less concerned with what claims are made than with how claims are made (Fairclough, 2003). This includes noting the overall tone of the article, how the author positions him or herself in the article and observing whether or not there is a sense of urgency. Certain words, such as "must" rather than "will" denote a greater sense of urgency, while the word "should" denotes an overt evaluation of how things should be. Similarly, texts often differ in how the information is situated as "true" or a possible truth. When a text positions its argument as the "right" one, the modality is subjectively asserted. In contrast, an approach may be taken where authors choose to position themselves as the "objective" reporter, never directly making claims but relying on the voices of sources to speak for themselves.

One tool that can be helpful in distinguishing these different approaches to modality are noting the presence/frequency of declarative, interrogative and evaluative statements (Fairclough, 2003). Declarative statements state "truths", or at least what is presented to be "true". This can be achieved through the journalist/political party's voice or through the voice of 
others - experts, stakeholders, politicians, research, etc. Interrogative statements are simply questions - often rhetorical. Finally evaluative statements relate back to the way things "should" be. Again, however, the focus when examining modality is not on noting what the assumptions are but on how the assumptions come to be.

\section{Legitimation}

Theoretically, any text can make any claim. Practically, however, claims have little value if they are not seen as legitimate by readers. The four main approaches to legitimation identified by Fairclough (2003) are authorization, rationalization, moral evaluation and mythopoesis. Authorization occurs when texts draw on an external authority on the issue to validate the claims made. An external authority includes but is not limited to appealing to empirical research, academics, researchers, statements by other policy experts or politicians and/or drawing on international comparisons (i.e., Canada ranks $25^{\text {th }}$ in ECEC policy out of 25 countries). Rationalization occurs when an intellectual, logical line of reasoning is used to legitimize an argument. Rationalization need not include any formal authority, but instead draws on "common sense" or logic to justify claims. In many ways, the problematizations themselves are examples of rationalization as each provides a logical "reason why" the lack of childcare in Canada is a problem (or not). Moral evaluation occurs when a direct appeal is made to what is ethically "right". Moral evaluation directly relates to ideological values in that what is "right" is determined by values. However, the concern in this part of the analysis is whether or not values emerge rather than an analysis of what the values themselves are. Finally, mythopoesis occurs when a narrative or story is told to bring legitimacy to a given "truth". In the case of childcare 
policy, it is possible to include the stories of parents who struggle with finding and accessing quality childcare. Connections between childcare and poverty or employment opportunity may also be illustrated through the stories of individuals. Mythopoesis provides readers a more direct path to relate to the issue on a human level, thereby legitimizing ideas through empathy and connection to the human experience.

\section{Existential and propositional assumptions}

Central to any analysis of discourse is identifying the underlying assumptions that permeate each and every discourse. Fairclough (2003) identifies three categories of assumptions that are important to recognize and deconstruct in the context of CDA. As Table 5.3 illustrates, these are existential (what is) and propositional (what is the case). Fairclough (2003) further differentiates the importance of identifying value assumptions on the level of discourse practice. Identifying ideology and the underlying value assumptions is consistently applied to every level of analysis in this project. For this reason, identifying value assumption has not been separated from the other concepts but is woven throughout the entire analysis. It is also the case that many propositional and existential assumptions were strongly rooted in value assumptions. For example, the idea that the federal government does not play a role in perpetuating inequality between classes or genders (propositional), or that inequity exists at all (existential) were some assumptions that could ultimately only be understood through identifying and deconstructing underlying values. Dean's (2012) framework for identifying ideological orientations to social policy discussed in Chapter 3 guides this analysis. 
Table 5.3: Fairclough's (2003) conceptualization and application of assumptions

$\begin{array}{lll}\begin{array}{l}\text { Concept } \\ \text { Assumptions }\end{array} & \begin{array}{l}\text { Definition } \\ \text { The taken-for-granted, } \\ \text { implicit meanings in } \\ \text { texts. }\end{array} & \begin{array}{l}\text { Question applied to text } \\ \text { What is assumed in the text? Are any } \\ \text { assumptions stated overtly in the text? What is } \\ \text { more subtly implied in the text? }\end{array} \\ \text { a. existential } & \begin{array}{l}\text { Assumptions about what } \\ \text { exists. }\end{array} & \text { What is assumed to be? } \\ \text { b. propositional } & \begin{array}{l}\text { Assumptions about what } \\ \text { is the case. More specific } \\ \text { ideas about what is } \\ \text { happening in a given } \\ \text { time and location. }\end{array}\end{array}$

To summarize, the overarching questions applied to the text on the level of discourse practice are:

1. What degree of interdiscursivity is evident in the texts? What discourses are given primacy? How?

2. To what degree is intertextuality drawn upon? How does this differ by papers/authors?

3. What process of legitimation is appealed to? (authorization, rationalization, moral evaluation, mythopoesis)

4. What modality characterizes the text?

5. What assumptions are made in the texts?

In answering these questions, Bacchi's (2009) questions probing the assumptions in texts and absence of problematizations (discourse) are also explored. 
The next chapter will report the findings from Part I of the project including patterns in coverage across years and papers as well as the frequency of the childcare policy problematizations.

Chapter 7 will provide more qualitative examples of the problematizations while Chapter 8 will discuss the findings of the CDA - the methodological focus of this chapter. 


\section{Chapter 6}

\section{Part 1: Overview of data and WPR findings}

This chapter provides a general overview of the data collected during Periods A and B as well the WPR findings. First, the number of articles collected in each period and each paper is visually represented through tables and bar/line graphs and described. Following this a more indepth exploration of the patterns of coverage in Period A and then Period B is reviewed with textual examples included. Finally the frequency of problematizations in the papers during Period A and Period B are visually represented through bar graphs and points of interest highlighted. Chapter 7 will provide more detailed descriptions and examples of the problematizations across both periods.

\section{Number of articles that met search criteria by paper, period and year}

The data reveal some interesting patterns in newspaper coverage of childcare policy in The Toronto Star, The National Post and The Globe and Mail from January 1, 2008 to November 19, 2015. As Figure 6.1 illustrates, discussion of childcare policy in Canadian newspapers between 2008 and October 13, 2014 (Period A) was relatively scarce, hovering between 30 and 60 articles a year. Slightly higher levels of coverage of childcare policy were observed in 2008 (69 articles) and 2011 (59 articles) -federal elections years in Period A. As was expected, there was a clear jump in coverage following the October 14, 2014 NDP announcement of its $\$ 15 /$ day childcare proposal. This surge in coverage was sustained throughout 2015 as childcare policy reemerged as a campaign issue. 


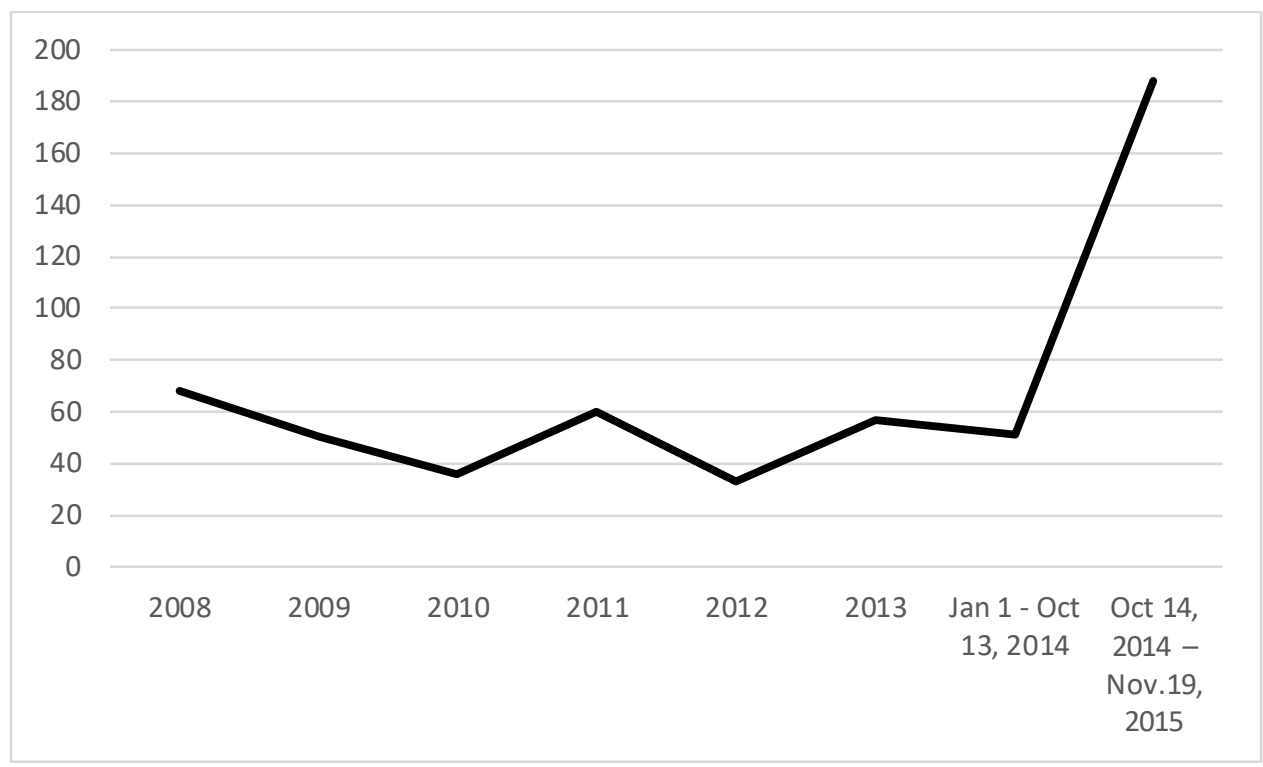

Figure 6.1: Number of articles (all papers) with coverage of childcare policy from 2008-2015

In just over a year, between October 14, 2014 and November 19, 2015, there were a total of 188 articles published that discussed childcare policy - more than half as many as were published during the seven prior years. Clearly, there was a renewed interest in childcare policy on the part of the media and general public. 
Table 6.1: Number of articles meeting the search criteria in all three papers by year

Number of articles

$\begin{array}{ll}\text { Year } & \\ 2008 & 68 \\ 2009 & 50 \\ 2010 & 36 \\ 2011 & 60 \\ 2012 & 33 \\ 2013 & 57 \\ \text { Jan 1 - Oct 13, 2014 } & 51 \\ \text { TOTAL PERIOD A } & 355 \\ \text { Oct 14 - Dec 31, 2014 } & 51 \\ \text { Jan 1 - Nov.19, 2015 } & 137 \\ \text { TOTAL PERIOD B } & 188\end{array}$

When the number of articles that met the search criteria were delineated by newspaper and time period (see Diagram 2), it became evident that The Star consistently published more articles on childcare policy than either of the other two papers. In the seven years of Period A, The Star published a total of 166 articles on the topic whereas The Post published 100 and The Globe 89. In the thirteen months of Period B, The Star published a total of 90 articles on the topic, The Post 51 and The Globe 47. 


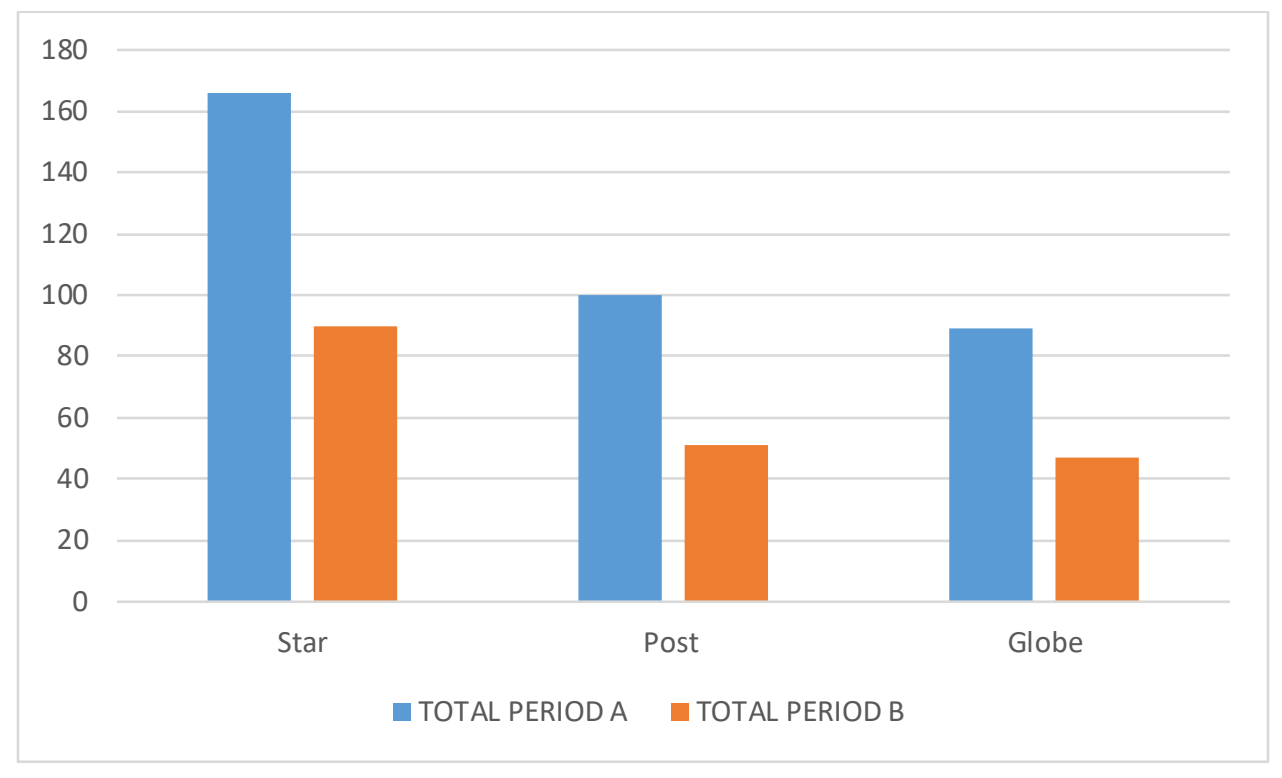

Figure 6.2: Number of articles addressing childcare policy by paper in Period A and Period B 


\section{A closer look at Period A}

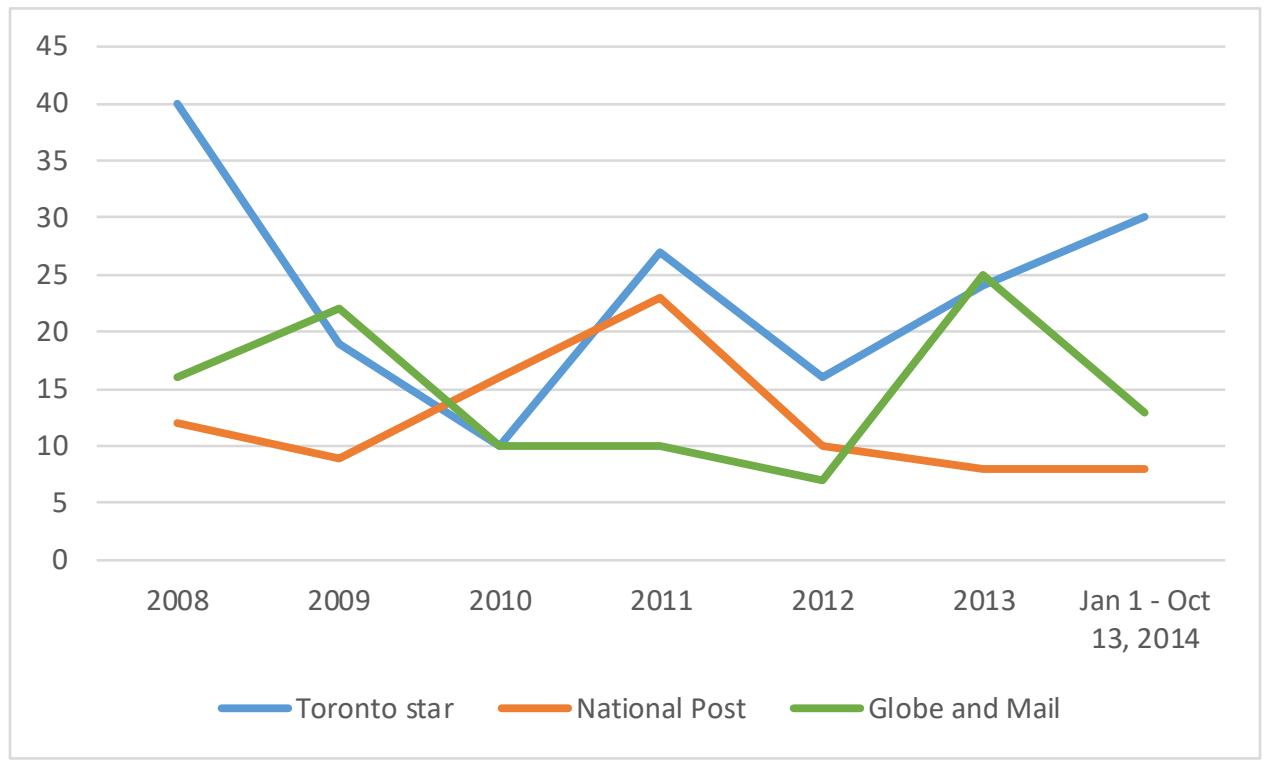

Figure 6.3: Number of articles published in each paper in Period A

When Period A data are delineated by newspaper and year as in Figure 6.3 above, The Star stands out as having the most coverage of childcare policy in 2008, 2011 and 2014. The high level of coverage is most pronounced in the federal election year of 2008 , though there is also increased attention to childcare policy in The Star and The Post during the 2011 federal election. The Star published 10 articles directly discussing childcare in the month and a half leadup to the 2008 federal election while The Post published only twelve the during entire year. ${ }^{41}$ In 2008 alone, The Star published 39 articles and was the only paper to report on an international report card released by UNICEF that ranked Canada $25^{\text {th }}$ of 25 developed countries on early

${ }^{41}$ The few articles that were published in The Post devoted significant ink to "The Frightful Food at Daycares" (Kuitenbrouwer, 16 May 2008). 
childhood education and care policy. Although The Globe did not publish many more articles than The Post in 2008 (16 in The Globe), five of these articles discussed childcare policy in Canada at length. For example, one Globe article written by a freelance journalist devoted 1051 words specifically to the discussion of childcare policy (Noik-Bent, 2008, 21 Feb).

In 2011, the other federal election year, where coverage of childcare policy was slightly higher than other years, a lively discussion of childcare was evident in both The Post and The Star in the months leading up to the election. Unlike 2008, The Post published more articles that discussed childcare policy (14) than The Star (12) prior to Election Day. Not one article in The Globe met the search criteria in the months before the 2011 federal election (all articles that met the search criteria were published after the federal election). In February 2011, the Liberals announced their plan to re-establish the 2005 ELCC Foundations program that had been cancelled by the Conservatives in 2006. This was met with criticism from The Post where "daycare" was described as a service in which children were "farmed out to strangers at a tender age" (Anonymous, 2011, Feb 5). This prompted a response by childcare advocates a few days later (also in The Post) titled "Why we need a national child-care program" (Rothman, Scott, \& Friendly, 2011, Feb 11). In this article, advocates drew on 11 problematizations of the issue, directly challenging the idea that childcare was akin to "pushing babies out of the nest" (Anonymous, 2011, Feb 5) and prioritizing childcare as a women's equity issue. The article concluded that "A thoughtful national child-care program can become a real social program like those at which Canada used to excel" (Rothman et al., 2011, Feb 11). Another Post reporter who frequently covers the issues, Tasha Kheiriddin, supported the anonymous February 5th article, 
arguing that the government should "Support parents, not the daycare industry" (Kheiriddin, 2011, Feb 11). A few days later, an anti-childcare advocate published a letter to the editor titled "Four votes against National daycare" (Mrozek, 2011, Feb 14). Here she referred to the Liberal plan to re-establish a national childcare policy as "dredge[ing] up an approach [to childcare] from the 1970s" (Mrozek, 2011, Feb 14). A few days before Election Day 2011, The Post published another article written by a guest columnist (a Swedish businessman) demonizing a national childcare system, claiming that Swedish children (who have access to a universal childcare system) are "less educated, and more distant from their parents" (Himmelstrand, 2011, Apr 26).

Excepting the articles written by childcare advocates, much of the content of The Post articles either denied that there was a childcare problem and/or situated childcare a private market and/or family responsibility. Articles published in The Star leading up to the 2011 federal election were all in favour of a comprehensive childcare policy. For example, a Star article written by full-time social justice reporter Laurie Monserbraaten was titled "Women are still waiting: In an increasingly female workforce, child-care programs are essential to economic prosperity" (Monsebraaten, 2011, Mar 6), while another article written by childcare advocate and researcher Kerry McCuaig argued: "Not on the backs of children: The economic case against cutting city services to children" (McCuaig, 2011, Jul 30).

Reporting on childcare policy was low in 2010 and 2012 in all papers. In 2010, most of the articles that met the search criteria were related to a debate in Quebec about introducing a 
policy that would ban religiously oriented books (the centre of the controversy was Noah's Arc) from childcare centres receiving public funds. Similarly, there was very little discussion of childcare policy in 2012 and that which did exist was mainly in The Star and predominantly discussed the childcare sector in relation to the roll out of full day kindergarten (FDK) in Ontario.

The few articles that were published in The Globe in 2012 highlighted the predominantly female struggle to "balance" 42 paid and unpaid labour. For example, titles of Globe articles read "The Motherload", "From the House to crèche, women are still juggling bebé and work" (Onstad, 2012, Dec 28), "School daze: Carving out a career on the kids' schedule" (Eichler, 2012, Jun 30) and "Go ahead: Sleep in and ignore the kids" (Pearce, 2012, Sep 14). Both Katarina Onstad and Leah Eichler were invited to write these articles as "specials," while Tralee Pearce is a full-time reporter with The Globe. Both The Post and The Globe reported on the work of Paul Kershaw (The Globe invited him to author an article) whose research illustrated the necessity of comprehensive childcare policy for generation Y.

Unlike the other two papers, the greatest volume and depth of coverage of childcare in The Globe occurred in 2013 when the paper ran a special series (6 lengthy articles over two months)

\footnotetext{
42 "Balance" is placed in quotation marks to highlight the fact that it is an ideal - not necessarily attainable though discursively the most common way of talking about how women juggle paid, unpaid and/or poorly paid labour.
} 
devoted to the topic. This special series was spearheaded by reporter Erin Anderssen who covers mental health, family issues and social policy for the paper. Some titles in this series included: "The case for publicly funded child care" (Anderssen, 2013, Oct 21), "10 lessons to guide a national discussion on how to improve child care in this country" (Anderssen, 2013, Oct 25) and "Why Canada needs to do better at helping all families" (Anderssen, 2013, Nov 15). Altogether, Anderssen devoted over 16000 words to childcare policy between June and December of 2013 twice as much ink as was devoted to the issue by The Post in all of 2013 and almost as much text as was devoted to the issue in The Star all year.

\section{A closer look at Period B}

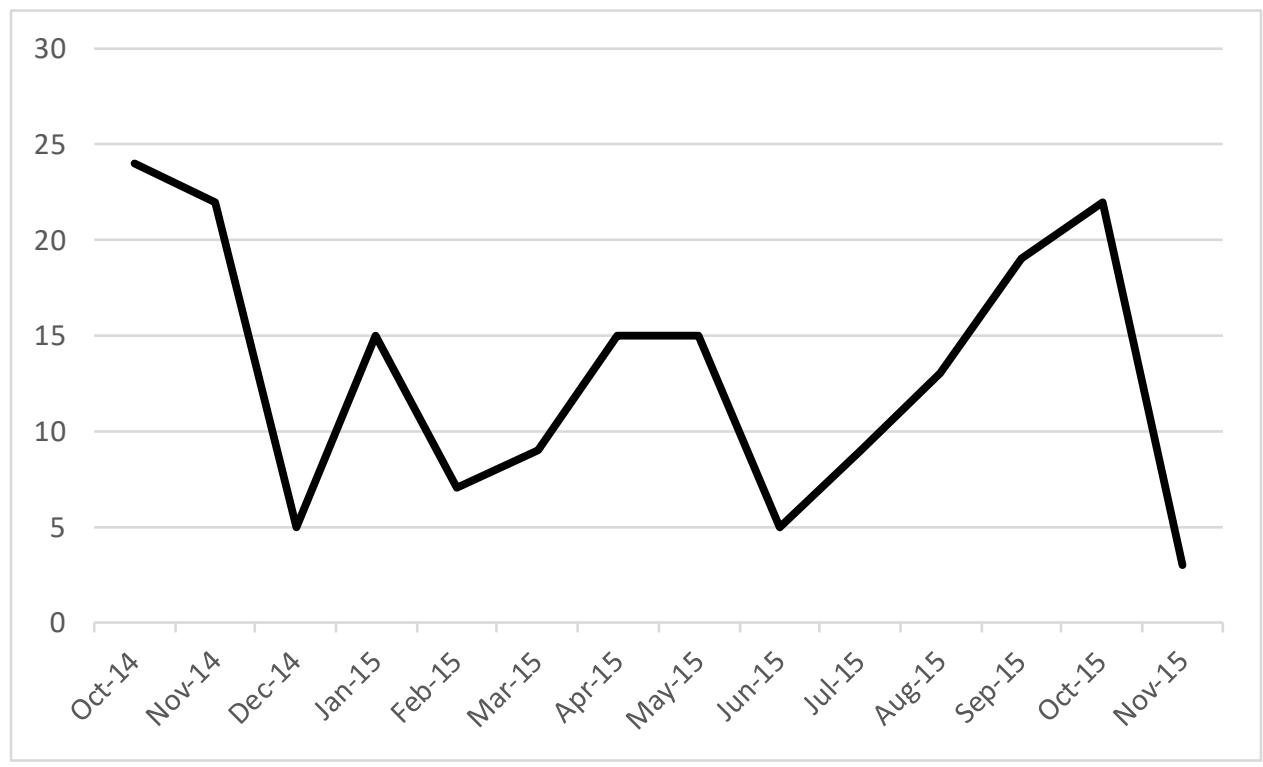

Figure 6.4: Number of articles discussing childcare policy in all papers in Period B

As Figure 6.1 at the beginning of this chapter illustrates, there was a pronounced increase in coverage during Period B. To gain an appreciation of how the coverage of the issue shifted 
throughout Period B, data were delineated by month. Figure 6.4 illustrates several peaks and valleys in coverage throughout this period with the greatest number of published articles addressing the issue in October and November of 2014 and October 2015. Between these two points, coverage appeared to rise and fall, dropping to its lowest point in December 2014 and June 2015. This diagram also illustrates that the number of relevant articles published steadily climbed from June 2015 until the October 19, 2015 federal election. Immediately following the Liberal majority win on Election Day, coverage dropped to its lowest point in the Period.

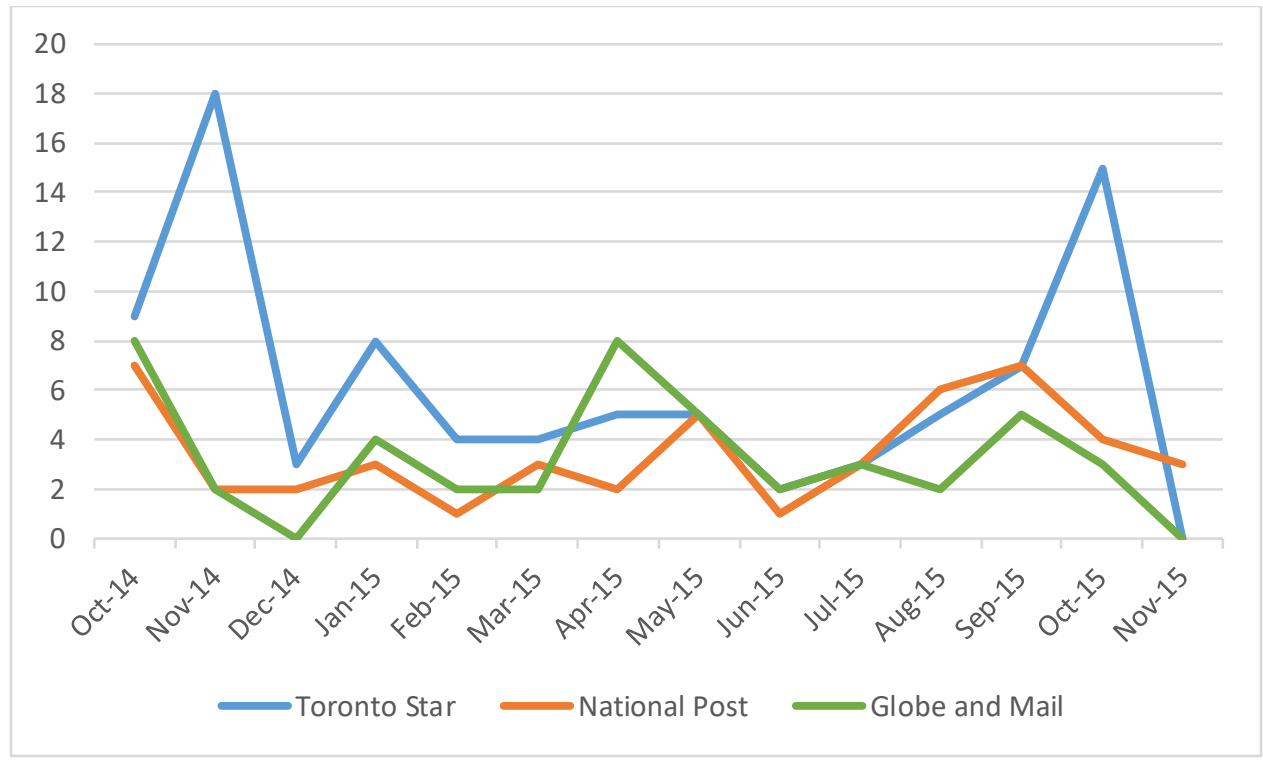

Figure 6.5: Number of articles discussing childcare policy in Period B by month and paper When the amalgamated newspaper data were delineated by newspaper as in Figure 6.5 above, it becomes clear that the peaks and valleys in Figure 6.4 were skewed by a disproportionate amount of coverage in The Star. While coverage of the issue as measured by number of articles was comparable across all three newspapers in October 2014 (9 in The Star, 7 in The Post and 8 
in The Globe), this quickly changed. Figure 6.5 illustrates that the apparent high level of coverage across papers in November 2014 was truly relevant only to The Star. This paper published eighteen articles that month that discussed childcare policy while The Post and The Globe published only two. Not only were there more articles in The Star, but they focused closely on national childcare policy. Nine articles published in The Star in November 2014 contained the primary search terms at least 5 times ("childcare" or "child care" or "day care" or “early learning") and "policy" while only 1 article in each of The Post and The Globe met this criterion. That childcare was not a priority in the two national newspapers appears to indicate that childcare was not a national priority in Period A, though the Toronto Star continued to press the issue as nationally significant.

Most of the articles in The Star in November 2014 debated the costs and benefits of the contrasting Conservative and NDP proposals related to childcare. Some titles include "Our kids, our future and two competing visions"(Harper, 2014, Nov 3) and "Tax cuts leave out 'vast majority' NDP says: Only 15\% of households will see impact of Harper's income-splitting measures" (Whittington, 2014, Nov 8). The Star was also the only paper to report on the $4^{\text {th }}$ annual national childcare policy conference held in Winnipeg, Manitoba that November. Social justice reporter Laurie Monsebraaten interviewed childcare experts and stakeholders in an attempt to position childcare as a key election issue: "Election battle looming over child care: Make-or-breakyear for creating national program, advocates say" (Monsebraaten, 2014, Nov $3)$. 
The Star also skewed the October 2015 peak in coverage that appears in Figure 6.4.

When data were disaggregated by paper, only The Star exhibited a peak in coverage in the month of the federal election with a total of 15 articles published that October (compared to 4 in The Post and 2 in The Globe). Interestingly, only one of these 15 articles from The Star was focused exclusively on childcare policy and it did so from a parent perspective. "Daycare dilemma calls for sacrifices: Parents take a wide range of measures to cope with a system that's failing them" (Monsebraaten, 2015, Oct 11). Other editorials authored by the paper itself discussed childcare as one of several policy issues: “Harper's final frantic pitch” (Toronto Star, 2015, Oct 14) and "The Conservative litany of misogyny" (Toronto Star, 2015, Oct 8).

The Post reached its highest point in coverage ( 7 articles) in September of 2015 and The Globe in April 2015 (8 articles). The Post published 3 articles during September 2015 that were highly critical of the role of state-funded/supported childcare. Post columnist Tash Kheiriddin authored an article titled "The dangers of daycare; Numerous studies have shown that children who spend more time in child care tend to have worse outcomes later in life" (Kheiriddin, 2015, Sept 24), while columnist and economist Stephen Gordon titled his piece "The daycare trade-off; Universal childcare lets more women go to work, but could have a negative effect on their children” (Gordon, 2015, Sept 29). The Post itself authored an editorial titled “Quebec's damaging daycare” (The National Post, 2015, Sept 25).

During its April 2015 peak, articles in The Globe did not focus on childcare but tended to draw on childcare as one example (of several) illustrating the polarity of positions the parties had 
taken on issues. For example, childcare is mentioned in a Globe and Mail editorial titled "The parties prepare for battle" (Globe and Mail, 2015, Apr 4) as well as by veteran journalist Jeffery Simpson: "Federal budget a triumph of tax madness" (Simpson, 2014, Apr 16). Other articles, one discussing the role of fathers in carrying out childcare responsibilities written by The Globe's popular culture journalist (Bielski, 2015, Apr 10) and the other written by Erin Anderssen discussing "Clinton-style feminism" (Anderssen, 2015, Apr 17) also mention, but do not go into great detail in their discussions of childcare policy.

\section{Word counts: Depth of coverage}

While The Star clearly emerged as the newspaper with the most articles discussing the issue, the depth of coverage across papers was comparable. Average word count across all years was 854 in The Star, 902 in The Post and 1010 in The Globe. For Period A, the average word count in The Star was 872, The Post 886 and The Globe 1029. For period B, the average word counts were 792 in The Star, 957 in The Post and 953 in The Globe. As Figure 6.6 illustrates below, there did not appear to be significant deviation in the word count between the papers or across the years, with the one noticeable exception being The Globe in 2013 when the paper ran a special series on the issue. The other noticeable deviation in depth of coverage occurred in The Post in 2012 when two lengthy articles discussed childcare policy at length. The first, a guest article of 2400 words authored by American journalist Jonathon Cohn focused on the neurological benefits of high quality childcare and damaging results of poor quality childcare although he concludes that the amount of money needed for such programs is too costly for most governments (including Canada) (Cohn, 2012, Jan 3). The second, written by staff reporter Sarah 
Boesveld (1900 words), compared North America child-rearing approaches with those of the French. Contradicting this paper's typical stance against childcare, journalist Boesveld noted that "Government support in the form of subsidized daycare is important" (Boesveld, 2012, Feb 11). Beyond these two outliers, the average word counts for all articles in all years fell between 742 and 1119. 


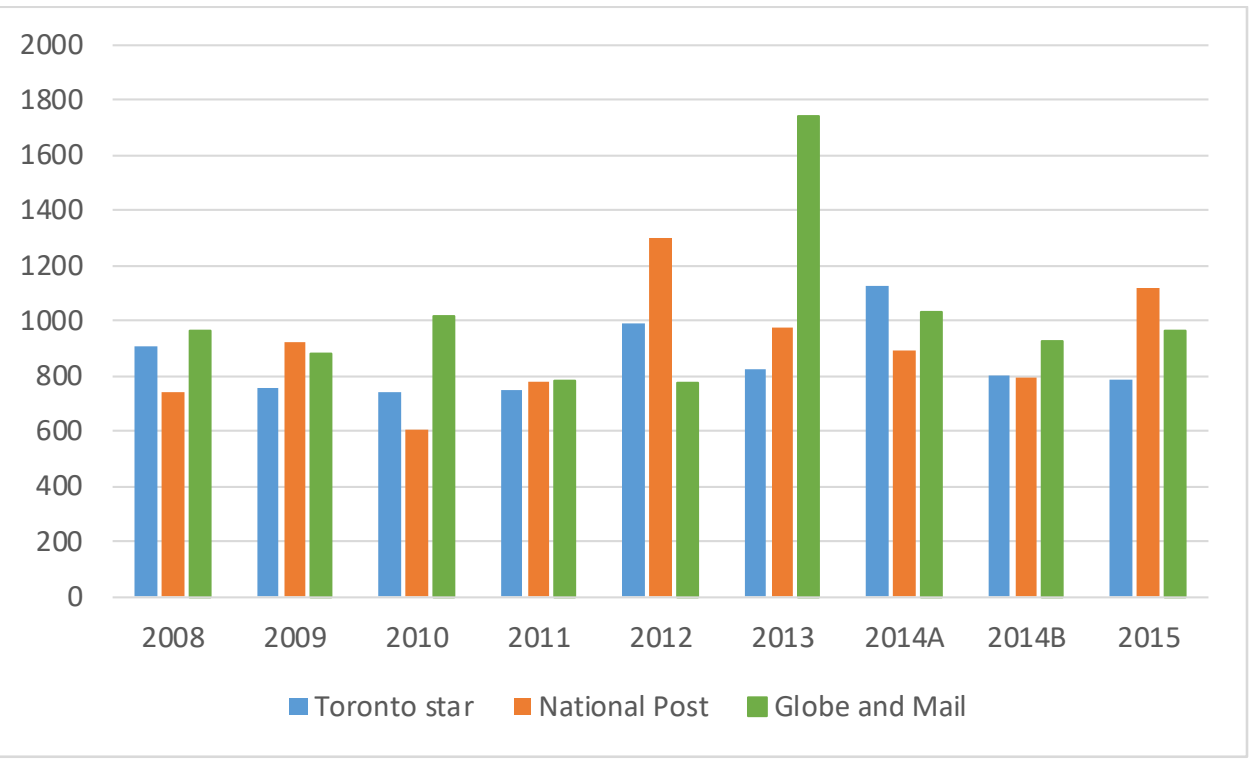

Figure 6.6: Average word counts across papers by year

\section{What is the problem represented to be?}

The findings in this section move beyond the quantity and depth of newspaper coverage to identifying Bacchi's (2009) fundamental question: What is the problem represented to be? The coding methods described in Chapter 4 and code book guided the process of problem identification. In Period A, the labour market support, private/family and market problematizations were most common overall. When data were delineated by paper in Period A, the labour market support, family equity, child well-being and public problematizations were most common in The Star. In The Post, the market, private/family and not a problem problematizations emerged most frequently while The Globe most frequently drew on the private/family, labour market support and market problematizations. In Period B, the most common problematizations shifted slightly. While the private/family and market 
problematizations remained dominant, the public problematization overshadowed the labour market support problematization across all papers. In The Star in Period B, the public problematization emerged in an overwhelming majority of articles $(85 \%)$, while the market and labour market support problematizations often accompanied this problematization. In The Post and The Globe in Period B, the market, private/family and public problematization emerged as dominant, though the public problematization was more heavily emphasized in The Globe and the market problematization in The Post.

Table 6.2: Overview of dominant problematizations by paper and time period

\begin{tabular}{|c|c|}
\hline Period A & Period B \\
\hline $\begin{array}{l}\text { Overall } \\
\text { 1. Labour Market Support } \\
\text { 2. Private/family } \\
\text { 3. Market }\end{array}$ & $\begin{array}{l}\text { Overall } \\
\text { 1. Public } \\
\text { 2. Market } \\
\text { 3. Private/family }\end{array}$ \\
\hline $\begin{array}{l}\text { Star } \\
\text { 1. Labour market support } \\
\text { 2. Family equity } \\
\text { 3. Public and child well-being }\end{array}$ & $\begin{array}{l}\text { Star } \\
\text { 1. Public } \\
\text { 2. Market } \\
\text { 3. Labour market support }\end{array}$ \\
\hline $\begin{array}{l}\text { Post } \\
\text { 1. Market } \\
\text { 2. Private/family } \\
\text { 3. Not a problem }\end{array}$ & $\begin{array}{l}\text { Post } \\
\text { 1. Market } \\
\text { 2. Private/family } \\
\text { 3. Public }\end{array}$ \\
\hline $\begin{array}{l}\text { Globe } \\
\text { 1. Private/family } \\
\text { 2. Labour market support } \\
\text { 3. market }\end{array}$ & $\begin{array}{l}\text { Globe } \\
\text { 1. Public } \\
\text { 2. Market } \\
\text { 3. Private/family }\end{array}$ \\
\hline
\end{tabular}




\section{Observations of problematization in Period A}

Figure 6.7 illustrates that across all newspapers there was a wide variety of problematizations included in Period A. For ease of comparison, frequency "clusters" were created and labelled highest, high, medium and low frequency (see Table 6.3). Across all newspapers, the high frequency problematizations included the labour market supply (44\% of articles), market (43\% of articles) and private/family ( $41 \%$ of articles). The medium frequency problematizations included family equity (35\% of articles), public (34\%), women's equity (34\%) and children's well-being ( $34 \%$ of articles). The low frequency problematizations were poverty ( $24 \%$ of articles), not a problem (23\% of articles), economic (21\%), human capital (20\%) and early childhood professionals (19\%), while the marginal problematizations were social solidarity (8\%), 
generational equity ( $7 \%$ of articles), population growth ( $7 \%$ of articles) and "other" ( $1 \%$ of articles).

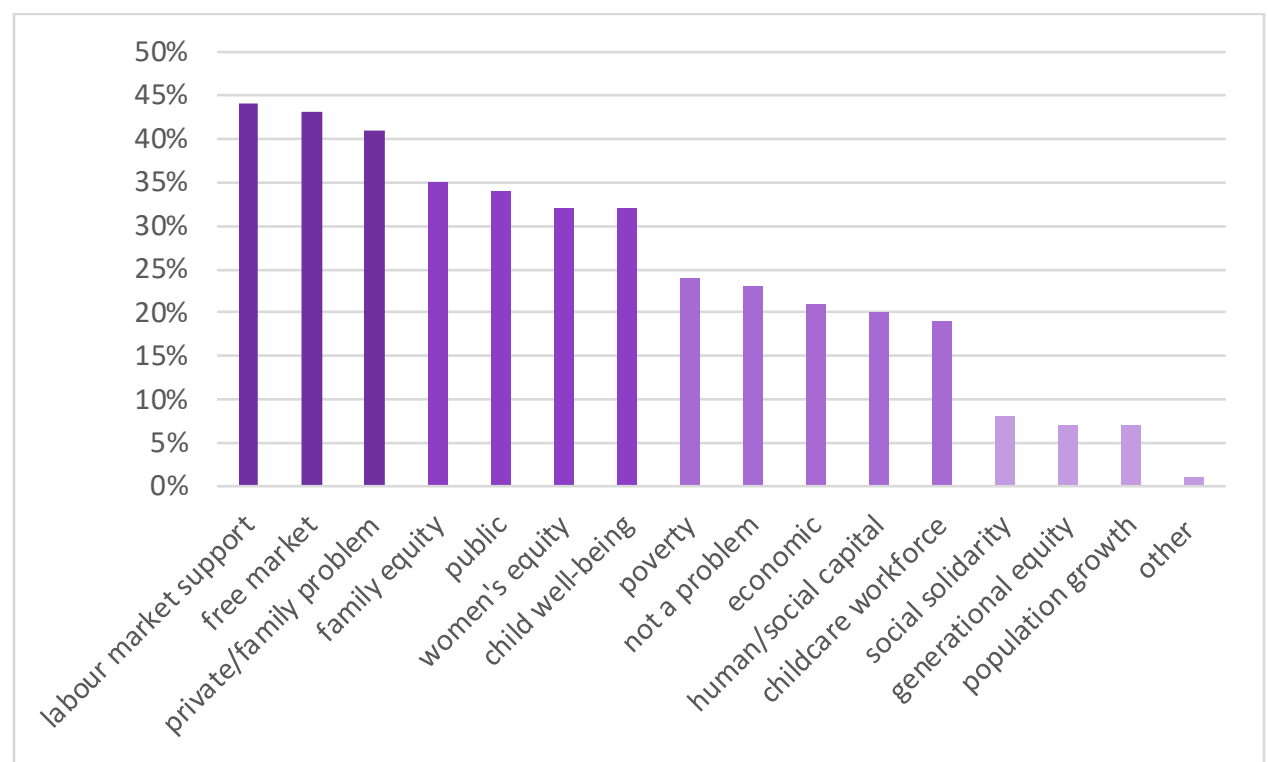

Figure 6.7: Frequency of problematizations in all newspapers in Period A

Table 6.3: Frequency categories for problematizations

\section{$\%$ of articles}

\section{Frequency category}

Highest

High

Medium

Low

Marginal
$60 \%+$

$40 \%-59 \%$

26-39\%

$15-25 \%$

$<15 \%$ 
While this overview is helpful in that it gives a broad snapshot of what childcare policy problematizations were evident overall, it was once again the case that results looked very different when data were delineated by newspaper. Illustrated in Figure 6.8, The Star most frequently discussed the lack of childcare policy in Canada as a labour market supply problem (60\% of articles) - the highest frequency of any problematizations in any of the papers in Period A. The family equity problematization was evident in about half of articles (49\% of articles). In The Star's medium frequency cluster was the children's well-being (40\% of articles), public ( $40 \%$ of articles), women's equity (37\%), economic (34\%), market (34\%), poverty $(31 \%)$, private/family (29\%) and childcare workforce (29\%) problematizations. The Star consistently problematized childcare from several perspectives -11 problematizations were evident at least a quarter of the time. The Star was also the only paper that discussed the lack of childcare in Canada as a problem in the "other" category - in this case, from the perspective of Aboriginal Canadian children and families. 


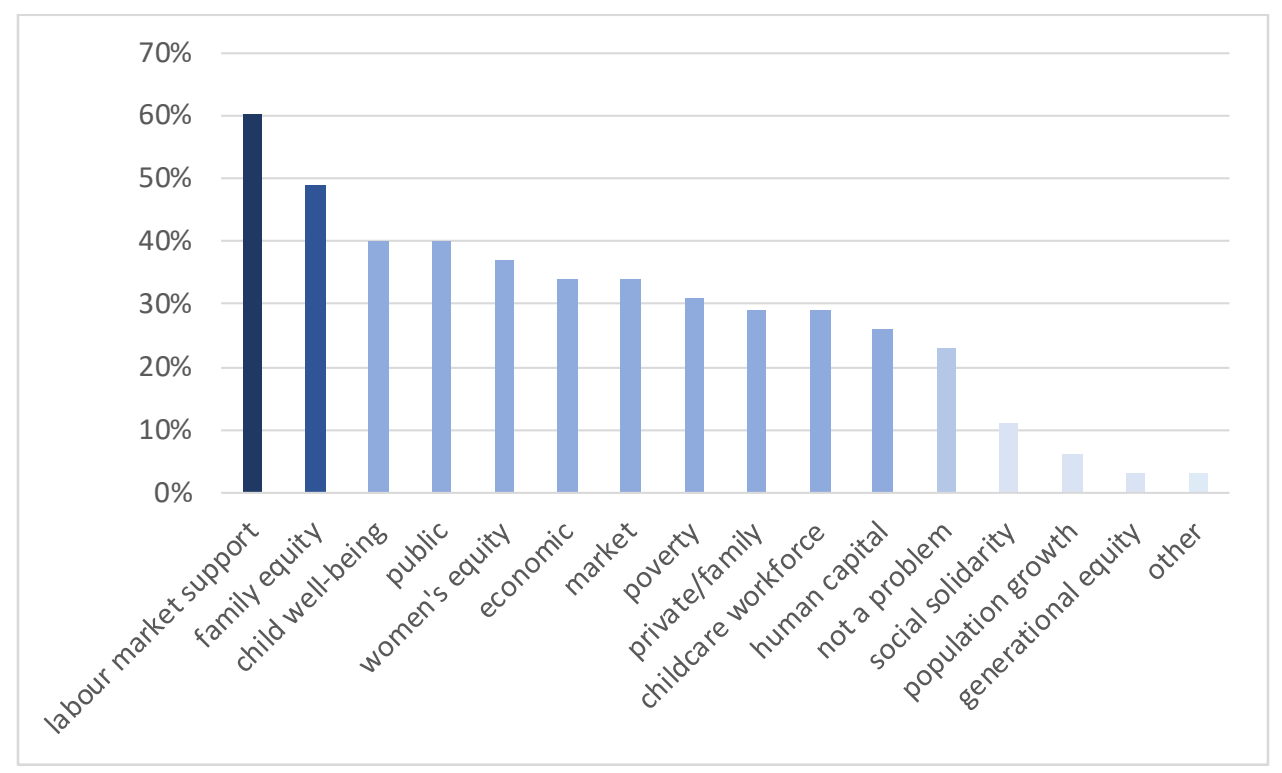

Figure 6.8: Frequency of problematizations in the Toronto Star in Period A

Figure 6.9 below illustrates that The Post had two problematizations in the high frequency category - market ( $48 \%$ of articles) and private/family ( $45 \%$ of articles). The idea that the lack of childcare in Canada is a private problem to be addressed by the market and parents dominated the discussion in this paper. The other two common problematizations, falling in the medium frequency category, project very different conceptualizations of childcare policy. At the upper threshold of the medium frequency category, The Post denied that there was a childcare problem in Canada (35\% of articles), while at the lower end of this category The Post acknowledged (and typically rejected) childcare as a public problem (26\% of articles). The Post was the only paper to consistently deny the childcare problem in Period A. All of the other problematizations fell into the low or marginal frequency categories indicating that there was less diverse representations of the issue in this paper. 


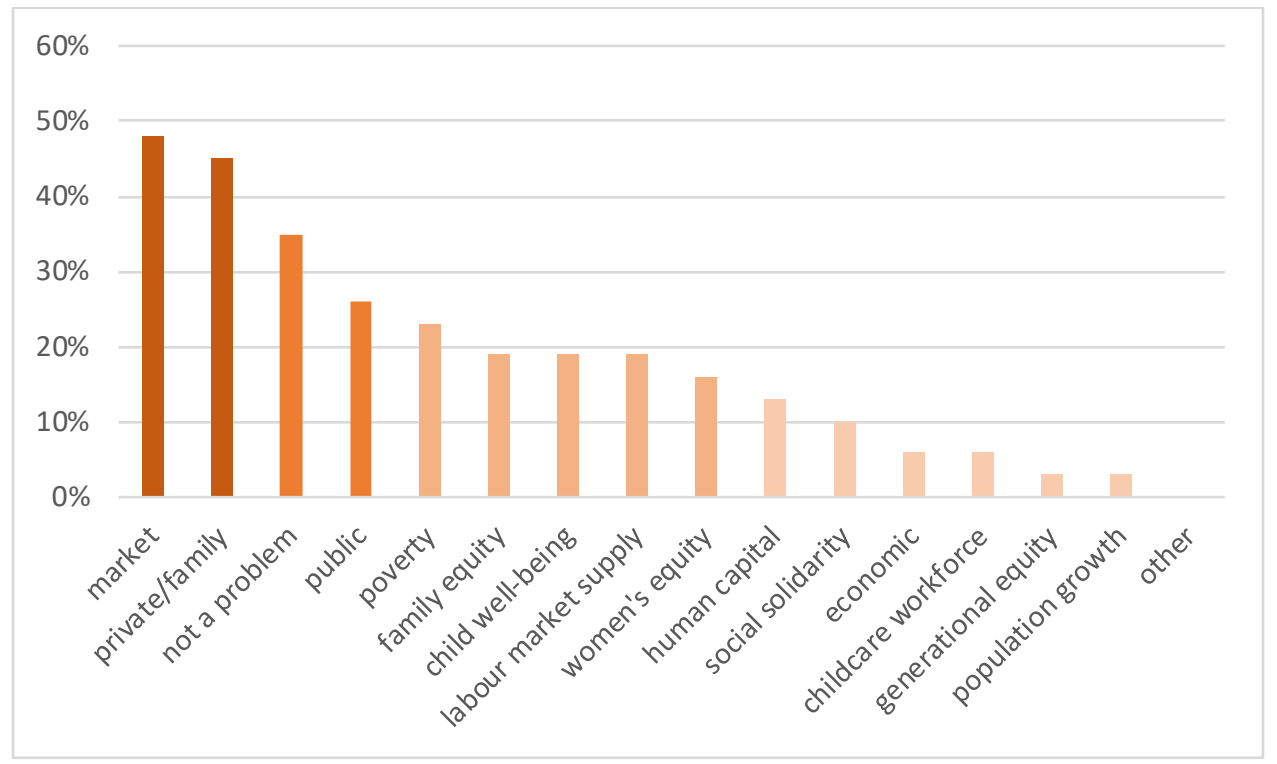

Figure 6.9: Frequency of problematizations in The Post in Period A

Finally, Figure 6.10 illustrates that The Globe presented the labour market supply (52\%), a private/family (52\%), a market (48\%) and the women's equity (42\%) problematizations in the high frequency category. Family equity (35\%), child well-being (35\%) and public (35\%) problematizations were also consistently discussed in this paper while all other problematizations fell into in the low or marginal categories. Like The Star, The Globe frequently drew on diverse representations of the policy problem with seven problematizations evident in at least $35 \%$ of the sampled articles. 


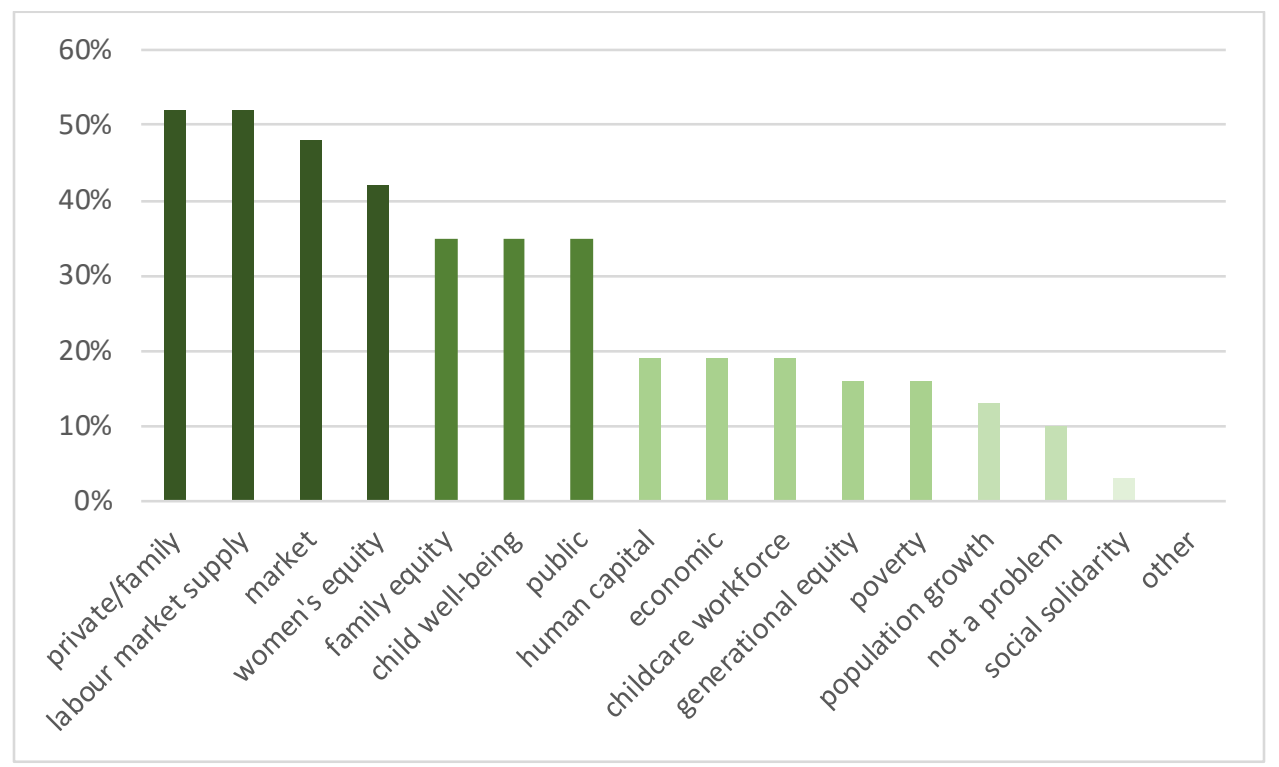

Figure 6.10: Frequency of problematizations in The Globe and Mail in Period A

Figure 6.11 below amalgamates Figures 6,7, 6.8 and 6.9. When compared in this way, it becomes evident that The Globe and The Star were more likely than The Post to consider childcare from a labour market supply and equity perspective (families, women and children) in Period A. However, both The Globe (52\%) and The Post (45\%) were more likely to problematize childcare as a private, family problem in comparison to The Star (30\%). Only The Globe consistently mentioned the generational equity problematization (16\% compared to about $3 \%$ in both The Star and The Post).

From a gendered perspective, The Globe and The Star were more inclined than The Post to include problematizations of childcare from a women's equity perspective as well as to highlight the importance of the childcare workforce in discussions of childcare policy. For example, a lack of affordable childcare was most frequently discussed as a women's equity problem in The 
Globe (42\% of articles), followed by The Star (39\% of articles) and The Post (16\% of articles). While not a significant focus of any paper, the perspective of childcare workforce was most likely to be discussed in The Star (29\%) followed by The Globe (19\%) and The Post (6\%).

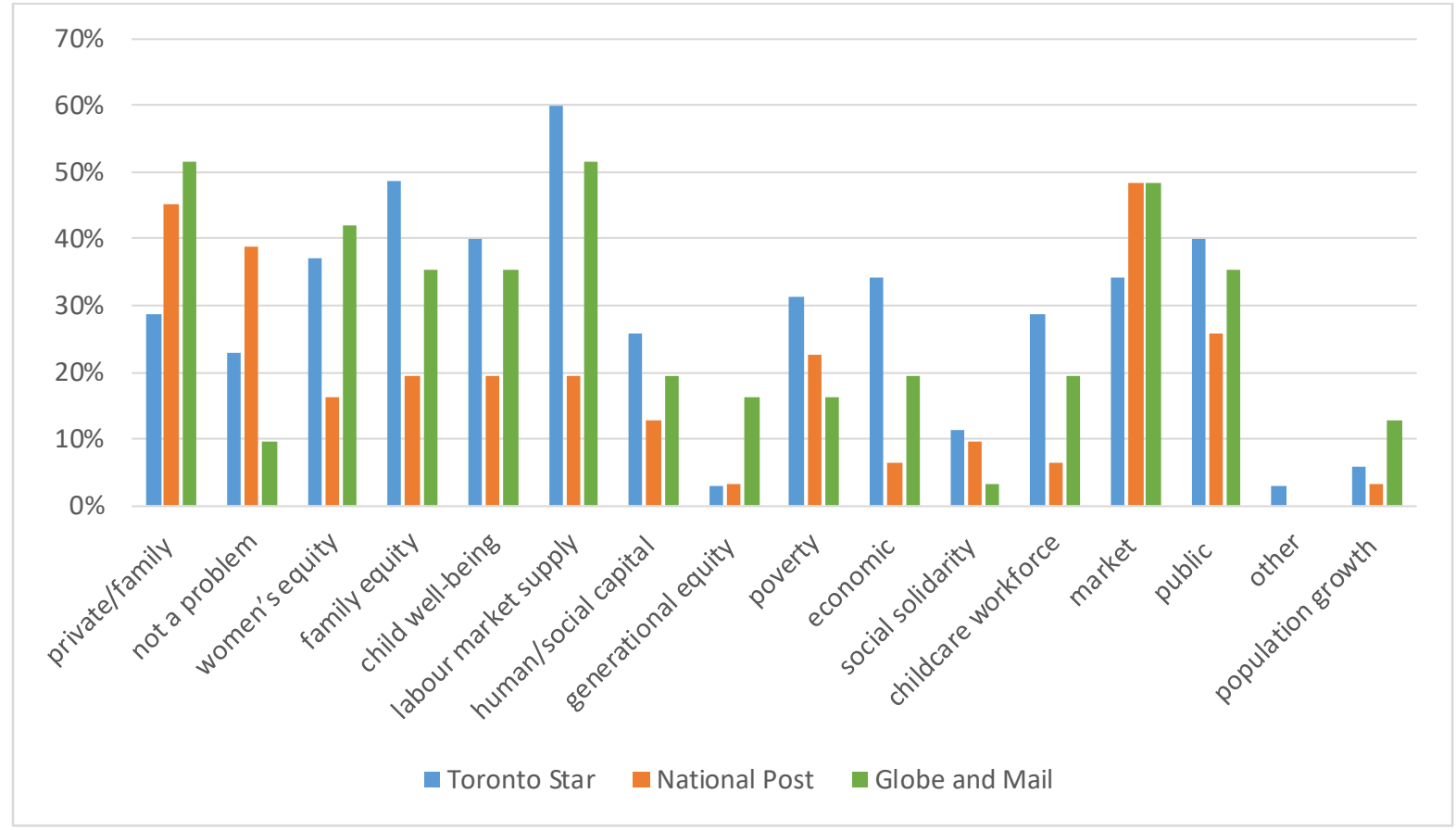

Figure 6.11: Frequency of problematizations by newspaper in Period A Observations of problematizations in Period B

Figure 6.12 represents the overall frequency of problematizations in Period B. Both the market and private family problematizations remain dominant, while the labour market supply problematization decreases in frequency and the public problematizations emerges as dominant (likely due to the emergence of the NDP's $\$ 15 /$ day plan). There appears to be a general shift in 
the conceptualization of childcare policy to the bigger picture rather than focusing on one or two reasons why the lack of childcare in Canada is an important problem.

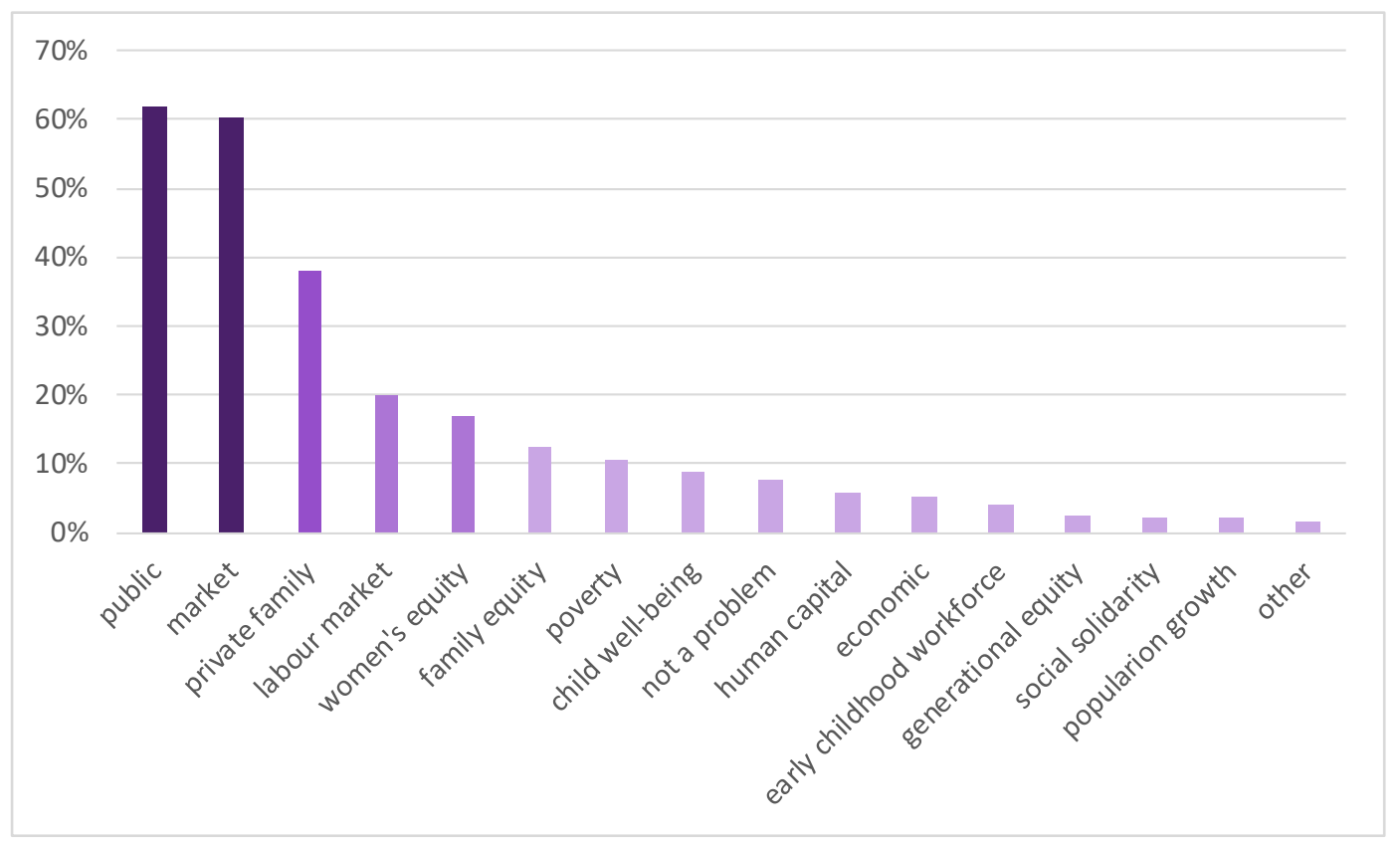

Figure 6.12: Frequency of problematizations by newspaper in period B

Figure 6.13 represents the frequency of problematizations in Period B delineated by paper. While clusters are evident with the three most common problematizations (private family, market and public), The Star appears more likely to draw on non-dominant problematizations of the issue (i.e., labour market supply, poverty, women's equity, family equity) compared to the other two papers. Figure 11 also illustrates that only The Post consistently denied the childcare problem in Canada. 


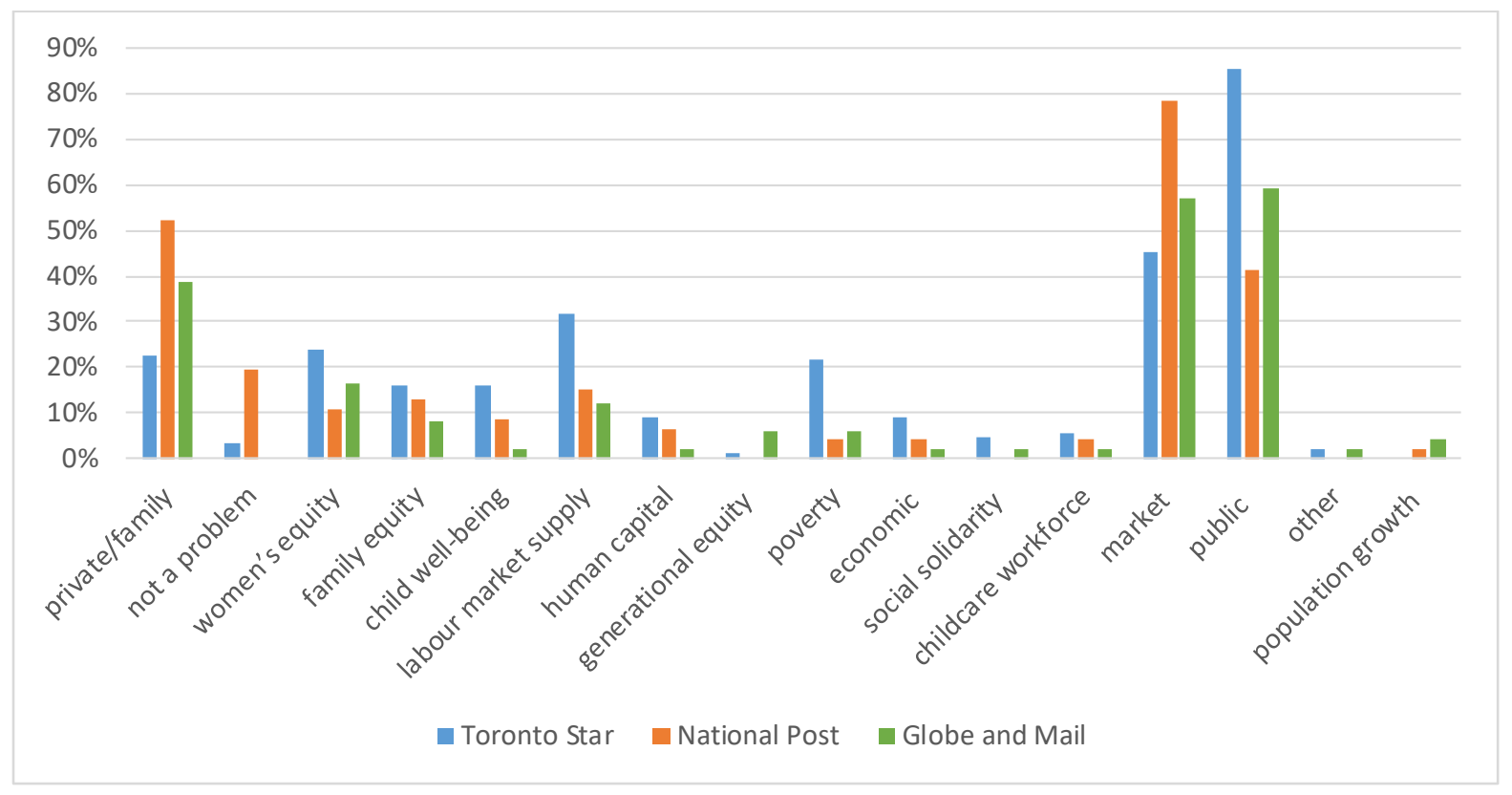

Figure 6.13: Frequency of problematizations by newspaper in Period B

Figures $6.14,6.15,6.16$ delineate the data by paper, while comparing the frequency of problematizations in Period B with the frequency in Period A. The solid bars represent the findings from Period B, while the textured bars represent the findings from Period A. The shading of the solid bars reflects the frequency category in which the problematization fell. It is also important to remember that the data from Period A was gathered through a sampling procedure while the data for period B included an analysis of the entire data set. Since raw number counts of occurrence of each problematization could not be compared across time periods, a proportionate measure (i.e., percentage) measure was used. The figures below include a comparison of the percentage of articles in Period A and Period B that included each problematization (calculated by dividing the number of articles that contained the 
problematization in each paper by the total number of articles that met the search criteria in each paper during the time period).

In Period B (Figure 6.14), The Star overwhelmingly discussed childcare as a public problem, with $85 \%$ of articles including this problematization (highest frequency category) compared to $40 \%$ in Period A (low end of the high frequency category). The market problematization fell into the high frequency category in Period B (45\%) rather than the medium frequently category (34\%) as it had in Period A. In contrast, the percentage of articles that presented childcare as a labour market supply problem was notably less in Period B (32\% in the medium frequency category) compared to Period A (60\% in the highest frequency category). Childcare policy was less frequently discussed specifically from a women's equity, family equity and/or child well-being perspective in period B than in Period A with these problematizations shifting from the high frequency to the low frequency category. The human capital, economic and childcare workforce problematizations similarly became less frequent in Period B than they had been in Period A shifting from the medium frequency category to the marginal frequency category. Only the "not a problem" problematization shifted from the low to marginal category while all other problematizations remained marginal in both time periods. 


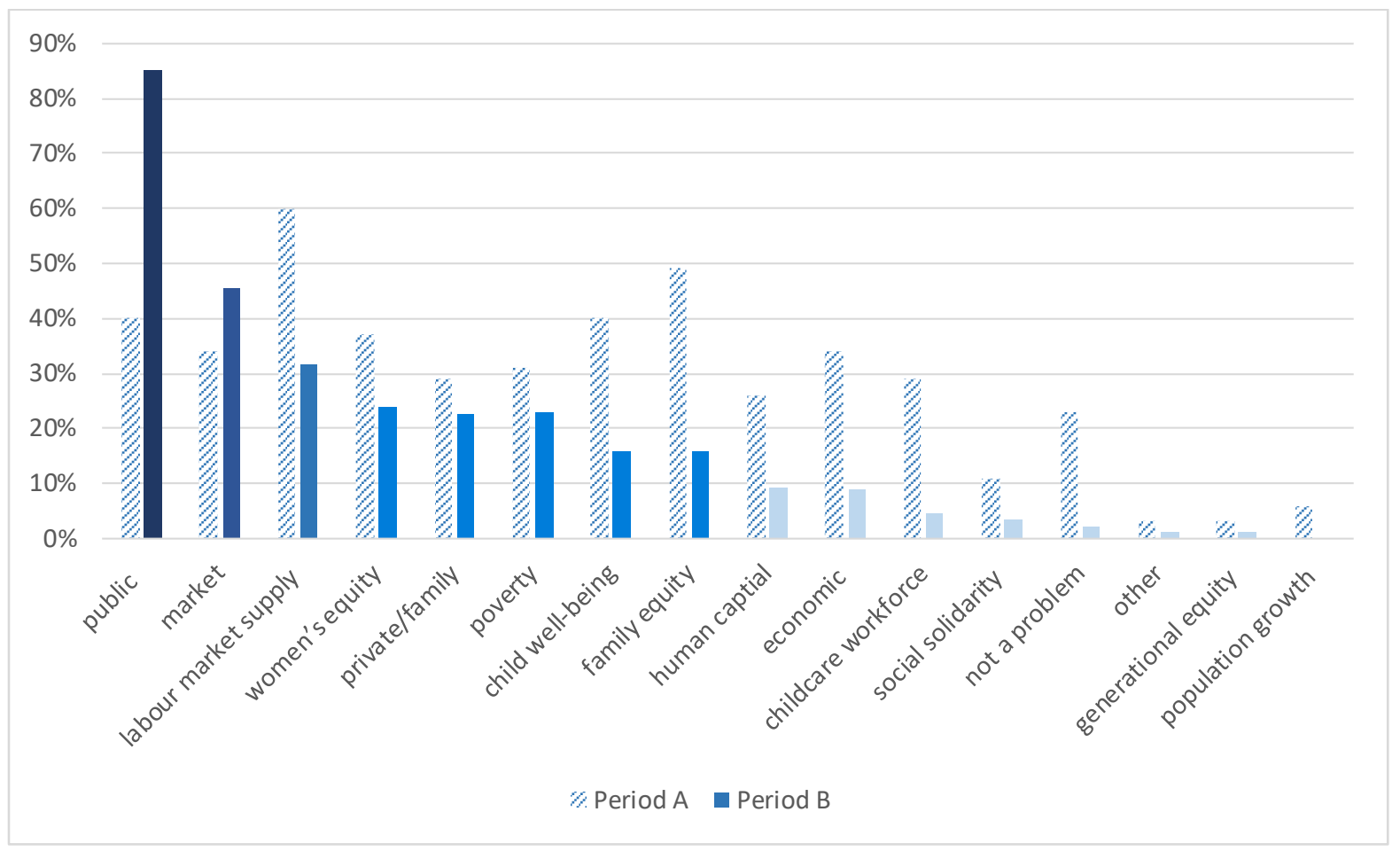

Figure 6.14: Frequency of problematizations in The Star in Period B compared to period A The Post saw a large increase in the market problematization from Period A to Period B, with the problematization shifting from the high category (48\%) in Period A to the highest category $(73 \%)$ in Period B. There was a modest increase in the public problematization of the issue in Period B, shifting from the lower threshold of the medium category to the upper threshold of the category (26\% in Period A to $39 \%$ in Period B). The private/family problematization remained in the high frequency category (45\% in Period A and 49\% in Period B), while the "not a problem" problematization fell from the medium to the low frequency category (35\% in Period A to $18 \%$ in Period B). Other problematizations were less frequently communicated in Period B than they were in Period A, with all other problematizations falling from the low to the marginal frequency 
category. This drop was particularly pronounced in relation to the poverty problematization where the frequency dropped from $24 \%$ of articles in Period A to $4 \%$ in Period B.

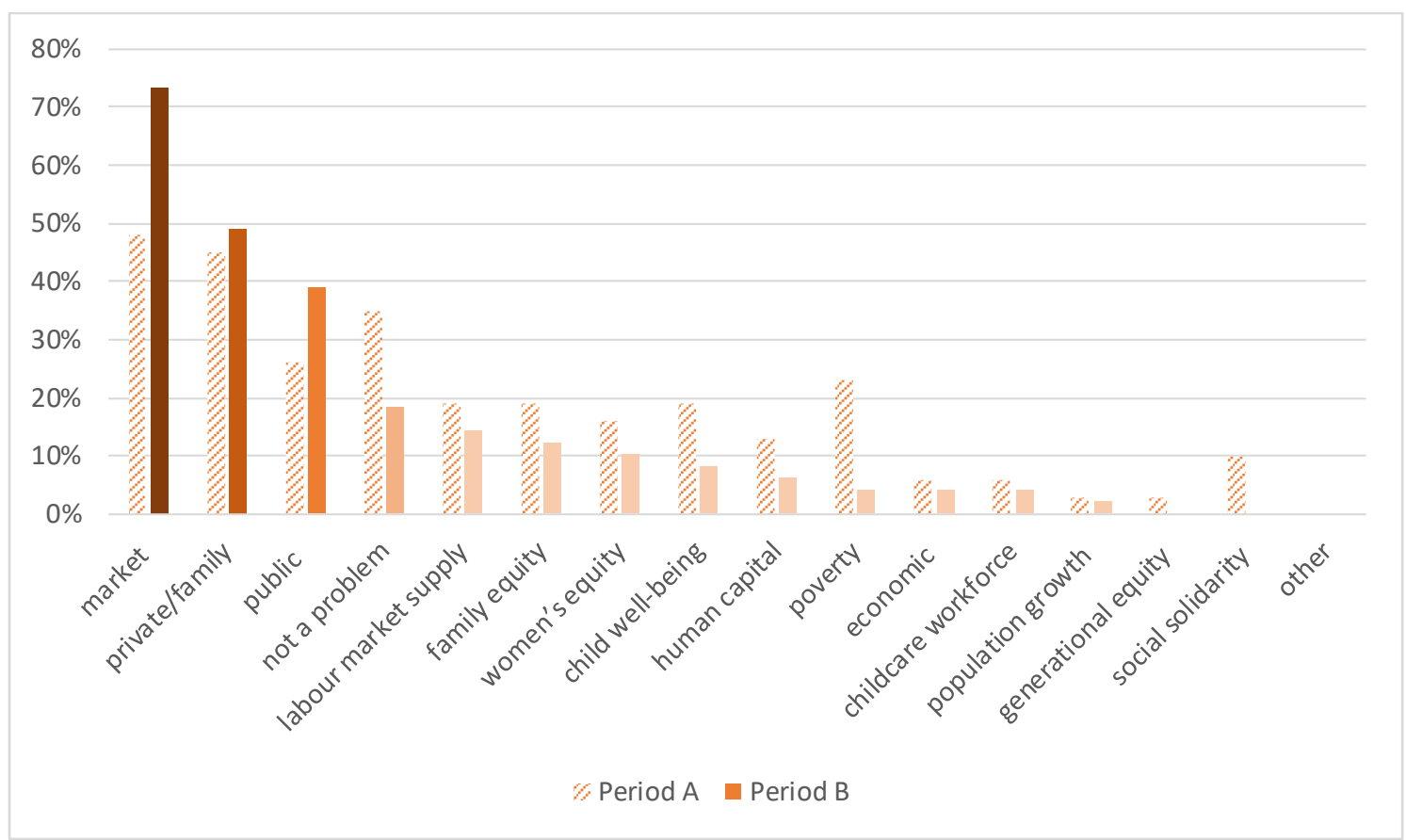

Figure 6.15: Frequency of problematizations in The Post in Period A and Period B

Finally, in The Globe the contradictory public and the market problem of childcare policy shifted from the medium frequency to the highest frequency category. In Period A, the public problem was evident in $35 \%$ of articles while it became evident in $63 \%$ of articles in Period B. Similarly, the market problematization rose from $47 \%$ in Period A to $63 \%$ in Period B. This finding suggests there was an active struggle in this paper as to whether or not childcare was best considered a private market problem (i.e., a commodity) or public resource. This paper was slightly less likely to discuss childcare as a private/family problem in period B (41\% down from $52 \%$ ), though this problematization remained in the high frequency category. The Globe did not 
exhibit the same diversity in problematizations in Period B as it did in Period A. For example, there are no problematizations in the medium frequency category and only two problematizations in the low frequency category (women's equity and labour market supply). The remaining problematizations all fall into the marginal category in Period B. This drop is particularly pronounced for both the family equity and child well-being problematizations. From a gendered perspective, there is a notable drop in the women's equity problematization whereby this problematization arose in 52\% of Period A articles and only $13 \%$ of Period B articles (high to low frequency categories). Similarly, the childcare workforce problematization fell from $19 \%$ in Period A to $2 \%$ in Period B.

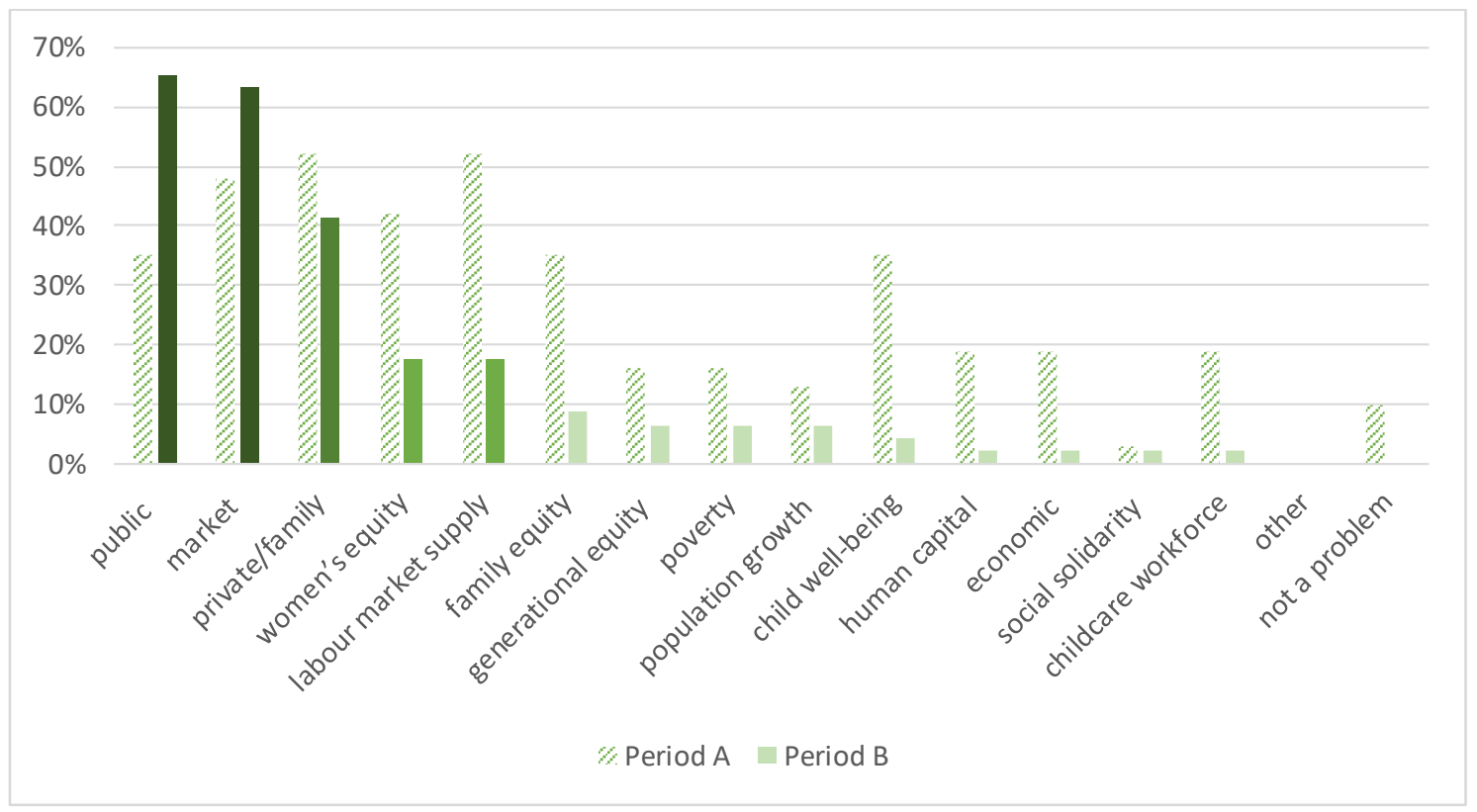

Figure 6.16: Frequency of problematization in The Globe period A and Period B 
The next chapter will compare each problematization across periods and newspapers as well as provide several textual examples of each. Chapter 8 will then critically analyze how these problematizations may have achieved their dominant status (or not). 


\section{Chapter 7}

\section{Part 2: Descriptions and examples of problematizations in both time periods}

This chapter will compare and provide examples of each of the problematizations in both time periods. Data are broken down by problematization moving from the highest to lowest frequency problematizations.

\section{Free market problematization}

In Period A, childcare was discussed as a market problem in $43 \%$ of articles, increasing to an average of $60 \%$ of articles in Period B. When delineated by newspaper as illustrated in Figure 7.1, it becomes evident that the market problematization was discussed in the highest frequency category only in The National Post, while it fell into the high frequency category in both The Star and The Globe. Most commonly, this problematization emerged in discussions of policy solutions including the UCCB, workplace childcare and discussions of for-profit childcare. With the first two policy solutions, a market model of childcare is proposed whereby government support is limited to cash-in-hand to parents to spend in the market how they "choose" or tax breaks are given to employers to support the creation of childcare spaces. Articles discussing government funding for the private, for-profit sector was also coded under the free market problematization, though here the focus was on stimulating market growth through a supply-side funding model.

Examples of the market problematization in reference to the UCCB in Period A are plentiful, as this was the primary existing childcare policy at the federal level at the time. 
Discussions of the UCCB often purported to give parents the "choice" to "choose" whatever care options they prefer in the free market. For example, in the midst of the 2008 election campaign a Globe article (authored by Canadian Press reporter Sue Bailey) states: "it's more equal and efficient to give cash directly to families" (Bailey, 2008, Apr 11). In 2010, in The Post a Conservative MP is quoted saying: “[the UCCB's method of cash to parents] is individual empowerment versus the Liberals'faith in a big government solution" (Gunter, 2010, Jul 7). The Post frequently claimed that parents prefer direct cash payments to supply-side funding models. One article authored by a Post reporter states: "two thirds of respondents call for direct funding to parents through direct payments or tax deductions" (Edmiston, 2013, May23). In early 2014, Post columnist John Ivison directly asks: "Why not simply extend and increase the existing universal child care benefit?" (Ivison, 2014, Feb 14). While articles in The Star did not generally support the UCCB, the centrality of this problematization was acknowledged. Prior to the launch of the 2008 election campaign, an article written by a childcare advocate noted "the pressure to maintain a market-based approach with no strings attached to public funding is formidable" (Anderson, 2008, Jul 9).

Articles in The Globe and The Post also frequently promoted the idea that the lack of childcare problem is best solved through increased provision of for-profit childcare. An article authored by Post columnist Peter Shawn Taylor, titled "Let Parents Choose" makes the argument that the federal government should follow Alberta's lead and encourage the growth of childcare spaces in the for-profit sector: "Alberta's evidence clearly suggests it makes sense to give parents choice and eliminate discrimination against the for-profit sector" (Taylor, 2009, 
May 19). The author positions individual entrepreneurs and corporations as best equipped to solve the childcare problem. Taylor goes as far as to suggest that "Scaring off eager new [forprofit] operators is a strange way to build capacity" (Taylor, 19 May, 2009). The same author also published an invited article in The Globe where he remarked "If you want more daycare spaces, let entrepreneurs do their thing" (Taylor, 2009, Jul 7). An editorial authored by The Globe purports that "there is no inherent contradiction between providing a good or necessary services and earning a profit," going on to suggest that "the alarms raised against for-profit daycare seem ideological, rather than practical" (The Globe and Mail, 2011, Dec 16). In 2012, the rapid expansion of corporate childcare chain Edleun was reported on positively by Globe reporter Adrian Morrow: "Daycare company Edleun is teaming up with one of the nation's largest landlords to bring much-needed new childcare spots to apartment buildings" (Morrow, 2012, Feb 6). The president and CEO of Edleun (now Brightpath Early Learning in Canada) is quoted as saying "we see opportunity to bring more availability of childcare to families that might not have access to childcare" (Morrow, 2012, Feb 6).

When the market problematization of childcare arose in The Star, it often did so in the context of workplace childcare. This solution conceptualizes private employers as best positioned to address the lack of affordable childcare. When workplace childcare is the solution, the care of children becomes a social responsibility of private, market-based employers. The policy solution is to provide incentives, typically though tax breaks, for workplaces that provide childcare spaces to employees. An article authored by veteran Star columnist Carol Goar observed that "the business community will decide whether we have an early childhood policy in 
this country...no other group has the power" (Goar, 2009, Jun 22). The Star also quoted a Conservative politician in an anonymous article who stated "We are also providing tax breaks to businesses that create child care spaces. We believe this is the approach Canadians want" (Anonymous, 2010, Mar 6).

In Period B, the focus shifted to the election platforms and announcements leading up to and continuing through the federal election campaign. Following the Conservative announcement of the enhanced UCCB in late 2014, Post columnist Andrew Coyne reported: "The NDP plan would benefit only the children in the 370, 000 spaces it would eventuallycreate, while for about the same money the UCCB benefits more than two million children now" (Coyne, 2014, Oct 16). Less supportive of the market-based approach, a national affairs Star columnist described the approach of the Conservative government: "First, he [Harper] pledged to increase and expand the universal child-care benefit, also known as the baby bonus. That's a scheme whereby the government sends cheques each month to families with young children" (Walkom, 2014, Nov 1). Similarly, a Globe editorial argues "They [Conservatives] have tried to achieve social objectives (such as child care) through the tax system, at great cost to the Treasury without measurable results" (The Globe and Mail, 2014, Nov 8).

In July 2015, the market problematization became pronounced when the Conservatives' retroactive, enhanced UCCB payment cheques were mailed out. This lump sum cheque was referred to as "Christmas in July" by Pierre Poilievre - the Conservative Minister of Employment and Social Development. An editorial authored by The Star comments: “...if it's ' 
Christmas in July' ...then just wait for the money to be clawed back after the election" (Star, 2015, Jul 25). A reporter in The Globe noted the broader economic effects of the market-driven, enhanced UCCB: “Ottawa's enhanced child-care benefit...turns out to be a happy economic coincidence. To the extent parents spend that cheque, rather than save it or pay down debt, it will provide a modest boost to the economy" (Yakabuski, 2015, Jul 17). Another article in The Globe authored by seasoned columnist Jeffery Simpson, pointed out the inconsistencies between the NDP's public childcare plan and their decision to keep the market-based UCCB: "The NDP, while promising \$15-a-day child care (at a guesstimated cost of \$5-billion), will also keep the very expensive Conservative child-tax benefit, again paying the Harper government another compliment" (Simpson, 2015, Sep 11).

Throughout the rest of the period, the market problematizations arose with relative consistency. For example, in April 2015 Post columnist Kheiriddin argued: "The laws of supply and demand, equity and parental preference would all point to supporting choice as the most sensible model of child care" (Kheiriddin, 2015, Apr 30). Another article in The Post, authored by economist Stephen Gordon, took this argument one step further when it said: “...there's already a functioning market, and the fact that many people might wish that the price were lower is not in itself evidence that the market itselfis dysfunctional" (Gordon, 2015, Aug 11). In both of these examples the Post authors reinforced the idea that the free market is capable of meeting the needs of Canadian families, and they should pay the cost. 
The market problematization of childcare also arose in relation to Trudeau's Canada Child Tax Benefit (CCTB) as this proposed policy was frequently compared to the UCCB. For example, an article in The Globe stated: "They [parents] would get a major tax cut and enhanced child-care benefits in the election-platform plan that Mr. Trudeau revealed Monday" (Ibbitson, 2015, May 5). This is a prime example of when the CCTB, not childcare policy, was discussed in the context of childcare (alternative to the UCCB) perpetuating a market driven, demand-side funding to childcare services. In contrast, a Star columnist challenges the CCTB as childcare policy noting: "Trudeau offers only crumbs (a modest increase to the National Child Benefit) to the 8 million Canadians too poor to pay income tax... what they need are sturdy social supports: affordable housing and childcare" (Goar, 2015, May 7). Here, the contrast between the market and public problematizations of the issue is illustrated.

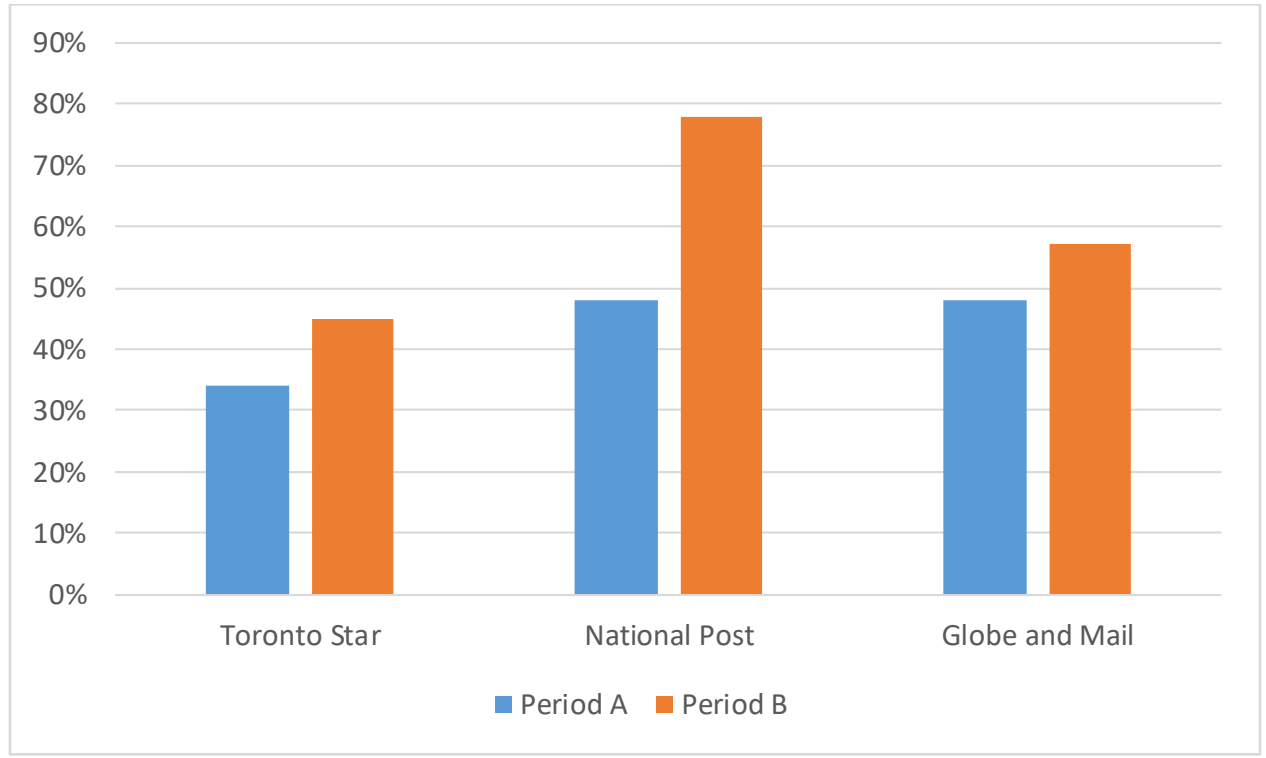

Figure 7.1: Frequency of market problematization across newspapers and time periods 


\section{Private/family problematization}

In Period A, childcare was conceptualized as a private/family problem in an average of $42 \%$ of articles with this dropping only slightly to $38 \%$ in Period B. As illustrated in Figure 7.2, this problematization was downplayed in The Star in both periods and most heavily emphasized in The Post in Period B and The Globe in Period A. When childcare is conceptualized as a private/family problem, solutions promote the parent's ability to directly care for their children and/or prioritize their role as the overseers and decision-makers in their child's care. In both periods, this problematization was connected to income-splitting and the UCCB. When the private/family conceptualization is connected to the UCCB the focus is on enabling parents to be the primary care providers rather than facilitating "choice" of care in the free market. The Post published several articles which reinforced the idea that parents are the ideal caregivers for parents. For example, guest opinion pieces in The Post written by Andrea Mrozek (founder of prowomenprolife.com) state: "more money into the hands of parents is a major and welcome shift" (Mrozek, 2008, Oct 9) and "giving money to [childcare] institution building at this stage in Canada's development hinders parents; it doesn't help" (Mrozek, 2011, Feb 14). Similarly, Post reporter Edmiston argues "Canadians want to see more stay-at-home parents according to a new poll commissioned by the Institute of Marriage and Family Canada" (Edmiston, 2013, May23). An anonymous article published prior to the 2011 election campaign in The Post reads: "However the choice [whether or not to place your child in childcare] is a personal choice that should be made by the parents, not by the government. We believe that parents are the best ones to make their choice for their children" (Anonymous, 2011, Feb 8). 
The Globe was also likely to embrace the private family problematization of childcare, tending to highlight the UCCB as a preferred policy over income splitting. For example, an invited article in The Globe authored by Public Policy Professor Rhys Kessleman reads: “...family-value advocates favour income splitting because it encourages stay-at-home parenting....other policy tools address childcare more effectively-such as enriching parental leave benefits or increasing the universal childcare benefit" (Kesselman, 2008, Apr 1).

Other Globe articles in Period A appear to be more progressive, though their message does not necessarily support an increased role of the government in the provision of high quality childcare services. For example, a Globe article written by reporter Erin Andersen suggests “The way out of the [childcare] burden that is imposed on mothers is for fathers to become involvedbeyond the model of mom 'the mangers' and dad 'the helper"' (Anderssen, 2011, May 7). Reflecting the growing phenomena of intensive mothering, Globe columnist Katrina Onstad concludes: "Turns out the best hope for successful offspring is attachment parents - - the cosleeping, sling-wearing 24/7 familial Panopticon" (Onstad, 2012, Dec 28). The Globe also positions parents as the best regulators of childcare when an editorial authored by the paper states: "The success or failure of any new private-sector daycare should ultimately depend on its ability to satisfy parents" (The Globe and Mail, 2011, Dec 16). All of these "solutions" to the childcare problem instantiate parents as the main care providers, with any government support limited to cash benefits or tax deductions. 
In Period B The Post stands out as the paper most likely to both draw upon and actively support the private/family problematization. The idea that parents prefer to care for children themselves is communicated. For example, Post columnist Kheiriddin states: "when asked what child care they prefer, parents name themselves, followed by family members, home daycare and lastly, centre-based care" (Kheiriddin, 2015, Apr 30). Guest Post commenter Andrea Mrozek furthered this sentiment: "We need an attitude shift so that parents can keep credentials and care for their young children without being compelled to use centre-based care full-time, a less than desirable option for most parents" (Mrozek, 2015, Mar 30). Another editorial by The Post days before the election, decidedly asserts that: "Overall, the Conservatives' offerings on social policy allow them [Canadians] to decide for themselves how to care for their children" (The National Post, 2015, Oct 15)

Though not as common as in period A, The Globe continued to problematize the issue from a private/family perspective in Period B. An editorial authored by The Globe in April 2015 states: "Conservatives are putting more money into the pockets of parents and leaving it up to those parents to decide whether to spend it on daycare or as a way to spend more time at home with the kids" (Globe and Mail, 2015, Apr 4). In a response to an article published in favour of public funding to childcare, a Globe letter-to-the-editor written by Helen Ward (President of Kids First Parent Association of Canada) reads:

These policies [supply side funding to childcare] are harming families by hogging funding and discriminating against women who do not fit the elite's preferred mould of a 
9-5 job for all parents and 8-6 daycare for all kids, as if we are too dumb to know what's best for our own families. Fund families, not spaces (Ward, 2015, Sept 8).

One interesting exchange pertinent to the private/family problematization emerged in The Post in September 2015 - a critical point in the federal election campaign. The National Bureau of Economic Research (an American think tank) published a working paper that suggested Quebec's childcare system was the cause of public problems rather than the solution. The Post picked up on this story and published three articles in five days (two of which were more than 900 words) that embraced the private/family problematization of childcare. An editorial authored by The Post states: "Children want and need to be at home most of the time - an intuition that is easily grasped by most people, even if it eludes daycare activists" (National Post, 25 Sep, 2015). Another article, again authored by columnist Kheiriddin, claims "instead of finding ways to outsource child care, we should develop policies that enable families to be the primary caregivers of their children" (Kheiriddin, 2015, Sept 24). An editorial by The Post a few days before the election clearly reflects the stance of the paper: "We prefer the approach taken by the Conservatives and Liberals: putting money directly in parents' hands, allowing them to choose the type of care that best suits their families" (The National Post, 2015, Sept 25).

Often when this problematization appeared in The Star in Period B, it was overtly challenged. For example, an editorial authored by The Star quoted Conservative finance minister (Joe Oliver) in the context of discussing the UCCB enhancement: "We trust Canadians to save and spend their hard-earned money better than all-knowing bureaucrats or social engineers" (The Toronto Star, 13 November, 2014). It went onto say: "granted, there are some people who 
don't agree, but that is what elections are about" (The Toronto Star, 13 November, 2014). This problematization was also mocked in both The Star and The Globe in Period B. For example, another Star editorial states: "Harper really does have social aims he hasn't had time to work on, and encouraging women to stay home is one of them" (The Toronto Star, 2014, Nov 14). Commenting on the Conservative's UCCB and income-splitting plan, Globe reporter Erin Andersen summarized Conservative leader Stephen Harper's message: “take a hint single moms: Find a man" (Anderssen, 2015, Oct 2).

Overall, the private/family problematization was embraced by The Post, rejected by The Star and both rejected and embraced by The Globe depending on the article.

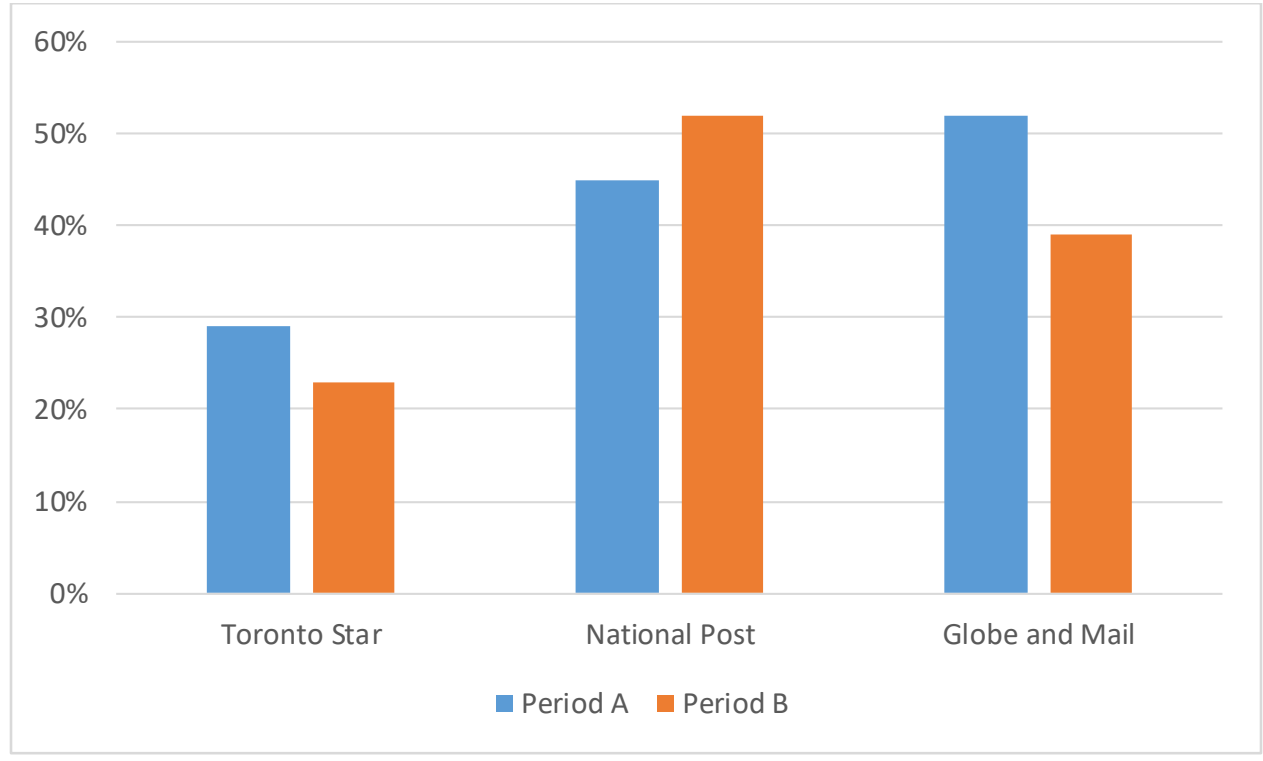

Figure 7.2: Frequency of the private/family problematization across newspapers and time periods 


\section{Labour market support problematization}

That childcare is a labour market supply problem, necessitating government involvement in childcare so that parents can work in the paid labour force, was much more prevalent in Period A than Period B. Figure 7.3 further illustrates that this change was much less pronounced in The Post than in the other two papers. Examples of this problematization in The Star include comments by childcare advocates Martha Friendly and Kerry McCuaig: "Canada can't work without childcare" (Friendly \& Rothman, 2009, Jan 8) and "More than 60000 parents in this city are able to go to work because their children have publicly supported childcare" (McCuaig, 2011, Jul 30). Similarly an anonymous article in The Star states: “When parents pursue paid employment, training or education outside the home, they want and need high quality, affordable services to support their child-rearing"(Anonymous, 2011, Feb 12). The Star and The Globe sometimes highlighted the stories of individual parents who wished to maintain full-time employment, but could not because of a lack of childcare. Star reporter Laurie Monsebraaten tells the story of a "former hairdresser would love to be working full-time but has been waiting since last spring for a subsidized childcare spot"(Monsebraaten, 2008, Dec 11). Economist and Globe columnist Marina Adshade quotes a mother: “I can't work part-time, my career doesn't allow for that ... and to advance my career it is absolutelynecessary to travel...childcare centres tend to run Monday to Friday and not after 5:30 pm" (Adshade, 2011, Dec 1). In the Post comment section, an article arguing in favour of a national childcare system authored by childcare advocates points out that "most women and men expect to have jobs and careers" in a (Rothman et al., 2011, Feb 11). 
There are several examples of this problematization in Period B as well, but it did not remain as frequent as it had in Period A. The problematization often emerged in The Star in reference to Mulcair's \$15/day childcare plan, as Mulcair consistently argued “the daycare program will pay for itself in tax revenue realized from greater participation in the labour force" (Harper, 3 Nov, 2014). A Star article written by the paper's work and wealth reporter highlighted this problematization with a great sense of urgency: “You can't blame parents [for relying on "dodgy" daycares] because what else can they do? They can't compromise their own work, so they have nothing" (Mojtehedzadeh, 11 Nov, 2014). Similarly, Globe columnist Elizabeth Renzetti frankly asks: "Do we want women to feel they can work outside the home if they choose?" (Renzetti, 25 Oct, 2014). The intersectionality of this problem with both the women's equity and poverty problematizations is embodied in the following quote authored by The Star: "Women living in poverty remain trapped because unaffordable child care means that they either can't work at all or their minimum wage budget and schedule don't fit with existing child-care options" (Toronto Star, 24 Jan, 2015). Another article by the Globe's Life-section reporter also highlights the intersectionality of childcare problems when it tells the story of a single mother living in poverty: “If I don't have daycare, I don't have a job” (McGinn, 07 Feb, 2015).

Articles in The Post tend to recognize the argument that investing in childcare (typically through tax breaks) will increase the labour market participation levels of parents. For example, Post columnist Bazel and Mintz concede "it is appropriate to write off the cost of incurring a livelihood, so child care expense deductions make sense" (Bazel \& Mintz, 11 Dec, 2014). Another article authored by economist and Post columnist William Watson asks: "we may 
maximize GDP when all parents work [with the support of publicly funded childcare], but do we maximise well-being?"(Watson, 17 Sep, 2015). His answer is clear: "Almost certainlynot" (Watson, 17 Sep, 2015).

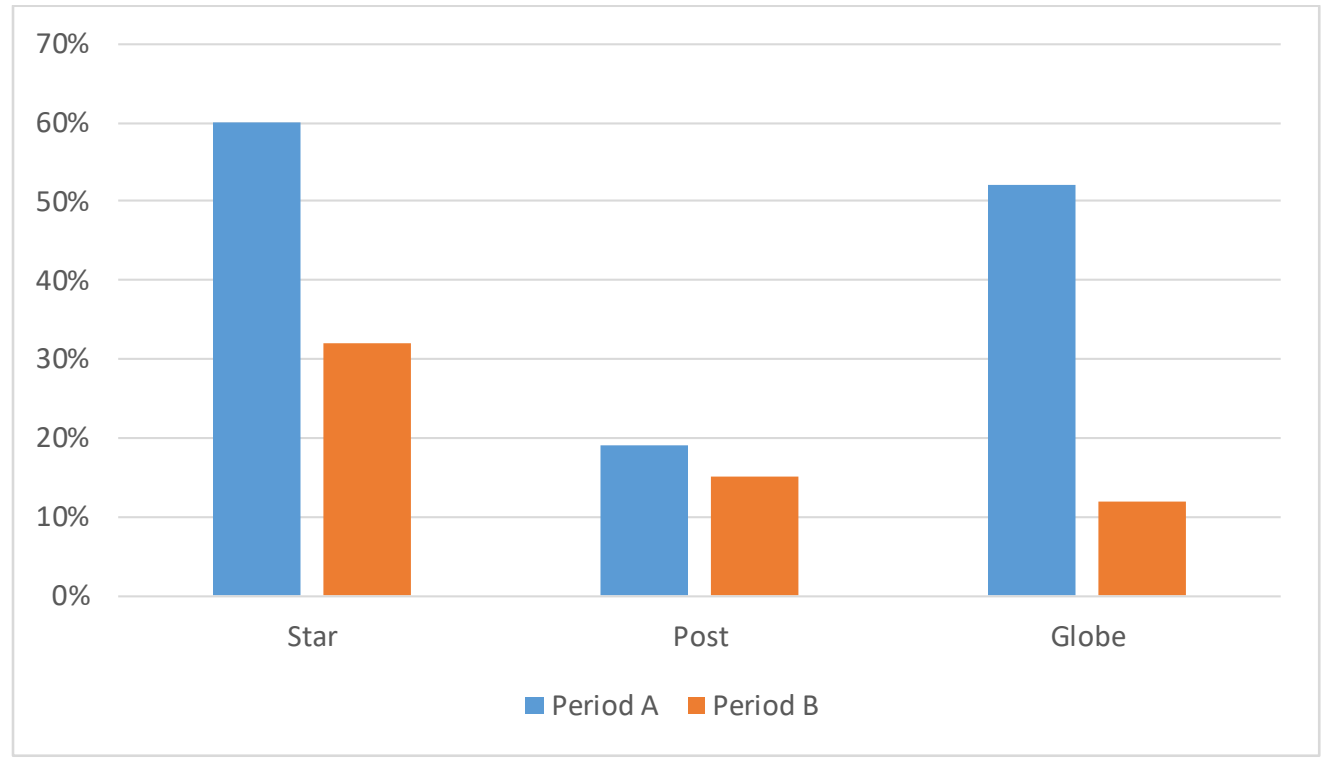

Figure 7.3: Frequency if the labour market supply problematization by newspaper in both periods

\section{Public problematization}

Childcare was presented as a public problem, whereby the government is positioned as the ideal leader/funder of high quality, affordable childcare services more frequently in all of the papers in Period B. As figure 7.4 illustrates, the public problematization increased $44 \%$ in The Star (41\% in Period A and $85 \%$ in Period B), $15 \%$ in The Post (26\% in Period A and $41 \%$ in Period B) and 24\% in The Globe (59\% in Period A and 35\% in Period B). This problematization is best articulated in a quote authored by Globe columnist Leah McLaren in the month before 
Election Day 2015: “Child care is not a women's issue. It's not even a family issue. Like health care or education, it's an all-of-us-in-it-togetherissue"(McLaren, 04 Sep, 2015).

Before discussing the large increase in this problematization in period $\mathrm{B}$, it is important to note when this problematization emerged in Period A. In 2008 and 2011 (federal election years) there was some discussion of national childcare policy as the Liberals had promised to increase funding to licensed childcare facilities in order to grow capacity. For example, one Star article written by a childcare advocate recommends "accountability for results through a focused public investment strategy that provides direct funding to child-care services" (Anderson, 2008, Jul 9). In 2011, health reporter for the Star Diane Zlomistic reported that "The Liberals have vowed to create a high-quality, affordable early childhood learning care space for every Canadian family that wants one" (Zlomistic, 2011, Apr 9).

Throughout the rest of the period, The Star appears to have made an explicit effort to stimulate discussion of childcare policy as a pressing public issue by including a handful of guest pieces directly from childcare advocates involved at various levels of government (i.e., (Anderson, 2008, Jul 9; Friendly, 2014, Jan 14; Friendly \& Rothman, 2009, Jan 8; McCuaig, 2011, Jul 30; Pascal, 2012, May 25). Titles of these articles include "Market failure and child care" (Anderson, 2008, Jul 9), "Budget memo on childcare-Canada can't work without it" (Friendly \& Rothman, 2009, Jan 8) and "Not on the backs of children-the economic case against cutting city services to children" (McCuaig, 2011, Jul 30). Many of these guest opinion 
pieces concurrently drew on the economic problematization of childcare situating the economy as the primary reason why childcare is a pressing concern of public policy.

There were also a handful of articles in The Globe and The Star that conceptualized the work/life balance struggles of women as a problem in need of a public childcare solution. One example was titled Mommy Dearest and published on Mother's Day 2008 (Anderssen, 2011, May 7). In 2013, as part of the special series on childcare run in The Globe, social policy reporter Erin Anderssen published an article titled "The case for publicly funded child care" (Anderssen, 2013, Oct 21) in which nearly 3000 words were devoted to supporting childcare as a public problem in need of a public solution.

The public problematization of childcare also emerged poignantly in relation to several infant and toddler deaths in unlicensed home daycares in Ontario in Period A. When reporting on these deaths, both The Star and The Globe clearly articulated an urgent need for government leadership at both the provincial and/or federal levels. In The Star childcare policy expert Maratha Friendly's response to the $3^{\text {rd }}$ death in an unlicensed childcare home within a few months is quoted: "We don't see child care as a public good or a public service. And that is the core problem" (Monsebraaten, 2013, Jul 12). Another Star article by Martha Friendly (referring to a different death) is titled: "Death by indifference: The government's failure to build a child care system has again proved fatal "(Friendly, 2014, Jan 14). In The Globe, an NDP critic for children and youth is quoted by a Canadian Press journalist saying: "Well, the Ministry didn't do 
the job right the first time, so we need to make sure we get it right" (Babbage, 2013, Jul 2013) ${ }^{43}$. When tragedy struck, the positioning of childcare as a public problem in need of a public solution emerged.

The articles in The Post that problematized childcare from a public perspective during period A were often letters-to-the editor or guest opinion pieces countering the private/family and/or market problematization of childcare. One childcare advocate responded to Andrea Mzorek assertion that "a national daycare system is trulypassê" (Mrozek, 2008, Oct 9) with "Mzorek's assertion is ridiculous - she should try telling that to parents in Sweden, Denmark, France or Norway where national systems of early learning and childcare have been popular cornerstones of their social policy for more than 30 years" (Ferns, 2008, Oct 10).

The large jump in the public problematization of childcare in Canada from Period A to Period B can be tied mainly to the NDP's $\$ 15 /$ day national childcare policy proposal. This was a policy rooted in a public problematization of the issue with a public solution as both funding and leadership was being promised. Some examples of this problematization in The Star include: "The result [of the NDP childcare plan] would be a comprehensive \$15/day program along the lines of the Quebec system" (Hebert, 2015, Sept 3) and "Mulcair is promising a full-blown, multi-billion dollars, national daycare policy aimed at creating 370, 000 new spaces over the

${ }^{43}$ The Post did report on the child deaths in unregulated childcare centres, but the articles were not included in my data as they did not meet the search criteria (i.e., "child care" and "policy"). For comparison's sake I reviewed these articles and found that the owners/operators, rather than the Ministry, was more likely to be blamed for the tragedies (perhaps also the reason the word "policy" or a derivative of this word was not included in the text). 
same period" (Walkom, 2015, Jan 29). An editorial authored by The Globe states: "The NDP wants to spend $\$ 5$ billion to create a national child care strategy [because they] believe that government incentives can create the most effective, and cost-effective, daycare program" (Globe and Mail, 2015, Apr 4). Simply stated in Globe columnist Leah McLaren: “Access to affordable early childhood education and child care is a public good" (McLaren, 2015, Sept 4).

Other events in Ontario, such as an Ombudsman's report highlighting government ineptitude in the childcare sector resulting in several children's deaths, can also be linked to the public problematization of the issue in Period B. An article by Star social justice reporter Monsebraaten in October 2014 (shortly after the Ombudsman's report was released), quotes a childcare advocate [Martha Friendly] criticizing the prevailing hands-off approach of the government:

Governments have known for decades that there is a whole underground system in childcare that they have actively chosen to ignore... The fact that they have chosen not to look at it for so long is [because] they haven't wanted to pay for the licensed childcare system families need (Monsebraaten, Marco, \& Ballingal, 2014)

In the same article, provincial NDP children and youth services critic is quoted as saying there is a " need for a licensed, not-for-profitchild care system in Ontario so that no family is forced to turn to illegal daycare" (Monsebraaten et al., 2014). There were also four articles published in The Star that discussed childcare policy as a component of Olivia Chow's policy platform in Toronto's 2015 municipal election. 
The public problematization of childcare was not as frequent in The Post. However, given the centrality of the NDP childcare platform leading up to and during the federal election campaign, this paper was required to at least address this problematization - even if rejecting it was the purpose of most articles. For example, Post columnist Stephen Maher states: “...the NDP is promising to keep the UCCB and start a national daycare program, relying on a pixiedust powered money-creating machine to presumably be revealed during the campaign" (Maher, 2015, Jul 21). Later in the year an editorial published by The Post states: “...progressives insist that only universal, government funded daycare in licensed not-for-profit centres will do" (The National Post, 2015, Sept 25). An article by another Post columnist notes "the party [NDP] is already committed to a $\$ 5$ billion childcare program" describing this program as "bold to the point of foolhardiness" (Ivison, 2015, Jan 16). At the same time, the paper did include an article written by childcare expert and advocate Martha Friendly. She made the case that "A Canadawide childcare program is best based on building - over time - a system of affordable, quality services supported directly by public funding" (Friendly, 2014, Aug 4).

Overall, it appears that childcare was broadly positioned as a public problem in Period B, while the specific reasons why childcare is usually associated with being a public responsibility (i.e., women's equity, children's well-being, poverty reduction, economic growth problematizations etc....) were less pronounced than in Period A. With a national childcare policy proposal on the table by the official opposition during the 2015 election, the bigger question of the role of the state in addressing the childcare problem became a focus. 


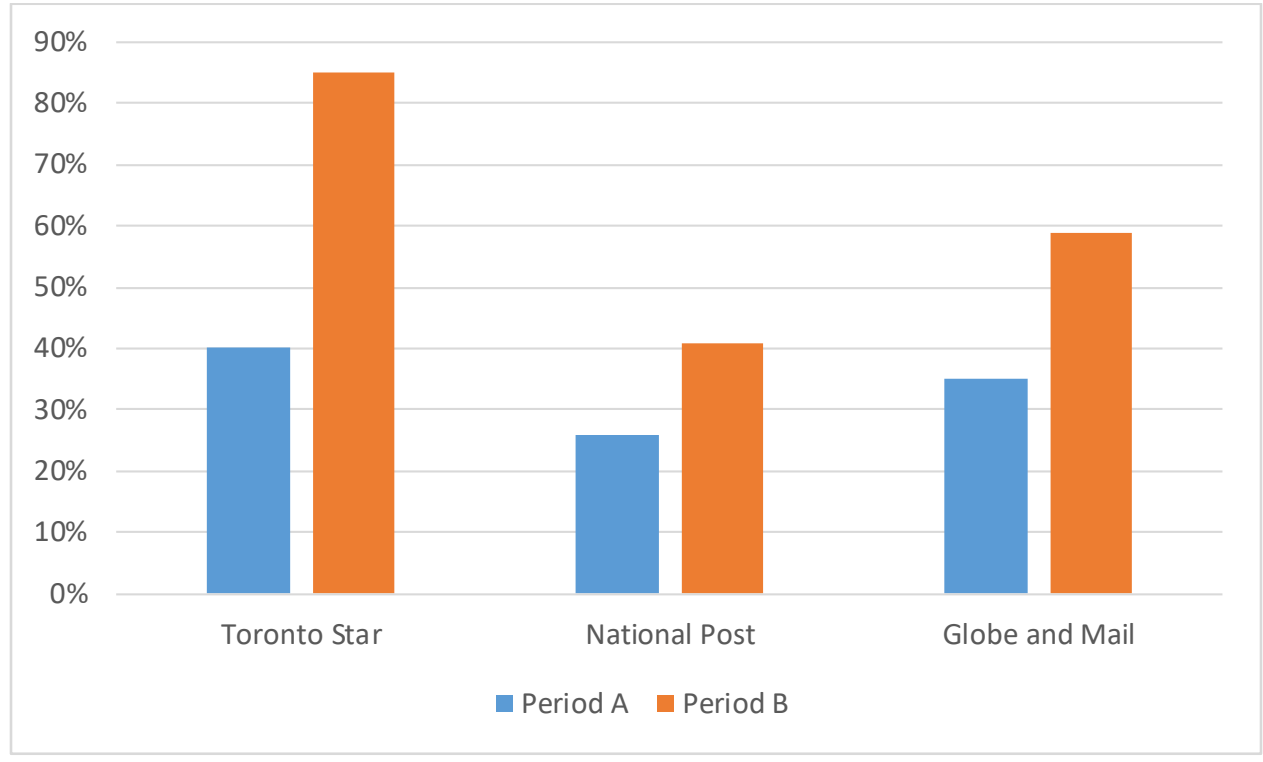

Figure 7.4: Frequency of the public problematization by newspaper and time period

\section{Women's equity problematization}

Figure 7.5 illustrates that childcare was discussed as a women's equity problem more frequently in all papers in Period A than Period B, on average falling from $32 \%$ in Period A to $17 \%$ in Period B. When the data are disaggregated by paper, this decrease remains across all papers - although it is most pronounced in The Globe, dropping from $42 \%$ of articles in period A to $16 \%$ of articles in Period B. The Star, rather than The Globe, was most likely to include this problematization in Period B. This problematization was never emphasized in The Post, though here it also dropped from $16 \%$ to $11 \%$. 
Articles in The Globe in Period A were most likely to explicitly embrace a gendered lens in the title of articles. For example, some Globe titles include "The Mother Load" (Onstad, 2012, Dec 28), "From the House to crèche, women are still juggling bébé and work" (Renzetti, 2012, Feb 11) and "Canadian mothers waiting for more help" (Adshade, 2011, Dec 1). While The Star was also likely to draw on a women's equity problematization of childcare, this was usually done more subtly in the text rather than in the title of the article. For example, Star reporter Monsebraaten refers to the UNCIEF 2008 Report Card to suggest that "high-qualitychildcare has the potential to boost school success and enhance the cognitive, emotional and social development of children, as well as advance women's equality and mitigate the effects of poverty" (Monsebraaten, 2008, Dec 11).

Several of the references to the women's equity problematization of childcare in Period A (again mainly in The Globe and The Star) directly quoted mothers who publicly shared their own experiences of how childcare was impacting their lives. Monserbraaten quoted a mother expressing gratitude that her husband's work schedule allowed her to pick up the "odd part time shift", but she goes on to say "with child care I could do so much more" (Monsebraaten, 2008, Dec 11). Similarly a mother in The Globe was quoted by Anderssen saying: "For myself and my friends, we're professional, educated women who want to do the jobs we were trained for and think we are good at.... if we don't have access to care, we can't contribute" (Anderssen, 2013, Oct 21). Globe columnist Katrina Onstad situated herself in the struggle: "motherhood in 2012 was infuriating, but mostly, exhaustingly unresolved" (Onstad, 2012, Dec 28). Other articles in these papers illustrate the frustration of mothers more broadly. For example, previous Star 
reporter Alison Cross states: "There seems to be a lot of talk amongst policy-makers about childcare, but not a lot of talk that includes mothers...Mothers across this city [Toronto] are frustrated with the state of child care" (Cross, 2011, May 9). The voices of individual women and/or mothers were notably absent from the discussion in Period B.

There were also a couple of high profile cases in Period A that brought attention to the issue of childcare from a women's equity perspective. In 2012, a female MP returned to the House of Commons 3 weeks after giving birth. She brought attention to the childcare issue as she struggled to be present in the House while needing to frequently nurse her infant. Globe columnist Renzetti picked up the story quoting the MP: “We don't want privileges, we want to be able to work and take care of our families" (Renzetti, 2012, Feb 11). In another high profile case, a mother working for the Canada Border and Security Agency (CBSA) was denied her request to work daytime shifts (her son's childcare centre was not open overnight hours). This mother challenged the CBSA's solution of reducing her to part-time hours with fixed daytime shifts so she could manage her childcare needs. While the case proceeded through the court system, a Star editorial noted the CBSA's response of reducing her to part-time fixed shifts 
would “...have hurt her chance of promotion, training, pension and other benefits" 44 (The Toronto Star, 2013, Feb 7).

In both periods The Star was most likely to highlight research and statistics to indicate that childcare is an essential part of women's equal participation in society. For example, in Period A a Star editorial claimed that " $23 \%$ of mother-led families still have incomes below the poverty line" (Zerbisias, 2011, Apr 3) while another anonymous article noted "70\% of mothers with a child under two work full-time" (Anonymous, 2011, Feb 8). The voices of childcare advocates also emerged in an invited article written by researcher and academic Charles Pascal. He noted Quebec's publicly funded childcare system resulted in "70 000 more women with young children entering the workforce who would not otherwise have been working" (Pascal, 2012, May 25). Similarly, Star columnist Heather Mallick noted: “70.5\% of mothers with school-age children worked outside the home" (Mallick, 2012, Jun 23). In Period B, a Star editorial reported that "almost $75 \%$ of mothers of young children are in the workforce, while licenced spots existfor just $22 \%$ of children under 5" (The Toronto Star, 2014, Nov 17) and the Work and Wealth reporter noted "research compiled by Pierre Fortin, up to $86 \%$ of mothers have now joined Quebec's labour force" (Mojtehedzadeh, 2014, Oct 26). Finally, Monsebraaten pointed out that

\footnotetext{
${ }^{44}$ In the end, this mother won her case on the grounds of family status discrimination and the CBSA was ordered to pay her back wages and accommodate her childcare needs.
} 
"[childcare] fees are worth $36 \%$ of a woman's income according to a recent study by the Canadian Centre for Policy Alternatives" (Monsebraaten, 2015, Aug 1).

While The Globe did draw on some of these same statistics, it did so far less frequently in both time periods. Research and statistics suggesting that publicly funded and delivered childcare was a women's equity issue were absent entirely in The Post. Instead, one Post columnist in Period A reported that "the public opinion poll found $76 \%$ of respondents believe it is best that children under six be home with a parent" (Edmiston, 2013, May23). In Period B, the idea that publicly funded childcare supported women's ability to equally participate in society was conceded in an article by columnist Stephen Gordon (the growing body of demographic and empirical research was getting difficult to ignore) but was positioned as occurring at the expense of children. This is evident in the title of one article: "The daycare trade-off: Universal childcare lets more women go to work, but could have a negative effect on their children" (Gordon, 2015, Sept 29).

Two articles in Period B provide one possible explanation as to why the women's equity problematization of childcare faded into the background in Period B. One Star columnist states:

There was a time when early childhood education was a fancy name for daycare. Women knew they couldn't convince politicians to support working mothers, so they made the case that investing in children was good public policy....early learning was no longer ghettoized as a women's issue (Goar, 2009, Jun 22). 
Similarly in 2015, Globe reporter Erin Anderssen argued that:

Good child care, for instance, can't be cast as a 'woman's issue'or sold as a work-life balance solution for stressed-out suburbanites: It's an essential economic and social policy to level the playing field"(Anderssen, 17 April 2015).

Finally, a Post reporter quoted a lawyer denying that childcare was a women's equity issue: “This [child care] is not a women's issue. To characterize it as a women's issue is a form of sexism" (Boesveld, 2015, Sep 22). This sentiment is never explained or elaborated on in the article.

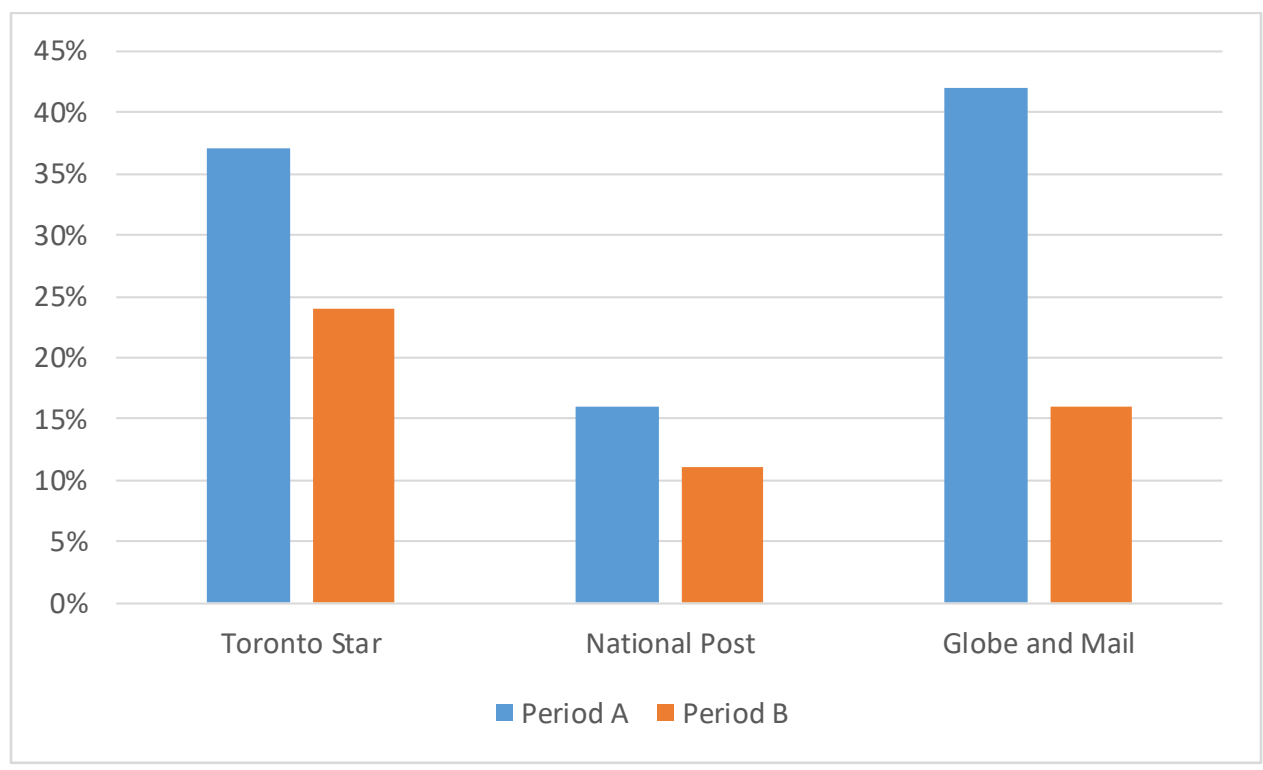

Figure 7.5: Frequency of the women's equity problematization by newspaper and time period 


\section{Not a problem}

That the lack of childcare in Canada was "not a problem" was more common in period A, occurring in an average of $24 \%$ of articles (compared to $7 \%$ in period B). This problematization was most common in The Post where almost $40 \%$ of articles in Period A denied the childcare problem in Canada. This was halved in Period B when only $19 \%$ of Post articles overtly denied the problem (see Figure 7.6 above).

The Post often argued that childcare policies were fine as they were. For example, one Post reporter suggests "...universal preschool is a "windfall" for middle-class families who are fine on their own" (Alcoba, 2009, Jun 20) while Andrea Mrozek claims "the idea of a national daycare system is truly passé" (Mrozek, 2008, Oct 9). Another approach taken in The Post was to draw on international comparisons to demonstrate that childcare policy in Canada was effective. An invited article by Himmelstrand (who has close links to the IMFC Canada) compares Canada to Sweden, noting the "social toll Sweden's childcare system is taking" and linking it to "psychosomatic disorders and mild psychological problems" (Himmelstrand, 2011, Apr 26). In another article, a Post reporter refers to Quebec's \$7/day childcare system “bad policy” on the grounds that "universal daycare for all ends up subsidizing even the rich who can afford to pay the full freight for childcare" (Milke \& McMahon, 2012, May 28). Finally, Post columnist Libin praises Prime Minister Harper's lack of interest in childcare policy: “his child-care allowance has effectively thwarted attempts by Ottawa to encroach on provincial education policy" (Libin, 2011, Oct 28). 
When this problematization emerged in The Star, it was typically acknowledged and then challenged. For example, a Star editorial quoted and challenged a private daycare operator who argued "we don't have any problem" (Marco Chown, 2013, Nov 30), as well as contested one Conservative MP's sentiment that suggested childcare policy was an irrelevant idea from "some old white guy" (Zerbisias, 2011, Apr 3). In other cases, Star articles contrasted opinions of different stakeholders. For example, an anonymous Star article quoted a parent who says: "if government was to be involved [in childcare] then the only way is to reduce the taxes on parents" (Anonymous, 2011, Feb 12). This statement effectively deflects government involvement in childcare to income tax policy.

In Period B, the childcare problem in Canada was rarely denied, though some Post columnists continued to reject the problem. One article authored by Post economist and columnist William Watson argued “the government doesn't need to do this [establish the \$15/day childcare plan] as Canadian parents currently find daycare for their children or provide it themselves" (Watson, 2015, Oct 15). Another invited comment piece in The Post by Andrea Mrozek mocks childcare supporters/income-splitting critics point that "the benefits [of income splitting] also go to couples where the nonworking spouse is pursuing hobbies, socializing, homemaker and other activities not directly related to childcare" (Mrozek, 2015, Mar 30). Here Mrozek draws on a classic political gaffe in the 2006 federal election whereby a Liberal campaign strategist (supporting childcare policy) indirectly and inadvertently accused parents of spending the UCCB money on beer and popcorn. Mrozek asserts: "Pursuing hobbies! Socializing! Might there be some beer and popcorn involved?" (Mrozek, 2015, Mar 30). 


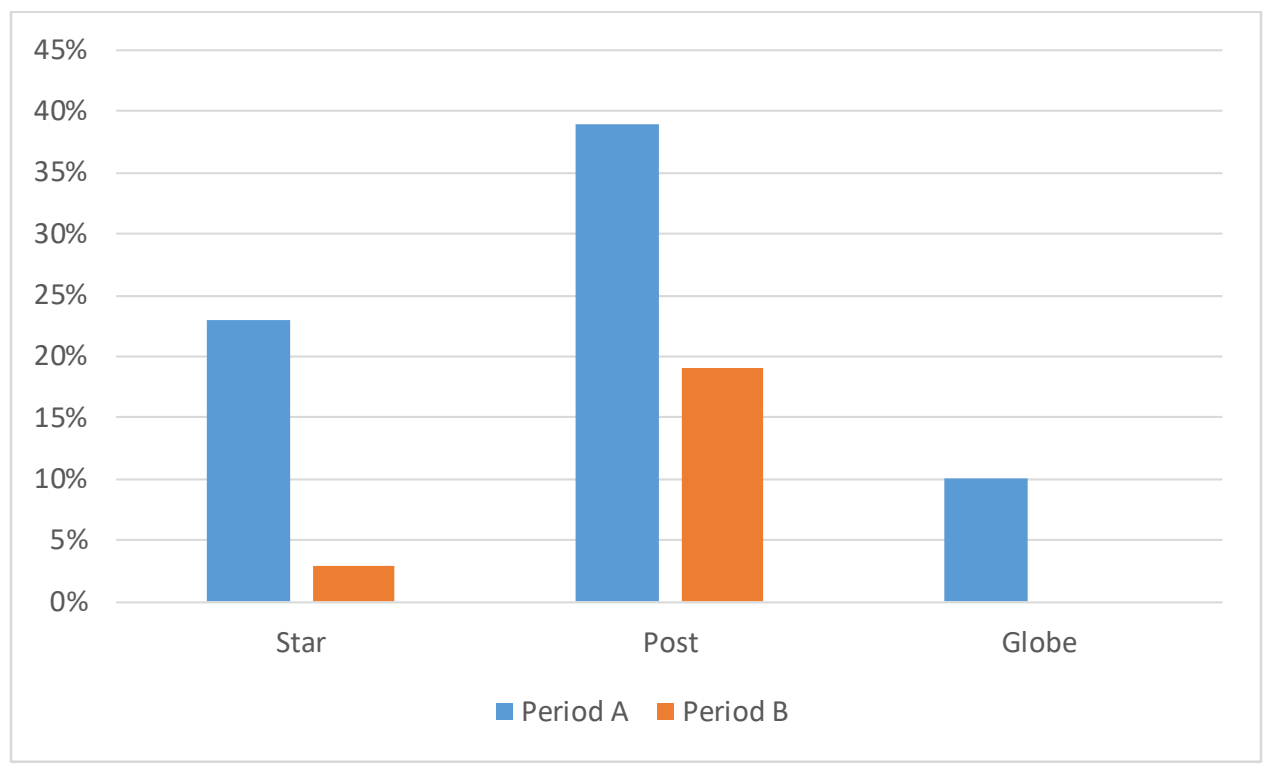

Figure 7.6: Frequency of the "not a problem" problematization by newspaper and time period

\section{Child well-being problematization}

Like the women's equity problematization, the children's well-being problematization was also much less likely to be emphasized in Period B than Period A (see Figure 7.7). On average, this problematization was evident in an average of $32 \%$ of articles in Period A and fell to just 9\% of articles in Period B. When data were delineated by newspaper as in Figure 7 this problematization was notably less common in The Globe than the other two papers. In Period A, high quality childcare services were mentioned in reference to "protecting the rights of children in their most vulnerable, formative years" (Monsebraaten, 2008, Dec 11). One columnist in The Globe challenges readers to think of a "system where child-care workers are valued, where children's well-being is valued" (Renzetti, 2012, Feb 11) while another article in The Star authored by an invited childcare advocate crunches number to conclude that if school boards and 
childcare centres worked together "youngsters could have quality care now" (McCuaig \& Murphy, 2013, Aug 17). One article in The Post, argues that "what's really key is for people to keep an eye on the notion that what we need is a high quality environment at home and a high quality environment when kids are outside the home" (Alcoba, 2009, Jun 20). Another Post comment piece authored by a childcare advocates argues that "young children can and do thrive in enriching environments outside their homes" (Rothman et al., 2011, Feb 11).

In Period B, the idea that the lack of childcare in Canada is a problem for the well-being of children was absent in the large majority of articles. When it did emerge in Period B, it was usually in The Star and the articles were typically focused on government at the provincial or municipal level. For example, The Star's Monsebraaten quotes the Ontario Ombudsman who condemned the government for not taking more of a leadership role in protecting the well-being of young children being cared for outside of the home: "Stakes in the childcare system are high. Mistakes put the lives and welfare of young children at risk" (Monsebraaten et al., 2014). While children's well-being was mentioned in The Post, high quality childcare was never presented as the solution. Instead, the private/family solution - whereby families stay at home with their children - was considered to be the solution to maximizing children's well-being. 


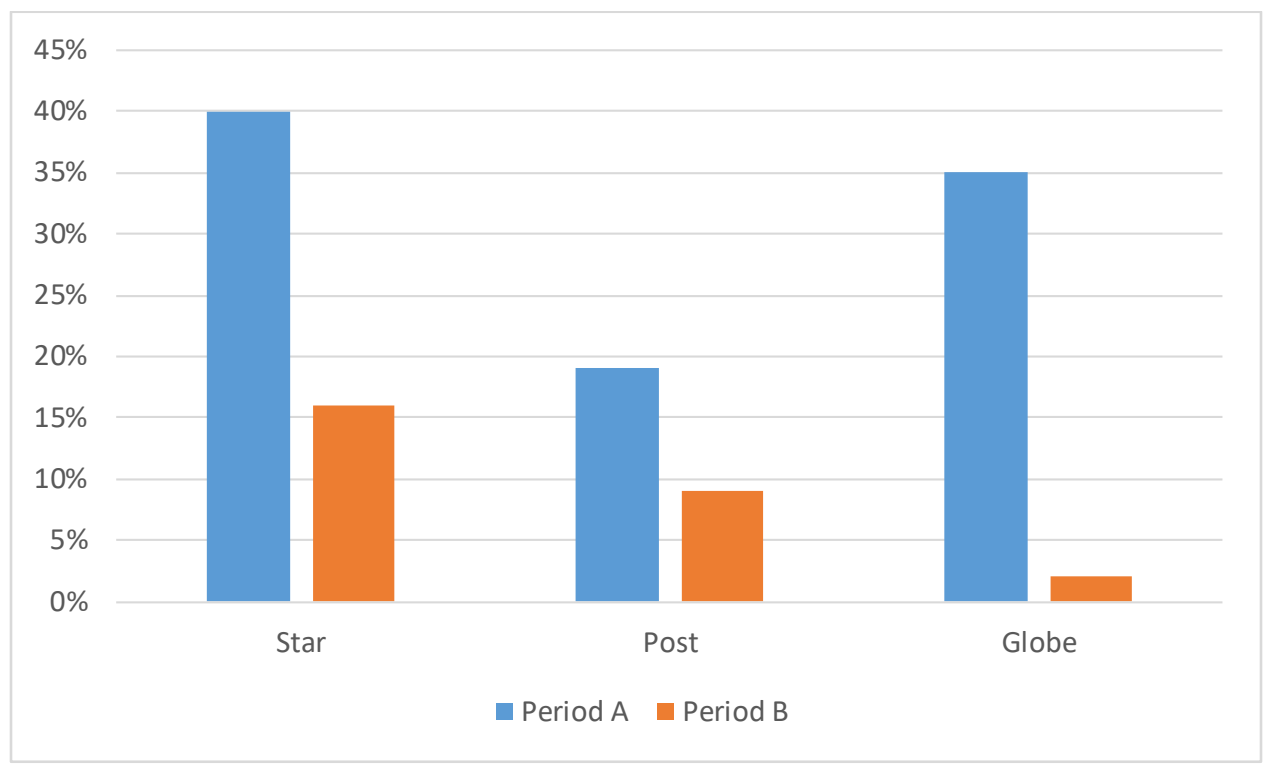

Figure 7.7: Frequency of the children's well-being problematization by newspaper and time period

\section{Economic problematization}

Like the other less common problematizations, the economic case for childcare was downplayed in Period B compared to Period A. The economic problematization was most common in The Star in both periods, although it was most pronounced in Period A as illustrated in Figure 7.8. It was also most likely to be highlighted in the title of articles in The Star in Period A. Examples of this include Star columnist Goar's "Early learning makes business sense” (Goar, 2009, Jun 22), childcare advocate Martha Friendly's invited piece “Budget memo on childcare; Canada can't work without it" (Friendly, 8 Jan, 2009), research and childcare advocate Kerry McCuaig's "Not on the backs of children: The economic case against cutting city services to children" (McCuaig, 2011, Jul 30) and an editorial authored by The Star "Child care key to economy" (The Toronto Star, 2014, May 13). The economic problematization emerged in The 
Globe, but never in the title of articles. Within their articles Renzetti acknowledged: "Freeing women for work makes economic sense" (Renzetti, 2012, Feb 11), researcher Kevin Milligan argued "new child-care initiatives should focus first on the interventions with the biggest social and economic payoffs" (Milligan, 2013, Oct 24) and reporter Erin Anderssen reiterated "there is a huge economic cost to not having a Canada-wide program for affordable and universal early education" (Anderssen, 2013, Oct 21).

In Period B, the economic problematization significantly faded, disappearing almost entirely. There were a few articles in The Star that brought attention back to childcare as an "economic priority" (Olive, 2015, Sept 28), but overall this problematization was absent in Period B. With the NDP's $\$ 15 /$ day platform, the focus appeared to centre on the economic cost to parents rather than the economic costs and benefits to society with public investment in high quality childcare. 


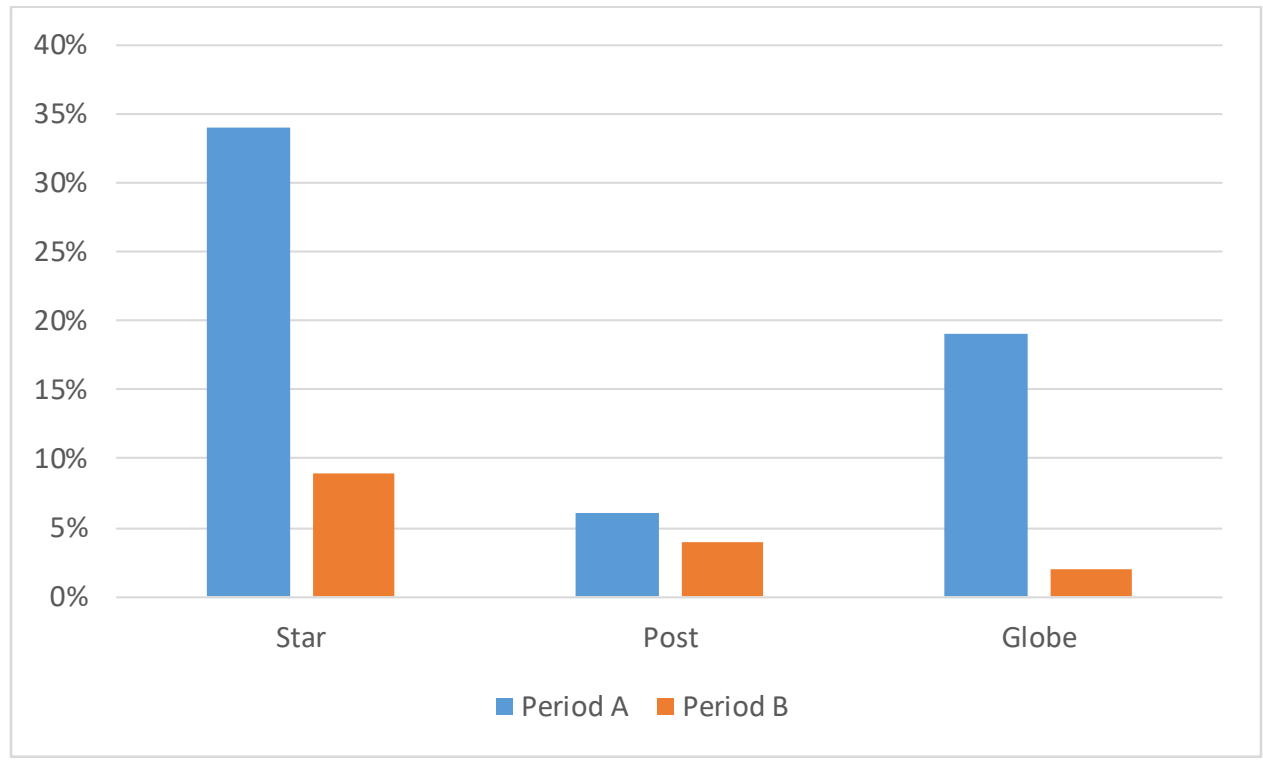

Figure 7.8: Frequency of the economic problematization by newspaper and time period

\section{Human capital problematization}

The human capital problematization became markedly less pronounced, dropping from an average frequency of $20 \%$ in Period A to an average of $6 \%$ in Period B. During Period A, The Star and The Globe frequently put forward the idea that "high-quality child care has the potential to boost school success and enhance the cognitive, emotional and social development of children" (Monsebraaten, 2008, Dec 11) and emphasized the "long-term economic benefits of decreased dropout rates among students" (Hammer, 2010, Sep 7) and the "patterns of malleability" (Goar, 2009, Jun 22) in preschooler's brains. Though less frequently, articles in The Post also acknowledged the human capital problematization. For example, columnist Alcoba concedes that "studies show early childhood education programs improve performance, regardless of socioeconomic background" (Alcoba, 2009, Jun 20). 
In Period B the frequency of this problematization was quartered. As illustrated in Figure 7.9, Star editorials and columnist were most likely to highlight the idea that childcare will “improve children's test scores" (The Toronto Star, 2015, May 7), “improve their [children's] future employment prospects" (The Toronto Star, 2015, May 16) and be an "important part of human capital development" (Mojtehedzadeh, 2014, Oct 26). The Star's Monsebraaten also pointed out that "provinces are recognizing the education benefits of early learning and childcare" (Monsebraaten, 2014, Nov 3) with the implication being that the federal government should also take a leadership role in childcare policy.

In Period B Post general assignment reporter Boseveld discusses the potential merits and downfalls of full-day kindergarten whereby the human capital rationale takes centre-stage. This article suggests that FDK “boosts children's engagement, vocabularies and social-emotional skills", that "kids are more primed for learning" and links it to "overall academic and social outcomes into adulthood" (Boesveld, 2015, Jun 23). A letter-to-the-editor in The Post, written by a Union representative, also emphasizes childcare's "positive impact on children" (Moist, 2015, Aug 13). Only a couple articles in The Globe in period B include this problematization. For example, along with several other questions embracing other problematizations, columnist Renzetti asks: "Do we want kids to feel they have a running start? (Renzetti, 2014, Oct 25). Overall, the human capital problematization was significantly downplayed in all papers in Period B, emerging most in The Star, occasionally in The Post and rarely in The Globe. 


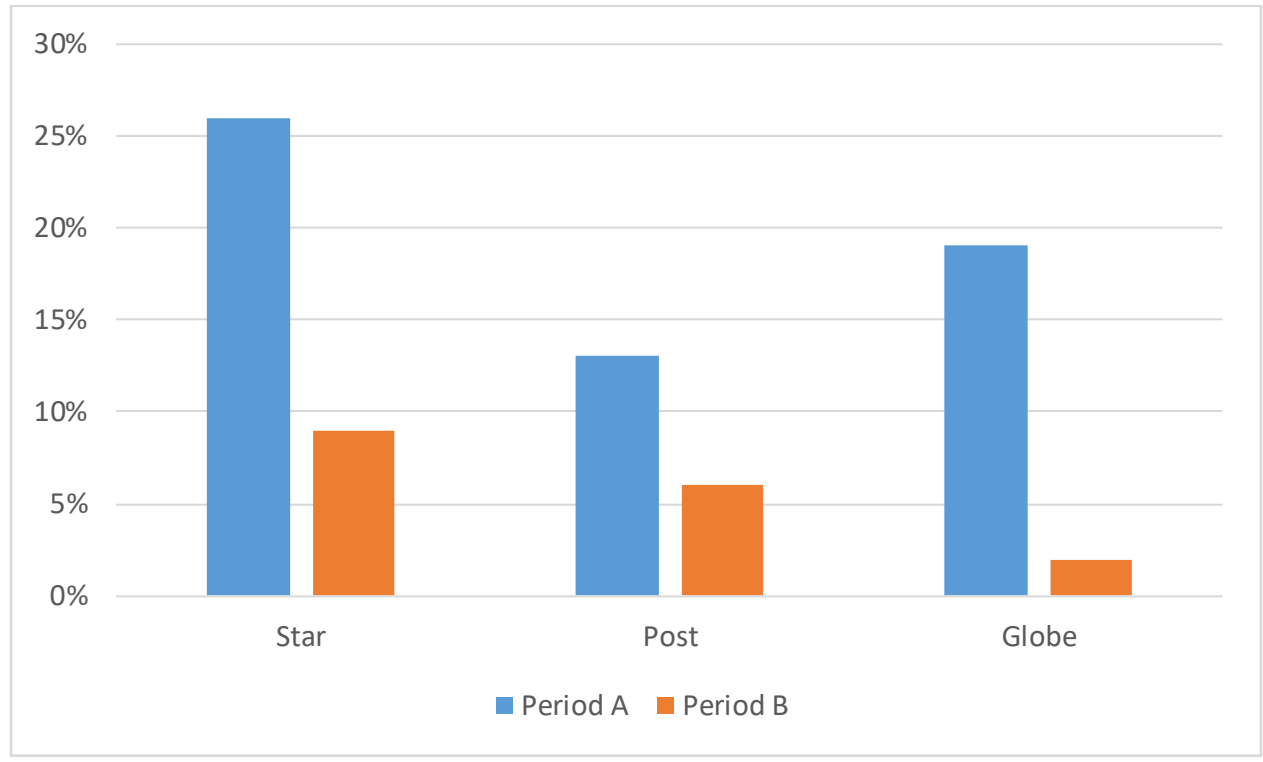

Figure 7.9: Frequency of the human capital problematization by newspaper and time period

\section{ECEC workforce problematization}

An essential component of examining childcare policy from a feminist perspective involves consideration of the overwhelmingly female, often young, classed and racialized childcare workforce. As has already been illustrated in Figure 7.5, childcare was likely to be discussed as a women's equity problem in Period A and not Period B. Figure 7.10 illustrates there was a similar drop in the discussion of childcare policy as a problem for the predominantly female, underpaid workforce. While both The Star and The Globe discussed the childcare workforce in period A ( $29 \%$ and 19\% respectively), this problematization seldom arose in period B (5\% and 2\%). In The Post, the ECEC workforce was rarely mentioned in either time period $6 \%$ in Period A and 4\% in Period B. 
A quote from The Globe's Renzetti in Period A articulates the critical link between childcare as a women's equity and a workforce issue: "If the government invested in a system where childcare workers are valued, where children's well-being is valued, and - this is crucial-women's ability to work without bankrupting themselves or losing their sanity is also valued..." (Renzetti, 2012, Feb 11). Similarly, Globe columnist and economist Marina Adshade notes "In the US, the growing divide between the wealthy and poor has created both a class of women who can afford to hire help in their homes and a pool of workers who are willing to provide it cheaply" (Adshade, 2011, Dec 1).

Most of the references to the childcare workforce occurred in the Star and were related to the infant death tragedies occurring in unregulated childcare homes, the implementation of FDK and in Period B, and the $\$ 2 /$ hour wage enhancement grant for childcare workers implemented by Ontario Premier Kathleen Wynne. Close to the 2015 election, The Star's Monsebraaten does quote a parent who brings attention to the childcare workforce "Amaral [a mother] is against paying parents money to hire nannies and other non-regulated care. Instead, she says, funds should go toward building high-quality daycares, paying workers better salaries and keeping fees low" (Monsebraaten, 2015, Oct 11). 


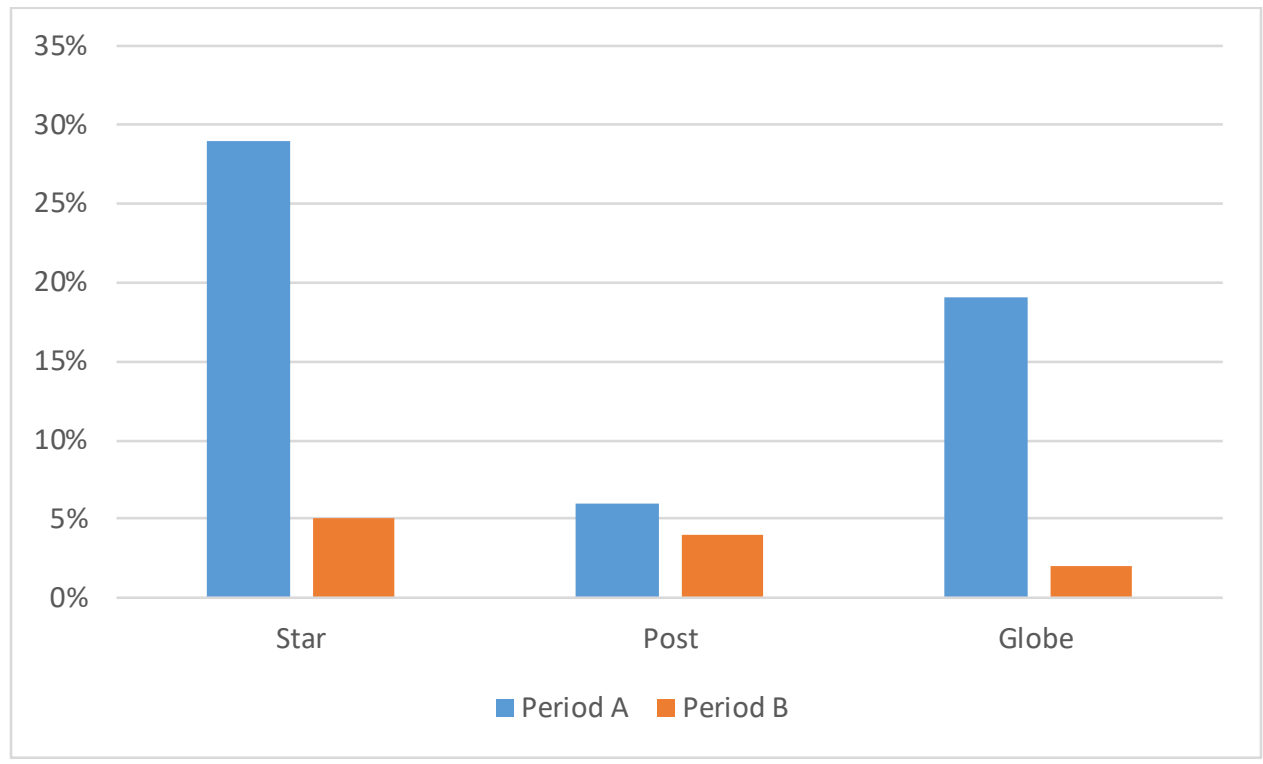

Figure 7.10: Frequency of the childcare workforce problematization by newspaper and time period

\section{Family equity problematization}

Like most of the other problematizations discussed thus far, the family equity problematizations surfaced less frequently in Period B. As illustrated in Figure 7.11, this problematization arose less in The Post overall, though it was present more in The Post than The Globe in Period B. While the frequency of this problematization was higher in Period A, many of the references to this problematization were brief and abstract, mentioned only in passing whereby "families" were one of several stakeholder groups. For example, an anonymous article in The Star suggests "child care in Ontario is an incomprehensible patchwork of policy...that does not work for families, providers, workers or the government" (Anonymous, 2008, Jun 20). Also in Period A, childcare advocate Lynell Anderson suggests the lack of childcare in Canada is "failing children, women, families and communities" (Anderson, 2008, Jul 9) while Star 
columnist Antonia Zerbisias refers to the lack of childcare as a "directattack on women and families" (Zerbisias, 2011, Apr 3). Making a similar point through a more positive tone, Star investigator Sue Bailey suggests "if we really want to have good quality early education and care programs for children and families, there has to be public policy and public money" (Bailey, 2008, Apr 11).

In Period B, most of the references to this problematization lacked depth, failing to strongly situate publicly supported childcare as a solution to the growing inequity between families with and without children. The Star's education reporter Kristin Rushowy problematizes the "huge gap in early childhood services that has provinces scrambling to 'fill the void' for families for three years until kids starts school" (Rushowy, 2014, Nov 12) while a financial columnist suggests that Tom Mulcair has been "scoring points with families with young children by promising to create a million daycare spaces" (Pape, 2015, Oct 10). Globe political columnist Campbell Clark tended to matter-of-factly relay the messages of political parties who claimed to be acting in the best interest of Canadian families. The Globe discussed the Liberals CCB in the context of childcare policy noting it will deliver "more to families" than the Conservative's UCCB which was said to "help all families" (Clark, 2015, May 11).

This idea that the UCCB "helped every single family in the country" (Coyne, 2015, May 23) was frequently drawn upon in The Post. Very much in line with the Conservative Party's messaging, economist and Post columnist John Ivison describes "families with children" as being “on the receiving end of the Harper governments' largess in the form of $\$ 3$ billion of 
enhanced UCCB" (Ivison, 2015, Jul 15). References to UCCB as the ideal solution to the lack of childcare problem in Canada was rarely critically deconstructed or elaborated on in The Post, whereas both The Star and The Globe were more likely to challenge the idea that equity can be achieved by supporting "all families" in the same way.

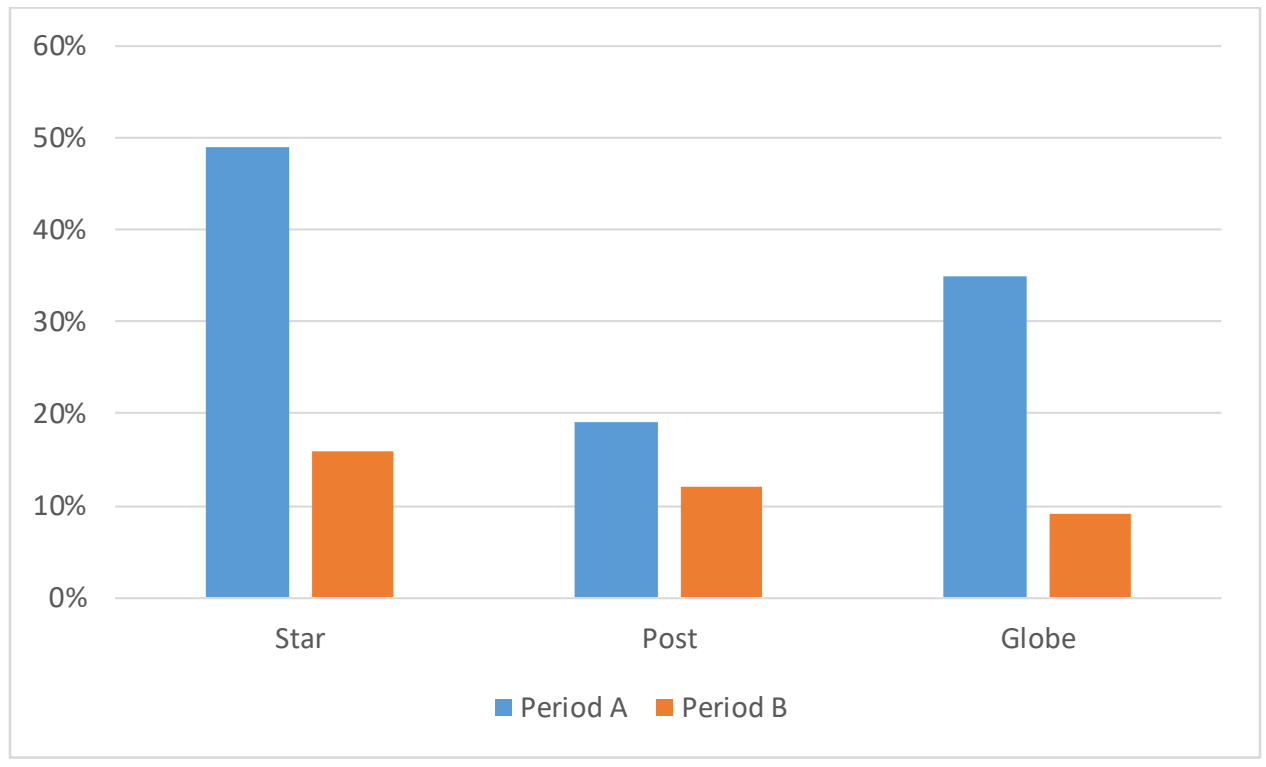

Figure 7.11: Frequency of the family equity problematization by newspaper and time period

\section{Poverty reduction problematization}

That the lack of childcare in Canada is a problem because it perpetuates poverty was evident in almost a third of articles in The Star and The Post in Period A. Figure 7.12 illustrates that this problematization dropped significantly in The Post in Period B, but not in The Star. The poverty problematization was never dominant in The Globe though it emerged more in Period A than period B. An early, anonymous article in The Star credits Quebec's universal childcare model for "reducing poverty in the past decade" (Anonymous, 2008, Dec 8) while other articles more 
generally noted the potential of high quality, affordable childcare to "mitigate poverty"

(Monsebraaten, 2008, Dec 11). When a news items pertaining to cuts to childcare centres appeared in The Star, an opinion piece by childcare advocate McCuaig made the argument that “child-care programs serve some of our most vulnerable families" (McCuaig, 2011, Jul 30) while an anonymous article furthered the idea that "it would not make sense to hurt struggling low-income parents who need childcare to upgrade education and hold on to low-paying jobs" (Anonymous, 2010, Oct 31).

Post articles in Period A appear to acknowledge that public support for childcare may help families escape poverty, but this was typically coupled with policy solutions that emphasized targeted rather than universal services. Rejecting the universal, \$7/day Quebec program, the Post article by columnist Taylor argued it is "better to target scarce resources toward families that really need the support" (Taylor, 2009, May 19). Another Post reporter suggested that "early childhood education programs improve performance, although children from low income or single parent homes often reap greater rewards than their wealthier counterparts" (Alcoba, 2009, Jun 20). The Globe also tended to draw on this problematization in relation to targeted childcare policies. One editorial authored by The Globe points out the fact that Quebec's "subsidized low-cost daycare [is] for everyone; those needing a financial leg up and the well-off who don 't" (The Globe and Mail, 2013, Oct 26). Another invited Opinion piece in The Globe by researcher/economist Kevin Milligan suggests that "gains can be found for children from more disadvantaged families, but broad improvements across the spectrum [due to universal childcare] are not evident" (Milligan, 2013, Oct 24). 
Childcare policy as a key solution to reducing poverty appeared most frequently in The Star in Period B. In early November Monsebraaten claimed that "child care is now recognized as a fundamental plank of the anti-poverty movement" (Monsebraaten, 2014, Nov 3) while an editorial authored by The Star highlighted the OECD suggestion that "increasing child-care spaces eases child poverty"(The Toronto Star, 2014, Nov 22). In Period B, The Globe's business reporter Richard Blackwell connected universal childcare to the alleviation of poverty when he said: "The route to go is a national anti-poverty strategy that would include a national homelessness strategy, a national housing strategy and national child-care policy" (Blackwell, 2015, Aug 22).

In Period B, The Post very rarely acknowledged childcare policy as a solution for poverty. On the rare occasions that it did connect poverty reduction to childcare, it again appeared to favour targeted rather than universal programs. For example, columnist Sarah Boseveld states: "it's bringing the people up who you want to be brought up - the most vulnerable - but it's not totally clear the effect it's having for the least vulnerable people" (Boesveld, 2015, Jun 23). 


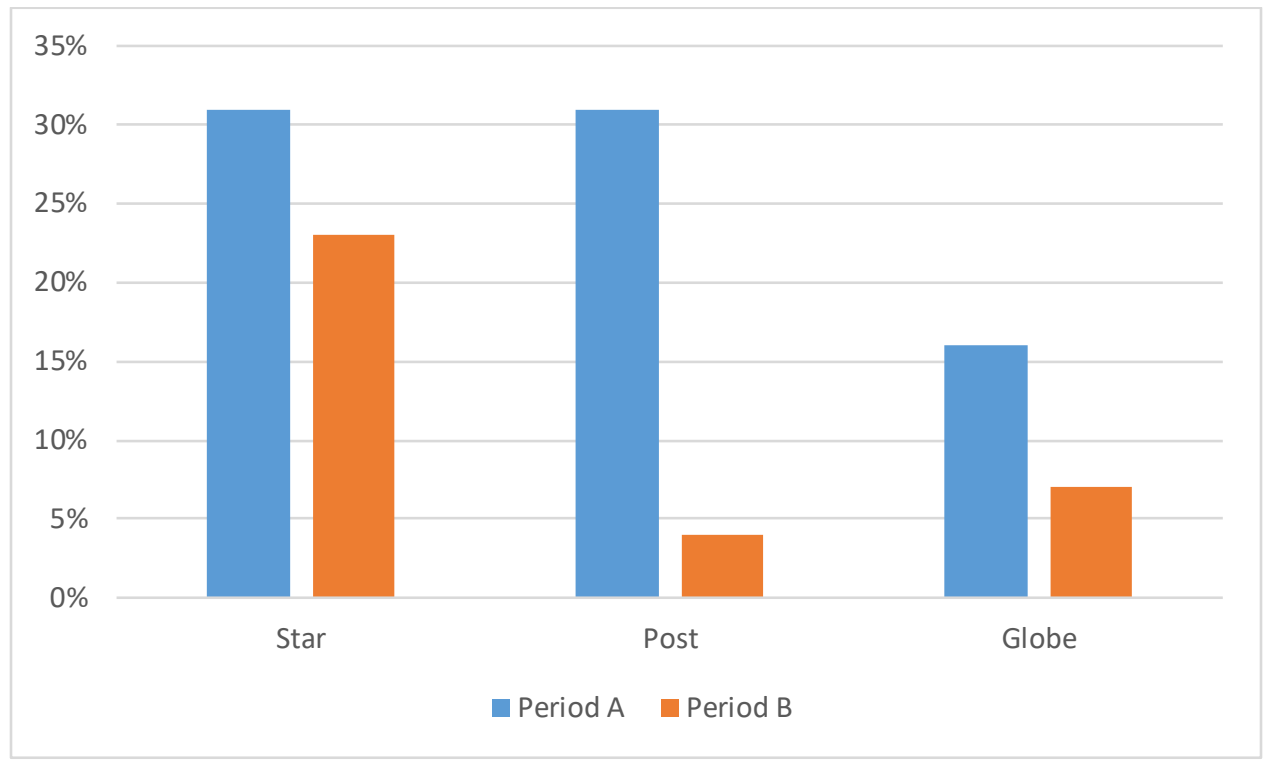

Figure 7.12: Frequency of the poverty problematization by newspaper and time period

\section{Generational equity problematization}

The generational equity problematization was scarce overall, although when it did emerge it was most likely to do so in The Globe in both periods. Researcher Paul Kershaw published an editorial in this paper in 2012 titled: "Forget Occupy, the real divide is generational". This article conceptualized affordable, high quality childcare as the solution to large and growing inequity between "boomers and their kids and grandkids" (Kershaw, 2012, Sep 15). The article explains that young families are "squeezed for child-care services, which often cost the equivalent of another mortgage" (Kershaw, 2012, Sep 15). Another Globe reporter notes the "difference between health-care funding and that of education and childcare is pitting generations against one another" (Bitonti, 2013, Feb 20). 
In Period B, this problematization was even less frequent with only a handful of acknowledgements in all papers. In February 2015, Globe columnist McKenna positioned childcare as a key solution to the fact that "young Canadians are falling further behind their parents and grandparents and grandparents in income and opportunity" (McKenna, 2015, Feb 16). Again researcher Kershaw is quoted recommending the government "focus on the needs of younger workers, through enhanced paid leave and investments in daycare" (McKenna, 2015, Feb 16).

\section{Population growth problematization}

That quality, affordable childcare is an essential component of population health and growth emerged infrequently in both time periods, although like the other problematizations it emerged more in Period A (7\%) than in Period B (2\%). In Period A, an anonymous article in The Star acknowledged "child care and generous parental leave spur population growth" (Anonymous, 2009, Aug 16), while Globe columnist Adshade article focused on childcare as the key solution to Canada's falling birthrate among "educated, working women" (Adshade, 2011, Dec 1). In Period B, the Globe's Rezentti posed the question "Do we actually want young people to keep procreating?"'(Renzetti, 2014, Oct 25).

\section{Social solidarity problematization}

The idea that affordable, high quality childcare is an important element of social cohesion emerged infrequently in both periods. Star columnist Goar (Goar, 2009, Jun 22) suggests that publicly supported childcare act as a "community hub" building bridges across differences while 
an opinion piece (written by childcare advocates) in The Post highlights the potential of inclusive childcare in welcoming newcomer families (Rothman et al., 2011, Feb 11). The Globe's Erin Anderssen notes that a lack of childcare in Canada is "tragic for children and families... and it spills over into our civic life together" (Anderssen, 2013, Oct 21). In period B, the examples are even scarcer. An editorial authored by The Star suggests that national childcare "helps to reduce income inequity and lead to a stronger society" (The Toronto Star, 2014, Nov 17) while an editorial in The Globe quotes a parent saying, "universaldaycare would do a lot more to benefit society as a whole than a bribe to families [referring to income-splitting] (The Globe and Mail, 2014, Nov 8). Outside of these examples, this problematization was significantly downplayed if not outright/y ignored.

\section{Other problematizations}

There were very few "other" problematizations that emerged in reference to childcare policy in Canada. In Period A, only one article (published in The Star) illustrated an alternative problematization that had not been anticipated -the lack of childcare in Canada is a problem from the perspective of Aboriginal Peoples. While this is the only population in Canada with federal funds specifically ear-marked to childcare, Star politics reporter Linda Diebel revealed a lack of oversight as to whether "the programs met federal policy that requires they be 'reasonably comparable' to provincial standards, as well as 'culturallyappropriate' so that aboriginal children won't lose their identity" (Diebel, 2009, Mar 17). In Period B, one article written by The Star's work and wealth reporter noted that childcare as a vital resource for immigrants - particularly women with children - attempting to make a life for themselves in 
Canada. It is stated that a "lack of affordable child care also means [immigrant] women delay getting jobs or training, leaving them with fewer prospects"(Mojtehedzadeh, 2014, Dec 4). Similarly, the Star business reporter Madhavi Acharya-Tom Yew's article mentions both of these problematizations suggesting: "We need better outcomes for aboriginals and immigrants... we need more equable access to affordable child care" (Yew, 2014, Nov 25). 


\section{Chapter 8}

\section{Critical Discourse Analysis of Period B Data}

The purpose of the CDA is to analyze articles in greater depth to appreciate how the childcare problematizations emerged in the patterns observed in the WPR analysis. As described in the methodology section, CDA delves deeper into the content and quality of text to gain insight into the specific text and discourse features that may have contributed to the dominance/absence of the different problematizations. The CDA focuses exclusively on data collected during Period B - a time when national childcare policy re-emerged on the federal policy agenda. Findings are described first on the text level whereby conversationalization, sensationalization, the use of metaphor, nominalization and the use of realis/irrealis statements are discussed. The analysis then moves to the level of discourse practice, where interdiscursivity, intertextuality, modality, approaches to legitimation and existential and propositional assumptions are deconstructed. This chapter relates the analysis to the ideological ideals of neoliberalism, social conservativism, social liberalism and social democratic principles described in Chapter 2.

\section{CDA at the Level of Text Analysis}

\section{Conversationalization and Sensationalization}

The analysis of conversationalization (the use of language normative to a casual communicative environment into a formal communication event) and sensationalization (exaggeration made for rhetorical effect) provides insight into the dominance of the 
private/family problematization in The Post. This paper frequently oversimplifies (or in some cases erroneously reported) empirical research findings, replacing cautious (and sometimes flawed) implications from research with catchy, unsupported, sensationalized headlines. For example, the dominance of the private/family problematization is presented through the headline “Busting Canada's daycare myths ...Is there really a child care shortage?” (Kheiriddin, 2015, Apr 30). The article goes on to report the findings of a non-peer-reviewed, methodologically questionable report published by a privately-funded and socially conservative Canadian think tank (The Institute of Marriage and the Family Canada - now "Cardus"). The premise of the article is that all childcare spaces are regulated by the watchful eye of parents, thereby significantly increasing the number of "regulated" childcare spaces in Canada. According to the report, anyone caring for children anywhere is considered "regulated", thereby making childcare shortages a "myth". Such a discourse perpetuates the downloading of care onto individual families and parents with no government oversight or funding. This example exemplifies how sensationalization is used to get the attention of readers, but often at the cost of the communication of accurate information.

In September 2015, the period where coverage of childcare policy was greatest in The Post, findings from another non-peer reviewed research report were again oversimplified and misrepresented. In this case headlines reads: "The daycare trade-off; Universal childcare lets more women go to work, but could have a negative effect on their children" (Gordon, 2015, Sept 29) and "The dangers of daycare; Numerous studies have shown that children who spend more time in child care tend to have worse outcomes later in life" (Kheiriddin, 2015, Sept 24). Both of 
these Post columnists, who are in a position to share their opinion, perpetuate the private/family problematizations by suggesting that anything other than parental care is harmful to children. As in the example above, these sensationalized headlines are presented as "objective" and rooted in third party research. However the conclusions are questionable on several grounds (as discussed in the section on irrealis statements and authorization).

Globe columnist Leah McLaren employs a unique approach to conversationalization. Without compromising the integrity of information, the author of the article creatively engages readers by drawing on popular culture references and conversational, accessible language. The headline of the article reads: "For parents, daycare is the real money pit: Move over Babar, there's a bigger elephant in the room - a long overdue need for a national, governmentsupported child care program” (McLaren, 2015, Sept 4). This discursive approach uses conversationalization to highlight the issue from a family equity perspective. Only parents of young children are likely familiar with "Babar" (the animated elephant cartoon character) thereby establishing an immediate alliance between the author and parents of young children. Most of these parents are also likely seeing a large portion of their incomes go to childcare bills, allowing them relate to the author when she refers to "daycare" as a "the real money pit". The article goes onto describe childcare as:

... an issue I had heard responsible people around me banging on about for years, but one that had sort of floated above my comprehension, like the sound of the grownups talking in the animated Charlie Brown. Like car insurance or taxes, I expected organizing child 
care to be a pain - one of those annoying but ultimately surmountable aspects of grownup life. What I did not expect it to be was a financially crippling, life-paralyzing quagmire (McLaren, 2015, Sept 4).

The conversational tone of "responsible people", "banging on", and "grown-ups" humourously makes the issue immediately understood by parents, bolstering the family equity problematization of the issue. Sensationalization (i.e., referring to childcare as " a financially crippling, life-paralyzing quagmire") reinforces this.

Conversationalization is similarly utilized by another Globe columnist, Elizabeth Renzetti who pokes fun at the Conservative critique of the NDP's childcare plan. At the time, Conservatives were commonly making the argument that the NDP's plan would result in the government "raising your kids for you". In response, Renzetti (2014, Oct 25) states:

Thomas Mulcair wants to "raise your kids for you," the Conservatives warned. (By the way? Excellent idea. Take my kids, Tom. They think Mountain Dew is a food group and they'll watch 25 episodes of Doctor Who in a row. Please have them back by 2020)

Renzetti enacts a hypothetical conversation with "Tom", colloquially and rather sarcastically pointing out the grave flaws with the Conservative's critique of the NDP plan. This comment challenges the private/family problematization, with the inference being that the public does have a role to play in caring for young children. 
Finally conversationalization is evident in an article by Globe staff reporter Erin Anderssen. This article brings attention to the centrality of the nuclear family model in the policy proposals of the Conservative government (specifically income-splitting). Anderssen summarizes the message of the reigning Conservative government stating: "Take a hint single moms, find a man" (Anderssen, 2015, Oct 2). This conversational tone is evident mainly in Globe articles authored by women, particularly by columnists Elizabeth Renzetti and Leah McLaren and staff reporter Erin Anderssen.

Conversationalization thus appears to exaggerate and over-simplify the ideas presented, though it arguably does make the position more accessible to readers. For authors coming from a social conservative ideological location, the idea is that childcare is "bad" for children. Authors with a more left-of-centre ideological orientation (social liberal and/or social democratic) scorned the idea that childcare replaces parental caregiving.

\section{Use of Metaphor}

When word counts are limited and ideas are complex, newspaper articles commonly draw on metaphors to simplify complicated relationships between social issues and policy. In this sample, metaphors often emerged through subtle, but loaded word choices. For example, Post columnist Andrew Coyne casually refers to government spending on childcare as "coughing up": "the NDP plan involves spending money on other governments' behalf - that is, the $40 \%$ of the cost the provinces would be expected to cough up" (Coyne, 2014, Oct 16). "Coughing up" is a physical process that is at best undesirable and at worst very painful. This metaphor therefore 
likens provincial childcare spending to a process to which most people have a strong aversion. This discursive metaphor serves to reinforce the belief that childcare is a private problem whereby taxpayers are not expected to go through the painful process of "coughing up" funds.

Jack Mintz, President of the School of Public Policy at the University of Calgary and columnist for The Post, also draws on discursive metaphors to perpetuate the private/family problematization. Mintz describes income-splitting (the Conservatives' alternative to a childcare system in the 2015 federal election) as "family friendly tax-breaks" and "family tax relief" (Mintz, 2014, Oct 31). In contrast to "coughing up", most people are looking for a "break" in their daily life while the term "relief" indicates an end to suffering. Taxes, specifically federal taxes that would support a national childcare system, metaphorically become an affliction from which citizens must be relieved. Furthermore, the "breaks" and "relief" are said to be "family friendly". The term "family friendly", typically used in the context of social situations where young children may not be included (i.e., dining, going to the theatre, vacationing), is likely to resonate with parents of young children who are constantly conscious of whether events/opportunities are appropriate for the whole family. Income-splitting metaphorically described with this text serves to reinforce a private/family conceptualization of the issue whereby individual families (narrowly conceptualized as a two-parent, nuclear family) are best supported through cash-in-hand rather than with high quality childcare services.

Also contributing to the dominance of the private/family problematization, Post columnist Tasha Kheiriddin and Globe columnist Elizabeth Renzetti, paint a grim picture of 
regulated childcare when they liken it to a parking lot for children. Kheiriddin states that "proponents of regulated care argue that those mothers would all speed back to work full-time if they only had a place to park their kids" (Kheiriddin, 2015, Apr 30), while Renzetti claims “when they're [children] little, they must be parked in a place where they can hit theirfriends over the heads with Thomas the Tank Engine while their parents are at work" (Renzetti, 2014, Oct 25). In both examples, caring for children is likened to abandoning an inanimate vehicle, though the intentions of the authors were likely quite different (with Renzetti coming from a more left-of-centre ideological position). Nevertheless, such an analogy conceptually occludes the possibility of high quality childcare environments where nurturing and consistent relationships (where children are not hitting each other with toys) can provide safe, nurturing, consistent and stimulating environments for children. Intentionally or not, the private/family problematization is perpetuated when parents/mothers are idealized as the only people capable of providing the care children need and deserve.

Post columnist and economist Stephen Gordon also draws on discursive metaphors to reinforce the private/family problematization presenting children's well-being as the "trade off" of "daycare". The title of his article reads: "The daycare trade-off: Universal childcare lets more women go to work, but could have a negative effect on their children" (Gordon, 2015, Sept 29). A “trade-off” is formally defined as "giving up of one thing in return for another" (MerriamWebster, 2017). In this metaphorical “trade-off”, a mother's ability to work in the paid labour force and her child's ability to have quality childcare are positioned in direct conflict with one another, with one compromising the other. Furthermore, the term "lets", as opposed to 
"supports" or "enables" implies that mothers are privileged to work and that they are doing so in their own self-interest rather than as necessity. This metaphorical and erroneous "trade-off' is used to bolster the private/family problematization of childcare arguing that children require the "superior" care of their mothers.

Finally, Post columnist Kheiriddin uses the word "exposure" in reference to "daycare" throughout the article. "Exposure" is typically used in relation to a substance or environment which poses a direct risk of harm (i.e., exposure to asbestos or death from cold exposure). In this article, "universal childcare" (specifically Quebec's "universal system") is positioned as the exposed risk from which children need protection. The article concludes that: “... children exposed to Quebec's universal childcare program are more likely to commit crime, have worse health outcomes and lower levels of life satisfaction later in life" (Kheiriddin, 2015, Sept 24). Since one of the primary tasks of all parents is to protect their child(ren) from harm, presenting regulated childcare as a risk factor can only create a strong deterrent for parents considering such care. Furthermore, the use of the word "exposed" in this article is strategic in that the empirical study's conclusion did not differentiate between youth who were enrolled in Quebec's childcare system and those who were not. Broad demographic data and delinquency rates were collected from an entire cohort of children regardless of whether they had actually been cared for in the publicly funded system. The word "exposed" glosses over this key difference. The study's conclusions could equally be explained by the effects on children who did not have access to the system. The metaphorical and strategic use of the word "exposed" in the article both heightens 
the emotional appeal of (misleading) findings as well as glazes over the deeply flawed methodological approach of the study.

One article in The Globe stands out as heavily relying on the overt use of metaphors. Shortly after the announcement of Muclair's proposed \$15/day childcare, Globe columnist Renzetti (2014, Oct 25) likens childcare policy to a "magical unicorn":

For 30 years this [national childcare policy] has been the magical unicorn of Canadian public policy, sometimes glimpsed at a distance in the forest but never actually captured.... Occasionally a brave politician tries to lasso the unicorn, but, faced with the scorn of the electorate and political rivals, sinks away in despair...it's going to be a tough sell, which is probably why the unicorn has remained free all these years, kicking up its heels.

This metaphor situates childcare policy as untouchable - a fantasy that cannot be broached without "scorn" or "despair". This troublesome, unicorn metaphor positions national childcare policy as an elusive dream, rather than as a concrete policy possibility for Canadians. Given that the NDP was attempting to situate childcare as a central plank of their party's platform, this “magical” conceptualization may have served to delegitimize the NDP's policy proposal situating it instead as a troublesome fantasy. In doing so, the public problematization is presented, but seen as an impossibility - something Canadians will ultimately reject no matter how hard anyone tries. 


\section{Nominalization}

Nominalization is a particular type of grammatical metaphor whereby active processes are reduced to static things (Fairclough, 2003). Put more simply, verbs are reduced to nouns obscuring the actions and actors involved in complex social processes. In this analysis nominalization frequently arose in relation to the use of the term "daycare" and "childcare". "Daycare" almost always functions as a noun, bringing the conceptual focus to the physical space in which children are being cared for. "Daycare" is not a process, but a place and typically not a place that conjures up images of high quality, enriching environments. Furthermore, "daycare" removes the child from the concept. In recent years, the word is increasingly used in reference to pets (i.e., doggie daycare), whose needs are clearly very different than those of young children. The term "childcare" is not immune to nominalization, but does more easily lend itself to a description of the broader concept of caring for children, regardless of time or place. "Childcare" may act as a noun, but more typically refers to a service or resource where caring for the child is emphasized. More formal terms, such as Early Childhood Education and Care typically used in academic and policy settings, very rarely arose in newspaper articles (probably due to the premium placed on word count in newspaper articles).

All papers used the term "daycare", though The Post relied most heavily on this term. While raw counts of terms are not typically used in CDA, with 18 articles undergoing analysis it was helpful to observe how often the different terms were used across papers. Sampled articles in The Post included 57 references to "daycare", compared to 28 in The Globe and 18 in The Star. Similarly, The Post was the only paper to refer to "daycare" more frequently than "childcare" 
with 57 references to the former and 41 references to the latter. In the sampled articles, The Star and The Globe included 55 and 57 references to "childcare" respectively.

Along with nominalization which reduces caring for children to the physical space where children are for the "day", the term "daycare" also lends itself to a dichotomization of parental and non-parental care. Whereas "childcare", or more accurately the care of children, may be carried out by parents or others inside or outside the home, "daycare" is a term exclusively reserved for care arrangements that take place outside the child's home and typically away from family. In the Post article entitled "The Dangers of Daycare", Kheiriddin describes "daycare" as "a mechanism to "take them [children] out of the house for 8 hours a day", going on to describe non-familial caregivers as "strangers" (Kheiriddin, 2015, Sept 24). In this way "daycare" is presented as a state-supported mechanism of removing children from the home, where unknown and potentially dangerous "strangers" will raise them. Parents and children are situated as powerless victims vulnerable to the forces of a paternalistic state. The idea that high quality childcare environments funded by federal governments could offer consistent, nurturing, responsive care environments wherein children form secure and stable attachments with caregivers is occluded entirely. The dichotomization between the loving care of parents and the institutional nature of "daycare" delegitimizes the significant government funding needed to create these high quality care environments in the first place (to recruit and retain consistent early childhood professionals). Instead of the government being portrayed as an ally in the care of young children as a public problematization of the issue supports, the dichotomization of parental and non-parental care through the use of the term "daycare" and statements such as 
Kheiriddin's above perpetuates the idea that the genuine care of children can be provided only by parents.

It is also interesting to note the words that were often paired with "daycare". It quickly became apparent, particularly in The Post but also in several Globe articles that words paired with "daycare" played into the free-market problematization of the issue. Like any market commodity, "daycare" was described as something that could be "outsourced" (Kheiriddin, 2015, Sept 24) while several other articles limit the discussion to daycare "spaces" and the "cost" of these spaces. Reducing the complexities of caring for children to the availability of "spaces", is yet another example of nominalization (granted, the language of the NDP campaign emphasized the government provision of $\$ 15 /$ day childcare "spaces" so it is not surprising that it was picked up in all papers.) "Space" as a metaphor for "care" reinforces the idea that the care of children can be reduced to a physical place - something that easily lends itself to neoliberalism's preferred commodification. As long as the discussion remains focused on "spaces" and the "cost" of providing these spaces, the free market appears to have the advantage as it can most quickly and inexpensively create these "daycare" spaces.

The other key word that has historically been and continues to be nominalized in discussions of childcare policy in Canada is "choice". When "choice" is nominalized (reduced from an active process to a static noun) the complex process of choosing is obscured. More specifically, the options necessary for one to be able to "choose" are obfuscated situating "choice" as a metaphor for individual freedom and agency (the cornerstone of neoliberal ideals). 
The nominalized "choice" discourse was central to the campaign of the Conservative Party in the 2015 federal election and was perpetuated in several Post articles. For example Kheiriddin (2015) states: "The laws of supply and demand, equity and parental preference would all point to supporting choice as the most sensible model of child care" (Kheiriddin, 2015, Apr 30). Similarly, Coyne argues that public funds allocated to childcare should "be sent directly to parents, to be allocated to the provider of their choice" (Coyne, 2014, Oct 16). In both cases the fact that the existing market model of childcare in Canada has failed to provide Canadian parents with real options necessary for there to be a real choice for parents looking for quality, affordable childcare goes unacknowledged. Coyne goes on to claim that: "money enables us to get what we want instead of what other people think we need" (Coyne, 2014, Oct 16). Here, not only is "choice" equated with individual freedom, but the government is situated as constraining freedom of choice with the provision/funding of high quality, childcare options.

Overall however, the nominalization of "choice", and the "choice" discourse it instantiates, was not picked up in newspapers in the same way it had been in the past (specifically as it had been during the 2006 federal election). In fact, there appeared to be an overt effort in several articles published in The Star and The Globe to overtly challenge this discourse. Star reporter, Monsebraaten uses the word "options" in the title: "Few child-care options for non-nine-to-fivers"(Monsebraaten, 2015, Sept 15). Similarly, Globe columnist McLaren (2015, Sept 4) illustrates the reality of the lack of "choices" parents face in a nation where quality childcare is largely inaccessible: 
Like most families, we shouldered the heavy financial burden of fulltime child care all on our own with no help from the government or extended family...It was either that or one of us quit working. Not a pretty choice, or a realistic one for most parents, either.

Some articles in The Post pointed to the limitations of the "choice" discourse, though the critique is limited to the dollar amount rather than to the mechanism of providing cash to parents. For example, in relation to the UCCB, Kheiriddin states: "monthly benefits, are inadequate to allow most parents to fully afford the choices they prefer" (Kheiriddin, 2015, Apr 30).

As becomes evident in all of these examples, nominalization becomes a mechanism of obscuring/omitting practical realities in favour of ideological values or ideas. The idea of "choice" resonates strongly with dominant and hegemonic neoliberal values. The word "daycare" in relation to state services becomes the antithesis of nurturing, responsible care (a social conservative perspective). Finally, a focus on "daycare spaces" reflects neoliberalism's preferred commodification of all things.

\section{Irrealis Statements}

Irrealis statements present as if objectively true, but are rooted in overtly false and/or misconstrued information (Fairclough, 2003). These statements are easy to interpret as "fact", particularly by those who do not have an intimate understanding of a given policy or social issue. This would include most consumers of newspapers. Irrealis statements were used in the large majority of newspaper articles in all papers, with frequent use of irrealis statements pertaining to 
misleading reporting on research papers. The National Post drew on irrealis statements in relation to published, but not peer reviewed, articles by The National Bureau of Economic Research (NBER), Institute of Marriage and Family Canada (IMFC), Center for Interuniversity Research and Analysis of Organizations (CIRANO). Interestingly, the report also draws on findings from the National Institute of Child Health and Human Development Study of Early Childhood Education and Care (NICHD) though the decontextualization of these findings from the original source leads to their "irrealis" nature.

As noted in the observations of conversationalization, one of The Post columnists Kherirddin's article stands out in its use of irrealis statements. To begin, it draws on the NBER study to claim that: “...children exposed to Quebec's universal child care program are more likely to commit crimes, have worse health outcomes and lower levels of life satisfaction later in life" (Kheiriddin (Kheiriddin, 2015, Sept 24). While this is what the study claims, the article failed to acknowledge that this was only a working paper that had been quickly dismissed with widespread critique from academics and childcare policy experts across the country. As mentioned above, the deeply flawed methodological approach of the study failed to differentiate between children who were enrolled in Quebec's publicly funded system and those who were not, meaning that the results could have easily been explained by children who were not enrolled in the program as by those who were. This is a prime example of misconstrued information being picked up and perpetuated by the media under the pretense of being objectively "true". 
This same article goes on to draw on another grossly misleading irrealis statement related to a study published by the NICHD: “The NICHD Study of Early Childhood Care, a $\$ 100$ million survey of 1100 children, found that the more time spent in child care of any kind or quality, the more aggressive the child" (Kheiriddin, 2015, Sept 24). In this case, the legitimacy of the reported findings is bolstered through mentioning the generous budget of the study and large sample size. The findings of the NICHD report were grossly extrapolated and decontextualized. What the NICHD (2005) actually concluded was this:

Children who spend many hours in child care show somewhat more behavior problems and more episodes of minor illness than those in fewer hours of child care...family features were stronger predictors of children's social behavior and development than was quantity of child care. (NICHD, 2005, p.17)

Furthermore, the NICHD goes on to heavily emphasise the importance of quality in child care settings when discussing any measure of child outcomes-- a concept completely neglected in this article. Finally, this article draws on research published by a Quebec-based think tank to claim that: "...the educational attainment of four-and-five-year-olds decreased over the first decade of Quebec's daycare program" (Kheiriddin, 2015, Sept 24). The CIRANO document referenced actually cautions against drawing such a conclusion when it states:

We conclude by emphasizing that we are estimating the effects of a particular complex daycare policy on the cognitive development of children who are 4 and 5 and not the effects of childcare per se. Therefore, there is no inconsistency with other types of studies 
that find positive effects of childcare on developmental outcomes (Lefebvre, Merrigan, \& Roy-Desrosiers, 2011).

As was the case with the NICHD research, the CIRANO document highlights the importance of quality of childcare in an evaluation of child outcomes. In this case, the report discloses that its findings are likely influenced by the fact that Quebec's childcare system has been "evaluated to be of medium or low quality on average" (Lefebvre et al., 2011).

Another article written by Kheiriddin, referred to in the discussion of conversationalization, claims that there is a surplus of childcare spaces in Canada: "the assumption is generally that child care spaces are rare as hen's teeth. But as the IMFC report shows, they aren't'" (Kheiriddin, 2015, Apr 30). Kheiriddin accepts the IMFC's (report authored by Helen Ward) "holistic" redefinition of "regulated" childcare to include all types of childcare including unlicensed care on the grounds that all care is informally regulated by parents. The misconstrued conclusion of this article reads: "If you build regulated spaces, children will not necessarily come" (Kheiriddin, 2015, Apr 30).

Post columnist Stephen Gordon takes a different approach to presenting irrealis statements, utilizing his own economic expertise. In a matter-of-fact manner the article states: "Parents who have high-paying jobs would be most likely to make this choice [to use publicly funded, licensed childcare]. Since one of the financial costs of staying at home is foregone wages, the cost of staying home is that much greater for high earners" (Gordon, 2015, Sept 29). This statement suggests that parents with high incomes who have the option and decide to stay 
home with their children make more of a sacrifice than dual-earning, and/or single-parent families who rely on and pay for publicly-funded, licensed childcare. While in a very literal sense, the raw dollar amount may be higher (i.e., giving up a $\$ 70 \mathrm{k} / \mathrm{a}$ job), such rhetoric delegitimizes the struggle of lower and middle-income families who are required to work to provide the necessities of life for their families. In other words, the relative sacrifice that low and middle-income families make to access licensed childcare is typically considerably more than that of the two-parent family where one parent is able to take extended time out of the paid labour force while maintaining a decent standard of living. In this way, the opposite claim is true: the most financially secure families are more likely to have the resources that allow them the option of a parent staying at home. The high earning family is not threatened by having one parent stay at home. So they are simply not making more of a sacrifice than low earning families. Furthermore, the cost of childcare is but one aspect of the childcare issue. The fact that there is a severe shortage of high quality care environments for children extraneous to cost indicates that a publicly-funded childcare system is a central crux of accessible childcare for even the wealthiest Canadian families. This irrealis statement thus reinforces both a private/family and market conceptualization of childcare. Individual families are positioned as bearing sole responsibility for either directly caring for or paying for care for their children while the market problematization is perpetuated through a focus on the cost of care.

The Globe and The Star were not free from irrealis statements, though their claims rarely carried the same weight in the public policy debate as the statements highlighted above. For example, McLaren idealizes Paul Martin's historical 2005 ELCC Foundations saying: "The 
vision was a new, Scandinavian-style era of universal child care for Canada" (McLaren, 04 Sept, 2015). Even the ELCC Foundations program of 2005 was far from a "Scandinavian-style" childcare system. As noted by Richardson (2011), this program was very much rooted in human capital principles, where the developmental and economic potential of children was prioritized over the Scandinavian focus on children's rights and well-being. Such rhetoric is consistent with a public problematization of the issue, though it risks equating universal childcare to a pie-in-thesky hope rather than a concrete policy possibility.

A passionate letter-to-the-editor published in The Globe uses poignant language in an irrealis statement when it states: "These policies [that support regulated childcare] are harming families, especially low-income, single-mother families like mine, by hogging funding and discriminating againstwomen" (Ward, 2015, Sept 8). Of course, all empirical and demographic evidence would actually suggest the opposite: low-cost childcare options for families are credited as being a key to, if not the key, policy that provides single-parent families (the large majority which are headed by women) with the opportunity to escape poverty ${ }^{45}$.

Star reporter Monsebraaten also draws on irrealis statements in an attempt to situate childcare as a key election issue. Stated as factual when more predictive in nature, the article is titled: "Key battle looming over childcare" (Monsebraaten, 2014, Nov 3). Similarly, Star

\footnotetext{
45 The recently released report from the Ontario Ministry of Labour's gender-wage gap consultations highlighted "insufficient options for child care and elder care" (Government of Ontario, 2016) as a key factor contributing to the gender wage gap in Ontario.
} 
columnist David Olive states: "The federal election is more than two months away. Yet it's already apparent why the NDP has a decent chance of winning it, with issues that turn on household economics" (Olive, 2015, Aug 4). The idea that "household economics" would be the crux of the election campaign responsible for the potential NDP victory was again nothing more than a prediction.

\section{Discourse Practice}

\section{Interdiscursivity}

In this study, interdiscursivity has been defined of the mixing of discourses (including problematizations) within a text. As mentioned earlier, numerical counts are not typically used in CDA, but with a sample of eighteen articles, some broad observations about the degree of interdiscursivity across newspapers are helpful as a starting point of analysis. The most straightforward approach to measuring the degree to which different discourses were drawn upon was to count the number of problematizations within articles. In the Toronto Star articles, an average of 6.5 problematizations were evident, with a minimum of three and maximum of ten per article. It was generally the case in The Star that a childcare policy was presented as a solution to a wide variety of social problems while counter arguments (i.e., the private/family and/or market problematizations) were acknowledged and challenged. In contrast, articles in The Post included an average of 3.6 problematizations, with a minimum of two and maximum of six, indicating a narrower representation of the problem overall. Furthermore, the private/family problematization of childcare was evident in all six Post articles. This was also the only paper in the CDA to overtly deny that childcare presents a policy problem at all (see Kheiriddin, 02 Apr, 
2015). Globe articles contained an average of 4.3 problematizations, with a minimum of one and a maximum of nine, suggesting that The Globe was more diverse in its representation of the problem than The Post, but less so than The Star. The Globe appeared to include individual articles that were both narrow and diverse in their conceptualization of the childcare problem in Canada whereas The Star is consistently diverse and The Post consistently narrow.

The Star's Monsebraaten and Olive (Monsebraaten, 2014, Nov 3; Olive, 2015, Sept 28) and The Globe's Renzetti (2014, Oct 25) drew on the greatest number of problematizations within any one article. Monserbraaten drew on 9 problematizations, including childcare as a human capital ("provinces are recognizing the educational benefits of early learning and child care", economic ("child care has a direct impact on the fiscal bottom line"), welfare ("child care is now recognized as a fundamental plank of the anti-poverty movement"), and child well-being problem ("the recent rash of deaths in unregulated home daycares in the Toronto area" (Monsebraaten, 2014, Nov 3). Similarly, Renzetti (2014, Oct 25) drew on the population growth, child well-being, early childhood professionals, family equity, women, human capital and economic discourses when sequentially posing the following questions:

Do we actually want young people to keep procreating? (Laugh if you will, but economic constraints are one of the main reasons people have fewer children, or none at all.) If both parents work, do we want a safe place to put children during the day - a place where they might actually be in the care of well-trained, happy professionals? Do we want kids to have a running start - all kids, not just the ones who won the birth lottery? Do we want 
women to feel they can afford to work outside the home, if they choose? Are we willing to invest in these things - not for our own children, because it's too late, but for theirs? (Renzetti, 24 Oct, 2014)

It is interesting to note that although columnist Olive includes 10 problematizations of the issue overall, the economic discourse is given the most weight with the headline reading: "Child Care should be an Economic Priority" (Olive, 2015, Sept 28). Almost all of the problematizations mentioned in the article are linked back to an economic interest, whereby women's equal participation in the labour force, population growth, human capital and child well-being are presented as having an economic bottom line. This infers that if we do not have healthy, safe, educated workers, we do not have a healthy economy. This article also acknowledges the dominance of the free market and private/family problematizations though it challenges them, noting the failure of the Conservative's UCCB and free market to create childcare options for families.

\section{Intertextuality}

In this study, the observation of intertextuality is included, noting the degree to which other texts (i.e., a recent report, research, political speech, interview, etc.) were directly quoted or paraphrased in the newspaper article. Having a high degree of intertextuality in and of itself is neither "good" nor "bad", but simply indicates that voices or ideas other than those of the authors have been considered and are included and/or reflected in text. As a starting point for an analysis, 
it was observed that an average of $29 \%$ of text in The Star, $26 \%$ in The Post and $14 \%$ in The Globe was taken directly from other texts.

In The Star, the voices of politicians (at all levels of government), policy experts, policy organizations (i.e., CCPA, United Way), policy authorities (i.e., the IMF or World Bank), lay Canadians (usually parents), academics, advocates and community groups were frequently quoted. The Star stands out as quoting and/or reporting on a wide variety of research, comparative policy data as well as the words of people who directly experience childcare policy decisions/indecisions in Canada. For example, Monserbraaten (03 Nov, 2014) includes reported speech from former Social Development Minister Ken Dryden, policy researcher Martha Friendly, a TD bank report, Conservative leader Stephen Harper as well as a Toronto mother. Similarly, Mojtehedzadeh (2015, Feb 28) includes reported speech from the CEO of YWCA, the Organization for Economic and Community Development, Canadian policy researcher Jane Jenson, Canadian economists Pierre Fortin and Kevin Milligan, and UNICEF. While not all of these stakeholders are in favour of comprehensive childcare policy, their voices and arguments have nonetheless been included.

While The Post exhibits a similar degree of intertextuality as The Star, on further analysis it became apparent that this paper drew on fewer voices. In comparison with The Star articles which drew on an average of 4.5 sources, The Post articles averaged 3.2 sources. Two of the external texts most heavily drawn on in Post articles were the IMFC report and NBER working papers mentioned in the irrealis statement findings above. Both of these reports reject the idea 
that the state should play a role in funding or providing affordable, accessible high quality childcare in in Canada. In fact, three of the six Post articles that are included in the CDA (and therefore contained significant content related to childcare policy in Canada) were primarily devoted to reporting the findings of these two documents.

Kheiriddin (24, Sept, 2105) stands out in its high degree of intertextuality (45\%) and diversity of sources quoted (8). In addition to referring to the NBER report and IMFC report discussed above, this article quotes the NICHD, the Quebec-based Center for Interuniversity Research and Analysis of Organizations (CIRANO), researcher/economist Kevin Milligan and “esteemed" medical doctors Dr. Gabor Maté and Dr. Gordon Neufield. This article culminates in the message of Dr. Mate and Dr. Neufield to claim that childcare is "bad" for children. Kheiriddin (2015, Sept 24) claims:

In a typical group child care setting, children do not get enough individual attention to adequately reinforce these behaviours. The result is that children instead learn from each other. Peers, not parents, become their moral compass.

This over-simplification of peer socialization, with no mention of the quality of interactions between childcare professionals/providers and children, contributes the dichotomization of parental and non-parental care (discussed more in the section on assumptions). It appears that pieces of texts from external sources are paraphrased and quoted without questioning the premises on which external authors have come to conclusions. The medical doctors that were the sources for this text made these claims in popular parenting books rather than through 
empirically informed research. In this rare Post article where a wide variety of texts and voices were included, it appears that the author strategically and superficially included external texts without critically questioning the validity of these texts. Furthermore, the directexperiences of stakeholders and/or opposing viewpoint were left out of the article.

Overall, sampled articles in The Globe exhibited much less intertextuality than the other papers. The Star sample included only one article that had less than $20 \%$ intertextuality and The Post two articles with less than 20\%, while five out of the six articles in The Globe had less than $20 \%$ intertextuality. Interestingly, two of these articles refer to other Globe articles written by fellow journalist Erin Anderssen in her 2013 series featuring childcare. For example, Renzetti states: "the problem [childcare] is enormous and getting worse, as my colleague Erin Anderssen outlined in a fine Globe series last year" (Renzetti, 2014, Oct 25). When it came to authors addressing childcare policy in the Globe, authors appear to rely more on developing their own arguments and ideas, rather than systematically reporting other texts.

Globe reporter Erin Andersen's article was an outlier with 45\% of her text drawing on or including text from other sources. At the same time, this long article (2013 words) foregrounded the voices and stories of three Canadian single mothers - referred to as the "forgotten moms" during the election campaign. The article began: "Viveca Ellis drove into the poverty wall, as she puts it, on an ugly, grey Vancouver afternoon" (Anderssen, 2015, Oct 2). This mother is directly quoted in describing the situation of herself and her impromptu care provider: "We were two women and one little boy among thousands, trapped in a culture of poverty created by low-wage 
work and unregulated child care in B.C." (Anderssen, 2015, Oct 2). The articles goes on to quote two other single mothers for whom a lack of affordable, high quality childcare has severely compromised their opportunity and well-being. Also included in this article is text from the CCPA, empirical research, Campaign2000 and an interview with the CEO of the YWCA. In this case, the intersectionality between women's equity and poverty problematizations of the issue were deeply explored and connected to lived human experiences.

Perhaps the most interesting observation pertinent to intertextuality is not just the differences between the newspapers, but the unexpected differences in degrees of intertextuality that emerged between the genders of the reporters. In analyzing articles it quickly became apparent that there were some differences in the degree to which male and female journalists drew on other texts. While female journalists did the majority of the reporting on the issue overall, two articles in The Star and The Globe and three articles in The Post were written by men. The average amount of intertextuality in articles written by men was $13 \%$ while the average for women was more than double this at $28 \%$. Furthermore, the three articles with the most reported text (one from each paper) were all written by women. In the sample, it appears that women were more likely than men to make their argument by drawing on ideas, research, thoughts or words of others. The different approaches of male and female authors became even more pronounced in the observations of modality. 


\section{Modality}

The primary goal when examining modality is to expose how the articles differ in the way claims are made. This involves analyzing the types of statements used (i.e., declarative, evaluative, imperative), noting how the journalist positions him, her or themselves in relation to claims and observing the strength of the language used to make the claims. An examination of modality instantiates the observation of how the article positions a "right" or "wrong" way of doing things, though it is less concerned with what claims are made than with how claims are made.

In an examination of modality, it became apparent that female authors - particularly those in The Star - were more likely to rely on the words of others to make declarative and evaluative claims. For example, Monsebraaten relies heavily on direct quotes from an incumbent report and policy experts rather than using her own words when attempting to situate nonstandard-hour childcare as an urgent public policy issue. The article opens with the findings of the report: "High cost and complicated logistics are the main reasons why licensed child care for parents who don't work regular 9-to-5 weekday hours is almost non-existent in Canada, according to a new report" (Monsebraaten, 2015, Sept 15). The solution the report puts forward is then directly quoted: "Creating and sustaining non-standard-hours child care requires a publicly funded, publicly managed, universal system' says the report being released Tuesday" (Monsebraaten, 2015, Sept 15). The article goes on to include direct quotes from an interview with the report's author - childcare policy researcher Martha Friendly. One of these quotes reads: “You need to have a system. But you also need a plan. You can't just expect it to happen' 
Friendly said in an interview" (Monsebraaten, 2015, Sept 15). Even the background information necessary to appreciate the complexity of the childcare problem is presented through the direct quote of an external source: “A recent survey by McMaster University and United Way Toronto found that more than half of parents in precarious employment in the Greater Toronto and Hamilton areas have trouble finding childcare" (Monsebraaten, 2015, Sept 15).

Similarly, The Star's work and wealth reporter, Sarah Mojtehedzadeh, uses the voice of YMCA CEO Heather McGregor to illustrate the connection between women's employment and childcare: "McGregor says this [affordable, high quality childcare] is 'critical'for women to be able to work and have a sustainable income so that they will have a better, healthier life for their children and themselves" (Mojtehedzadeh, 2014, Oct 26). This once-removed approach to modal claims seemingly positions the journalist in a more objective light. However, it may mute the poignancy of the argument. Instead of arguing that "this is the way things are", female journalists were more likely to take the approach of "he/she/it said this is the way things are".

Female authors in The Globe and The Post were more likely to than female authors in The Star to make direct claims in their own voices, although these claims were always backed by an appeal to objective data or evidence. For example, Kheiriddin draws on "studies" to position childcare as "dangerous". One title reads: "Numerous studies have shown that children who spend more time in child care tend to have worse outcomes later in life" concluding "we should develop policies that enable families to be the primary caregivers for their children" (Kheiriddin, 2015, Sept 24). In another article Kheiriddin makes a strong claim after positioning the claim as 
rooted in the findings of the IMFC report. She states: "if it is true [the findings from the report] then the very concepts of 'universal child care' is wrong-headed" (Kheiriddin, 2015, Apr 30). Finally, taking a more progressive stance, Globe columnist McLaren draws on the damning findings of an Ontario Ombudsman's report (2013) to suggest: “What Canada has long needed, and in fact very nearly once achieved, is a universal, federally regulated and provincially implemented child-care program" (McLaren, 2015, Sept 4). In these examples, a clear "right" policy direction is directly inferred in the author's voice, although the claims are justified through the "evidence" external to the author.

In contrast, male reporters frequently took strong positions on issues in the absence of “evidence”. For example, Post columnist Andrew Coyne begins his article with: "There are three ways to look at the NDP's proposed new national child-care plan: as a contribution to debate, as policy, and as political strategy" (Coyne, 2014, Oct 16). The article goes on to explain what the author means by each of these three conceptualizations of the NDP childcare proposal, making the case that the NDP proposal is little more than political strategy. Similarly, veteran Globe columnist Jeffery Simpson asserts: "It was always a joke to believe that the Conservatives' family allowance scheme (wrongly called a child benefit) of $\$ 100$ a month per child 6 and under was a childcare policy”(Simpson, 2015, Sep 11). Making a similar point, Star reporter David Olive states: "So difficult is it to imagine a more ill-advised public policy than the UCCB that one wonders why the Tories even bothered" (Olive, 2015, Sept 28). While the positions of these journalists differ, the unapologetic manner in which they report their opinions 
was remarkably similar: they each asserted strong declarative and/or evaluative statements in their own voice in the absence of "evidence" to support the claims.

The Post columnist, Stephen Gordon, took a unique, passive aggressive modal approach to reporting the findings from the NBER working paper. In the first paragraph, he claims: " $i t$ 's hard to understand the shock and surprise with which it [the report] has been greeted" (Gordon, 2015, Sept 29). The article goes on to describe other studies/reports that were understood to have similar findings, casually placing "they did" in brackets to support the seemingly well-founded idea that childcare is bad for children:

This results [of earlier research published in 2008] spawned several subsequent studies as other researchers checked to see if they could reproduce Baker, et al.'s results (they did). The goal of Baker, et al.'s latest study was to see if the negative effects they had identified earlier had persisted (they did). (Gordon, 2015, Sept 29)

This modal approach to reporting the findings gives the reader the impression that childcare's supposed "negative effect on children" is common knowledge or, at the very least, something in which the public should already be aware. Leaving the questionable methodology and findings of the working NBER working paper aside, he situates the perceived negative reaction of the public as reflecting on the intelligence and awareness of the population more broadly. This approach capitalizes on projected naivety and encourages a sense of inadequacy - perhaps even embarrassment - on the part of consumers. This is an effective way to silence discourse counter 
to the private/family problematization of the issue. If readers feel inadequately informed, as this quote suggests they are, the probability of them challenging the discourse would be lessened.

\section{Legitimation}

Claims or arguments made in newspaper articles carry little weight for readers if they are not perceived as legitimate. The key mechanisms of legitimation examined here were authorization (claims are made legitimate through the voice of an authority), rationalization (claims are made legitimate through logical reasoning), morality (claims are made legitimate through appealing to what is morally "right") and mythopoesis (claims are made legitimate through personal narrative).

\section{Authorization}

Legitimation through authorization relates closely to the discussion of intertextuality and modality whereby the words of experts, politicians and policy makers bring legitimacy to a perspective on the issue. Reference to external reports, documents, and research has a direct impact on the legitimation of statements and ideas. While this has been discussed above in regards to intertextuality and modality, the focus here is on noting how different people or organizations were positioned as authorities on the issue.

The Star stands out as most heavily drawing on international organizations that are typically regarded as legitimate authorities by virtue of their international status and economic orientation. More specifically, The Star appealed to observations made by the Organization for 
Economic and Community Development (OECD) and the International Monetary Fund (IMF). For example, Star reporter Mojtehedzadeh states “The Organizationfor Economic Co-operation and Development figures show that there is still a gap between female employment and maternal employment nationwide" (Mojtehedzadeh \& Ansari, 2015, Feb 28) while Star columnist Olive notes "In 2013, the OECD called Canada to task for spending just $0.3 \%$ of GDP on childcare" (Olive, 2015, Sept 28). Drawing on the authority of these esteemed international organizations also directly instantiates a leadership role of the federal government in addressing childcare policy - an idea that The Post was not keen to concede.

Other Canadian organizations such as The Wellesley Institute, The Canadian Centre for Policy Alternatives (CCPA), the Canadian Union of Postal Workers (CUPW) and the Canadian Union of Public Employees (CUPE) were also frequently referenced as authorities on the issue in The Star, although these organizations may be seen as less "legitimate" in that they all have a left-of-centre political orientation. The Star frequently allied itself with and drew on the expertise of nationally and internationally recognized policy childcare researcher Martha Friendly who was positioned as an authority on the issue when a quote by her was followed by identifying her role as "the executive director of the Childcare Resource and Research Unit" (Monsebraaten, 2014, Nov 3). This article in The Star also included the voice of former Social Development Minister responsible for the childcare file, Ken Dryden. In fact, his voice was referred to before Friendly's in Monsebraaten's article and likely carries with it an increased authority due to his celebrity status as a national and international hockey star. The voice of other authorities were highlighted through identifying their role as "executives" at community organizations and/or 
professor status (Kevin Milligan and Pierre Fortin). Most of the authorities appealed to in The Star supported a public problematization of childcare whereby citizens, led by the government, play a central role in caring for young children. The one exception was economist Kevin Milligan (author of the NBER working paper), who's research was interpreted as providing an alternative perspective (the idea that childcare is "bad" for children and families). Overall The Star not only drew on the most diverse body of authorities, but also appears to have made an explicit effort to situate external sources as high level authorities on the issue.

As became clear in the analysis of intertextuality, The Post drew heavily on a few papers and people who were positioned as authorities on childcare policy in Canada. Not one of the articles in The Post referred to an international organization in any capacity. Instead, three articles in The Post heavily referenced the NBER working paper whereby the "Professor" status of authors at esteemed universities was highlighted. For example, Gordon (2015, Sept 29) explicitly defines the professional designation of the report's authors in the first sentence of the second paragraph of the article: "Michael Baker of the University of Toronto, Jon Gruber of the Massachusetts Institute of Technology and Kevin Milligan of the University of British Columbia" while Kheiriddin (2015, Sept 24) notes the findings were "based on four different data sets from Statistics Canada". As mentioned above, Kheiriddin (2015, Sept 24) further appeals to the authority of medical doctors to support the findings of the NBER paper even though the book cited was a non-peer-reviewed parenting book rather than a methodologically robust empirical study. The "esteemed" positions of the authors, as well as the "doctor" status of the Dr. Mate and Dr. Neufield served to silence critical methodological questions as it is reasonable for consumer 
to assume that these professionals have done due diligence in reaching their conclusions.

However, the reality is that neither the professors nor the doctors in this case had their work reviewed by their peers and both drew on questionable methodological approaches that would likely have been rejected within their own professional communities.

The other approach The Post took was to appeal to the elusive, ideological ideas of historical figures. For example, Coyne (2014, Oct 16) appealed to playwright George Bernard Shaw's (likely decontextualized) sentiment that "money enables us to get what we want instead of what other people think we need" to legitimize the market problematization of the childcare problem. Similarly, columnist Jack Mintz extensively referred to the nostalgic but outdated Carter Report published half a century prior. This report argued in favour of income splitting because it "recognized that households use theirfamily income to cover joint costs of living" (Mintz, 2014, Oct 31). Both the message of this report (that dual-parent families are best served by policies that reinforce a traditional family with a stay-at-home mother) and the manner in which this report was used (relying on traditional, historical ways of doing things) reflect an authoritative appeal to tradition. In both cases, the private/family problematization is reinforced.

Finally, The Post stood out as a paper where the authors of articles themselves were positioned as authorities. More specifically, the titles of Stephen Gordon and Jack Mintz were highlighted in their articles. Mintz (2014, Oct 31) identifies his own position when he states: “Jack M. Mintz is the Palmer Chair, School of Public Policy, University of Calgary”. Less directly, Gordon (2015, Sept 29) highlights his authority as an economist in the following quote: 
Here I am put in the unfamiliar position of an economist being obliged to point out that GDP is not a measure of social welfare and that GDP doesn't necessarily make us better off (usually this exchange goes the other way). Just because more people are working doesn't mean they're happy about it. (Gordon, 2015, Sept 29)

This statement, counter-intuitive coming from an economist, directly challenges the human capital, economic and public problematization of the issue instead favouring the private/family problematization. As an economist and specialist on the topic himself, Gordon concedes the impressive economic payoffs of public investment in childcare, but dismisses it from a "social welfare" perspective. GDP - the thing seemingly most important to an economist - is positioned as contradictory to the "social welfare" of citizens. Thus Gordon draws on his own expertise to challenge neoliberalism's bottom line, but not from a social liberal or social democratic position as is typically the case. A social conservative counter-narrative, whereby people (women) are better off when they stay home and care for their children, is put forward. While a robust body of objective evidence and data would contradict this claim (on the basis of poverty reduction alone) Gordon's authority as an economist is used to effectively legitimize his claim and with it the private/family problematization of the issue.

As with intertextuality, The Globe appears to rely less on appeals to authorization than the other papers. While organizations and individuals were referred to for the legitimation of claims, there was not the same push to identify a wide body of external authorities as there was in The Star nor were a handful of "authorities" belaboured as The Post did. Columnist Renzetti 
(2014, Oct 25) referred to the 2013 Ontario Ombudsman report condemning the province for its lackadaisical approach to childcare while Anderssen (2015, Oct 2) highlighted a "Toronto study" and an article "published in the Canadian Review of Sociology" to articulate the idea that childcare is an essential support for single-parent families attempting to escape poverty. In terms of individual authority figures, the expertise of Martha Friendly and economist Pierre Fortin were drawn upon, though each only once and briefly. For example, supporting the public problematization of childcare, Friendly is again identified as the "executive director of Canada's Childcare Resource and Research Unit" (McLaren, 2015, Sept 4) immediately following the claim "If we really cared about supporting child care, we'd be putting money directly into the services, not sending it out to people. We'd treat it more like health care" (McLaren, 2015, Sept 4). Other articles in The Globe did not draw on external authority figures at all (Simpson, 2015, Jan 21; Ward, 2015, Sept 8).

An examination of authorization also provides some insight into the strong modal claims made by the seasoned male journalists discussed in observations of modality (Jeffrey Simpson from The Globe, Andrew Coyne and Stephen Gordon from The Post and David Olive from The Star). Each of these male authors have careers that span over 30 years as columnists for the papers and all hold other high profile positions/titles (i.e., book authors, members of political panels on national news broadcasts, high level university positions). It is possible that their position as perceived policy experts (even if childcare policy was not their area of expertise) served to legitimize the many overt evaluative claims without the support of external sources. Whether or not the female journalists did not have the same perceived notoriety (despite their 
extensive experience), whether they chose to downplay their experience and perspectives or whether they were encouraged (by themselves or others) to draw more heavily on "evidence" to be seen as legitimate can't be known. But it is likely not accidental that the most established and esteemed male journalists were able to present the strongest, most direct claims independent of external authority figures/data/research.

It is also worth noting that authors who were the most cautious in their reporting style, downplaying their own expertise/authority on the issue (i.e., The Star's Work and Wealth reporter Sarah Mojtehedzadeh, Social Justice Reporter Laurie Monsebraaten and The Globe's Social Policy and Family Issues reporter Erin Anderssen) were also all full-time reporters as opposed to occasional columnists. The more assertive and subjective style taken by columnists could also reflect the structural process of journalism whereby columnists offer alternative or invited viewpoints on issues. However, this does not negate the gendered nature of authority observed above. Male columnists were most frequently called upon to provide and communicate these alternative perspectives and took a more confrontational approach to doing so (i.e., relying less on research and more on subjective, unfounded assertions). . Even when The Post's female columnist Tasha Kheiriddin made the exact same claims as her male colleagues (i.e., childcare is bad for children), they were always backed by "evidence" and "facts" indicating her arguments would not be acceptable without such evidence. 


\section{Rationalization}

As would be expected, almost all articles in all papers rationalized changes (or lack thereof) to childcare policy in a particular direction. The findings from Part I of the study illustrated that the public problematization of childcare was often present in Period $\mathrm{B}$, though the reasons why childcare is/should be a public problem in need of a public solution was less discussed than it had been in Period A. An analysis of legitimation in the CDA articles (again, the articles most focused on childcare policy) revealed that the key logical "reason why" childcare policy was situated as a public problem related to supporting the participation of mothers in the paid labour force. This rationale intersects with the women's equity problematization and labour market supply problematization, although again problematizations were less explicit than they had been in Period A. In the CDA articles, the labour market support problematization arose in three of the six articles in The Globe and The Post and five of the six articles published in The Star. Similarly, this was often paired with the women's equity problematization which occurred in two of the six Post articles, three out of the five Globe articles and four of the six Star articles. Perhaps because a robust body of demographic and empirical evidence from Quebec was readily available and illustrated the strong correlation between women's labour force participation and affordable accessible childcare, articles in all papers acknowledged/conceded the rational argument that public investment in childcare policy would help increase the rate of labour force participation by mothers.

To cite some concrete examples, reporter Mojtehedzadeh`s (2014, Oct 26) article in The Star is titled "Daycare money goes in, moms with jobs emerge." Globe columnist McLaren 
(2015, Sept 4) observes that “In Quebec the \$7-a-day system has proved hugely popular ...acting as it does as an engine for workplace production and gender equality in that province" (McLaren, 2015, Sept 4). Even sample articles published in The Post conceded that national childcare policy would lead to increased labour force participation rates of mothers. Gordon (2015, Sept 29) refers to the "uncontested statistical linkbetween the implementation of universal daycare in Quebec and an increase in female labour-market participation rates."

The key difference between articles that drew on this rational argument to support national childcare policy and those that conceded this point and went on to refute the public problematization of childcare policy was how this argument interacted with value assumptions. More specifically, the socially conservative idea that childcare is "bad" for children and/or not desired by mothers was highlighted as more important than the rate of mothers' labour force participation in several articles published in The Post. In fact, all six of the sample articles from The Post put forward this perspective in some capacity (compared to two in The Star and three in The Globe). Instead of ignoring or denying this empirically robust relationship, Post articles acknowledged the labour market support alongside the private/family problematization to suggest that the increased labour force participation rates of mother were occurring at the expense of children. For example, Gordon's (2015, Sept 29) article was titled: “Universal childcare lets more women go to work, but could have a negative effect on their children" (Gordon, 2015, Sept 29). Similarly, Kheiriddin (2015, Apr 30) challenges the idea that mothers want to be working at all: "While proponents of regulated childcare argue that those mothers would all speed back to work full-time if they only had a place to park their kids, that isn't true". 
In these examples, the idea that childcare supports the ability of mothers to work is rationally conceded but considered to be unwanted. Again, the ideological underpinnings of the private/family problematization appears to trump other rationally grounded problematizations.

Another rational argument that was frequently drawn upon to support the public problematization of childcare related to the exorbitant cost of regulated childcare for parents. McLaren (04 Sep, 2015) identifies "daycare as the real money pit" while Monsebraaten quotes a Toronto mother whose childcare costs exceed $\$ 15000$ for "a baby in Toronto" (Monsebraaten, 2014, Nov 3). Several articles in The Star and The Globe appeal to rationalization to highlight the fact that the existing UCCB covers only a small fraction of the cost of childcare. For example, Olive (28 Sep, 2015) states that "the UCCB covers just $12 \%$ of the median Toronto family's annual tab of \$15,888-per-toddler in daycare expenses" while Anderssen reveals that “Universal Child Care Benefit cheques from Ottawa, even with recent increases, don't come close to covering [the cost of childcare]" (Anderssen, 2015, Oct 2). From this perspective, government action is presented as legitimate when it reduces the significant and undeniable financial burden working parents of young children face to access licensed childcare. However, these critiques do not reposition childcare from a market to a public problem. Instead, they merge the two, implying that the state should play a role in adjusting the current unaffordable cost of childcare.

Comparing Canadian childcare policy to childcare policies in other countries is also rooted in a rational approach to legitimation. An if-they-can-do-it-why-can't-we logic underlies 
this approach to rationalization. Mojtehedzadeh brings attention to the high labour force participation rate of women in countries that "boast comprehensive national child-care programs" (Mojtehedzadeh \& Ansari, 2015, Feb 28). Challenging the common rhetoric that Canada lacks the resources to provide high quality childcare to children, Mojtehedzadeh notes:

For variety, consider tiny Slovenia. Despite being neither Nordic nor particularly wealthy, Slovenia has the second-highest maternal employment rate in the OECD. At least 84 per cent of its women with children are in the workforce. Slovenia's GDP is a fraction of the size of Ontario's but almost 90 per cent of children between the ages of 3 and 6 are accommodated by the country's universal early education system. (Mojtehedzadeh \& Ansari, 2015, Feb 28)

Another approach used to rationally support an increased role of the government in childcare was through focusing on the immediate financial benefits to society - the economic problematization. For example Mojtehedzadeh quotes Canadian economist Pierre Fortin: “In 2008 in Quebec, we estimated that the two levels of government pocketed $\$ 900$ million over and above the additional cost it incurred by going universal" (Mojtehedzadeh, 2014, Oct 26). Similarly, Anderssen's (2015, Oct 2) statement that “investing in single mothers - with social infrastructure such as affordable child care and housing - needs to be seen as an economic step to reducing child poverty" bridges the poverty reduction and economic problematization of the issue. In these examples, a very clear, rational cost/benefit analysis supports the position that childcare should be seen as an immediate economic and, therefore, a public concern. 
While the fundamental "reasons why" childcare is a public problem was discernable in the CDA sample, the reasons why childcare is a public problem (i.e., the economic, poverty reduction, labour force participation and women's equity problematizations) were not as prevalent in Period B articles outside the CDA sample. There were more many articles in Period B that put forth the idea that childcare is a public problem but fewer that deconstructed how and why this conceptualization of childcare is warranted. The rationales that did emerge in the CDA were consistent with the rationales that emerged in Period A though they did not get as much "play" or "air" at a time when public childcare policy was a more tangible possibility (i.e., a key plank of at least one federal party).

\section{Moral evaluation}

Appeals to legitimacy through moral evaluation are difficult to discuss outside of value assumptions and ideology, since moral systems are deeply rooted in the underlying values and beliefs of people. Articles published in The Star and The Globe generally took the position that the state has a moral obligation to assist hard working parents who struggle to find care for their children in their absence - especially those who are following society's neoliberal "rules". For example, Olive states: “it's worth repeating that most people go to work every day" (Olive, 2015, Aug 4). This article goes on to describe the childcare struggles of a woman employed full-time. Affordable, accessible childcare is described by Star reporter Mojtehedzadeh, (28 Feb, 2015) as “critical' for women to be able to work and have a sustainable income so that they will have a better, healthier life for their children and themselves". Similarly, The Globe's Anderssen (2015, Oct 2) tells the "heartbreaking" story of a well-educated single mother in Vancouver who 
was struggling to escape poverty. Globe columnist Renzetti simply asks: "If both parents work, do we want a safe place to put children during the day?" (Renzetti, 2014, Oct 25). The idea that groups of hard working Canadians and their children consistently face barriers to inclusion in society because they participate in the paid labour force was frequently positioned as a moral problem legitimizing the public problematization of childcare in both The Star and The Globe.

More radical is the moral claim put forth by Globe columnist McLaren: "Child care is not a women's issue. It's not even a family issue. Like health care or education, it's an all-of-usin-it-together issue" (McLaren, 2015, Sept 4). This claim steps outside of social liberal and neoliberal logic to embrace social democratic values. High quality care for children is reconceptualised as a necessary resource to which every Canadian, whether they fit the neoliberal mould or not, have a right. The moral idea that every citizen, through mechanisms of the state, has a responsibility to ensure that young children are well cared for is suggested.

Moral evaluation was a key, if not the key, mechanism of legitimization in most Post articles - although the moral code appealed to was much different than the other two papers. Rather than focusing on childcare as a necessary mechanism of opportunity for parents as most articles in The Star and The Globe did (i.e. the necessary opportunity to enter/remain in the paid labour force), The Post emphasized children's well-being as being inextricably connected to the ability of parents to provide full-time, direct care for their children. As mentioned in other sections, non-parental childcare was referred to as "a place to park kids" (Kheiriddin (Kheiriddin, 2015, Apr 30), something in which children should not be "exposed" and/or akin 
"taking children out of the house" (Kheiriddin, 2015, Sept 24). Kheiriddin suggests that parents opt for "daycare" "because raising small children is a thankless, exhaustingjob" whereby "the soulless office cubicle suddenly becomes a beckoning oasis" (Kheiriddin, 2015, Sept 24).

Similarly, Post columnist Stephen Gordon's positioning of "daycare" as a "trade-off" ("letting" more women work but having "a negative effective on their children") also suggests that mothers should stay home and not use "daycare" to provide for the well-being of their children. Such discourse is rooted in social conservative moral judgements about the "good" mother and/or "good" parent. Romantic and idealized notions of what children need to be well - parents (typically mothers) at home - was positioned as morally superior to calls to support parents' access regulated, affordable childcare.

Of course, the material realities of the large majority of Canadian parents requires both parents to work in the paid labour force. Appealing to moral arguments so far removed from the material realities of Canadian children and families has ideological appeal, but little policy relevance in a context where it is practically impossible to have one parent solely devoted to childrearing for the first five or ten years of a child's life. Furthermore, such a sentiment sets up an impossible situation for parents (again, mainly mothers), who struggle with feelings of inadequacy when they are unable to be both a full-time parent and full-time worker. Kheiriddin's policy recommendation that the state should be supporting parents to do more "...we [the state] should educate parents to better care for them [children], not simply take them out of the house for eight hours a day" (Kheiriddin, 2015, Sept 24), furthers the conceptualization of ideal parent as one who does more and learns more despite having less time and fewer resources to do so. 
Appeals to these social conservative values legitimize the idea that parents do not need more state support in caring for their children, but rather need to make a greater personal sacrifices in order to better care for their children.

\section{Mythopoesis}

In contrast to authorization, rationalization and moral evaluation, mythopoesis embraces subjectivity and the raw, emotional stories that bring social policy to life. Narrative brings a human aspect to the abstract nature of public policy with people coming to personally identify/empathize with the struggles of other beings. What theoretically "should" be, on rational, authoritative or moral grounds, is translated into what is or has been for particular people in a given time or place. For example, Anderssen (2015, Oct 2) quotes a mother who describes her own and her childcare provider's situation with unpredictable work and lack of access to quality, affordable childcare: "We were two women and one little boy among thousands, trapped in a culture of poverty". Similarly Olive (2015, Sept 28) relays the story of his "friend", a Tim Horton's worker, who wants to have another child but cannot due to the prohibitive cost of childcare for a second child: "One of my friends behind the counter at my local Tim Hortons would like to have a second child. But with daycare expenses of $\$ 12000$ a year, she and her husband cannot afford to do so". In a rare approach to reporting, Globe columnist Leah McLaren relays her own experiences struggling to find childcare as a young mother: "The single most shocking thing to me about becoming a mother was the lack of affordable child care in Canada" (McLaren, 2015, Sept 4). 
Interestingly, mythopoesis was largely absent in articles published by The Post. Abstract ideas and misrepresented "facts", rather than real human experiences, were predominant in legitimizing arguments. Rather than interviewing parents (or children for that matter), articles in The Post appealed to a narrow body of research, most of which was not peer-reviewed, to further social conservative ideological claims and elusive neoliberal ideals (i.e., the Bernard Shaw quote). The words of on-the-ground stakeholders - including community leaders and parents were largely absent. Again, the lack of real-world voices speaks to the strong role of ideology in legitimizing both the dominant market and private/family problematizations in this paper. The ideas that the free market can offers parents "choice" and that mothers are able to make more sacrifices to be better caregivers for their children simply has not been experienced by a great number of people - even in places where policies purport to further both of these ideals. In this way, real-life stories and narratives typically refute rather than support these problematizations.

One letter-to-the-editor in The Globe stands out as using mythopoesis to legitimize the private/family problematization. In this letter, author Helen Ward (President of socially conservative Kids First Parenting Association of Canada) draws on her experiences to argue against public investment in childcare spaces:

These polices [policies supporting regulated childcare] are harming families, especially low-income, single-mother families like mine, by hogging funding and discriminating against women who do not fit the elite's preferred mould of a 9-to-5 job for all parents 
and 8-to-6 daycare for all kids as if we are too dumb to know what's best for our own families. Fund families, not spaces. (Ward, 2015, Sept 8)

Typically narrative examples include details that bring policies to life. In this case, the author claims that childcare policies are "harming" her family through "hogging" funding, though it is left entirely unclear how or why she, as a single mother working mother of young children (seemingly children who require full-time childcare), is better served by policies that provide direct funding. Furthermore, the accusation that public investment in childcare suggests she is a "dumb" parent is puzzling given no supporter of regulated childcare has ever made such a claim. The idea that regulated childcare undermines the ability of parents is an idea entirely constructed by those, like herself, who embrace a social conservative ideology. In this case, such a judgement appears to be self-imposed rather than externally valid.

\section{Existential and Propositional Assumptions}

Existential and propositional assumptions are closely intertwined with ideological assumptions. The core values of people significantly influence how they understand or even acknowledge the existence of social phenomena (i.e., women's inequity). In most articles that underwent CDA from The Globe and The Star, affordable, accessible, high quality childcare was assumed to be a key component of breaking down systemic barriers to equitable participation in society. For example, sample article titles from The Star read: "Five Ways to Reduce Income Inequality" (Mojtehedzadeh \& Ansari, 2015, Feb 28), "Money Goes in Moms with Jobs Emerge" Mojtehedzadeh (Mojtehedzadeh, 2014, Oct 26), "Few Child-Care Options for Non-nine-to- 
fivers" (Monsebraaten, 2015, Sept 15). Similarly, titles from The Globe include: "For parents, daycare is the real money pit" (McLaren, 2015, Sept 4), and "forgotten moms: During campaigns, the ever-iconic, two-parent, middle-class family always gets the spotlight..." (Anderssen, 2015, Oct 2). In these examples, the existential assumption is that social inequity exists and is perpetuated through a lack of childcare policy in Canada.

After in-depth examination of the newspaper articles, a more subtle, related propositional assumption emerged: it appeared that the role childcare policy played in social equity was discussed primarily in relation to adults, usually parents, rather than to children. Put more simply, when equity issues arose and were related to childcare policy in the more progressive Globe and Star it was almost always in relation to the equity of and opportunity of adults rather than children (as the examples above illustrate). The underlying assumption here is that when parents are well, children are more likely to be well. More transparently, when parents can work full-time stable jobs and have access to high quality childcare services, children benefit not only from high quality childcare services, but also from access to secure housing, nutritious food, extracurricular programs and so on. In contrast, articles in The Post were guided by the social conservative, ideological assumption that a full-time, stay-at-home parent was essential for children's well-being. The solution from this perspective is to support parents to be do more and be more for their children. In essence, the solution to children being well is greater sacrifices on the part of parents. 
Related to this idea of parental sacrifice is the assumption that childcare and parental care are dichotomous rather than complimentary resources in the lives of young children. Articles in The Post (and the aforementioned letter in The Globe) often positioned childcare as a barrier to parenting rather than as a necessary resource for parents. National Post Articles 1, 3, 5 and 6 all make the assumption that childcare services compromise the freedom and/or undermine the ability of parents. For example, Post columnist Andrew Coyne states: "The only way to take advantage of the NDP plan is to enrol your kids in the kinds of care they think best" (Coyne, 2014, Oct 16). This example reinforces the idea that comprehensive childcare policy will inhibit the abstract "choice" of parents rather than support them with a tangible options. The idea that childcare policy is a barrier rather than a support to parents is perhaps best embodied in the Globe letter-to-the-editor written by Helen Ward:

The policies Leah McLaren and Martha Friendly endorse have already diverted billions of dollars to daycare centres for a minority of families. This has been done on the backs of parent like me, who prioritize parental child care, and the back of our kids who receive no child-care funding other than the universal child-care benefit. These policies are harming families... (Ward, 2015, Sept 8)

Interestingly, Ward is also the author of the Institute of Marriage and the Family Canada's report (reported on by Kheiriddin in her April 30, 2015 article) claiming that there is a surplus, rather than deficit, of childcare spaces in Canada. Further reflecting this never-mentioned alliance 
between Ward and Kheiriddin, Kheiriddin indicates that childcare is replacing rather than supporting parents in their role as parents when she states:

Could it be that parents play a crucial role in the development of these "non-cognitive skills," such as a sense of personal security? Or that parental separation and spending time in a group setting for long periods of time at a very young age is a stressful experience for small children — and that experience, over time, leads to increased aggression and hyperactivity? (Kheiriddin, 2015, Sept 24)

To suggest that enrollment in childcare mitigates or interferes with the "crucial" role parents play in their children's social/emotional development and that "parental separation for long periods of time" is "stressful" is again little more than an assumption rooted in a social conservative ideology. It is also entirely possible that young children develop stable and secure attachments with caregivers in a high quality, formal childcare setting, which does not interfere with parenting but actually supports parents with the difficult task of parenting.

On a more basic level, social conservative assumptions about what constitutes the family and roles within the family also emerged in the analysis of existential and propositional assumptions. In four of the six articles published in The Post, "family" was conceptualized as the prototypical Mom/Dad/child(ren) family unit. Jack Mintz, President of the School of Public Policy at the University of Calgary and columnist for The Post, distinguishes just two family types in his article on income splitting: "single earner" and "dual earner" families. "Single earner" families refer to two-parent families where there is one breadwinner while "dual earner" 
families are two-parent families with two breadwinners. Single-parent families - a large and growing demographic in Canada - are completely overlooked. Furthermore, families are typically assumed to be composed of a man and a woman whereby parents assumed traditional gender roles. Kheiriddin claims:

Mothers of children under five who work outside the home put in an average of 16 hours less a week than fathers, and 38 per cent are not in the labour force at all. While proponents of regulated care argue that those mothers would all speed back to work fulltime if they only had a place to park their kids, that isn't true: when asked what child care they prefer, parents name themselves, followed by family members, home daycare, and lastly, centre-based care. (Kheiriddin, 2015, Apr 30)

Rather than challenging the disproportionate amount of unpaid labour women produce in the home, Kheiriddin reinforces traditional gender roles suggesting women prefer to be at home. In Mintz's article, women are positioned as stakeholders in the policy debate based on their dependent marital status: "the shift to individual taxation pushed more women into the workforce since the family had to pay more tax, even if the wife would pay less on her earnings under individual compared to family taxation" (Mintz, 2014, Oct 31). The assumption here is that "the wife" is the lower earning spouse and that she has been "pushed" into the labour force rather than actively chosen to seek her own social and financial security. In this way, much of the discussion of childcare policy in The Post does not seem to reflect the actual situations and needs of the broad spectrum of Canadian parents and children who are affected by childcare policy and 
programs, but rather outdated assumptions about what constitutes a "family" as well as roles within the family unit. 


\section{Chapter 9: Discussion}

This chapter will interpret the key overarching empirical findings from Parts I and II of the project through the postmodern concepts and sociopolitical processes described in Chapters 2 and 3. The findings will be connected to the colonization of the lifeworld by systems as originally theorized by Habermas and subsequently integrated into Fairclough's (1999; 1995, 2003) work. A look at this colonization will provide insight into how and why the diversity of policy problematizations, considered central to a democratic social order by Bacchi, may have been compromised. The focus of this discussion is in exploring how the state and its economic systems create and deliver parameters of possible understandings of childcare policy during time periods when childcare was both on and off the federal policy agenda. The nature, extent, and potential implications of discourse produced through colonization on people's lived experiences in the lifeworld is also explored. This is important because, although research has shown that childcare is both an issue of concern for many individual citizens and their families in Canada, and that there are real benefits to the state in providing quality childcare, the federal government has failed to develop a comprehensive, effective childcare policy.

The second aspect of the findings that will be discussed is how the overall narrow and polarized conceptualization of childcare policy relates to the conceptual idea that discourse can be both constitute and productive as well as emancipatory and oppressive. These premises are evident in the theories of Foucault, central to the work of Chouliaraki \& Fairclough (1999) and relevant to Bacchi's WPR model of the policy process in that discourse (or discursively constructed problematizations) can be a mechanism of reinforcing and/or shifting political 
understanding and social process. The critical discourse analysis of dominant problematizations revealed that the oppressive aspects of discourse overshadowed the emancipatory aspects of discourse - again likely due to the strong colonizing forces of economic and administrative systems. Nevertheless, it is important to note and understand that emancipatory discourse did exist even in a context where active resistance to dominant norms may seem to be absent entirely.

Finally, and not specifically a goal of the project at the outset, the differences in reporting based on the position and gender of authors is explored. In regard to the position of the author, it appears that the colonization process defined the parameters through which reporters holding different positions (i.e., columnist, full-time reporter) were able to assert claims/ideas related to childcare policy. This ultimately resulted in an ideologically slanted representation of childcare policy. Also unexpected was the emergence of gendered childcare policy discourse whereby female and male reporters appear to have taken different qualitative approaches to discursively constructing the childcare policy problem. This phenomena is explored by applying Fraser's feminist critiques of Habermas" "public" and "private" spheres as well as incorporating the ideas of Canadian feminist political economy (FPE) theorists. Both Fraser and FPE theorists bring attention to and problematize the marginalization/systemic devaluation of social reproductive work and women's experiences of this in the contemporary, neoliberal sociopolitical context. A focus on “women's" work and women's experiences of gendered social reproductive work provides insight into how/why the gendered differences in reporting on childcare policy may have existed. While it is impossible to infer that gender discourse was explicitly strategic on the 
part of female authors, it certainly does not seem coincidental that female authors embraced a qualitatively different approach to reporting on the issue than their male colleagues.

\section{Colonization of the lifeworld by systems - volume of coverage}

A central tenet of this project, theoretically grounded by Fairclough $(1999 ; 2012 ; 1995$, 2003) and Bacchi $(1999,2009)$, is that the representation of contemporary social issues in the media plays a key role in determining people's understanding of these issues. Consequently, it affects thought and action related to these issues. Results of this study suggest that what appears to be missing related to childcare policy in the newspapers is the open discussion of the lifeworld, which is necessary to achieve consensus and to ensure that this consensus drives the system rather than the system driving the lifeworld. Rooted in Habermas' pioneering theory of communicative action in the public sphere as fundamental to a progressive democratic state, Fairclough embraces a deliberative democratic political order whereby political consensus pertaining to contemporary social issues is ideally achieved through open and honest communications independent of systemic influences (i.e., state, economy). While Bacchi does not endorse consensus regarding any specific social or political issue, WPR theory embraces diversity of understanding as a central component of a democratic social order. The findings from Part I of this project indicate that both economic and state systems had a major influence on the nature and extent of what was communicated about childcare policy (i.e., limiting the diversity of problematizations) and as well as how it was communicated (i.e., text and discourse

processes revealed through $\mathrm{CDA}$ ). The low levels of coverage of childcare policy (particularly in Period A) reflected explicit attempts by the prevailing Conservative government to 
downplay/ignore the care of young children as a pressing policy issue. In this way, public communication about the issue in the media immediately diverged from a democratic social order according to both Fairclough and Bacchi in the sense that communication about the issue was minimal, even though it remained very relevant to the lived experiences of Canadians particularly parents (mothers) and their children. The message that childcare was a private rather than public issue was articulated simply through the absence of childcare policy discussion in Period A and reinforced in Period B through the limited available problematizations (private market and family).

Fairclough (1995) brings heightened attention to the role that mediated communications (or lack thereof) entrenched in market systems and state systems may play in furthering the needs/interests of a select few rather than genuinely communicating information relevant to a broad audience. On a very practical level, the existence of major media outlets is dependent on the public's willingness to purchase and/or view articles, which Fairclough explicitly views as problematic (the tension between communication and entertainment). For Habermas, communicative action is fundamental to the process of reaching a common understanding and this is key to achieving rational, informed change. Again, the low levels of coverage of the issue were not likely related to the fact that the issue ceased to be important to people, but rather that there was seemingly no opportunity to explore the issue in a sociopolitical context that was opposed to change in the state's involvement in childcare policy. Just as Habermas and Fairclough caution, communications about processes within the lifeworld were vulnerable to colonization by systems. Newspapers, undermined by the economic bottom line, have a vested 
interest in publishing on topics which citizens feel are not only directly relevant to their lives, but also are possible to address in the existing sociopolitical climate. With a federal government unapologetically closed to acknowledging the childcare problem in any capacity in Period A and no formal childcare policy actions to report on, discussion of childcare policy was likely perceived to be irrelevant by newspaper editors ultimately interested in attracting readers and moving papers The idealized, Habermasian public sphere immediately broke down as policy discussions became limited to "hot" topics compatible with the existing sociopolitical order rather than topics relevant to the daily life of real, embodied people (particularly women and children's).

\section{Peaks in media coverage of childcare policy within this colonial process}

The findings illustrated an increased focus on childcare policy during election campaigns both in Period A and Period B. From a CDA perspective, it makes sense that economic systems (underscored by the ability to sell papers) become more open to communicating ideas that challenge existing systems at a time when the stability and authority of state systems is in question (i.e., election years/campaigns). If it is true that interest in the issue did not disappear as newspaper coverage did (based on demographic evidence alone), then it makes sense that election years offered newspapers the opportunity to capitalize on a less stable sociopolitical order. The issue would be perceived as potentially more relevant and more likely to attract readers. In essence, mediated communication systems could be seen to have had an opportunity because of the temporary vulnerability of state systems. While colonization was still predominant, the issues relevant to citizens have a better opportunity of being 
acknowledged/recognized through the mediated communication systems. The Star and The Globe, in particular, did publish some articles divergent from the prevailing sociopolitical order, suggesting that these papers were well positioned economically to present alternative viewpoints. More simply, people dissatisfied with the prevailing state systems would seemingly buy papers/view articles that directly challenged existing state systems. Therefore, election years provided a viable opportunity for newspapers to present alternative viewpoints on social issues and to refocus public attention on childcare as a public policy issue. A greater degree (though still far from ideal) of communicative action was evident as the mechanism of colonization shifted (from state to market).

Outside of election years, coverage of childcare policy increased in the face of immense grief. In 2013 both The Star and The Globe reported on several infant and toddler deaths in unregulated childcare homes in Ontario. These tragedies provided an opportunity for newspapers to challenge the prevailing state order. As described by Fairclough (1995), mediated texts allowed the private grief of the bereaved families to be experienced by a broad, public audience. As in election years, this provided an opportunity for The Globe and The Star to challenge prevailing state systems (or lack thereof) overseeing childcare programs and services (specifically in Ontario). Interestingly, The Post did not report as extensively on these tragedies, and articles that did report on it were largely in favour of the existing lack-of-state systems. In The Post, responsibility for the deaths was placed squarely on the shoulders of individual providers, furthering existing, neoliberal/social conservative processes of governing. In contrast, in The Star and The Globe these tragedies provided an opportunity for the children's well-being 
problematization to emerge whereby the concern suddenly and only temporarily shifted to the health and well-being of children requiring care. Unfortunately, this problematization was shortlived and was not meaningfully incorporated into ongoing policy debates.

\section{Colonization through superficial depth of coverage}

The other aspect of the findings from Part I of the study that are relevant to this discussion relates to the word counts of articles across papers. Based on the word count alone, it appears that childcare was discussed in more depth in newspapers in both periods than other research on this topic has indicated. More specifically, Albanese et al (2010) observed average words counts in the 600 range, while this study observed average word counts in the 800-900 word range. A logical inference from this finding would be that more text translates into a more thorough exploration of the issue from different perspectives within the papers themselves. Based on word count alone, it appears that when economic and political systems aligned to offer the opportunity for childcare policy to be discussed in new spapers (mainly during election campaigns), this opportunity was maximized.

However, this was not the case when these results were viewed in light of other findings. Across both periods, only a handful of problematizations were presented to readers (though these did shift between periods) indicating a rather narrow conceptualization of the problem. Furthermore, an analysis of interdiscursivity revealed that word counts were comparable across papers even though articles in The Star and The Globe included more diverse discursive representations of the issue than articles in The Post. Many articles in The Post devoted a large 
number of words to only one or two perspectives. The Globe, on the other hand, published fewer articles overall on the topic, but published some of the longest articles where diverse problematizations were most thoroughly explored (i.e., Anderssen's series in 2013). It appears that more words and/or articles did not immediately translate into a more nuanced, detailed exploration of the issue. Instead, it seems that there were some clear parameters, seemingly defined by state and market systems that outlined the degree to which counter discourses were permissible. While there was some opportunity within the economic system to challenge the state, it turned out to be limited. From a WPR perspective, the parameters of discussion were immediately compromised, which has troubling implications for a democratic social order. Furthermore, problematizations highlighting the perspectives of women were largely ignored precisely the concern Bacchi developed WPR theory to address.

Overall, Habermas and Fairclough's concern about the "colonization of the lifeworld by systems" provides some key insights into the results found here. It becomes apparent that widely produced and consumed public communications, ideally free from the influences of state and economic systems, are actually completed entrenched within these systems. Communication is ultimately motivated by strategic factors - selling papers, getting the most "likes" and sharesrather than by genuine communicative factors providing for the presentation and engaging discussion of genuine information. When an organization is fundamentally dependent on the state (some media organization receive public funds) or economic systems for survival, their ability to independently report and critically discuss issues is immediately compromised. Today, with organic and unscripted communications being systematically replaced with the sharing and 
consumption of mediated communications, Habermas' and Fairclough's concern about the breakdown of a democratic social order becomes increasingly amplified. Reaching consensus through communicative action in the public sphere - the prerequisite steps for "knowledge" in a deliberative democracy for Habermas (1962) and Fairclough- shifts further and further away from the realm of possibility. As Bacchi's theory highlights, the very issues that are discussed in a public forum have in many ways been predetermined by forces beyond our individual control (for her, through a process of governmentality rather than formal systems per se although the two concepts inherently overlap here). This occludes some problematizations from entering the conversation at all. CDA encourages the critical critique of normative discourse in an effort to highlight how and where hegemonic power relations manifest through discourse. More specifically, Fairclough critiques the role neoliberalism plays in normative, mediated discussions about a wide number of issues. This project reveals that even when state and economic systems provide an opportunity to debate issues in normative, mediated communicates, parameters around the depth of discussion is limited. Ultimately, the volume and depth of childcare policy discussion in the media appears to be underpinned by hegemonic power relationships. Nuanced discussions that challenge the sociopolitical order, including problematizations of childcare policy that reflect those most vulnerable and impacted by a lack of childcare policy (i.e., women, families and young children) remain unexplored. Both the lack of discussion, and the superficiality of the discussion (wherein different understandings remain unexplored) reinforce the prevailing sociopolitical order whereby the care of children is largely accepted as a private matter (family and market). 


\section{Implication of colonization: Occlusion of other ways of being}

The most concerning implication of a lack of discussion overall and a lack of a nuanced discussion related to childcare policy is that different ways of living and being are inherently occluded. Citizens, in this case women and children, cannot come to understand the existing, hegemonic state of the world in a progressive way without the awareness that other ways of being are possible. When thinking consistent with prevailing state and economic systems is further reflected in key discussions in a public forum, the opportunity for debating alternatives is denied. Normative social practices and ways of being become the only ways of being. Furthermore, when childcare policy debate consistently emerges only as a result of an impending election, citizens may come to think of childcare policy as little more than political strategy - a sentiment put forward by a few authors included in this study. This would make citizens even more weary of engaging in discussion of the possibilities of alternative childcare policy problematizations or discourse (should they exist) as citizens may feel they are being manipulated or taken advantage of for political gain. From a WPR perspective, the overall lack of childcare policy discussion and lack of depth of discussion when it did emerge continues to situate the care of children as a private "problem" of individual people - mainly of women and mothers - rather than a collective issue in need of a public solution. Existing ways of being and doing are reinforced rather than challenged in the public sphere, perpetuating hegemonic power relations. As long as these social practices and discursive representations of these social practices remain normative there is little space for critical reflection and progressive action. Deliberative democracy remains elusive in every sense. 
Findings show that some newspapers, typically The Star, but also The Globe, were better able to provide alternative conceptualizations of the childcare "problem" than The Post (though still far from diverse). These papers, with their more left-of-centre ideological orientation, probably had a more progressively oriented readership base. Unfortunately, when articles challenging existing systems are made available in papers likely to have a progressive readership base, it is unlikely that alternative understandings are reaching the citizens who would benefit most from thinking about the issue differently - a problem related more to the contemporary, largely digitized construction of communications in society rather than newspapers per se. Furthermore, articles may be immediately discredited by citizens by virtue of being published in a particular newspaper. In this way, unless different problematizations are available in all papers reaching a broad and diverse readership, divergent thinking about an issue is unlikely. When such insular thinking occurs, the existence of $a$ public sphere, ideal or not, is called into question as divisive public spheres are created. While the spaces are public, the people who occupy the spaces are divided, typically along ideological lines.

In a contemporary sociopolitical climate where newspapers are arguably read more through social media channels than any other channel (i.e., sharing articles through Facebook or Twitter), insular communications more closely reflecting one's existing understanding of the world increasingly become the ones to which we are exposed. In this way, a double colonization process occurs - that between what makes it into the public space (the formal journalistic processes which have been critiqued above) and that which is widely disseminated through the public space (the less formal processes of sharing articles). In the case of the latter, citizens self- 
classify and colonize creating divisions in the public discourse - divisions which appear to be becoming more and more entrenched and polarized. Of course, with few articles published that represent the views of "progressives", alternative public spaces cannot remain viable let alone grow. In most of Period A, as well as much of Period B, it appears that there was little room for progressive childcare policy debate in any public space.

\section{A narrow and increasingly polarized conceptualization of the childcare policy "problem"}

Looking at the communications that existed pertaining to childcare policy between 2008 and 2015, the WPR findings revealed that a narrow conceptualization of the childcare policy problem was available to readers in both time periods. This narrow conceptualization of the problem was ironically more pronounced in Period B when the overall volume of coverage increased. The private/family problematization was dominant in The Post and The Globe in both Periods (and still very common in The Star), while the market problematization was dominant in all three papers in both Periods. The public problematization surged in all three papers in Period B compared to Period A. These findings suggest that there was an increased polarity of understanding of childcare policy in Canada in that there was an effort to both challenge and endorse existing understandings of childcare policy in the limited public discussion of childcare policy that did emerge. The most extreme problematizations took centre stage while the space to contemplate a wide range of childcare policy problematizations between these polarities was actually reduced in Period B compared to Period A. This finding, interpreted from a postmodern perspective, speaks to the fluid and relational conceptualization of power (foundational to both 
WPR and CDA) that embraces discourse as both oppressive and emancipatory. At the same time however, it appears to suggest that discourse during election periods may be limited as positions become over-simplified and the nuanced arguments supporting these positions are downplayed.

According to Chouliaraki \& Fairclough (1999), discourse is oppressive when it systematically disadvantages or takes advantage of certain groups of people. The oppressive potential of discourse was perhaps most pronounced in Period A, when there was an absence of discourse on childcare policy altogether. Even though the discourses that did exist in Period A were more diverse, the diversity of problematizations holds little weight, if no one is paying attention to them. Competing problematizations existed, but the whole issue was so seldom discussed that none received much attention in the media. Drawing on Bacchi's metaphor, it was as if several dogs were barking in the distance (each representing a childcare policy problematization), but none loud enough to be heard or acknowledged. In this way, childcare policy was rendered invisible and uncontestable.

In Period B, three of those "dogs" moved into the foreground and barked loudly. The private family and market problematizations were competing with the broad public problematization of childcare. Compared to Period A, a surge of attention was brought to childcare policy in newspaper articles but the field of possibilities for understanding the problem was reduced. Two of the dominant problematizations reinforced the existing sociopolitical order whereby childcare was conceptualized as a private responsibility (i.e., the private family and market) and one challenged this (the public problematization). The problematizations that 
hedged these polar problematizations in different ways were notably absent (i.e., labour market participation, economic, poverty reduction).

The polarity of dominant problematizations also speaks to Chouliaraki and Fairclough (1999) and Bacchi (2009), with its emphasis on both the constitutive and productive aspects of discourse/problematizations. In regards to the latter, Foucauldian notions of governmentality explain the dominance of the private family and market problematizations. The existing nature of childcare policy, entrenched in social, historical and economic norms, is perpetuated through discourse that reflects the status quo. Historically, most voting/consuming adults across Canada have been cared for by friends or family members in unregulated, informal and unremunerated childcare environments (parents, grandparents, friends, neighbours). More recently, as economic and demographic realities have made it less possible for families to provide this care, the solution has been to purchase care in a market, even though market principles (i.e., lucrative profit margins) and care work (emotional, labour intensive practice) are fundamentally incompatible. The private family and market problematizations reflect existing social practices in North America and are therefore easy to understand and embrace for Canadians. The CCED tax refunds and monthly UCCB deposits (the policy solutions that flow from the private/family and market problematization) were already incorporated into existing childcare arrangements and household budgets. From Bacchi's perspective, the subjectification effects of these private problematizations meant that people had come to understand their childcare struggles in an oppressive way - as their own personal failure rather than as a systemic problem (recall the example of the single mother of twins in Chapter 2). In this way, discourse both constructed and 
perpetuated hegemonic power relations in society whereby both parents (typically mothers) and (poorly) paid predominantly female caregivers bear the sole responsibility for caring for young children.

However, Chouliaraki \& Fairclough (2009), and less directly Bacchi (2009), are also adamant that discourse can be emancipatory. Bacchi (1999) highlights the importance of broadening conceptualizations of policy problems from different perspectives, particularly from the perspective of women. More directly, Fairclough \& Chouliaraki (1999) emphasize that discourse is as much a constructive tool as it is a constructed by society. These authors are overtly committed to the critical analysis of discourse as a tool for an emancipatory democracy. The broad public problematization of the issue also becoming dominant in Period B would appears to indicate that there was evidence of discursive/hegemonic struggle. While two of the three "dogs" were attempting to maintain the status quo, one of the "dogs" was committed to changing it. The pronounced emergence and dominance of the public problematization indicates that an alternative way of being was also widely available. In this way, discourse - and the fluid power relations negotiated through it - appears to have the potential to be both oppressive and emancipatory.

Unfortunately, a closer examination of data related to the discursive construction of the public problematization in Period B suggests that this struggle was much more muted and therefore less emancipatory than it could have been. While there was widespread acknowledgement of childcare as a public problem, there was remarkably little discussion as to 
how or why the public problematization was justified. The children's well-being, family equity, women's equity problematizations - central pillars of a public problematization of childcare actually faded further into the background than in Period A. Simply put, there was a major positive shift in the availability of the public problematizations, but rarely did newspaper articles adequately or thoroughly explain or expand upon what a public problematization of childcare meant. The reasons why it is important for the government to take a leadership role in caring for children was downplayed, while the elusive idea that the government should play a key role was magnified. Referring back to Bacchi's metaphor, the dog barked, but there was little opportunity to find out why she was barking. Without that information, the barking (in this case articulations of the public problematizations) likely grew redundant. In contrast, the CDA analysis revealed that articulations of the private family and market problematizations were bolstered through discursive strategies that were accessible and resonated with people. Both the redundant and superficial articulation of the public problematization and discursive strategies reinforcing the private problematizations are further discussed below.

\section{The limitations of the discursively constructed public problematization}

The NDP's $\$ 15 /$ day national childcare plan was mentioned to varying extent in the majority of articles in Period B. It was this childcare policy proposal, initiated by the official opposition that brought childcare policy back into the spotlight. However, the analysis revealed that this problematization was rarely discussed or explained beyond what came to be a $\$ 15 /$ day slogan. In this way, a focus on the cost to parents - even if it was a reduced cost - risked reinforcing the commodification of care rather than strengthening the reconceptualization of 
childcare as an essential public resource. Furthermore, the NDP coupled their \$15/day childcare policy with a promise of keeping the UCCB - two policies which are ideologically and practically at odds with each other. The common "problem" these policy solutions share is offsetting the high commodified cost of childcare for parents. The focus is not related to the actual care of children. It is no surprise that newspapers embraced the commodification of care through a focus on "cost", though it is surprising that the commodification of care became inextricably linked to the public problematization. In this way, although the public problematization was frequently mentioned, it was discursively presented as congruent with neoliberal, market logic rather than as an alternative to such a conceptualization. On the rare occasions when a public system of childcare was meaningfully contemplated, it was often dismissed as being utopian or unrealistic (a "magical unicorn"). In fact then, the way the public problematization was articulated frequently functioned as a mechanism for the reinforcement of the policy of the existing neoliberal, hegemonic sociopolitical order rather than providing a challenge or alternative to the status quo.

\section{Discursive articulation of childcare as a private problem reinforced a hegemonic and gendered sociopolitical order}

When childcare policy re-emerged in the media in 2015, all three dominant problematizations largely reinforced existing governance and governmentality structures in society. Since the private/family and market problematizations instantiated dominant ways of approaching the care of young children, discursive strategies reinforcing these problematizations were plentiful and relatively easy to access. In the simplest sense, these childcare 
problematizations were consistent with how people already understood the care of children-a responsibility of the private family to either provide themselves or purchase in the free market. That the conversation frequently focused on "daycare". "daycare spaces" and even "childcare spaces" rather than the active and complex process of caring for young children, attests to a wide acceptance of childcare policy as the pursuit of low-level, custodial care services in physical buildings/spaces outside of the home. Relying on such language closes the door to understanding and appreciating the active, intensive and emotional process of caring for children, while also completely overlooking children's experiences of care. Care becomes a place that can be purchased or a mechanisms for increasing the market's bottom line rather than a complex, intensive process that is absolutely central to the existence and well-being of both children and caregivers. Such a phenomena again illustrates the colonization of the lifeworld whereby the experiences of women and children are discursively and therefore practically ignored in favour of economic gain.

Perhaps most concerning was the finding that the public problematization was predominantly discussed in a way that was consistent with a neoliberal conceptualization of childcare (i.e., reducing the cost to parents for the commodified service or appealing to the economic benefits of affordable childcare rather than challenging the commodification of care altogether). This appears to have severely compromised the emancipatory potential of discourse. While there were a few examples of authors who, at times, challenged neoliberal understandings of care in Period B (Anderssen, 2015, Oct 2; Mojtehedzadeh \& Ansari, 2015, Feb 28; Monsebraaten, 2015, Sept 15; Renzetti, 2014, Oct 25), the majority of articles that included the 
public problematization of childcare did so in ways that drew on arguments consistent with neoliberalism's separation of social and economic production rather than fundamentally challenging the dichotomization of these two interdependent aspects of production.

In this way, the hegemonic status quo is not only maintained but actively reinforced even in articles where the public problematization was evident. As described and elaborated on by FPE scholars, the continued, neoliberal separation of social and economic production systematically disadvantages women who carry out the bulk of both underpaid and unpaid care work. The knowledge, skills and capacities of caregiving professionals continue to be extremely undervalued in a context that considers such work separate from, rather than central to, economic production. Instead, such work continues to be understood as "natural" for women, ultimately the product of love and passion rather intensive, complex and skilled work worthy of adequate financial remuneration. Similarly, it is assumed that unpaid social reproductive work in the home will be assumed by women who are also working in the formal labour market. That this places women in an impossible situation as full-time caregivers and paid workers is essentially ignored.

\section{Discursive reinforcement of the private/family problematization}

While the dominance of the private market problematization is concerning (yet understandable in a neoliberally saturated society), the dominance of the private/family problematization is a little more difficult to understand and/or interpret. From a neoliberal perspective, this problematization is seemingly outdated as there are in reality very few parents who are in a position to not engage in formal, paid labour for their own and their family's 
survival. Yet, the idea that a parent (usually the mother) should be at home with her child(ren) continued to occupy much of the childcare policy conversation. The findings, interpreted through the conceptual tools in this project, suggest that the inherent tension between meditated texts as communication versus entertainment as well as the discursive dichotomization of parental and non-parental care of young children contributed to the dominance of the private/family discourse.

The tension between mediated texts as a communicative tool versus entertainment was particularly pronounced in The Post. Highly emotive words such as "exposure", "harm", "risk" and "danger" were repeatedly associated with regulated "daycare" services, ultimately suggesting that Canada's current lack-of-childcare, which leaves thousands of young children to be cared for by unqualified caregivers in a multitude of unregulated, unknown care environments, is a better alternative than placing children in regulated childcare services. Relying on such sensationalized language, often in the context of irrealis statements no less (as in the case of Post reporting on the NBER working paper), lent itself to situating "daycare" policy as the problem rather than a solution to the current care crisis in Canada. Again, this discursive strategy illustrates how discourse may be used as a mechanism of colonization (reflecting a newspaper's economic bottom line) rather than as a tool for the genuine communication of information in a public space. These poignant, emotive words, especially when associated with young children, catch the very limited attention of citizens (ultimately positioned as consumers in our neoliberal society) scrolling through their newsfeed on their morning commute. As 
Fairclough (1995) explicitly cautions, the commercial bottom line of "news" organizations appears to have trumped the informative function of communication in the public sphere.

Also contributing to the dominance of the private/family problematizations was the dichotomous conceptualization of informal care provided by parents and formal, regulated care provided by others. Rather than affordable, accessible high quality regulated childcare being discussed as a support to parents in caring for their children, childcare was often discussed as an alternative to parental care. The overarching assumption here is that childcare is necessary only when parents fail to provide the care young children require. That there could be value in nonparental, formal care relationships and processes extraneous to the formal economic production was notably absent from the childcare policy discourse. Seemingly, the experiences and opportunities which early childhood educators and childcare offer young children are assumed to be necessary/valuable only in the absence of parental care.

Even more concerning, however, is the discursive construction of the private/family problematization mainly evident in The Post (and in one letter to the editor in The Globe). The private/family problematization was often constructed in a way that suggested regulated childcare actually interferes with the ability and/or willingness of parents to care for and therefore parent their children (i.e., Ward, Kheiriddin, and Gordon). This premise is extremely problematic in a sociopolitical context that necessitates that mothers ${ }^{46}$ engage in formal

46 The term "mothers" instead of "parents" is used here to highlight the reality that mothers still take on the majority of unpaid care labour. This is not to diminish the increased role of fathers in the unpaid care labour within 
economic production. Essentially, social conservative ideals come into direct conflict with neoliberal realities whereby mothers are placed in an impossible situation. They are considered inadequate and selfish, both for pursuing paid labour (thereby abdicating care responsibilities) and for abdicating paid labour responsibilities in favour of full-time caregiving. The ideal mother/worker "balances" both, even though such "balance" is practically impossible given that she cannot be in two places at once. Rather than being regarded as the impossible situation that it is for mothers, the way in which the private/family problematization was communicated in The Post positioned mothers as being uneducated, unorganized and even irresponsible in regards to "balancing" paid and unpaid labour. Solutions discussed included parent education programs and greater parental sacrifice - as if more education and/or less leisure time would somehow allow mothers to be full-time caregivers and workers. Even more ironically, this problematization was bolstered through a discursive approach that situated children as the ultimate losers when mothers engage in formal economic production. Regulated childcare arrangements were projected not only to be directly harmful to children, but also harmful to the foundational relationship between mothers and their children. Time spent outside of primary relationships with mothers was discussed in a way that compromised the security of these relationships rather than supported them.

families, but simply to highlight that the bulk of this labour is still predominantly carried out by women in the majority of families. 
These findings illustrate the necessity of Fraser's critique of Habermas' separate social spheres. Childcare policy simply cannot be addressed without bringing to light the explicitly gendered nature of the private lifeworld, where the care of children is projected to occur in the dominant private/family problematization. In The Post in particular, women/mothers were explicitly delegated to the private lifeworld whereby all other roles were positioned as not only secondary to her unique and essential role as mother, but fundamentally incompatible with her role as mother (to be anywhere else was positioned as threatening the health and safety of her child). Because a neoliberal socioeconomic order concurrently demands that she engage in formal economic production, navigating these responsibilities is left entirely to her as an individual regardless of the fact that such "balance" truly cannot exist. To ignore the gendered nature of care in the lifeworld alongside the economic necessity of women in the formal market serves to not only reinforce but strengthen hegemonic power relationships between genders. As long as the care of children is conceptualized as private and the economic climate demands that mothers work, Canadian women will remain systematically disadvantaged.

\section{The role of individual authors in the reporting process - examining the position and gender of authors in relation to the discursive construction of the issue}

Although not an explicit goal of this project at the outset, it became apparent through the CDA that the position and gender of individual authors may have played a key role in the discursive representation of the issue in the different newspapers. In reference to the former, the author's position as a regular columnist, full-time reporter or guest author/columnist appears to 
have influenced the discursive construction of stories. While all authors were reporting through the same overarching genre (newspapers) they are arguably positioned very differently within the colonial, economically driven mass media industry, with some more directly attached to the economic bottom line than others. Full-time reporters appear to represent the ideas or position of the papers perhaps because they are the accountable to the editorial committee of the papers. Full-time reporters would seemingly be much more concerned about the feedback of editors considering their editors are also their employers. To stray too far from the wishes of the editors could directly compromise their employment and therefore well-being. On the other hand, guest authors/columnists and even regular columnists seemingly have more leeway to report different or more extreme positions on the issue. Not only are guest authors permitted to give their opinion, but they may be encouraged to do so. Interestingly, the majority of articles addressing childcare policy in The Star were written by full-time reporters with some written by regular columnists. In contrast, the majority of article written about childcare policy in The Post were written by regular and guest columnists. In The Globe there was a wider mix of authorship with guest columnists, regular columnists and full-time reporters covering the issue. Authors in The Post seemingly had the most leeway in making extreme, ideological and often overly oppressive claims. More specifically, the extreme socially conservative and neoliberal claims made by Stephen Gordon and Tasha Kheiriddin in the right-of-centre Post and Helen Ward in The Globe were not counterbalanced with contrasting social democratic claims made by full-time reporters in the left-of-centre Star (i.e., articles written by Laurie Monsebraaten and Sarah Mojtehedzadeh). 
The implications for democracy are troubling as reporting becomes inherently lopsided. The structure of mediated newspaper systems themselves come to favour ideas and values that are overtly oppressive to already marginalized groups in society. While papers may appear to be more progressive in that they have full-time reporters devoted to the issue (for example, Laurie Monsebraaten in The Star), in actual fact this may be a liability in terms of countering dominant discourse. Unless full-time reporters are permitted and encouraged to construct overt counterdiscourse, something any paper would hesitate to do given the potential economic ramifications of an organization presenting itself in a controversial light, dominant discourses perpetuate themselves. Occasional guest authors appear to have the upper hand in communicating extreme and, in the case of The Post, oppressive perspectives. The resulting discourse, consistent with bolstering the existing sociopolitical order, is likely not intentional by any person or institution, but it does help to explain how and why the public problematization was poorly developed in comparison to the dominant private problematizations, that ultimately result in oppressive rather than emancipatory discourse.

While The Globe included more authors from diverse positions (i.e., full-time reporters, regular and guest columnists) it is worth noting a major, positive exception to the above discussion. Some of the most progressive articles written between 2008 and 2015 were written by one full-time Globe reporter - Erin Anderssen. Through her lengthy special series on childcare in 2013 and other articles published throughout this timeframe, Anderssen appears to have been able to provide emancipatory childcare policy discourse challenging the sociopolitical order while also holding a position as a full-time reporter. Her articles always included a public 
problematization of the issue and went to great lengths to justify this problematization on several grounds. Further research to explore both how and why Anderssen was able to resist the widespread power of colonization inherent in mediated processes would be worth pursuing. Whether this was a purely individual endeavor, or an individual endeavor supported broadly by her employer (or perhaps one member allied editor), could help provide insight to other progressive reporters who may not currently see themselves as in a position to take overtly progressive positions and to help rectify the ideologically lopsided reporting on childcare policy.

\section{Gendered differences in reporting}

Even more pronounced than the differences noted in reporting related to the positions of the authors were the qualitative differences between female and male authors in discursively reporting on the childcare policy problem in Canada. Unlike Rinehart (2007), who observed an overt male editorial bias to reporting on childcare in newspapers, slightly more women than men reported on the issue than between 2008 and 2015. However, it became apparent that female authors approached their reporting qualitatively differently than their male colleagues in two notable ways. First, female authors embraced a once removed modal approach whereby they were more likely to rely on the voices of others to make claims rather than asserting a claim or position in their own voice. In doing so, female authors had a much higher degree of intertextuality than male authors. Whether supporting (i.e., articles by Laurie Monsebraaten or Erin Anderssen) or rejecting (i.e., articles by Tasha Kherirddin's) government lead childcare policy initiatives, female authors looked to reputable and varied sources to both assert a claim and back it up (i.e., "he/she said x, the study suggested x" rather than "this is the way things 
are"). While male authors often drew on many of the same ideas supported by experts or "research", they were far more likely to make the claims assertively in their own voice without referencing external sources. Essentially, female authors constructed their argument through research, statistics or expert quotes while downplaying their own subjective opinions, interpretations or claims.

The once-removed modal approach to reporting, typical of female authors, suggests a gendered, double-standard to reporting in the public sphere. For no apparent reason other than being female, female authors may have felt it necessary (consciously or unconsciously), or perhaps were overtly required to draw on the "legitimate" voices of "others" to situate arguments within the "objective". Objective evidence holds weight in a neoliberal society that gives primacy to data, facts, and ultimately the economic bottom line. It ties in naturally to the quantitative, objective nature of the systems rather than the qualitative, subjective nature of the lifeworld. Female authors were more likely to make their arguments through such "evidence" than were their male colleagues. This gendered differences in modality of discourse appears to reflect a hegemonic power structure whereby female authors must go above and beyond the requirements of male authors to both make and support claims. This finding also confirms Fraser's (1990) critique of the gendered nature of the public sphere because it appears that female authors either feel the need to or are required to justify their presence, thoughts and ideas through an external, objective "other" in a way that male authors do not consider necessary. 
This finding also relates to Mahon's (2009) observation that "neoliberal logic treats women exactly like men" (p.52). Not only is women's paid and unpaid reproductive labour taken for granted and notoriously undervalued in a neoliberal sociopolitical context, as the discussion of the dominant problematizations illustrated, but it appears that female authors were required to produce discourse that was congruent with a dominant, non-gendered neoliberal sociopolitical order. Rather than embracing their own subjectivity, particularly on an issue that has likely impacted them more profoundly than their male colleagues, female authors downplayed their subjective experiences ${ }^{47}$. Whereas David Olive of The Star drew on his subjective experiences through mentioning the Tim Horton's worker he encountered daily (who wished to have another child but could not afford it), the female authors rarely shared their own experiences. Whether or not this was an overtly strategic approach on the part of the authors is impossible to know from this study. Further exploration of this observation though direct discussion with newspaper columnists and reporters would appear to be worthwhile.

The second unique feature of articles written by women relates to their greater reliance on mythopoesis. While hegemony appears to be evident in the downplaying of their own experiences and subjective opinions by female authors, an examination of mythopoesis revealed that this modal approach may have concurrently offered an opportunity to challenge hegemonic

\footnotetext{
${ }^{47}$ The one exception to this was Globe columnist Leah McLaren risked sharing her own struggles as a mother trying to find and afford childcare to strengthen her position. Her position as a columnist, rather than full-time reporter, may have allowed her to take this risk.
} 
power structures in society through featuring the voices of other women. An examination of mythopoesis revealed that only female authors acknowledged, included and related childcare policy to the contextualized, emotional experiences of the women most affected by a lack of childcare policy in Canada. While certainly not common, a handful of articles in The Globe and The Star stand out in their attempt to tell the individual stories of mothers facing isolation, poverty, and social exclusion, due to their lack of access to high quality affordable childcare for their children. Of note, full-time reporters Laurie Monsebraaten and Erin Anderssen repeatedly made explicit efforts to directly quote individual mothers who continue to bear the brunt of the dominant, private problematizations. Erin Andersen's lengthy article (over 2000 words) in The Globe, published shortly before Election Day 2015 departs remarkably from virtually every other article written on the topic, as she tells the stories of three mothers "trapped in a culture of poverty created by low-wage work and unregulated child care" (Anderssen, 2015, Oct 2). This article does not shy away from the emotional, though it solidly embeds these emotional stories within data and research and never brings in the subjectivity of the author herself. Anderssen effectively situates the struggles of women in the private lifeworld as a central concern in the public sphere thereby challenging the gendered dichotomization of the two. Again, Anderssen's discursive approach directly illustrates that active resistance through discourse is possible. It may not be probable, but that it exists at all in mainstream media provides hope that mediated communications can become a mechanism of social justice.

Taking these findings relating to the gendered nature of reporting together, it becomes evident that articles written by female authors draw on more diverse ways of knowing. Female 
authors were more apt to appeal to traditional, masculine "objective" sources/facts to make their claims but concurrently made a greater effort to also include the nuanced subjective narratives of individual women. In this way, female authors both played by neoliberalism restricting rules (downplaying their own subjectivity) and challenged them (telling emotive stories). In fact, it could be argued that several of the female authors included here were particularly skilled at bringing in the subjective experiences of women through a notably objective approach. The gendered lived experiences in the private lifeworld were communicated in a manner consistent with dominant neoliberal ways of understanding and being. Mastering this delicate dance between the objective and subjective, quantitative and qualitative, is fundamental to any discourse challenging the stubborn hegemonic and gendered power structures in society that continue to demarcate the public and private spheres and allow systems to maintain their control over the lifeworld. 


\section{Chapter 9: Conclusion}

The goal of this chapter is to highlight the important contribution of this project to academic literature and to childcare advocacy efforts. Emerging out of the findings and discussion chapters, the implications of this project for women, children, politicians, policymakers, researchers, advocates and journalists are explored. Building on this, possible avenues for further research, as well as practical recommendations for those both producing and consuming childcare policy discourse are examined. Finally the key theoretical, methodological and practical limitations of this study are acknowledged and discussed.

\section{Implications}

This project has illustrated the deep connections between the discursive representation of childcare policy and ongoing - often gendered - hegemonic power relationships in society. Consistent with Dorfman and Woodruff (1999), research published almost 20 years ago, it is clear that dominant childcare policy representations emphasize the care of young children as a private commodity and/or familial responsibility rather than a public resource. Even when a public problematization became dominant in Period B, a closer analysis revealed that this problematization was articulated superficially, ultimately leaving the care of children commodified. As was discussed in the last chapter, the colonial processes of state and economic systems left little room for the active resistance of contextualized people. While this systematically disadvantages many groups in society, the positioning of women and mothers is

particularly concerning. The contemporary mechanism of emancipation for mothers - paid work 
- is positioned as a barrier to their children's well-being through the dominant private/family problematization. At the same time, the mechanism of accessing paid work - high quality care for their children - is positioned as accessible primarily through commodification in the dominant market problematization. Essentially then, the representation of childcare policy in Canada rarely reflects the struggles of mothers, their children and families, who are bearing the brunt of policy neglect. In fact, the childcare policy discourses reflected the struggles of mothers less so when childcare policy re-emerged on the federal policy agenda (Period B) than it had in in the 7 years prior (Period A).

The implications of this are extremely concerning in a neoliberal context where women and families increasingly struggle to "balance" work and childcare (Principe, 2014; Sauve \& People Patterns Consulting, 2009; Working Families \& Bright Horizons, 2017). As long as neoliberal ideals continue to omit gender from the childcare policy discourse, women will be vulnerable to feeling that their failure to achieve this "balance" is a personal rather than systemic. Unless the struggle can be positioned externally rather than internally, there will be no political motivation to actively resist the sociopolitical and economic barriers instantiating their (our) struggles. The problem will continue to be seen as the responsibility of individual mothers (or "families") to either provide the care young children require themselves or be organized/educated/employed enough to be able to pay for it (assuming that quality care even exists). 
As feminist political economists point out, the reality is that robust social, economic and political barriers prevent women from being successful in the constantly conflicting roles of fulltime mothers and full-time workers. There needs to be a shift in the public childcare policy discourse, one that acknowledges the gendered nature of paid and unpaid care work, for the gap between "mothers" and "others" (Principe, 2014) to be meaningfully challenged. Until the equitable participation of women in society is achieved, young children become the ultimate losers. The care they require becomes a piece of an ongoing, precarious balancing act rather than something to which every child has an inherent right.

This study has also illustrated that both the position and gender of reports/authors plays a role in how the childcare policy discourse is constructed. Laurie Monsebraaten's objective reporting style supporting an increased role of the government in the provision of childcare services simply does not have the same emotional appeal or urgency as anti-childcare policy articles written by Tasha Kheiriddin in The Post. Newspapers that embrace a progressive stance on the issue are more likely to have one or two full-time reporter covering the issue (The Star had two full-time reporters covering the issue, The Globe one and The Post none) yet these fulltime reporters have less ability to reframe the conversation than do occasional columnists or guest authors in papers that do not have a full-time staffer covering the issue. The implications of this are that the spectrum of possible understandings tend to occlude/downplay the most progressive and normalize oppressive representations of childcare policy. Over time, this leads to a muted conversation from a progressive perspective, while dominant understandings (free market and private family) are taken to a more extreme level. "Progressive" conversations, and 
policies, become one of mitigating dominant conceptualizations (i.e., reducing the cost of childcare as a commodity), rather than reconceptualising the issue altogether (i.e., considering childcare a public resource like education). In fact, discourse that did ultimately attempted to reframe the issue from this perspective was dismissed as a pipe dream in some cases (i.e., the "magical unicorn"). As long as conceptualizing childcare as a genuine public resource is omitted from the public discourse, advocating for comprehensive childcare policy will feel incredibly burdensome. Considering that those most affected by a lack of childcare policy are already overburdened mothers of young children and the $97 \%$ female early childhood workforce, the energy and time required to go into such efforts remain elusive.

The other gendered aspect of the childcare policy discourse that has important implications for society is the different modal styles of male and female authors. Female author's claims that "he/she says $\mathrm{x}$ is a bad idea" do not carry the same emotive appeal as male author's tendency to simply state "x is a bad idea". While it is appreciated that the integrity of journalists is, like other sectors including academia, rooted in the "objective", the reality is that the care of children is a deeply emotional issue for most people. The implications of this are that male reporter's ability to take a stronger stance on issues contributes to the perception that they are a greater authority on the issue. While women are "following the rules" in that they are more likely to draw on other people's words to appeal to legitimacy, it is possible that in doing so their message may again be diluted rather than strengthened. Combining this with the fact that all of the full-time reporters who covered the issue were women, the perspective of women is doubly muted. It appears that in order to be considered legitimate in a neoliberal society that is 
ultimately structured around the unattached, able-bodied, white male person, journalists are limited to playing by their rules rather than having the opportunity to re-write those rules. The glaring and inspiring exception to this is Erin Anderssen reporting on the issue in The Globe, where she was able to push these boundaries to a greater degree. Still however, Anderssen was cautious and continued to weave a neoliberal lens throughout her work (i.e., the human capital, market and economic problematizations).

\section{Recommendations}

A renewed focus on political messaging by advocates, politicians and journalists alike

To counterbalance the influence of systems on the lifeworld, representation from the lifeworld needs to adequately be represented, both in terms of the presence of issues as well as the representation of these issues. Given the primacy of the fiscal bottom line in a neoliberally saturated sociopolitical context, this becomes extremely difficult, if not impossible, to achieve. Ideally, the experiences of women and children in the lifeworld would be embraced as a central concern of public policy. In reality, these issues are becoming more invisible as gender-blind profit margins trump the experiences of people - particularly women and children - in given sociopolitical locations. While NGOs/third sector organizations and alternative media outlets (including grassroots social media efforts) may be able to take on some of the task of representing these issues in a public space, their ability to consistently and meaningfully contribute to the discursive construction of issues in widely accessed forums will continue to be 
compromised by money and politics. These are challenging times for any social/political issue that is not well served by a neoliberal, market model.

This project illuminates however is that resistance to dominant conceptualizations of social issues is not only possible but necessary. Resistance may be minimal and generally overshadowed by dominant ideas, but it exists. Moments of vulnerability emerged in state and economic systems which permitted progressive conceptualizations of the childcare problem to emerge. They key moving forward will be preparation to act during these moments of vulnerability in state or economic systems (i.e., election campaigns, tragedies relating to existing childcare policy solutions or any other opportunity that may emerge). It is recommended that groups, organizations and political parties devoted to furthering childcare policy are able to clearly, internally articulate why it is that childcare policy is important for them and what it is they/we want. These are difficult conversations, and ones that often get muddled with political strategy, but the fundamental motivation for pursing comprehensive childcare policy must be clear before furthering policy in any direction.

Translating these core motivations into public messaging that is both genuine and politically engaging is the next step. It would be naïve to suggest that politics doesn't matter. It does. The conversations that take place in the meeting rooms of academics, childcare researchers, politicians and advocates are not necessarily the same ones that should presented to the public. If nothing else, Donald Trump's electoral success illustrates that how knowledge (or lack thereof) is presented matters. Similarly, in this project, it was surprising to see the saliency 
of the private family problematizations in 2015, regardless of the fact that this understanding of the issue completely overlooks the reality of the large majority of Canadian women, children and families. Political discourse is not rational, but it can be both genuine and strategic in a way that does not compromise the integrity of either. To do this, however, the underlying motivations and rationales for pursing childcare policy in a particular direction must be communicated in way that resonates with people who experience the policy in their daily lives (whether they realize it or not). This is precisely what authors that effectively took a progressive stance on the issue were able to do - they challenged dominant understandings of the childcare policy problem through contextualizing the issue, often highlighting the stories of people rather than appealing to abstract (often very neoliberal) ideals. Such an appeal to emotive and personal aspects of stories has also been found in other areas of journalism reporting. For example, Wardle (2006) found that contemporary newspaper stories profiling murder cases are much more likely to include the narrative stories of survivors/family members who have been impacted than they have been in the last several decades. Wardle (2006) emphasis the idea that "it could happen to you" as a key point of resonance with readers. Exploring how this raw, narrative approach to reporting particularly in relation to the numerous tragedies in childcare settings - interacts with public opinion on the issue could be an interesting avenue for further research.

However, I do not believe this difficult task can be left solely to reporters and columnists. Most notably, political parties - particularly parties who are committed to progressive childcare policy - must carefully consider how to frame and present their policy solution. The NDP's \$15/day campaign in the 2015 election did not provide journalists/columnists/guest authors the 
opportunity to thoroughly report on the issue because the policy was rarely discussed beyond the price tag to parents by the party itself. Moving beyond this superficial public problematization of childcare, which actually feeds into the commodification of care when analyzed in any depth, was very difficult. In fact, the articles that did move beyond this superficially "public" problematization rarely focused on the \$15/day NDP proposal. From the perspective of political messaging, this appears to be a case where political strategy did compromise the integrity of the motivations behind the policy. The NDP is typically the political party in Canada most committed to actualizing social security/rights. Yet, this was downplayed through a focus on the cost of childcare for individual parents (albeit a reduced cost).

\section{Increased advocacy and knowledge mobilization efforts, and structural support for these efforts, from academics and researchers}

The other group who I believe must play a central role in influencing the childcare policy discourse is academics and researchers. To be clear, I do not intend to suggest that these groups have stood idly by in the last decade. Indeed, there has been some inspiring initiatives pursued by various researchers and academics across the country. However, there is still much work to be done. Academics occupy a unique space in the global neoliberal context that places a high value on education and a low value on social reproduction. Particularly academics whose works intersects with childcare policy in some way (be it in development sciences, political science, sociology, psychology, women's studies, etc....), it is necessary to extend research and theory beyond academic journals to popular discourse. I understand this is difficult and complex, given the legitimacy of academics very much relies on their positioning as objective authorities on 
issues, rather than their subjective positions on issues and that most formal academic channels do not formally recognize this work. However, if empirically informed political positions on issues by academics are deemed irrelevant or even a liability, than there is little value in empirical research in the first place. Save the efforts of journalists/reports/columnists who pick up on publically available published work, political discourse will be limited to the ideological and the lived experiences of people in the lifeworld will remain elusive. I would not go as far as to say that academics have a duty to engage in political discourse; however, I would suggest that as people who are knowledgeable and relatively secure economically and socially, they remain an under-tapped resource in shaping political discourse on this issue. In Canada as in the United States, the volumes of academic literature that supports public investment in high quality childcare services of young childcare and their families remains far too disconnected from childcare policy discourse ${ }^{48}$.

Along similar lines, the complete absence of the childcare workforce problematizations suggests that the early childhood workforce is an under-tapped resource for progressive childcare policy discourse. It is known that there are over 50000 registered early childhood educators in Ontario alone and that most childcare programs employ several childcare workers for every RECE employed. Furthermore, we also know that there are hundreds of thousands of children

\footnotetext{
${ }^{48}$ I recognize that the role of academics in advocacy work is a controversial topic that indeed would be worthy of its own dissertation. I make this recommendation partly to spark conversation/debate about this and partly to call on academics to embrace the opportunity to engage in political discourse.
} 
across Canada being cared for full-time by nannies and babysitters - many of whom face precarious citizenship status. The perspective of this group of women who experience the intersectionality of a lack of care services from both the perspective of paid and unpaid labourer, virtually never enter the childcare policy discourse. While this is a diverse group of people, it is recommended that existing institutions these women encounter encourage their political participation in society. While this may be particularly challenging for women without permanent residence or citizenship status, who may overtly avoid formal institutions of any kind, it is reasonable to suggest that post-secondary institutions offering early childhood education related programs require students to reflect on and engage with the larger system issues. Courses designed to engage students to critically identify and deconstruct systemic barriers to their work is essential for this perspective to receive widespread attention. Organizations that represent this perspective, such as the Association of Early Childhood Educators in Ontario, are struggling to remain operational amidst a neoliberal push to "professionalization" that does not recognize the poor remuneration and working conditions of the workforce. Without systemic support from/to post-secondary educational institutions and workforce sector organizations to critically engage in sociopolitical issues, the very workforce providing care is extremely vulnerable to the saliency of hegemonic childcare policy discourse.

\section{Research probing the existing understanding of childcare services and policy by Canadians}

Another piece of work that is missing in relation to childcare policy discourse is a broader appreciation of how Canadians - parents, children and others - currently 
understand/conceptualize childcare services and policy. Even the best informed policy-advisor, political candidate or advocate may fail to effectively communicate a childcare policy solution, if they are discussing the issue in a way that is beyond most people's comprehension. Very little research has been done to gain insight into how Canadians think about childcare services and policy. Outside a small study that engaged parents in focus groups to gain insight into their understanding of early learning and childcare (Hennessy \& Leebosh, 2011), we simply do not know how parents, educators and lay Canadians think about childcare. Consistent with how childcare was predominantly discussed in newspapers over the last decade, these authors revealed that Canadian parents had a very narrow understanding of childcare services as custodial, institutional service accessible only through a market system (Hennessy \& Leebosh, 2011). When information (including a video) was shared illustrating other conceptualizations of childcare (from other jurisdictions) their opinion of childcare services and policy significantly shifted. Research both expanding on and updating this study is urgently needed both to expand the horizon of possibilities for people affected by the issue as well as to develop policy messaging that is both genuine to the communicatory and understandable for consumers.

A greater understanding of how the issues is currently understood by parents - as well as a host of other groups - would allow those with access to widely accessed public space (i.e., journalists, politicians) to construct childcare policy discourse that is both genuine and connected to contemporary understanding of the issue. For example, the failures of the NDP's $\$ 15 /$ day "daycare" initiative becomes easier to understand if we know that Canadians largely understand "daycare" to be custodial care in sterile settings. Therefore, there appears to be value in 
educating, illustrating and communicating to a broad public the possibilities of high quality childcare services. As it stands now it is incredibly difficult to garner support and/or advocate for a service which is conceptualized on such a basic, custodial level. Understandably, parents do not want to place their children in many existing, poor quality childcare centres and therefore do not advocate for public funds to go towards creating more of these centres. If a high quality system could be envisioned - with adequately paid staff, planning time, purpose built facilities (indoor and outdoor), fresh food etc.... - there would likely be more public support for creating it.

Merging these last two recommendations, it is also possible for Canadian academics to explore research methodologies that embrace an advocacy lens. The unique component of Hennessy \& Leebosh's (2011) study was its concurrent focus on transformation (though it was never labelled by the authors as such). While remaining open to emerging themes, the authors put forward different ideas about what childcare could look like. Part of the research process was engaging in discussion pertaining to the suggested ideas as well as responding to ideas, thoughts and comments put forward by participants. While the research process yielded some very interesting insights into current conceptualizations of childcare, it was equally (if not more) valuable in its ability to engage in grassroots discussions of important policy issues. Indeed, this may be a modern day alternative to the coffee houses described by Habermas in reference to his theorized "public sphere". 
Other recommendations for further research flow directly out of this study's limitations are described below.

\section{Limitations}

The findings and insights this project offer have several practical and theoretical limitations. Many of these limitations have been acknowledged throughout other chapters, though it is important to highlight them here as all the piece of the project are synthesised. The practical limitations relating to the design/operationalization of the study will first be discussed, followed by some of the broader, theoretical limitations that relate to the insights offered in the discussion chapter.

\section{Methodological limitations}

\section{Data collection}

Some of the limitations of the study relate to the data collection process itself. Limiting data to newspaper articles inherently leaves out a host of other widely accessible mediated outlets - including social media networks, television and YouTube (to name a few). The scope of mediated discourse relevant to childcare policy is incredibly broad and to suggest that newspapers captures the conversation in its entirety is of course unrealistic. Future research exploring how childcare policy is discussed through these different genres of communication could be illuminating. Indeed, it would likely be the case that childcare policy would be presented through a very different lens, if tweets, blogs, comment pages or other social media posts were examined. The fact that these mediated channels permit anonymity would in and of 
itself likely lead to much more extreme positions and problematizations. Similarly, television segments are also unique in that the time permitted to report an issue is typically less than one minute and contains constant visual imagery to accompany the text. Again, examining these data may reveal a different perspective or intensification of existing perspectives. Further research could indeed explore and compare some of the differences and similarities between how the childcare issue is represented in newspaper articles and other media outlets.

Another limitation of this study is that newspaper texts were not limited to online versions of articles. It can safely be assumed that the majority of people reading newspaper articles between 2008 and 2015 were doing so online. However, because ProQuest Newsstand database (and other data bases which contained the papers) listed only the full version of articles, it was not possible to distinguish between versions of articles accessed through print or accessed/shared online. It is possible that the data in this project is a generous estimate of childcare policy discourse, given the full-text available through ProQuest Newsstand database is likely more extensive than what was available to readers online. Future research could focus solely on newspaper articles available online (though this too would be limited in that all articles over the time period are not available today).

Also relevant to the data collection process, it became apparent that the inclusion of "policy" as a search term lowered the return rate of articles that met the search criteria in the online database. While returned articles with the word "policy" likely had more of a focus on childcare at the policy level with the search term, other articles that did not contain "policy" were 
occluded entirely even though they may have been very relevant to the policy level. To ensure that all relevant articles are included, excluding "policy" and manually sorting through articles would have been a more robust (though very time consuming) approach to data collection.

The other key limitation of this project is that it did not include the policy platforms of the political parties themselves. While this was part of the original project, it was ultimately decided that this would be best approached through a separate project where the representation of childcare policy in political party platforms over the past decade could be compared. With insights from such a project, it would then be interesting to note the similarities and differences between how political parties communicated their childcare policy directions and how these proposals were communicated by newspapers or other media outlets.

\section{Coding}

The coding process both at the level of the WPR and CDA was also inherently limited in several ways. Creating and refining the WPR codebook was a process through which decisions had to be made. Every effort was made to make the nodes categorically separate though there were times when problematizations overlapped with each other at the level of the sentence. To delineate the nodes as thoroughly as possible, the codebook was extensively revised while coding the first dozen articles. The other key methodological limitation is that the coding process did not account for how much text within articles was devoted to each problematization. It would be interesting to note how much of texts that presented the public problematizations actually devoted a considerable volume of discourse to this problematization. The CDA analysis suggests 
this problematization was not nearly as well developed as other dominant problematization, though observing the quantity of text devoted to this problematization could also be illuminating. In some academic/popular contexts with a more positivist theoretical orientation, this quantitative measure may carry more "legitimacy" than the CDA results provided here.

A key limitation of this study is how CDA was operationalized. CDA is broad theoretically and specific methodologically. Because of practical limitations, only a handful of concepts could be examined here. In the original coding process, more concepts were observed and inputted into charts; however it became apparent in the write-up process that there was simply not enough time/space to report on every concept analysed. Truly CDA is best conducted on a very small sample of articles in which several concepts/ideas can thoroughly be analyzed on their own and in relation to each other. While this is how I began this project - attempting to extend this detailed level of analysis to a larger sample - it became clear that the nuances of each text could simply not be adequately analyzed and presented even within the 15 articles of the CDA sample. Instead of reducing the number of articles, I reduced the number of concepts included and/or simplified the operationalization process. In regards to the later, reported findings relating to intertextuality and interdiscursivity notably deviate from a genuine CDA. These concepts were reduced to numeric counts of other texts and discourses, rather than observations of the unique positioning of other texts within texts and discourses with each other. Some of this analysis came through in other aspects of the analysis (i.e., modality, appeals to legitimacy) though other aspects were lost. It would be interesting for further research to include one or two articles from each paper and explore these concepts, and others not included in this 
study, in greater detail. More subtle features of texts and discourse would likely be observed in relation to the broader findings this study presents.

\section{Theoretical limitations}

One of the main struggles of this project relates to the theoretical underpinnings and conceptual framework employed. This project was narrowly focused on the discursive representation of policy problems in major media outlets; however, it must be recognized that problem representation is only one piece of political/policy analysis. Therefore, it is important not to downplay other aspects of the policy-making process which ultimately influence policy outcomes. Fairclough \& Fairclough's (2012) broader theory of political discourse, which examines five overarching premises (value, goal, circumstantial, means-goal, claim), may have yielded different insights. Indeed, Fairclough \& Fairclough (2012) are critical of Bacchi’s (2009) work on the grounds that it overemphasizes the role of policy problem representation and negates to consider other aspects of the policy process.

Similarly, there are other theoretical frameworks that may lead to a different interpretation of the data. Though theorizing over a hundred years ago, Walter Lippmann's work (2012) about the media's role in shaping public opinion could have been an interesting framework through which to interpret the findings of the project. This theory focuses less on the discursive construction of representations, and more on how "images" (the representations themselves) influence the public's understanding of issues. Related to the contemporary work of political psychologist George Lakoff (2005), Lippmann makes connections between widely 
available"images", emotion, understanding and political action. The findings from this project could provide fruitful data from which to explore the formation of childcare policy opinion. These theories would also be ideal to inform the aforementioned recommendation that future research actively engage with Canadians (parents, ECEs, others) to gain insight into how the issue is currently understood. This could ultimately help to inform political messaging moving forward in a way that can only be loosely speculated from this project's insights.

\section{Conclusion}

This project has achieved its three core objectives. First, it has made concrete connections between how childcare policy was discussed in newspapers between 2008 and 2015, power relationships in society and (lack of) policy outcomes. The representation of childcare policy problems was limited to ideological ideals that perpetuate gendered, hegemonic power relations in society. Ultimately this has contributed to a continuation of the status quo - with no significant shift in childcare policy at the federal level. Second, a closer analysis of selected texts published in the year leading up to the 2015 election revealed that several text and discourse processes allowed dominant discourses, not in the interests of those most affected by childcare (i.e., women, children and families) to remain largely unchallenged. While there were a few cases of active resistance to dominant discourse, the majority of newspapers articles failed to effectively reconceptualize the issue from a progressive perspective. While the newspaper articles that go through the formal publication process appears to be more limited in scope in contemporary society than they once were, formal mediated channels are still a key source of information often acting as a starting point for interactive conversations on social media. The 
mainstream media's role is to make sure social movement voices are well-represented and that political ideas are questioned and challenged on a broad level (rather than within the silos of social media networks). In contemporary society, citizens become aware of political struggles/debates through the media, typically on their phone through digital articles. Rarely do citizens go to the policy proposals themselves. Finally, this project has demonstrated that a CDA theory and methods can be effectively used alongside a WPR method to provide a more thoroughly analysis of how dominant problematizations maintain their dominance despite robust evidence refuting these representations.

Ultimately the insights this project offers must move off the page and into the lifeworld. Childcare policy in Canada has been at a seemingly perpetual roadblock despite the best efforts of a vibrant (though largely voluntary) advocacy community. There is an opportunity with the current federal government to move policy forward, though it appears that movement will be slow and incremental. But elections are inevitable and childcare will not cease to be an issue as long as children require care and women/parents are required to be in the paid labour market. The critical task now is refining messaging and ideas about what constitutes this issue as well as broadening the lens of future possibilities. Reconceptualising anything requires cognitive and emotional effort. Reconceptualising an issue that is so central to our own well-being and the well-being of the people we care most about is that much more difficult. The bottom line is that the childcare "problem" cannot continue to be treated as an individual one. The problem is systemic, and therefore political. If political parties and governments are serious about bettering the well-being of women, children and families than childcare policy must be a central piece of 
the equation. The task is communicating this message effectively amidst a neoliberally saturated society that largely occludes such an understanding of the issue. 


\section{Appendix A: Code book}

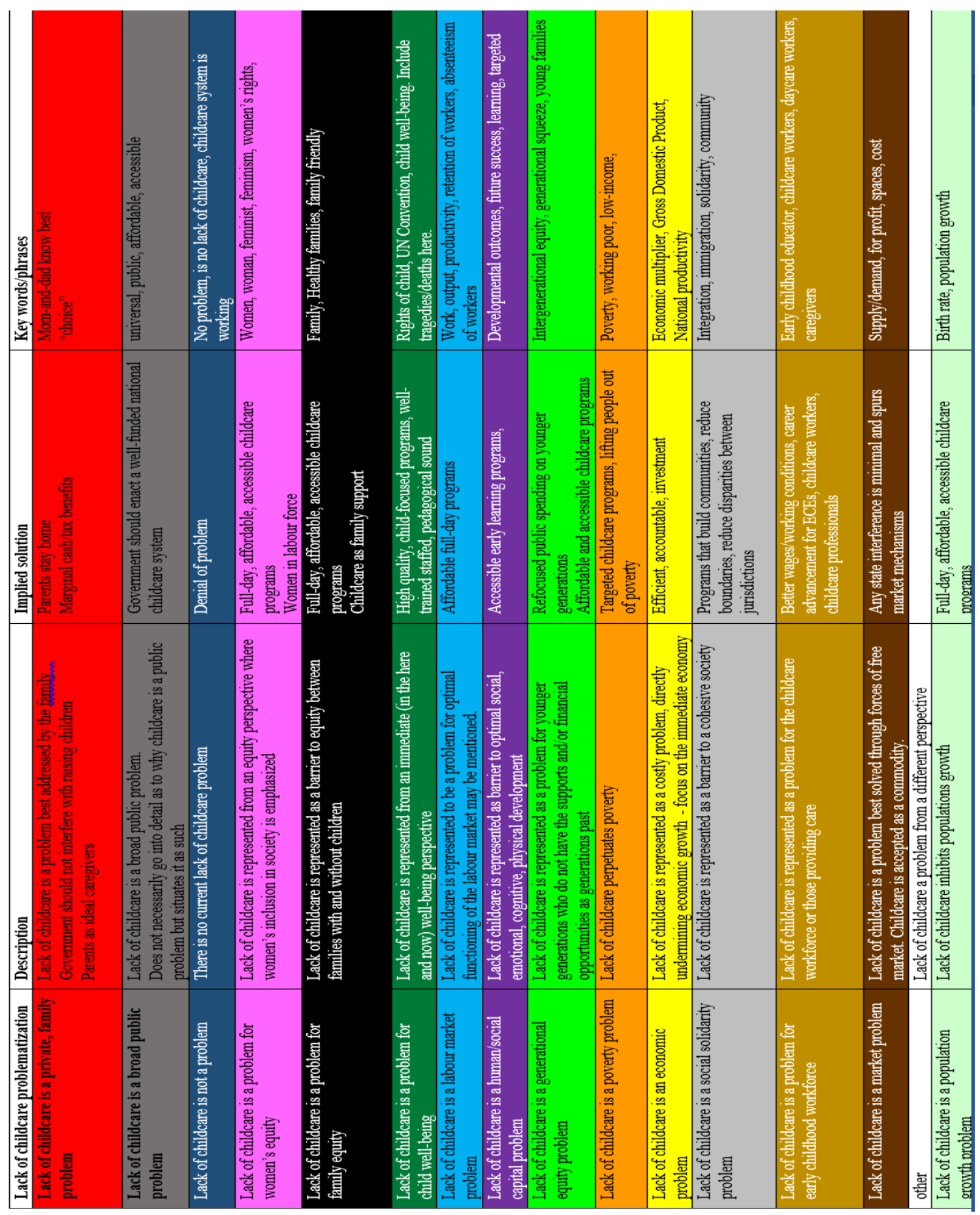




\section{Appendix B: Summary of childcare platforms in the 2015 federal election}

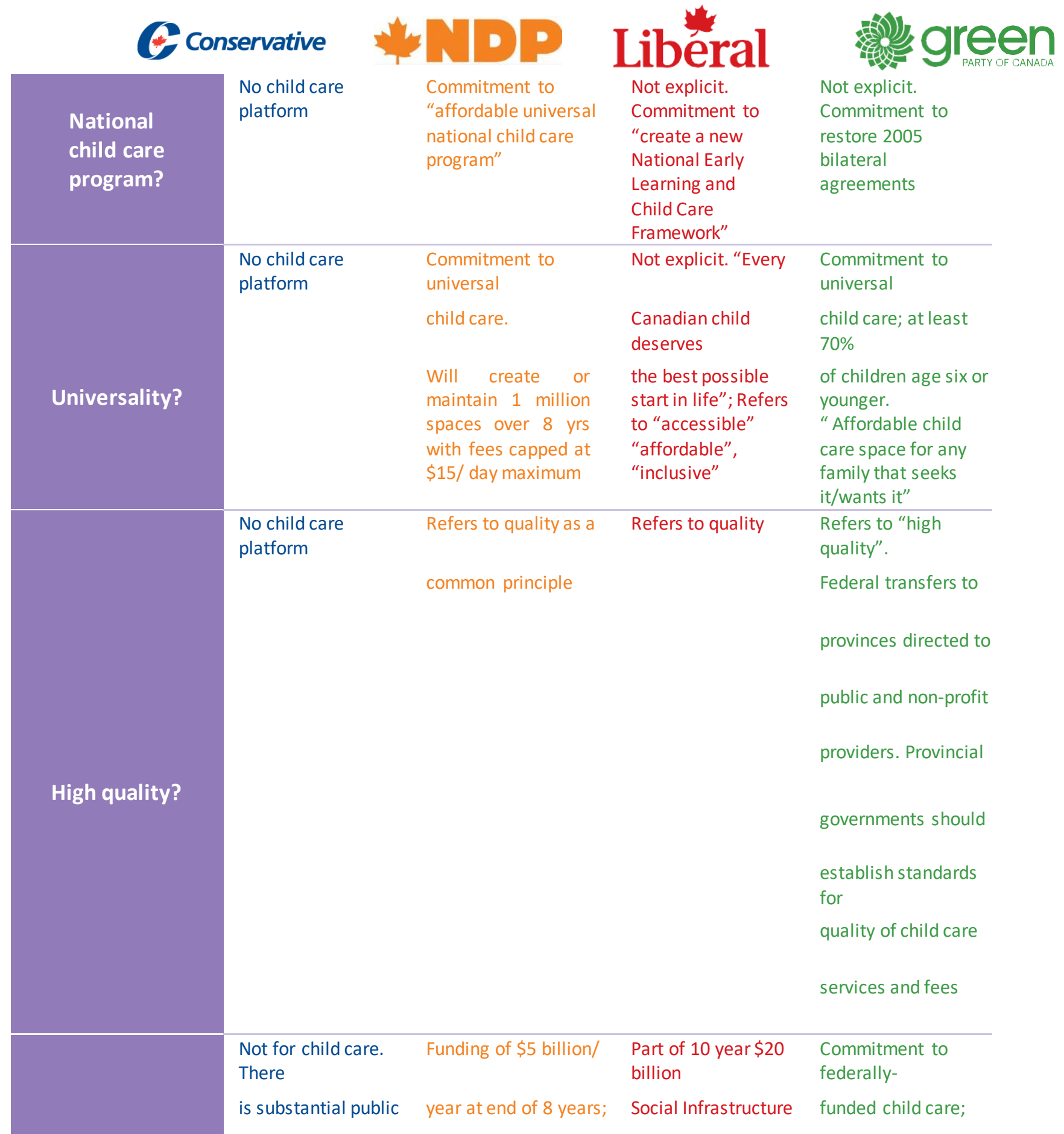




\begin{tabular}{|c|c|c|c|c|}
\hline & funding for income & commitment to long- & $\begin{array}{l}\text { fund (includes } \\
\text { housing, }\end{array}$ & $\begin{array}{l}\text { Restore } 2005 \\
\text { bilateral }\end{array}$ \\
\hline & $\begin{array}{l}\text { splitting (Family Tax } \\
\text { Cut), }\end{array}$ & $\begin{array}{l}\text { term, predictable } \\
\text { funding, }\end{array}$ & $\begin{array}{l}\text { seniors). Not } \\
\text { earmarked }\end{array}$ & $\begin{array}{l}\text { agreements (\$1 } \\
\text { billion }\end{array}$ \\
\hline & $\begin{array}{l}\text { the Universal Child } \\
\text { Care }\end{array}$ & cost shared $60 / 40$ with & $\begin{array}{l}\text { specifically for child } \\
\text { care }\end{array}$ & annually for 5 years) \\
\hline & $\begin{array}{l}\text { Benefit (UCCB) and } \\
\text { Child }\end{array}$ & provinces/territories & & \\
\hline & $\begin{array}{l}\text { Care Expense } \\
\text { Deduction }\end{array}$ & & & $\begin{array}{l}\text { Establish } \\
\text { reconstituted/ }\end{array}$ \\
\hline funding? & (CCED) & & & $\begin{array}{l}\text { expanded CST, to } \\
\text { substantially } \\
\text { increase } \\
\text { number of child care }\end{array}$ \\
\hline & & & & $\begin{array}{l}\text { spaces; } \$ 1,500 \text { tax } \\
\text { break/ }\end{array}$ \\
\hline & & & & $\begin{array}{l}\text { per space for } \\
\text { workplace }\end{array}$ \\
\hline & & & & child care \\
\hline $\begin{array}{l}\text { Child care } \\
\text { workforce? }\end{array}$ & Not referred to & Not referred to & Not referred to & Not referred to \\
\hline & $\begin{array}{l}\text { No child care } \\
\text { platform }\end{array}$ & Not explicit. National & $\begin{array}{l}\text { Not explicit. } \\
\text { Commitment }\end{array}$ & Not explicit \\
\hline & & legislation. Common & $\begin{array}{l}\text { to develop a } \\
\text { framework }\end{array}$ & \\
\hline & & principles "such as" & $\begin{array}{l}\text { for agreements } \\
\text { based on }\end{array}$ & \\
\hline & & $\begin{array}{l}\text { affordability, } \\
\text { availability, }\end{array}$ & $\begin{array}{l}\text { research, evidence- } \\
\text { based }\end{array}$ & \\
\hline & & $\begin{array}{l}\text { quality. Commitment } \\
\text { to }\end{array}$ & $\begin{array}{l}\text { policy, and best } \\
\text { practices }\end{array}$ & \\
\hline & & $\begin{array}{l}\text { measurable } \\
\text { benchmarks, }\end{array}$ & & \\
\hline & & public reporting & & \\
\hline & $\begin{array}{l}\text { No child care } \\
\text { platform }\end{array}$ & Commitment to lead & Collaboration with & Federal funding and \\
\hline
\end{tabular}




\begin{tabular}{|c|c|c|c|c|}
\hline $\begin{array}{c}\text { Federal } \\
\text { leadership/ } \\
\text { collaboration } \\
\text { with provinces/ }\end{array}$ & & $\begin{array}{l}\text { and to collaborate with } \\
\text { provinces/territories } \\
\text { and Indigenous } \\
\text { communities, } \\
\text { recognizing } \\
\text { provincial } \\
\text { jurisdiction }\end{array}$ & $\begin{array}{l}\text { provinces, territories } \\
\text { and } \\
\text { Indigenous } \\
\text { communities, } \\
\text { commitment to } \\
\text { federal } \\
\text { government- } \\
\text { initiated } \\
\text { meeting within "first } \\
100 \\
\text { days" to begin } \\
\text { developing } \\
\text { national framework }\end{array}$ & $\begin{array}{l}\text { direction on transfer } \\
\text { payments. } \\
\text { Some federal } \\
\text { and provincial } \\
\text { responsibilities } \\
\text { are } \\
\text { identified }\end{array}$ \\
\hline \multirow{11}{*}{$\begin{array}{l}\text { Other policy } \\
\text { for families? }\end{array}$} & $\begin{array}{l}\text { An expanded UCCB } \\
\text { to }\end{array}$ & Commitment re & Commitment to new & Establish a National \\
\hline & $\begin{array}{l}\$ 160 / \text { month for 0-6 } \\
\text { year }\end{array}$ & maternity/parental & $\begin{array}{l}\text { geared-to-income } \\
\text { child }\end{array}$ & $\begin{array}{l}\text { Children's } \\
\text { Commissioner. }\end{array}$ \\
\hline & $\begin{array}{l}\text { olds, } \$ 60 / \text { month for } \\
7-18\end{array}$ & benefits - additional 5 & benefit incorporating & $\begin{array}{l}\text { Abolish income } \\
\text { splitting }\end{array}$ \\
\hline & $\begin{array}{l}\text { year olds; Increasing } \\
\text { the }\end{array}$ & $\begin{array}{l}\text { week dedicated leave } \\
\text { for }\end{array}$ & Universal Child Care & $\begin{array}{l}\text { and the Universal } \\
\text { Child }\end{array}$ \\
\hline & $\begin{array}{l}\text { CCED; income } \\
\text { splitting for }\end{array}$ & $\begin{array}{l}\text { second parent } \\
\text { including }\end{array}$ & $\begin{array}{l}\text { Benefit and Canada } \\
\text { Child }\end{array}$ & $\begin{array}{l}\text { Care Benefit. } \\
\text { Mentions }\end{array}$ \\
\hline & couple families & same sex couples and & Tax Benefit. & $\begin{array}{l}\text { "workplace child } \\
\text { care" }\end{array}$ \\
\hline & & $\begin{array}{l}\text { adoptive parents; } \\
\text { doubling leave for } \\
\text { parents of multiples. }\end{array}$ & $\begin{array}{l}\text { Commitment to } \\
\text { abolish income } \\
\text { splitting. } \\
\text { Proposal to allow } \\
\text { parents } \\
\text { to use parental leave }\end{array}$ & \\
\hline & & income splitting and & $\begin{array}{l}\text { benefit more flexibly } \\
\text { to }\end{array}$ & \\
\hline & & retain Universal Child & $\begin{array}{l}\text { support a possible } \\
\text { longer }\end{array}$ & \\
\hline & & Care Benefit & $\begin{array}{l}\text { leave (up to } 18 \\
\text { months at }\end{array}$ & \\
\hline & & & a lower pay level). & \\
\hline
\end{tabular}

Authorized by the Child Care Advocacy Association of Canada 


\section{References}

Adshade. (2011, Dec 1). Canadian mothers waiting for more help. The Globe and Mail. Retrieved from http://search.proquest.com.ezproxy.lib.ryerson.ca/docview/907035858/C3063DB0E9954 2B4PQ/49? accountid=13631

Albanese, P., \& Farr, T. (2012). “I'm Lucky" . . to Have Found Child Care: Evoking Luck While Managing Child Care Needs in a Changing Economy. International Journal of Child, Youth and Family Studies(1), 83-111.

Albanese, P., \& Rauhala, A. (2015). A decade of disconnection: Childcare policies in changing economic times in the Canadian context. International Journal of Child, Youth and Family Studies, 6(2), 252-274.

Albanese, P., Rauhala, A., Ferns, C., Johnstone, J., Lam, J., \& Atack, E. (2010). Hiding the Elephant: Child Care Coverage in Four Daily Newspapers. Journal of Comparative Family Studies, 41(5), 817-836.

Alcoba, N. (2009, Jun 20). What's best for children?; Advocates, critics of early education agree the Finns seem to have the most success. The National Post. Retrieved from http://search.proquest.com.ezproxy.lib.ryerson.ca/docview/330899895/C466EDCD88634 $\underline{304 \mathrm{PQ} / 10 \text { ?accountid=13631 }}$

Anderson, L. (2008, Jul 9). Market failure and child care. Toronto Star. Retrieved from http://ezproxy.lib.ryerson.ca/login?url=http://search.proquest.com/docview/439465738?a c countid=13631

Anderssen, E. (2011, May 7). Mommy dearest. The Globe and Mail. Retrieved from http://search.proquest.com.ezproxy.lib.ryerson.ca/docview/865073069/C3063DB0E9954 $\underline{\text { BB } 4 \mathrm{PQ} / 24 \text { ? accountid }=13631}$

Anderssen, E. (2013, Nov 15). Why Canada needs to do better at helping all families. The Globe and Mail. Retrieved from http://search.proquest.com.ezproxy.lib.ryerson.ca/docview/1458498163/1E733D1CDA7 $\underline{\mathrm{D} 4186 \mathrm{PQ} / 43 \text { ? accountid }=13631}$

Anderssen, E. (2013, Oct 21). The case for publicly funded child care. The Globe and Mail. Retrieved from 
http://search.proquest.com.ezproxy.lib.ryerson.ca/docview/1039334173/EE310F34A16B 4AA1PQ/29? accountid=13631

Anderssen, E. (2013, Oct 25). 10 lessons to guide a national discussion on how to improve child care in this country. The Globe and Mail. Retrieved from http://search.proquest.com.ezproxy.lib.ryerson.ca/docview/1444843120/1E733D1CDA7 $\underline{\mathrm{D} 4186 \mathrm{PQ} / 37 \text { ?accountid }=13631}$

Anderssen, E. (2015, Apr 17). Is Clinton-style feminism the right kind for 2016? The Globe and Mail. Retrieved from http://search.proquest.com.ezproxy.lib.ryerson.ca/docview/1673698243?accountid=1363 $\underline{1}$

Anderssen, E. (2015, Oct 2). The forgotten moms: During campaigns, the ever-iconic, twoparent, middle-class family always gets the spotlight. But the real way to support Canadian families? Make life easier for single moms. Erin Anderssen explains why. The Globe and Mail. Retrieved from http://search.proquest.com.ezproxy.lib.ryerson.ca/docview/1718249431?accountid=1363 $\underline{1}$

Anonymous. (2008, Dec 8). Good day for poverty foes. The Toronto Star. Retrieved from http://ezproxy.lib.ryerson.ca/login?url=http://search.proquest.com/docview/439527479?a c countid=13631

Anonymous. (2008, Jun 20). Ontario lags on day care. The Toronto Star. Retrieved from http://ezproxy.lib.ryerson.ca/login?url=http://search.proquest.com/docview/439438877?a c countid $=13631$

Anonymous. (2009, Aug 16). Who will step up to fight for families? Toronto Star. Retrieved from http://ezproxy.lib.ryerson.ca/login?url=http://search.proquest.com/docview/439595796?a c countid $=13631$

Anonymous. (2010, Mar 6). Funding our childcare crisis. Toronto Star. Retrieved from http://ezproxy.lib.ryerson.ca/login?url=http://search.proquest.com/docview/439645352?a c countid=13631

Anonymous. (2010, Oct 31). Anti-poverty activists give benefit of the doubt to Ford. The Toronto Star. Retrieved from 
http://ezproxy.lib.ryerson.ca/login?url=http://search.proquest.com/docview/761230848?a ccountid=13631

Anonymous. (2011, Feb 5). Dust-up over daycare. The National Post. Retrieved from http://search.proquest.com.ezproxy.lib.ryerson.ca/newsstand/docview/849604082/fulltext 17843FF00121E4F38PQ/4?accountid=13631

Anonymous. (2011, Feb 8). Tories, Liberals play up child care. The National Post. Retrieved from http://search.proquest.com.ezproxy.lib.ryerson.ca/docview/851208699/A15C63C1C4B54 AE8PQ/6? accountid=13631

Anonymous. (2011, Feb 12). The daycare disconnect. Toronto Star. Retrieved from http://ezproxy.lib.ryerson.ca/login?url=http://search.proquest.com/docview/851362207?a ccountid=13631

Arat-Koç, S. (2006). Whose social reproduction?: Transnational motherhood and challenges to feminist political economy. In K. Bezanson \& M. Luxont (Eds.), Social Reproduction: Feminist Political Economy Challenges Neo-Liberalism (pp. 75-92). Montreal, QU: McGill-Queens University Press.

Austin, N., Davis, L., Heyninck, E., \& Singh, P. (2016). Final Report and Recommendations of the gender wage gap strategy steering committee. Retrieved from Toronto, ON https://files.ontario.ca/7198_mol_gwg_finalreport_eng_wa_08f_v2_1.pdf

Babbage, M. (2013, Jul 2013). Child's death prompts calls for probe by ombudsman. The Globe and Mail. Retrieved from http://search.proquest.com.ezproxy.lib.ryerson.ca/docview/1399667641/1E733D1CDA7 D4186PQ/25? accountid=13631

Bacchi, C. (1999). Women, Politics and Policy: the construction of policy problems. Thousand Oaks, California: Sage.

Bacchi, C. (2009). Analysing Policy: What's the Problem Represented to Be? Melbourne, Australia: Pearson Australia.

Bacchi, C. (2012). Why Study Problemizations? Making Politics Visible. Open Journal of Political Science, 2(1), 1-8. 
Bailey, S. (2008, Apr 11). Regulated child-care spaces way down, report says. The Globe and Mail. Retrieved from http://search.proquest.com.ezproxy.lib.ryerson.ca/docview/382727468?accountid=13631

Bakker, I. (2003). Neo-liberal governance and the reprivatisation of social reproduction: Social provisioning and shifting gender orders. In S. Gill \& I. Bakker (Eds.), Power, Production and Social Reproduction: Human In/security in the Global Political Economy (pp. 6882). London, UK: Palgrave Macmillan.

Bakker, I., \& Gill, S. (2003). Global political economy and social reproduction. In I. Bakker \& S. Gill (Eds.), Power, Production and Social Reproduction: Human In/security in the Global Political Economy (pp. 3-15). New York, NY: Palgrave-MacMillan.

Bancroft, R., \& Underwood, K. (2015). A vision for inclusive child care. Our Schools, Our Selves, 24(4), 95-106.

Banerjee, R. (2009). Income growth of new immigrants in Canada: evidence from the survey of Labour and Income Dynamics. Relations Industrielles, 64(3), 466-488.

Baumgartner, F., \& Jones, B. (1993). Agendas and instability in American politics. Chicago, IL: University of Chicago Press.

Bezanson, K. (2006). The Neo-liberal State and Social Reproduction: Gender and Household Insecurity in the Late 1990s. In K. Bezanson \& M. Luxton (Eds.), Social Reproduction: Feminist Political Economy Challenges Neo-Liberalism (pp. 173-214). Montreal, Quebec: McGill-Queens University Press.

Bezanson, K., \& Luxton, M. (2006). Introduction: Social Reproduction and Feminist Political Economy. In K. Bezanson \& M. Luxton (Eds.), Social Reproduction Feminist Political Economy Challenges Neo-Liberalism (pp. 3-10). Montreal, Quebec: McGillQueens University Press.

Bielski, Z. (2015, Apr 10). Working dads under pressure to spend more time with kids. The Globe and Mail. Retrieved from http://search.proquest.com.ezproxy.lib.ryerson.ca/docview/1673295543?accountid=1363 $\underline{1}$

Bitonti, D. (2013, Feb 20). Child-care tax credit in works for 2015. The Globe and Mail. Retrieved from 
http://search.proquest.com.ezproxy.lib.ryerson.ca/docview/1288978604/6F27F07928BD4 271PQ/7? accountid=13631

Black. (2014, November 28). New rules for federal live-in caregivers program. Toronto Star. Retrieved from https://www.thestar.com/news/canada/2014/11/28/new_rules_for_federal_livein_caregiv ers_program.html

Blackwell, R. (2015, Aug 22). A boundless, borderless anti-poverty force: Leilani Farha, executive director of Canada Without Poverty. The Globe and Mail. Retrieved from http://search.proquest.com.ezproxy.lib.ryerson.ca/docview/1705941131?accountid=1363 $\underline{1}$

Boesveld, S. (2012, Feb 11). Raising bebe; The latest cross-cultural parenting guide extols the wisdom of the laissez-faire French method. The National Post. Retrieved from http://search.proquest.com.ezproxy.lib.ryerson.ca/docview/921272564/753A42ED70D84 $\underline{180 \mathrm{PQ} / 7 \text { ? accountid=13631 }}$

Boesveld, S. (2015, Jun 23). More than expensive daycare? Jury still out on whether Ontario's full-day; Kindergarten program has paid off. The National Post. Retrieved from http://search.proquest.com.ezproxy.lib.ryerson.ca/docview/1690592315?accountid=1363 $\underline{1}$

Boesveld, S. (2015, Sep 22). Dial shifting on what constitutes a women's issue. The National Post. Retrieved from http://search.proquest.com.ezproxy.lib.ryerson.ca/docview/1714543006?accountid=1363 $\underline{1}$

Braedley, S., \& Luxton, M. (2010). Neoliberalism and Everyday Life. Montreal, Quebec: McGill-Queens University Press.

Bragg, B., \& Wong, L. (2016). "Cancelled Dreams": Family Reunification and Shifting Canadian Immigration Policy. Journal of Immigrant \& Refugee Studies, 14(1), 46-65.

Brickner, R., \& Straehle, C. (2010). The missing link: Gender, immigration policy and the Livein Caregiver Program in Canada. Policy and Society, 29(4), 309-320.

Campaign2000, \& Family Service Toronto. (2015). Let's Do This, Let's end child poverty in Canada 2015 Report Card on Child and Family Poverty in Canada. Retrieved from 
Toronto, ON.: http://www.cwp-

csp.ca/resources/sites/default/files/resources/NationalReportCardEn2015.pdf

Campbell, S. (2001). Acting Locally: Community Activism in Edmonton 1940-1970. In S. Prentice (Ed.), Changing Childcare: Five Decades of Child Care Advocacy and Policy in Canada (pp. 81-95). Winnipeg, MA: Fernwood.

Canadian Association of Family Resource Programs. (2011). Family is the foundation: why family support and early chlidhood education must be a collaborative effort. Retrieved from Ottawa ON:

http://www.frp.ca/index.cfm?fuseaction=document.viewDocument\&documentid=995\&d ocumentFormatId $=1734$

Catlaw, T., \& Stout, M. (2011). Postmodernism and public policy. In E. Berman (Ed.), Encyclopedia of Public Administration and Public Policy (2nd ed., pp. 1524-1529). London, UK: Taylor and Francis.

Child Care Advocacy Association of Canada. (2017). Multi-year funding in budget welcome but need significant boost in annual allocations to build accessible, affordable, quality child care system over time [Press release]. Retrieved from https://acpsgeccaac.files.wordpress.com/2017/03/ccaacmediarelease_2017fedbudget.pdf

Child Care Human Resources Sector Council. (2009a). Literature review of socioeconomic effects and net benefits: Understanding and addressing workforce shortages in early childhood education and care (ECEC) project. Retrieved from Ottawa, ON: http://www.ccsc-cssge.ca/sites/default/files/uploads/Projects-Pubs-Docs/2.8WFS LitSocioMain Eng.pdf

Child Care Human Resources Sector Council. (2009b). A portrait of Canada's ECEC workforce. Retrieved from Ottawa, ON.: http://www.ccsccssge.ca/sites/default/files/uploads/Projects-Pubs-Docs/1.1portraitbrochure_e.pdf

Child Care Human Resources Sector Council. (2013). You bet we still care! A survey of centrebased early chlidhood education and care Canada. Retrieved from Ottawa, Ontario: http://www.ccsc-cssge.ca/sites/default/files/uploads/Projects-PubsDocs/EN\%20Pub\%20Chart/YouBetSurveyReport Final.pdf

Childcare Resource and Research Unit. (2013). Social Solidarity. Retrieved from http://www.childcarecanada.org/why-good-child-care-equity-social-solidarity-cohesion 
Chouliaraki, L., \& Fairclough, N. (1999). Discourse in late modernity: Rethinking critical discourse analysis. Edinburgh, Scotland: Edinburgh University Press.

Clark, C. (2015, May 11). Liberal ads to focus on 'ordinary folks': Trudeau team to pitch tax breaks and child benefits in effort to show they're more fair-minded than Conservatives. The Globe and Mail. Retrieved from http://search.proquest.com.ezproxy.lib.ryerson.ca/docview/1679843663?accountid=1363 $\underline{1}$

Cleveland, G., \& Krashinsky, M. (1998). The benefits and costs of good child care: the economic rationale for public investment in young children (- 9781896051031;1896051030;). Retrieved from Toronto, ON:

Cleveland, G., Krashinsky, M., Colley, S., \& Avery-Nunez, C. (2016). Technical Report: City of Toronto Licensed Child Care Demand and Affordability Study. Retrieved from Toronto, $\mathrm{ON}$ :

http://www1.toronto.ca/City\%200f\%20Toronto/Children's\%20Services/Files/pdf/T/Toro nto $\% 20$ Demand $\% 20 \& \% 20$ Affordability $\% 20$ Study $\% 20$ \%20technical\%20report\%202016.pdf

Cohn, J. (2012, Jan 3). The two-year window; Neuroscience has shown that emotional damage done to infants lasts a lifetime. But there's no money to find solutions. The National Post. Retrieved from http://search.proquest.com.ezproxy.lib.ryerson.ca/docview/914279603/753A42ED70D84 $\underline{180 \mathrm{PQ} / 1 \text { ? accountid=13631 }}$

Conservative Party of Canada. (2015). Protect our economy: Our Conservative plan to protect our economy. Ottawa, ON: Conservative Party of Canada Retrieved from file://C:/Users/Brooke/Documents/Dissertation/Data/party\%20platforms/conservative.pd f.

County of Wellington Childcare Services. (2012). The Economic Value of Child Care. Retrieved from Guelph, Ontario: https://www.oise.utoronto.ca/atkinson/UserFiles/File/News/The_Economic_Value_of_C hild_Care_January2012.pdf

Coyne, A. (2014, Oct 16). NDP uses child care to press Liberals; Plan is designed to push rivals out of the centre. National Post. Retrieved from http://ezproxy.lib.ryerson.ca/login?url=http://search.proquest.com/docview/1613374624? accountid=13631 
Coyne, A. (2015, May 23). Bogus gaffe charge obscures debate. The National Post. Retrieved from http://search.proquest.com.ezproxy.lib.ryerson.ca/docview/1682729637?accountid=1363 $\underline{1}$

Creswell, J. (2009). Research design: qualitative, quantitative and mixed methods appraoches (3rd ed.). Thousand Oaks, California: SAGE.

Creswell, J. W. (2014). Research design: qualitative, quantitative, and mixed methods approaches. Thousand Oaks, California: Sage.

Cross, A. (2011, May 9). The daycare dilemma. Toronto Star. Retrieved from http://ezproxy.lib.ryerson.ca/login?url=http://search.proquest.com/docview/865221264?a ccountid=13631

Daly, K. (2007). Gender inequality: Growth and global ageing. Retrieved from New York, NY: http://20-first.com/1613-0/

Dean, H. (2012). Short Introductions: Social policy. Cambridge, UK: Polity Press.

Diebel, L. (2009, Mar 17). Bureaucrats indifferent to Indian Affairs fiasco; At hearings about the funding of First Nation child-care services, civil servants had few answers. The Toronto Star. Retrieved from http://ezproxy.lib.ryerson.ca/login?url=http://search.proquest.com/docview/439570669?a countid=13631

Dobrowolsky, A., \& Jenson, J. (2004). Shifting Representations of Citizenship: Canadian Politics of "Women" and "Children". Social Politics: International Studies in Gender, State and Society, 11(2), 154 - 180.

Dobrowolsky, A. Z. (Ed.) (2009). Women and Public policy in Canada. Toronto, ON: Oxford University Press.

Dorfman, L., \& Woodruff, K. (1999). Child care coverage in the U.S. newspapers. Berkeley Media Studies Group(7), 1-16.

Doucet, A. (2015). Parental Responsibilities: Dilemmas of Measurement and Gender Equality. Journal of Marriage and Family, 77(September 2015), 224-242. 
Edmiston. (2013, May23). Canadians want more stay-at-home parents: poll; $76 \%$ think kids under 6 should have guardian. The National Post. Retrieved from http://search.proquest.com.ezproxy.lib.ryerson.ca/docview/1354604849/AA1988FB4BE4 4EE9PQ/14? accountid=13631

Eichler, L. (2012, Jun 30). School daze: Carving out a career on the kids schedule. The Globe and Mail. Retrieved from http://search.proquest.com.ezproxy.lib.ryerson.ca/docview/1022678445/EE310F34A16B $\underline{4 A A 1 P Q / 19 ? \text { accountid=13631 }}$

Esping-Andersen, G. (1990). The three worlds of welfare capitalism. Bristol, UK: Polity Press.

Fairclough, I., \& Fairclough, N. (2012). Political discourse analysis: a method for advanced students. New York, NY: Routledge.

Fairclough, N. (1992). Discourse and Social Change. Cambridge, UK: Polity Press.

Fairclough, N. (1995). Media Discourse. New York, NY: Bloomsbury Academic Press.

Fairclough, N. (2003). Analyzing Discourse: Textual analysis for social research. London, UK: Routledge.

Fairholm, R. (2010). Early Learning and Care Impact Analysis. Retrieved from Milton, ON: http://ywcacanada.ca/data/research_docs/00000122.pdf

Ferns, C. (2008, Oct 10). Canadians want national childcare. The National Post. Retrieved from http://search.proquest.com.ezproxy.lib.ryerson.ca/docview/330732378/CF5578AD41A84 983PQ/30?accountid=13631

Finlayson, J. G. (2005). Habermas: a very short introduction. New York, NY: Oxford University Press.

Fischer, F. (2003). Reframing public policy: discursive politics and deliberative practices. New York, NY: Oxford University Press.

Fladmoe, A. (2011). Education in the News and in the Mind: PISA, News Media and Public Opinion in Norway, Sweden and Finland. Nordicom Review, 32(2), 99-116. 
Flaxman, S., Goel, S., \& Rao, J. (2016). Filter bubbles, echo chambers and online news consumption. Public Opinion Quarterly, 80, 298-320.

Flyvberg, B. (1998). Habermas and Foucault: Thinkings for civil society? The British Journal of Society, 49(2), 210-233.

Fortin, P., Godbout, L., \& St-Cerny, S. (2011). Economic Consequences of Quebec's Educational Childcare Policy. Paper presented at the OISE: Early Years Economics Forum., Toronto, ON. https://www.oise.utoronto.ca/atkinson/UserFiles/File/Events/201106-22\%20-\%20Economic\%20Forum/EarlyLearningEconomicForum Fortin.pdf

Foucault, M. (1978). The History of Sexuality, Vol. I: An Introduction. Harmondsworth, UK: Penguin.

Foucault, M. (1980). Truth and Power. In C. Gordon (Ed.), Power/Knowledge (pp. 107-133). Brighton: Harvester.

Foucault, M. (1981). The order of discourse. In R. Young (Ed.), Untying the text: a poststructuralist reader. Boston, MA: Routledge.

Foxcroft, T. (Writer). (2013). Who's Watching the Kids? [Documentary], Marketplace: Canadian Broadcast Corporation.

Fraser, N. (1985). Michel Foucault: A young conservative? Ethics, 96(1), 165-184.

Fraser, N. (1989). Unruly practices: power, discourse, and gender in contemporary social theory. Minneapolis, Minnesota: University of Minnesota Press.

Fraser, N. (1990). Rethinking the Public Sphere: A Contribution to the Critique of Actually Existing Democracy. Social Text, 25-26, 56-80.

Friendly, M. (2006). Canadian early learning and child care and the Convention on the Rights of the Child (-9781896051321;1896051324;). Retrieved from Toronto, ON: http://www.childcarecanada.org/publications/occasional-paper-series/06/06/canadianearly-learning-and-child-care-and-convention-rig

Friendly, M. (2014). Getting less bang for the child care buck - all $\$ 6.8$ billion of them [Press release] 
Friendly, M. (2014, Aug 4). Public funding works. The National Post. Retrieved from http://search.proquest.com.ezproxy.lib.ryerson.ca/docview/1701245571 ?accountid=1363 $\underline{1}$

Friendly, M. (2014, Jan 14). Death by indifference: The government's failure to build a child care system has again proved fatal. The Toronto Star. Retrieved from http://search.proquest.com.ezproxy.lib.ryerson.ca/docview/839742058/D1EAF7E439224 $\underline{1 \mathrm{~B} 2 \mathrm{PQ} / 2 \text { ?accountid=13631 }}$

Friendly, M., Grady, B., Macdonald, L., \& Forer, B. (2015). Early Childhood Education and Care in Canada 2014. Retrieved from Toronto, ON: http://childcarecanada.org/sites/default/files/ECEC-2014-full-document-revised-10-0316.pdf

Friendly, M., \& Prentice, S. (2009). About Canada: childcare. Winnipeg, Manitoba: Fernwood Publishing.

Friendly, M., \& Rothman, L. (2009, Jan 8). Budget memo on child care Canada can't work without it; The economic downturn makes investment in children and families more important than ever. Are you listening, Mr. Flaherty? Toronto Star. Retrieved from http://ezproxy.lib.ryerson.ca/login?url=http://search.proquest.com/docview/439537187?a ccountid=13631

Globe and Mail. (2015, Apr 4). The parties prepare for battle. Globe and Mail. Retrieved from http://search.proquest.com.ezproxy.lib.ryerson.ca/docview/1716676694?accountid=1363 $\underline{1}$

Goar, C. (2009, Jun 22). Early learning makes business sense. Toronto Star. Retrieved from http://ezproxy.lib.ryerson.ca/login?url=http://search.proquest.com/docview/439570235?a c countid=13631

Goar, C. (2015, May 7). Justin Trudeau takes mildly progressive stance: Goar. The Toronto Star. Retrieved from https://www.thestar.com/opinion/editorials/2015/05/07/justin-trudeautakes-mildly-progressive-stance-goar.html

Gordon, S. (2015, Aug 11). The folly of universal childcare. The National Post. Retrieved from http://search.proquest.com.ezproxy.lib.ryerson.ca/docview/1703219458?accountid=1363 $\underline{1}$ 
Gordon, S. (2015, Sept 29). The daycare trade-off; Universal childcare lets more women go to work, but could have a negative effect on their children. National Post. Retrieved from http://search.proquest.com.ezproxy.lib.ryerson.ca/docview/1717453475?accountid=1363 $\underline{1}$

Government of Canada. (1985). Canadian Multiculturalism Act. Ottawa, ON: Canada Minister of Justice Retrieved from http://laws-lois.justice.gc.ca/eng/acts/c-18.7/page-1.html.

Gramsci, A. (1993). Prison Notebooks (Vol. 1). New York, NY: Columbia University Press.

Guba, E., \& Lincoln, Y. (2003). Paradigmatic Controversies, Contradictions and Emerging Influences. In N. Denzin \& Y. Lincoln (Eds.), The Landscape of Qualitative Research: Theories and Issues (2nd ed., pp. 253-291). Thousand Oaks, California: Sage.

Gunter, L. (2010, Jul 7). From Pearson to Ignatieff, the party of elitism; On his surprisingly candid blog, a Liberal MP identifies his party's real problem. The National Post. Retrieved from http://search.proquest.com.ezproxy.lib.ryerson.ca/docview/605728666/AB1EA39EE4624 $\underline{4 \mathrm{C} 0 \mathrm{PQ} / 15 \text { ? accountid }=13631}$

Habermas, J. (1984). The theory of communicative action: reason and the rationalization of society (Vol. 1). Boston, MA: Beacon Press.

Habermas, J. (1991). The structural transformation of the public sphere: An inquiry into Bourgeois Society. Boston, MA: MIT Press.

Hammer, K. (2010, Sep 7). The Kindergarten Diaries. The Globe and Mail. Retrieved from http://search.proquest.com.ezproxy.lib.ryerson.ca/docview/749676946/FA7467E797F249 $\underline{F 1 P Q / 28 ? \text { accountid }=13631}$

Harper, T. (2014, Nov 3). Our kids, our future and two competing visions. Toronto Star. Retrieved from http://search.proquest.com.ezproxy.lib.ryerson.ca/docview/1619272032/E06D45E9D45E 4703PQ/107? accountid=13631

Hartsock, N. (1990). Postmodernism and Political Change: Issues for Feminist Theory. Cultural Critique, 14, 15-33.

Hebert, C. (2015, Sept 3). Plenty of unanswered questions about NDP. The Toronto Star. Retrieved from 
http://search.proquest.com.ezproxy.lib.ryerson.ca/docview/1709123348?accountid=1363 $\underline{1}$

Hennessy, T., \& Leebosh, D. (2011). Focus groups summary and analysis: Public perceptions of early childhood education and care. Retrieved from Ottawa, ON:

http://eys3.ca/media/uploads/more-files/hennessy-leebosh-

early_learning_and_child_care_focus_group_summary.pdf

Hertzman, C. (2004). Making early childhood development a priority: lessons from Vancouver. Retrieved from Ottawa, ON:

https://www.policyalternatives.ca/sites/default/files/uploads/publications/BC Office Pub s/early childhood.pdf

Himmelstrand, J. (2011, Apr 26). The limits of the welfare state; Two generations of universal daycare have left Sweden's children less educated, and more distant from their parents. The National Post. Retrieved from http://search.proquest.com.ezproxy.lib.ryerson.ca/docview/863909004/A15C63C1C4B54 $\underline{\mathrm{AE} 8 \mathrm{PQ} / 31 \text { ?accountid}=13631}$

Ibbitson, J. (2015, May 5). A clean platform for the middle tax bracket: The Liberal Leader is offering a major tax cut and child-care benefits - for those earning between $\$ 44,700$ and $\$ 89,400$. The Globe and Mail. Retrieved from http://search.proquest.com.ezproxy.lib.ryerson.ca/docview/1678412794?accountid=1363 $\underline{1}$

Ivison, J. (2014, Feb 14). Tories trade income splitting for child benefit. The National Post. Retrieved from http://search.proquest.com.ezproxy.lib.ryerson.ca/docview/1498261506/6F59E12817A44 $\underline{7 \mathrm{~A} 6 \mathrm{PQ} / 2 \text { ? accountid }=13631}$

Ivison, J. (2015, Jan 16). Mulcair shuffles crucial staffers; Leader's reboot aims to spark caucus. The Globe and Mail. Retrieved from http://search.proquest.com.ezproxy.lib.ryerson.ca/docview/1646268467/6875E4BA0FB7 $\underline{482 \mathrm{FPQ} / 2 \text { ?accountid }=13631}$

Ivison, J. (2015, Jul 15). Race to the ballot box on tax cuts. The National Post. Retrieved from http://search.proquest.com.ezproxy.lib.ryerson.ca/docview/1696575749?accountid=1363 $\underline{1}$ 
Johnston, D., \& Swanson, D. (2006). Constructing the "Good Mother": The Experience of Mothering Ideologies by Work Status. Sex Roles, 54(7-8), 509-519.

Kan, M. Y., Sullivan, O., \& Gershuny, J. (2011). Gender Convergence in Domestic Work: Discerning the Effects of Interactional and Institutional Barriers from Large-scale Data. Sociology, 45(2), 234-251.

Kelly-Scherer, R. (2001). Federal child care policy development: From world war II to 2000. In S. Prentice (Ed.), Changing child care: five decades of child care advocacy and policy in Canada (pp. 171-180). Halifax, Nova Scotia: Fernwood Publishing.

Kershaw, P. (2012, Sep 15). Forget Occupy, the real divide is generational. The Globe and Mail. Retrieved from http://search.proquest.com.ezproxy.lib.ryerson.ca/docview/1041319834/EE310F34A16B $\underline{4 \mathrm{AA} 1 \mathrm{PQ} / 31 \text { ? accountid=13631 }}$

Kershaw, P. (2015). Generation squeeze: measuring the gap in Canadian social spending. Retrieved from Vancouver, British Columbia:

Kesselman, J. (2008, Apr 1). It's a misguided idea. The Globe and Mail. Retrieved from http://search.proquest.com.ezproxy.lib.ryerson.ca/docview/382727209/512BF7BC9BFC4 $\underline{5 \mathrm{~F} 2 \mathrm{PQ} / 18 \text { ?accountid }=13631}$

Kheiriddin, T. (2011, Feb 11). Support parents, not the daycare industry. The National Post. Retrieved from http://search.proquest.com.ezproxy.lib.ryerson.ca/docview/851443614/A15C63C1C4B54 $\underline{\mathrm{AE} 8 \mathrm{PQ} / 8 ? \text { accountid}=13631}$

Kheiriddin, T. (2015, Apr 30). Busting Canada's daycare myths. National Post. Retrieved from http://ezproxy.lib.ryerson.ca/login?url=http://search.proquest.com/docview/1677606749? accountid=13631

Kheiriddin, T. (2015, Sept 24). The dangers of daycare; Numerous studies have shown that children who spend more time in child care tend to have worse outcomes later in life. National Post. Retrieved from http://search.proquest.com.ezproxy.lib.ryerson.ca/docview/1716255031 ?accountid=1363 $\underline{1}$

Krippendorff, K. (2013). Content analysis: an introduction to its methodology (3rd ed.). Thousand Oaks, California: Sage. 
Lakoff, G. (2005). Don't think of an elephant: know your values and frame the debate. White River Junction, Vermont: Chelsea Green Publishing.

Lefebvre, P., Merrigan, P., \& Roy-Desrosiers, F. (2011). Québec's Childcare Universal Low Fees Policy 10 Years After : Effects, Costs and Benefits. Retrieved from Montreal, Quebec: http://www.cirpee.org/fileadmin/documents/Cahiers_2011/CIRPEE11-01.pdf

Liberal Party of Canada. (2015). Real change: a new plan for a strong middle class. Ottawa, ON: Liberal Party of Canada,.

Libin, K. (2011, Oct 28). Spirit of West still not settled; Bumper-sticker demands met, but Tories seek more. The National Post. Retrieved from http://search.proquest.com.ezproxy.lib.ryerson.ca/docview/900987463/D89CFC7A7A74 $\underline{42 \mathrm{~F} 4 \mathrm{PQ} / 50 ? \text { accountid}=13631}$

Lindblom, C. (2005). The Science of “Muddling Through” In J. Shafritz, K. Layne, \& C. Borick (Eds.), Classics of public policy. New York, NY: Pearson.

Lippmann, W. (2012). Public opinion. San Bernadina, California: Renaissance Classics.

Macdonald, D. (2014). Income Splitting in Canada

Inequality by Design. Retrieved from Ottawa, ON:

Macdonald, D. (2015). They Go Up So Fast: 2015 Child Care Fees in Canadian Cities. Retrieved from Ottawa, ON: https://www.policyalternatives.ca/sites/default/files/uploads/publications/National\%200f fice/2015/12/They_Go_Up_So_Fast_2015_Child_Care_Fees_in_Canadian_Cities.pdf

Maher, S. (2015, Jul 21). Vote buying becomes shameless; Santa Harper hands out billions just before vote. The National Post. Retrieved from http://search.proquest.com.ezproxy.lib.ryerson.ca/docview/1697668625?accountid=1363 $\underline{1}$

Mahon, R. (2009). Child Care and Varieties of Liberalism in Canada. In A. Dobrowolsky (Ed.), Women and Public Policy in Canada: Neoliberalism and After? Toronto, ON: Oxford University Press. 
Mahon, R. (2011). Canada's Early Childhood Education and Care Policy: Still a Laggard? International Journal of Child Care and Education Policy, 3(1), 27-42.

Mallick, H. (2012, Jun 23). Running on the spot, guilty, frantic. Toronto Star. Retrieved from http://ezproxy.lib.ryerson.ca/login?url=http://search.proquest.com/docview/1021819946? accountid=13631

Marco Chown, O. (2013, Nov 30). Private schools, daycares operate in legal loophole. Toronto Star. Retrieved from http://ezproxy.lib.ryerson.ca/login?url=http://search.proquest.com/docview/1462516161? accountid=13631

Marin, A. (2014). Careless about childcare: Investigation into how the Ministry of Education responds to complaints and concerns related to unregulated daycare providers. Retrieved from Toronto, ON: https://www.ombudsman.on.ca/Files/sitemedia/Documents/Investigations/SORT\%20Inve stigations/CarelessAboutChildCareEN-2.pdf

McCain, M., \& Mustard, F. (1999). Early years study: final report: reversing the real brain drain. Toronto, ON: The Canadian Institute for Advanced Research.

McCain, M., Mustard, F., \& McCuaig, K. (2011). Early years study 3: making decisions, taking action. Retrieved from Toronto, ON: http://ecereport.ca/media/uploads/pdfs/early-yearsstudy3-2011.pdf

McCuaig, K. (2011, Jul 30). Not on the backs of children. Toronto Star. Retrieved from http://search.proquest.com.ezproxy.lib.ryerson.ca/docview/882606680/514EDFCB325B4 A87PQ/38?accountid=13631

McCuaig, K., \& Murphy, C. (2013, Aug 17). A remedy for this child-care tragedy. Toronto Star. Retrieved from http://ezproxy.lib.ryerson.ca/login?url=http://search.proquest.com/docview/1425500302? accountid=13631

McKenna, B. (2015, Feb 16). It's time to help young Canadians bear the burden of higher costs. The Globe and Mail. Retrieved from http://search.proquest.com.ezproxy.lib.ryerson.ca/docview/1655217514/5AEFB0B56CC E4C5APQ/15? accountid=13631 
McLaren, L. (2015, Sept 4). For parents, daycare is the real money pit. The Globe and Mail. Retrieved from http://ezproxy.lib.ryerson.ca/login?url=http://search.proquest.com/docview/1709328483? $\underline{\text { accountid=13631 }}$

McLaren, M. (2002). Feminism, Foucault and Embodied Subjectivity. Albany, New York: State University of New York.

Merriam-Webster. (Ed.) (2017).

Milke, M., \& McMahon, F. (2012, May 28). Some inconvenient facts about equalization; In a week-long series beginning today, experts from Canada's finest think-tanks make the case for reforming Canada's bloated system of inter-governmental transfer payments. The National Post. Retrieved from http://search.proquest.com.ezproxy.lib.ryerson.ca/docview/1017740752/753A42ED70D8 $\underline{4180 \mathrm{PQ} / 19 ? \text { accountid=13631 }}$

Milligan, K. (2013, Oct 24). How to ensure child-care investments pay off. The Globe and Mail. Retrieved from http://search.proquest.com.ezproxy.lib.ryerson.ca/docview/1444445289/1E733D1CDA7 $\underline{\mathrm{D} 4186 \mathrm{PQ} / 36 ? \text { accountid }=13631}$

Mills, S. (2003). Michel Foucault. New York, NY: Routledge.

Ministry of Finance. (2017). Building a Strong Middle Class \#budget2017. Retrieved from Ottawa, Ontario: http://www.budget.gc.ca/2017/docs/plan/budget-2017-en.pdf

Mintz, J. M. (2014, Oct 31). Family-friendly tax breaks; Harper's tax package removes inequities and helps all families with kids. It's a good start. The National Post. Retrieved from http://ezproxy.lib.ryerson.ca/login?url=http://search.proquest.com/docview/1619165000? accountid=13631

Moist, P. (2015, Aug 13). Quality child care all families can afford. The National Post. Retrieved from http://search.proquest.com.ezproxy.lib.ryerson.ca/docview/1703876088?accountid=1363 $\underline{1}$

Mojtehedzadeh, S. (2014, Dec 4). Immigrant workers facing precarious employment. Toronto Star. Retrieved from 
http://ezproxy.lib.ryerson.ca/login?url=http://search.proquest.com/docview/1629876697? $\underline{\text { accountid }=13631}$

Mojtehedzadeh, S. (2014, Oct 26). Daycare money goes in, moms with jobs emerge. The Toronto Star. Retrieved from http://ezproxy.lib.ryerson.ca/login?url=http://search.proquest.com/docview/1616309157? $\underline{\text { accountid }=13631}$

Mojtehedzadeh, S., \& Ansari, S. (2015, Feb 28). Five ways to reduce income inequality. The Toronto Star. Retrieved from http://ezproxy.lib.ryerson.ca/login?url=http://search.proquest.com/d ocview/1660461232? $\underline{\text { accountid=13631 }}$

Monbiot, G. (2016, November 14). Neoliberalism - the ideology at the root of all of our problems. The Guardian. Retrieved from https://www.theguardian.com/commentisfree/2016/nov/14/neoliberalsim-donald-trumpgeorge-monbiot

Monsebraaten, L. (2008, Dec 11). Child-care report card Canada fails. Toronto Star. Retrieved from http://ezproxy.lib.ryerson.ca/login?url=http://search.proquest.com/docview/439529814?a ccountid=13631

Monsebraaten, L. (2011, Mar 6). 'Women are still waiting'. Toronto Star. Retrieved from http://search.proquest.com.ezproxy.lib.ryerson.ca/docview/855128985/D1EAF7E439224 $\underline{\text { B2PQ/14? accountid=13631 }}$

Monsebraaten, L. (2013, Jul 12). Advocates push for review of system. Toronto Star. Retrieved from

http://ezproxy.lib.ryerson.ca/login?url=http://search.proquest.com/docview/1399538354? accountid=13631

Monsebraaten, L. (2014, Nov 3). Key election battle looming over child care. Toronto Star. Retrieved from http://search.proquest.com.ezproxy.lib.ryerson.ca/docview/1619272080/E06D45E9D45E 4703PQ/105? accountid=13631

Monsebraaten, L. (2015, Aug 1). The Greater Toronto daycare dilemma. Toronto Star. Retrieved from 
http://ezproxy.lib.ryerson.ca/login?url=http://search.proquest.com/docview/1700464974? $\underline{\text { accountid }=13631}$

Monsebraaten, L. (2015, Oct 11). Daycare dilemma calls for sacrifices. Toronto Star. Retrieved from http://search.proquest.com.ezproxy.lib.ryerson.ca/docview/1721168406?accountid=1363 $\underline{1}$

Monsebraaten, L. (2015, Sept 15). Few child-care options for non-nine-to-fivers. The Toronto Star. Retrieved from http://ezproxy.lib.ryerson.ca/login?url=http://search.proquest.co m/docview/1712133281? accountid=13631

Monsebraaten, L., Marco, O., \& Ballingal, A. (2014, October 22, 2014). Report slams 'government ineptitude'. Toronto Star. Retrieved from http://ezproxy.lib.ryerson.ca/login?url=http://search.proquest.com/docview/1615176487? accountid=13631

Morrow, A. (2012, Feb 6). For-profit daycare targets apartments. The Globe and Mail. Retrieved from http://search.proquest.com.ezproxy.lib.ryerson.ca/docview/919896408/EE310F34A16B4 AA1PQ/4? accountid=13631

Mrozek, A. (2008, Oct 9). Good riddance, national daycare. The National Post. Retrieved from http://search.proquest.com.ezproxy.lib.ryerson.ca/docview/330747640/CF5578AD41A84 $\underline{983 \mathrm{PQ} / 29 \text { ? accountid=13631 }}$

Mrozek, A. (2011, Feb 14). Four votes against national daycare. The National Post. Retrieved from http://search.proquest.com.ezproxy.lib.ryerson.ca/docview/851914776/A15C63C1C4B54 AE8PQ/9? accountid=13631

Mrozek, A. (2015, Mar 30). Split those incomes, parents. The National Post. Retrieved from http://search.proquest.com.ezproxy.lib.ryerson.ca/docview/1667859902/fulltext/D025D9 2063444902PQ/1? accountid=13631

National Institute of Child Health and Human Development. (2005). The NICHD study of early child care and youth development. Retrieved from Rockville, MD: http://www.icpsr.umich.edu/icpsrweb/ICPSR/series/00233 
National Research Council and Institute of Medicine. (2000). From neurons to neighborhoods: the science of early childhood development (D. Phillips \& J. Shonkoff Eds.). Washington, DC: National Research Council, Committee on Integrating the Science of Early Childhood Development.

New Democratic Party of Canada. (2015). Building the country of our dreams: Tom Mulcair's plan to bring change to Ottawa. Ottawa, ON: New Democratic Party of Canada.

Noik-Bent, S. (2008, 21 Feb). No Greater Investment. The Globe and Mail. Retrieved from http://search.proquest.com.ezproxy.lib.ryerson.ca/docview/383373286/512BF7BC9BFC4 5F2PQ/8? accountid $=13631$

Olive, D. (2015, Aug 4). Household economics key for NDP federal victory. The Toronto Star. Retrieved from http://ezproxy.lib.ryerson.ca/login?url=http://search.proquest.com/docview/1700904200? accountid=13631

Olive, D. (2015, Sept 28). Child care should be an economic priority. The Toronto Star. Retrieved from http://ezproxy.lib.ryerson.ca/login?url=http://search.proquest.com/docview/1716882934? $\underline{\text { accountid }=13631}$

Olssen, M. (2006). Michel Foucault: materialism and education. New York, NY: Routledge.

Onstad, K. (2012, Dec 28). The Mother Load. The Globe and Mail. Retrieved from http://search.proquest.com.ezproxy.lib.ryerson.ca/docview/1257489049/EE310F34A16B $\underline{4 A A 1 P Q / 40 ? \text { accountid=13631 }}$

Organisation for Economic Co-operation and Development. (2006). Starting Strong II: Early Childhood Education and Care. Retrieved from Paris, France: http://www.oecd.org/edu/school/startingstrongiiearlychildhoodeducationandcare.htm

Organization for Economic and Community Development. (2004). Early childhoodeducation and care policy: Canada country note. Retrieved from Paris: http://www.oecd.org/canada/33850725.pdf

Ostrom, E. (2006). Institutional Rational Choice: An Assessment of the Institutional Analysis and Development Framework. In P. Sabatier (Ed.), Theories of the policy process (pp. 21-64). Boulder, CO: Westview Press. 
Pape, G. (2015, Oct 10). In the privacy of the voting booth, personal finances will decide ballots. The Toronto Star. Retrieved from http://ezproxy.lib.ryerson.ca/login?url=http://search.proquest.com/docview/1724582873? $\underline{\text { accountid}=13631}$

Pascal, C. (2012, May 25). Context and values shape Quebec political struggle. Toronto Star. Retrieved from http://ezproxy.lib.ryerson.ca/login?url=http://search.proquest.com/docview/1015793042? accountid=13631

Pearce, T. (2012, Sep 14). Go ahead: sleep in and ignore the kids. The Globe and Mail. Retrieved from http://search.proquest.com.ezproxy.lib.ryerson.ca/docview/1039334173/EE310F34A16B 4AA1PQ/29? accountid=13631

Prentice, S. (2009a). High Stakes: The "Investable" Child and the Economic Reframing of Childcare. Signs, 34(3), 687-710.

Prentice, S. (2009b). Tackling children's and women's poverty: Early learning and care services are part of the solution. Retrieved from http://eyeonkids.ca/docs/files/tackling_poverty_ecec_copy\%5B1\%5D.pdf

Principe, C. (Writer). (2014). The Motherload. In C. Principe (Producer), The Doc Zone: Canadian Broadcast Corporation.

Rauhala, A., Albanese, P., Ferns, C., Law, D., Haniff, A., \& Macdonald, L. (2012). Who says what: Election coverage and sourcing of child care in four Canadian dailies. Journal of Child and Family Studies, 21(1), 95-105.

Renzetti, E. (2012, Feb 11). From the House to crèche, women are still juggling bebé and work. The Globe and Mail. Retrieved from http://search.proquest.com.ezproxy.lib.ryerson.ca/docview/920992853/EE310F34A16B4 AA1PQ/5? accountid=13631

Renzetti, E. (2014, Oct 25). Daycare is a tough electoral sell, but kids are about more than politics. The Globe and Mail. Retrieved from http://ezproxy.lib.ryerson.ca/login?url=http://search.proquest.com/docview/1616015467? $\underline{\text { accountid }=13631}$ 
Richardson, B. (2011). A matter of choice: a critical discourse analysis of ECEC policy in Canada's 2006 federal election. (M.A.), Ryerson University, Toronto, ON. Retrieved from http://www.childcarecanada.org/sites/default/files/OccasionalPaper25.pdf

Richardson, B., Langford, R., Friendly, M., \& Rauhala, A. (2013). From Choice to Change: An Analysis of the 'choice' Discourse in Canada's 2006 Federal Election. Contemporary Issues in Early Childhood, 2(14), 155-167.

Richardson, J. (2007). Analysing newspapers: an approach from critical discourse analysis. New York, NY: Palgrave Macmillan.

Rinehart, D. (2008). Baby Talk: How gender issues affected media coverage of the childcare debate in the last federal election. Canadian Journal of Media Studies, 4(1), 1-40.

Rothman, L., Scott, K., \& Friendly, M. (2011, Feb 11). Why we need a national daycare program. The National Post. Retrieved from http://search.proquest.com.ezproxy.lib.ryerson.ca/docview/851442385/A15C63C1C4B54 $\underline{\mathrm{AE} 8 \mathrm{PQ} / 7 \text { ? accountid}=13631}$

Rushowy, K. (2014, Nov 12). Canada lagging in child care, reports say. The Toronto Star. Retrieved from http://ezproxy.lib.ryerson.ca/login?url=http://search.proquest.com/docview/1622543884? $\underline{\text { accountid }=13631}$

Sabatier, P., \& Weible, C. (Eds.). (2006). Theories of the Policy Process (2 ed.). Boulder, CO: Westview Press.

Sauve, R., \& People Patterns Consulting. (2009). Family life and work balance: an uneasy balance. Retrieved from Ottawa, ON: http://www.bollettinoadapt.it/old/files/document/11181work life 2009.pdf

Schatz, A., \& Mann, B. (2006). Shifting Paradigms of Child Care: From Women-Focussed to Family-Centred. Perspectives, 2(Winter), 17-24.

Simon, R. (1982). Gramsci's political thought: an introduction. London, UK: Lawrence and Wishart.

Simpson, J. (2014, Apr 16). Federal budget a triumph of tax madness. The Globe and Mail. Retrieved from 
http://search.proquest.com.ezproxy.lib.ryerson.ca/docview/1673295543?accountid=1363 $\underline{1}$

Simpson, J. (2015, Jan 21). The good, the bad and the ugly. The Globe and Mail. Retrieved from http://ezproxy.lib.ryerson.ca/login?url=http://search.proquest.com/docview/1646900764? accountid=13631

Simpson, J. (2015, Sep 11). Even if the Tories lose, they win on key issues. The Globe and Mail. Retrieved from http://search.proquest.com.ezproxy.lib.ryerson.ca/docview/1710894221 ?accountid=1363 $\underline{1}$

Smith, K., \& Larimer, C. (2013). Public Policy Theory Primer (2nd ed.). Boulder, CO: Westview Press.

Star, T. T. (2015, Jul 25). Tory strategy: vote buying, attack ads: Election goodies: thank only your fellow taxpayers, Opinion July 22 Why the Tories attack Trudeau, but not Mulcair, Opinion July 19 Child benefits sweetest in Tory territory, July 20. The Toronto Star. Retrieved from http://search.proquest.com.ezproxy.lib.ryerson.ca/docview/1698573088?accountid=1363 $\underline{1}$

Statistics Canada. (2011). Women in Canada: A Gender-based statistical report. Retrieved from Ottawa ON: http://www.statcan.gc.ca/pub/89-503-x/89-503-x2010001-eng.pdf

Statistics Canada. (2013). Report on the Demographic Situation in Canada, 2008 to 2012. Retrieved from http://www.statcan.gc.ca/daily-quotidien/130709/dq130709a-eng.htm

Statistics Canada. (2014). The surge of women in the workforce. Retrieved from http://www.statcan.gc.ca/pub/11-630-x/11-630-x2015009-eng.htm

Statistics Canada. (2015). Chart 4: Proportion of the population aged 0 to 14 years and 65 years and older, July 1, 2015, Canada, provinces and territories. Retrieved from http://www.statcan.gc.ca/daily-quotidien/150929/cg-b004-eng.htm

Tan, \& Weaver. (2010). Media Bias, Public Opinion, and Policy Liberalism from 1956 to 2004: A Second-Level Agenda-Setting Study. Mass Communication and Society, 13, 412-434.

Taylor, P. S. (2009, Jul 7). When times are tough, private-sector daycare proves its worth. National Post. Retrieved from 
http://search.proquest.com.ezproxy.lib.ryerson.ca/docview/382626340/994D1884E3AE4 915PQ/22?accountid=13631

Taylor, P. S. (2009, May 19). Let parents choose. The National Post. Retrieved from http://search.proquest.com.ezproxy.lib.ryerson.ca/docview/330864853/9B28D2B492544 B9BPQ/7? accountid=13631

The Conference Board of Canada. (2011). Women Still Missing In Action From Senior Management Positions In Canadian Organizations [Press release]. Retrieved from http://www.conferenceboard.ca/press/newsrelease/11-08-

31/women still missing in action from senior management positions in canadian or ganizations.aspx

The Globe and Mail. (2011, Dec 16). Let parents choose for their children. The Globe and Mail. Retrieved from http://search.proquest.com.ezproxy.lib.ryerson.ca/docview/911125061/C3063DB0E9954 2B4PQ/52?accountid=13631

The Globe and Mail. (2013, Oct 26). We don't all need to be Quebec. The Globe and Mail. Retrieved from http://search.proquest.com.ezproxy.lib.ryerson.ca/docview/1445057718/1E733D1CDA7 $\underline{\mathrm{D} 4186 \mathrm{PQ} / 38 \text { ?accountid }=13631}$

The Globe and Mail. (2014, Nov 8). Talking Point: A helping hand for families? Nods all around - good idea, as Canadian as motherhood and maple syrup. But what kind of hand? Which families? Readers, print and digital, enter the debate on income splitting and universal daycare. The Globe and Mail. Retrieved from http://search.proquest.com.ezproxy.lib.ryerson.ca/docview/1621691027/6A6FCAA80548 4DD5PQ/49? accountid=13631

The National Post. (2015, Oct 15). National Post View: The Choices Before Us, Part 3: Social Policy. The National Post. Retrieved from http://news.nationalpost.com/fullcomment/national-post-view-the-choices-before-us-part-3-social-policy

The National Post. (2015, Sept 25). Quebec's damaging daycare. The National Post. Retrieved from http://search.proquest.com.ezproxy.lib.ryerson.ca/docview/1716676694?accountid=1363 $\underline{1}$ 
The Toronto Star. (2013, Feb 7). Match jobs and child care. The Toronto Star. Retrieved from http://search.proquest.com.ezproxy.lib.ryerson.ca/docview/1284692137/C5C343F8DC6C 438EPQ/7? accountid=13631

The Toronto Star. (2014, May 13). Childcare key to economy. The Toronto Star. Retrieved from http://search.proquest.com.ezproxy.lib.ryerson.ca/docview/1523868826/3B37F5C5EC27 $\underline{4122 \mathrm{PQ} / 43 \text { ? accountid }=13631}$

The Toronto Star. (2014, Nov 14). Ontario desperately needs regulated child-care system. The Toronto Star. Retrieved from http://search.proquest.com.ezproxy.lib.ryerson.ca/docview/1624877644/E06D45E9D45E $\underline{4703 \mathrm{PQ} / 120 ? \text { accountid }=13631}$

The Toronto Star. (2014, Nov 17). Good for kids - and the economy. The Toronto Star. Retrieved from http://ezproxy.lib.ryerson.ca/login?url=http://search.proquest.com/docview/1625289283? accountid=13631

The Toronto Star. (2014, Nov 22). Time to end the excuses. The Toronto Star. Retrieved from http://ezproxy.lib.ryerson.ca/login?url=http://search.proquest.com/docview/1626861158? $\underline{\text { accountid }=13631}$

The Toronto Star. (2015, May 7). A child-benefit plan that makes sense. The Toronto Star. Retrieved from http://ezproxy.lib.ryerson.ca/login?url=http://search.proquest.com/docview/1679011063? $\underline{\text { accountid }=13631}$

The Toronto Star. (2015, May 16). Solutions for six challenges facing the GTA. THe Toronto Star. Retrieved from http://ezproxy.lib.ryerson.ca/login?url=http://search.proquest.com/docview/1681076595? accountid=13631

Toronto Star. (2015, Oct 8). The Conservative litany of misogyny. Toronto Star. Retrieved from http://search.proquest.com.ezproxy.lib.ryerson.ca/docview/1719886156?accountid=1363 $\underline{1}$

Toronto Star. (2015, Oct 14). Harper's final frantic pitch. Toronto Star. Retrieved from http://search.proquest.com.ezproxy.lib.ryerson.ca/?accountid=13631 
Tungohan, E. (2013). Reconceptualizing Motherhood, Reconceptualizing Resistance: migrant domestic workers. International Feminist Journal of Politics, 15(1), 39-57.

UNICEF. (2008). The Child Care Transition: A league table of early childhood education and care in economically advanced countries: Innocenti Report Card 8 (9788889129708;8889129700;). Retrieved from Florence, Italy: https://www.unicefirc.org/publications/pdf/rc8_eng.pdf

United Nations Human Rights Office of the High Commissioner. (1989). Convention on the rights of the child. Retrieved from http://www.ohchr.org/EN/ProfessionalInterest/Pages/CRC.aspx

Walkom, T. (2014, Nov 1). PM's flawed child-benefit plan has upside. Toronto Star. Retrieved from http://ezproxy.lib.ryerson.ca/login?url=http://search.proquest.com/docview/1619018420? accountid=13631

Walkom, T. (2015, Jan 29). NDP bets on warmed-over Laytonism. Toronto Star. Retrieved from http://ezproxy.lib.ryerson.ca/login?url=http://search.proquest.com/docview/1648847490? accountid=13631

Ward, H. (2015, Sept 8). Prioritize parental. The Globe and Mail. Retrieved from http://ezproxy.lib.ryerson.ca/login?url=http://search.proquest.com/docview/1709919515? accountid=13631

Wardle, C. (2006). " IT COULD HAPPEN TO YOU', The move towards " personal" and "societal" narratives in newspaper coverage of child murder, 1930-2000. Jouralism Studies, 7(4), 515-533.

Watson, W. (2015, Oct 15). Stephen Harper's Canada good for kids. The National Post. Retrieved from http://business.financialpost.com/fp-comment/william-watson-stephenharpers-canada-good-for-kids

White, L. (2001). From ideal to pragmatic politics: National Child care Advocacy groups in the 1980s and 1990s. In S. Prentice (Ed.), Changing child care:five decades of child care advocacy and policy in Canada (pp. 97-115). Halifax, Nova Scotia: Fernwood Publishing. 
White, L. (2014). Understanding Canada's Lack of Progress in Implementing the UN Convention on the Rights of the Child: The Intergovernmental Dynamics of Children's Policy Making in Canada. International journal of Children's Rights, 22(1), 164-188.

Whittington, L. (2014, Nov 8). Tax cuts leave out 'vast majority,' NDP says. Toronto Star. Retrieved from http://search.proquest.com.ezproxy.lib.ryerson.ca/docview/1621757151/E06D45E9D45E $\underline{4703 \mathrm{PQ} / 109 ? \text { accountid }=13631}$

Working Families, \& Bright Horizons. (2017). The modern families index 2017. Retrieved from London, UK:

Yakabuski, K. (2015, Jul 17). Harper's doppelganger Down Under parts ways on austerity. The Toronto Star. Retrieved from http://search.proquest.com.ezproxy.lib.ryerson.ca/docview/1696829723?accountid=1363 $\underline{1}$

Yew, M. A.-T. (2014, Nov 25). U.S. inequality a threat to Canada, report says. The Toronto Star. Retrieved from http://ezproxy.lib.ryerson.ca/login?url=http://search.proquest.com/docview/1627636325? accountid=13631

Zeitel-Bank, N. (2017). Dimensions of polity, politics and policy in the Austrian media system: Media coverage of the 'refugee/ asylum seeker crisis'. International Journal of Media \& Cultural Politics, 13(1-2), 91-109.

Zerbisias, A. (2011, Apr 3). Tory legacy leaves little to attract women. Toronto Star. Retrieved from http://ezproxy.lib.ryerson.ca/login?url=http://search.proquest.com/docview/859683299?a ccountid=13631

Zhao, X. (2016). Effects of Perceived Media Diversity and Media Reliance on Public Opinion Expression. International Journal of Public Opinion Research, 28(3), 355-375.

Zlomistic, D. (2011, Apr 9). Can Liberals get child care in place soon? The Toronto Star. Retrieved from http://search.proquest.com.ezproxy.lib.ryerson.ca/docview/861085341/2EF65F5AB8314 $\underline{6 \mathrm{~F} 4 \mathrm{PQ} / 22 \text { ?accountid=13631 }}$ 